\author{
Universidade de São Paulo \\ Instituto de Física
}

\title{
Investigação Sobre a Dispersão de Poluentes na Região Metropolitana de São Paulo,
}

Cubatão e Arredores

\author{
Atenágoras Souza Silva
}

Orientador: Prof. Dr. Américo Adlai Franco Sansigolo Kerr

Dissertação de mestrado apresentada ao Instituto de Física para a obtenção do título de Mestre em Física

Banca Examinadora:

Prof. Dr. Américo Adlai Franco Sansigolo Kerr (Instituto de Física)

Prof. Dr. Alexandre Lima Correia (Instituto de Física)

Prof. Dr ${ }^{a}$. Rita Yuri Ynoue (Instituto de Astronomia e Geofísica)

São Paulo 
FICHA CATALOGRÁFICA

Preparada pelo Serviço de Biblioteca e Informação

do Instituto de Física da Universidade de São Paulo

Silva, Atenágoras Souza

Investigação sobre a dispersão de poluentes na região metropolitana de São Paulo, Cubatão e arredores. São Paulo, 2017.

Dissertação (Mestrado) - Universidade de São Paulo. Instituto de Física. Depto. Física Aplicada.

Orientador(a): Prof. Dr. Américo Adlai Sansigolo Kerr

Área de Concentração: Física da Poluição do Ar

Unitermos: 1.Poluição atmosférica; 2.Modelagem de dispersão Lagrangeana; 3.Modelagem atmosférica .

USP/IF/SBI-067/2017 
Dedico este trabalho aos meus pais, Jucundina Santos Souza e Wilson Silva, aos meus irmãos, Juliana Souza Silva e Diógenes Souza Silva, aos meus amigos, aos trabalhadores desta universidade, aos militantes do movimento de Software Livre que entendem sua importância social e política, e aos que lutam por justiça social e um ambiente equilibrado no mundo todo. 


\section{Agradecimentos}

Gostaria de Agradecer ao Thiago Gomes Veríssimo, pelo suporte com computação e convivência pacífica e amistosa.

Também pelo suporte computacional, gostaria de agradecer a todos que trabalham no laboratório MASTER, no IAG.

Agradeço aos Pesquisadores da Arianet, especialmente Gianni Tinarelli e Sandro Finardi, por todo apoio na realização do acoplamento dos modelos BRAMS e SPRAY.

Agradeço ao amigo Luís Mendes por ter me ensinado a lidar com dados de Radiossondagem.

Ao Prof ${ }^{\mathrm{O}}$ Américo Kerr que foi muito importante tanto pela orientação quando pela maior habilidade de comunicação e interação com demais grupos para efetiva colaboração.

Agradeço por fim a todo o apoio e compreensão da minha família e amigos. 


\section{Resumo}

\section{SILVA, A., S. Investigação Sobre a Dispersão de Poluentes na Região Metropoli-}

tana de São Paulo, Cubatão e Arredores 2016150 p. Dissertação (Mestrado em Física) - Instituto de Física, Universidade de São Paulo, São Paulo, 2017.

O presente trabalho realizou simulações meteorológicas e de dispersão de poluentes com fontes de emissão da Região Metropolitana de São Paulo (RMSP) e de Cubatão, entre 23 a 26/08/2006. Neste período ocorreu um experimento de inverno realizado pelo IGC-USP, medindo e fazendo a análise elementar de Material Particulado Inalável (diâmetro aerodinâmico médio $<10 \mu m, M P_{10}$ ) em Cubatão e em outros dois pontos de amostragem da RMSP (USP e Juquitiba). Empregou-se de modo articulado o modelo meteorológico de mesoescala BRAMS (Brazilian Regional Atmospheric Modelling System) e o modelo lagrangeano estocástico de dispersão de partículas SPRAY. Na área da RMSP considerou-se a dispersão das emissões de Monóxido de Carbono (CO) por veículos, enquanto em Cubatão tomou-se o MP proveniente das fábricas do Polo industrial de Cubatão. Os resultados da simulação de dispersão foram comparados com os valores medidos nas estações da CETESB (Companhia Ambiental do Estado de São Paulo), na estação meteorológica do IAG-USP e no experimento de inverno. O acoplamento BRAMS/SPRAY mostrou boa habilidade para simulação da meteorologia e das concentrações de poluentes. Foi possível discutir o transporte de poluentes entre a RMSP, Cubatão e arredores, durante este período, considerando inclusive um episódio particular ocorrido nos dias 25 e 26/08/2006.

Palavras-chave: Poluição atmosférica, Modelagem de Dispersão, Transporte de Poluentes; São Paulo, Cubatão e arredores. 


\begin{abstract}
SILVA, A., S. Study of air pollution dispersion at the Metropolitan Area of São Paulo, Cubatão City and nearby areas

This work performed meteorological and pollutants dispersion simulations using sources of the Metropolitan Area of São Paulo (MASP) and Cubatão city, between 23 and 26 August, 2006. During this period, a wintertime experiment was realized by IGC-USP (Institute of Geosciences - University of São Paulo) to measure and make the elemental analysis of the inhalable particulate matter from Cubatão, USP (In São Paulo, capital of São Paulo State, and MASP's major city) and Juquitiba (a MASP's border limits city). BRAMS/SPRAY (Brazilian Regional Atmospheric Modelling System, and the lagrangean stochastic dispersion Model SPRAY) were coupled to simulate meteorological variables and pollutant concentrations. The vehicular emissions of CO was the source used as input at MASP for SPRAY, and the imput used at Cubatão was the industrial emissions of PM at Cubatão industrial city. The results of the simulations were compared with meteorological data and the concentrations of pollutants measured in the CETESB's stations (CETESB - São Paulo's Environmental Agency), at IAG's meteorological station (IAG - Institute for Astronomy, Geophisics and Atmospheric Sciences of University of São Paulo), and in the wintertime experiment stations. BRAMS/SPRAY coupled model showed good skill to simulate meteorological data and the concentrations of pollutants. They enabled the discussion of the pollutants transport between MASP, Cubatão and nearby areas, during studied period, specially a particular episode that took place in August 25 and 26, 2006.
\end{abstract}

Keywords: Atmospheric pollution, Dispertion modelling, Pollutants Transport, São Paulo, Cubatão and nearby areas. 


\section{Lista de Figuras}

1.1 Limites máximos de emissão de cada poluente para veículos leves em cada fase do PROCONVE. . . . . . . . . . . . . . . . . . . . 33

1.2 Série Temporal de medidas de CO na Estação de Cerqueira César . . . . . . . . 34

1.3 Série Temporal de medidas de CO na Estação de Congonhas . . . . . . . . . . 34

1.4 Série Temporal de medidas de $O_{3}$ na Estação de Ibirapuera . . . . . . . . . . . 35

1.5 Série Temporal de medidas de $O_{3}$ na Estação de Moóca . . . . . . . . . . . . 35

1.6 Série Temporal de $M P_{10}$ em Cubatão - Estações Centro e Vila Parisi. . . . . . 36

1.7 Série Temporal de Máximas $M P_{10}$ em Cubatão - Estações Centro e Vila Parisi. 37

3.1 Grades da simulação no Mapa. As grades 2 e 3 são as regiões de interesse para a simulação. Imagem de Domínio Público forncedida pela NASA editada com os softwares Marbles, GIMP e kolourpaint. . . . . . . . . . . . . . . . . . 54

3.2 Representação da fonte de CO feita com 169 quadrados de $5 X 5 \mathrm{~km}^{2}$, representando a emissão veicular deste poluente na RMSP (valores registrados nas células em $\mathrm{kg} / \mathrm{h}) \ldots \ldots \ldots \ldots \ldots \ldots$

3.3 Modulação das Intensidades de $M P_{10}$ e CO por hora do dia, a partir das concentrações medidas na estação de Congonhas em 2006. Há boa correlaçãoentre $M P_{10}$ e CO, o que alimentou a aproximação feita neste trabalho para relacionar as simulações de $\mathrm{CO}$ com $M P_{10}$ nas comparações com o experimento de inverno relacionadas à fonte veicular. . . . . . . . . . . . . . . . . . . . . . . . 59

3.4 Posição das fábricas inventariadas pela CETESB em 2006 cuja emissão de $M P$ em Cubatão foi simulada pelo SPRAY. Os pontos verdes representam estações de monitoramento da CETESB. O ponto verde extremo a NE também continha a estação Vale do Mogi do experimento de inverno. O ponto preto é a Refinaria Presidente Bernardes. Os pontos marrons são as fábricas de Fertilizantes. Os pontos azuis são fábricas de outros ramos. Todas as fábricas estão, no máximo a 10m do nível do mar. Notar as limitações na resolução da topografia no BRAMS 60 
3.5 Posição das fábricas em Cubatão em mapa do projeto Open Street Maps. Companhia Brasileira do Estireno não aparece no mapa, mas fica próximo à Ultrafertil (Cubatão), nos entornos da SP-148. Gerado com o software Marble. 61

3.6 Estações de Monitoramento de poluentes e/ou meteorológicas. 13 estações da CETESB, três utilizadas para o experimento de Inverno e uma estação do IAG. Os números na figura referem-se às estações descritas na tabela 3.3

4.1 Umidade simulada pelo BRAMS e observada nas estações indicadas em cada gráfico: Série Temporal e gráfico de espalhamento . . . . . . . . . . . . . . 71

4.2 Umidade simulada pelo BRAMS e observada nas estações indicadas em cada gráfico. Continuação . . . . . . . . . . . . . . . . . 72

4.3 Umidade simulada pelo BRAMS e observada nas estações indicadas em cada gráfico. Continuação . . . . . . . . . . . . . . . . 73

4.4 Umidade simulada pelo BRAMS e observada nas estações indicadas em cada gráfico. Continuação . . . . . . . . . . . . . . . . . . . 74

4.5 Temperaturas simuladas pelo BRAMS e observadas nas estações: Série Temporal e gráfico de espalhamento . . . . . . . . . . . . . . 76

4.6 Temperaturas simuladas pelo BRAMS e observadas nas estações. Continuação 77

4.7 Temperaturas simuladas pelo BRAMS e observadas nas estações. Continuação 78

4.8 Temperaturas simuladas pelo BRAMS e observadas nas estações. Continuação 79

4.9 Comparação dos ventos U simulados pelo BRAMS e os medidos nas estações . 82

4.10 Comparação dos ventos U simulados pelo BRAMS. Continuação . . . . . . . . 83

4.11 Comparação dos ventos U simulados pelo BRAMS. Continuação . . . . . . . . 84

4.12 Comparação dos ventos U simulados pelo BRAMS. Continuação . . . . . . . . 85

4.13 Comparação dos ventos U simulados pelo BRAMS. Continuação . . . . . . . . 86

4.14 Comparação dos ventos U simulados pelo BRAMS. Continuação . . . . . . . . 87

4.15 Comparação dos ventos V simulados pelo BRAMS e os medidos nas estações . 89

4.16 Comparação dos ventos V simulados pelo BRAMS e os medidos nas estações . 90

4.17 Comparação dos ventos $\mathrm{V}$ simulados pelo BRAMS e os medidos nas estações.

Continuação . . . . . . . . . . . . . . . . . . . . 91

4.18 Comparação dos ventos $\mathrm{V}$ simulados pelo BRAMS e os medidos nas estações.

Continuação . . . . . . . . . . . . . . . . . . . . . . . . 92

4.19 Comparação dos ventos $\mathrm{V}$ simulados pelo BRAMS e os medidos nas estações.

Continuação . . . . . . . . . . . . . . . . . . . . 93 
4.20 Comparação dos ventos V simulados pelo BRAMS e os medidos nas estações. Continuação . . . . . . . . . . . . . . . . . . . . . . . 94

4.21 Rosa dos Ventos nas estações. Vento Observado e Simulações . . . . . . . . . . 98

4.22 Rosa dos Ventos nas estações. Vento Observado e Simulações. Continuação . . 99

4.23 Rosa dos Ventos nas estações. Vento Observado e Simulação. Continuação . . 100

4.24 Rosa dos Ventos nas estações. Vento Observado e Simulação. Continuação . . 101

4.25 Rosa dos Ventos nas estações. Vento Observado e Simulação. Continuação . 102

4.26 Rosa dos Ventos nas estações. Vento Observado e Simulação. Continuação . . 103

4.27 Comparação entre a Radiossondagem realizada no Campo de Marte e a interpolação dos resultados do BRAMS . . . . . . . . . . . . . . . . . . 105

4.28 Comparação entre a Radiossondagem realizada no Campo de Marte e a interpolação dos resultados do BRAMS. Continuação . . . . . . . . . . . . . . 106

4.29 Comparação entre a Radiossondagem realizada no Campo de Marte e a interpolação dos resultados do BRAMS. Continuação . . . . . . . . . . . . . . . . . 107

4.30 Comparação entre a Radiossondagem realizada no Campo de Marte e a interpolação dos resultados do BRAMS. Continuação . . . . . . . . . . . . . . . . . 108

4.31 Comparação entre a Radiossondagem realizada no Campo de Marte e a interpolação dos resultados do BRAMS . . . . . . . . . . . . . . . . 109

4.32 Comparação entre a Radiossondagem realizada no Campo de Marte e a interpolação dos resultados do BRAMS. Continuação . . . . . . . . . . . . . . . . . 110

4.33 Comparação entre a Radiossondagem realizada no Campo de Marte e a interpolação dos resultados do BRAMS. Continuação . . . . . . . . . . . . . . . . . 111

4.34 Comparação entre a Radiossondagem realizada no Campo de Marte e a interpolação dos resultados do BRAMS. Continuação . . . . . . . . . . . . . . . . . 112

4.35 Comparação entre a Radiossondagem realizada no Campo de Marte e a interpolação dos resultados do BRAMS . . . . . . . . . . . . . . . . . . 113

4.36 Comparação entre a Radiossondagem realizada no Campo de Marte e a interpolação dos resultados do BRAMS. Continuação . . . . . . . . . . . . . . . . . 114

4.37 Comparação entre a Radiossondagem realizada no Campo de Marte e a interpolação dos resultados do BRAMS. Continuação . . . . . . . . . . . . . . . . . 115

4.38 Comparação entre a Radiossondagem realizada no Campo de Marte e a interpolação dos resultados do BRAMS. Continuação . . . . . . . . . . . . . . . . . 116

4.39 Comparação entre a Radiossondagem realizada no Campo de Marte e a interpolação dos resultados do BRAMS . . . . . . . . . . . . . . . . 117 
4.40 Comparação entre a Radiossondagem realizada no Campo de Marte e a interpolação dos resultados do BRAMS. Continuação . . . . . . . . . . . . . . . . 118

4.41 Comparação entre a Radiossondagem realizada no Campo de Marte e a interpolação dos resultados do BRAMS. Continuação . . . . . . . . . . . . . . . . . 119

4.42 Comparação entre a Radiossondagem realizada no Campo de Marte e a interpolação dos resultados do BRAMS. Continuação . . . . . . . . . . . . . . . . . 120

4.43 Comparação entre a Radiossondagem realizada no Campo de Marte e a interpolação dos resultados do BRAMS

4.44 Comparação entre a Radiossondagem realizada no Campo de Marte e a interpolação dos resultados do BRAMS. Continuação . . . . . . . . . . . . . . . . . 122

4.45 Comparação entre a Radiossondagem realizada no Campo de Marte e a interpolação dos resultados do BRAMS. Continuação . . . . . . . . . . . . . . . . . 123

4.46 Comparação entre a Radiossondagem realizada no Campo de Marte e a interpolação dos resultados do BRAMS. Continuação . . . . . . . . . . . . . . . . . 124

4.47 Comparação entre a Radiossondagem realizada no Campo de Marte e a interpolação dos resultados do BRAMS

4.48 Comparação entre a Radiossondagem realizada no Campo de Marte e a interpolação dos resultados do BRAMS. Continuação . . . . . . . . . . . . . . . . . 126

4.49 Comparação entre a Radiossondagem realizada no Campo de Marte e a interpolação dos resultados do BRAMS. Continuação . . . . . . . . . . . . . . . . . 127

4.50 Comparação entre a Radiossondagem realizada no Campo de Marte e a interpolação dos resultados do BRAMS. Continuação . . . . . . . . . . . . . . . . . 128

4.51 Comparação entre a Radiossondagem realizada no Campo de Marte e a interpolação dos resultados do BRAMS

4.52 Comparação entre a Radiossondagem realizada no Campo de Marte e a interpolação dos resultados do BRAMS. Continuação . . . . . . . . . . . . . . . . . 130

4.53 Comparação entre a Radiossondagem realizada no Campo de Marte e a interpolação dos resultados do BRAMS. Continuação . . . . . . . . . . . . . . . . . 131

4.54 Comparação entre a Radiossondagem realizada no Campo de Marte e a interpolação dos resultados do BRAMS. Continuação . . . . . . . . . . . . . . . . . 132

4.55 Comparação das concentrações de CO simuladas pelo modelo acoplado BRAMS/SPRAY e observadas nas estações . . . . . . . . . . . . . . . . . . . . 135

4.56 Comparação das concentrações de CO simuladas pelo modelo acoplado BRAMS/SPRAY e observadas nas estações - Parte 2 
4.57 Comparação das concentrações de CO simuladas pelo modelo acoplado BRAMS/SPRAY e observadas nas estações. Continuação . . . . . . . . . . . . . . . . . 137

4.58 Comparação das concentrações de CO simuladas pelo modelo acoplado BRAMS/SPRAY e observadas nas estações. Continuação . . . . . . . . . . . . . . . . 138

4.59 Comparação das concentrações de CO simuladas pelo modelo acoplado BRAMS/SPRAY e observadas nas estações. Continuação . . . . . . . . . . . . . . . . 139

4.60 Comparação das concentrações de CO simuladas pelo modelo acoplado BRAMS/SPRAY e observadas nas estações. Continuação . . . . . . . . . . . . . . . . . . . 140

4.61 Comparação das concentrações de CO simuladas pelo modelo acoplado BRAMS/SPRAY e observadas nas estações. Continuação . . . . . . . . . . . . . . . . . . . 141

4.62 Transporte de CO da RMSP à Baixada Santista . . . . . . . . . . . . . . . . . 143

4.63 Transporte de CO da RMSP para a Baixada Santista. . . . . . . . . . . . . . . 144

4.64 Comparação das concentrações de $M P_{10} \mathrm{~s}$ imuladas pelo modelo acoplado BRAMS/SPRAY e observadas nas estações . . . . . . . . . . . . . . . 147

4.65 Comparação das concentrações de $M P_{10}$ simuladas pelo modelo acoplado BRAMS/SPRAY e observadas nas estações - Continuação . . . . . . . . . . 148

4.66 Concentrações de $P M_{10}$ no nível do solo durante o trasporte de $M P_{10}$ de Cubatão à RMSP . . . . . . . . . . . . . . . . . . . . . . . . . . . . . . . . 149

4.67 Vento associado ao Transporte de $P M_{10}$ de Cubatão para RMSP. Cortes verticais de $(-23.89763,-46.33309)$ a $(-23.56594,-46.52566) \ldots \ldots \ldots$ 


\section{Lista de Tabelas}

1.1 Padrões de Qualidade do Ar para $M P_{10}$ : Valores estabelecidos pelo CONAMA e OMS. As metas referem-se a padrões intermediários sugeridos pela OMS antes da principal ser atingida. . . . . . . . . . . . . . . 23

1.2 Padrões de Qualidade do Ar para $M P_{2,5}$ : Valores estabelecidos pelo CONAMA e OMS. As metas referem-se a padrões intermediários sugeridos pela OMS antes da principal ser atingida. . . . . . . . . . . . . . . . 24

1.3 Padrões de Qualidade do $\mathrm{Ar}$ para $\mathrm{NO}_{2}$ : Valores estabelecidos pelo CONAMA e OMS.

1.4 Texto para a tabelaPadrões de Qualidade do Ar para $\mathrm{O}_{3}$ : Valores estabelecidos pelo CONAMA e OMS. As metas referem-se a padrões intermediários sugeridos pela OMS antes da principal ser atingida. . . . . . . . . . . . . 26

1.5 Padrões de Qualidade do Ar para CO: Valores estabelecidos pelo CONAMA e

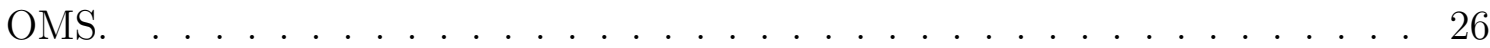

1.6 Padrões de Qualidade do Ar para $\mathrm{SO}_{2}$ : Valores estabelecidos pelo CONAMA

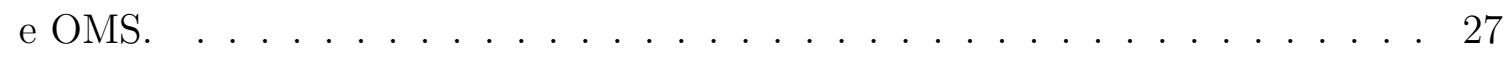

1.7 Anos das fases do PROCONVE . . . . . . . . . . . . . . . . 32

3.1 Grade utilizada nos modelos BRAMS e SPRAY. Em negrito, as regiões de interesse para as simulações . . . . . . . . . . . . . . . . 54

3.2 Localização geográfica de fontes industriais em Cubatão. . . . . . . . . . . . . 61

3.3 Estações meteorológicas e/ou de monitoramento de poluentes . . . . . . . . . . 62

4.1 Parâmetros estatísticos para Pressao em várias estações. . . . . . . . . . . . 68

4.2 Parâmetros estatísticos para Pressao em várias estações (Continuação) . . . 68

4.3 Parâmetros estatísticos para Umidade em várias estações. . . . . . . . . . . . . 69

4.4 Parâmetros estatísticos para Umidade em várias estações (Continuação) . . . . 69

4.5 Parâmetros estatísticos para Temperatura em várias estações. . . . . . . . . . 75

4.6 Parâmetros estatísticos para Temperatura em várias estações (Continuação) · 75 
4.7 Parâmetros estatísticos para U em várias estações. . . . . . . . . . . . . . . . 80

4.8 Parâmetros estatísticos para U em várias estações. (Continuação) . . . . . . . 80

4.9 Parâmetros estatísticos para $\mathrm{V}$ em várias estações. . . . . . . . . . . . . 88

4.10 Parâmetros estatísticos para V em várias estações. (Continuação) . . . . . . . 88

4.11 Parâmetros estatísticos para Magnitude em várias estações. . . . . . . . . . . . 95

4.12 Parâmetros estatísticos para Magnitude em várias estações. (Continuação) . 96

4.13 Correlações e valores-p do teste T para as componentes zonal e meridional do

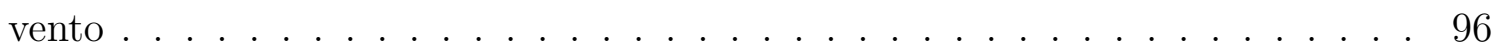

4.14 Pressão: Correlação entre radiossondagem e valores simulados pelo BRAMS interpolados nos mesmos níveis de medição. . . . . . . . . . . . . . . . . . 108

4.15 Umidade Relativa (UR): Correlação entre radiossondagem e valores simulados pelo BRAMS interpolados nos mesmos níveis de medição. . . . . . . . . . . . . 112

4.16 Temperatura: Correlação entre radiossondagem e simulação BRAMS interpolada para os níveis medidos f . . . . . . . . . . . . . . . 116

4.17 Vento U: Correlação entre radiossondagem e simulação BRAMS interpolada para os níveis medidos . . . . . . . . . . . . . . . . . . . . . . . 120

4.18 Vento V: Correlação entre radiossondagem e simulação BRAMS interpolada para os níveis medidos . . . . . . . . . . . . . . . . . . . . . . . . . . . 124

4.19 Magnitude do Vento: Correlação entre radiossondagem e simulação BRAMS interpolada para os níveis medidos . . . . . . . . . . . . . . . . . . 132

4.20 Parâmetros estatísticos para CO em várias estações. . . . . . . . . . . . . . . . 133

4.21 Parâmetros estatísticos para CO em várias estações (Continuação) . . . . . . . 133

4.22 Parâmetros estatísticos para MP10 em várias estações. . . . . . . . . . . . . . 145

4.23 Parâmetros estatísticos para MP10 em várias estações (Continuação) . . . . . 145

4.24 Comparação entre o $M P_{10}$ observado e simulado nas estações. Os valores observados em Cubatão foram comparados com a simulações com fontes das fábricas de fertilizantes, e também com as fontes completas para a cidade, inventariadas pela CETESB . . . . . . . . . . . . . . . . 151 


\section{Lista de Abreviaturas}

NO Monóxido de Nitrogênio

$\mathrm{NO}_{2}$ Dióxido de Nitrogênio

$N O_{X}$ Óxidos de Nitrogênio

$\mathrm{O}_{3} \quad$ Ozônio

$\mathrm{SO}_{2} \quad$ Dióxido de Enxofre

BRAMS Brazilian Regional Meteorological Modeling System

CETESB Companhia Ambiental Do Estado De São Paulo

CIESP Centro das Indústrias do Estado de São Paulo

CO Monóxido de Carbono

CONAMA Conselho Nacional do Meio Ambiente

COSIPA Companhia Siderúrgica Paulista

CPTEC Centro de Previsão do Tempo e Estudos Climáticos

ENEL Ente Nazionale per Energia Elettrica

EPA Environmental Protection Agency - Agência de Proteção Ambiental do Estados Unidos

FAC2 Fraction of two

FB Fractional BIAS

GEPA Grupo de Estudos da Polução do Ar

GEPA Grupo de Estudos de Poluição do Ar do Instituto de Física da Universidade de São Paulo 
IAG Instituto de Astronomia, Geofísica e Ciências Atmosféricas da USP

IFUSP Instituto de Física da USP

IGC Instituto de Geociências da Universidade de São Paulo

IME Instituto de Matemática e Estatística

INPE Instituto Nacional de Pesquisas Espaciais

M71 Black Carbon de Referência Monarch 71

MABS Metropolitan Area of Baixada Santista

MAC Metropolitan Area of Campinas

MASP Metropolitan Area of São Paulo

MMA Ministério do Meio Ambiente

MP Material Particulado

$\mathrm{MP}_{10}$ Material Particulado Inalável - diâmetro aerodinâmico menor ou igual à $10 \mu \mathrm{g} / \mathrm{m}^{3}$

$\mathrm{MP}_{2,5}$ Material Particulado Fino - diâmetro aerodinâmico menor ou igual à 2,5 $\mu \mathrm{g} / \mathrm{m}^{3}$

NMSE Normalized Mean Square Error

NRMSE Normalized Root Mean Square Error

NRMSVE Normalized Root Mean Square Vector Error

OMS Organização Mundial da Saúde

RAMS Regonal Meteorological Modeling System

RMBS Região Metropolitana da Baixada Santista

RMSE Root Mean Square Error

RMSP Região Metropolitana de São Paulo

RMSVE Normalized Root Mean Square Vector Error

USGS United States Geological Survey

USP Universidade de São Paulo 
UTC Universal Time Coordinated

UTM Sistema de Coordenadas Universal Transversa de Mercartor

WHO World Health Organization

WMO World Meteorological Organization

WRF Weather Research \& Forecasting Model 


\section{Conteúdo}

$\begin{array}{ll}\text { Lista de Figuras } & 4\end{array}$

$\begin{array}{ll}\text { Lista de Tabelas } & 9\end{array}$

1 Introdução $\quad 17$

1.1 Apresentação . . . . . . . . . . . . . . . . . . . . . . . . 17

1.2 Estado de São Paulo . . . . . . . . . . . . . . . . . . . . . . . 18

1.2.1 Geografia e Clima da RMSP e Cubatão . . . . . . . . . . . . . . . . 18

1.2.2 Desenvolvimento Econômico e Urbano da RMSP e de Cubatão . . . . . 19

1.2.2.1 Cubatão . . . . . . . . . . . . . . . . . 20

1.3 Diretrizes para Controle de Poluentes Atmosféricos . . . . . . . . . . . . 22

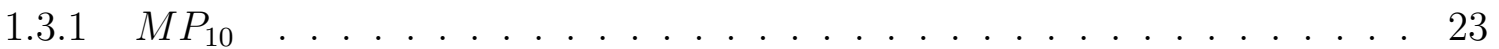

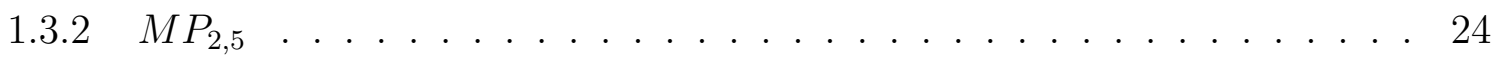

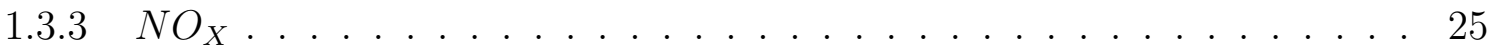

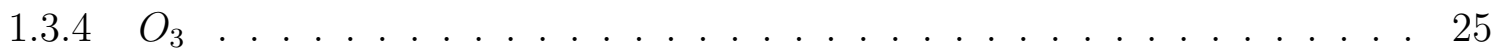

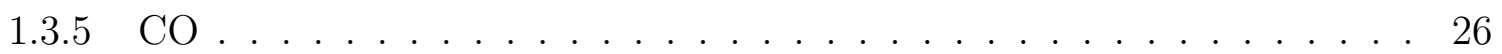

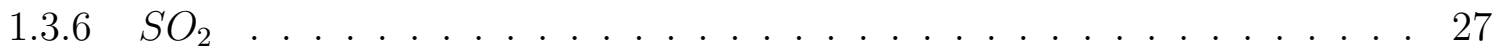

1.4 Poluição do Ar na RMSP e Cubatão . . . . . . . . . . . . . . . . . . . . . 27

1.4.1 Planos de Controle de Emissões e Redução das Concentrações de Poluentes 28

1.4.1.1 PROCONVE ........................ 29

1.4.1.2 Cubatão . . . . . . . . . . . . . . . 35

2 Teoria da Difusão Atmosférica 38

2.1 Modelos Estocásticos Lagrangianos - Uma Introdução . . . . . . . . . . . . . . 38

2.1.1 Difusão Atmosférica . . . . . . . . . . . . . . . . . . . . 38

2.1.2 Difusão Molecular - Formulação Euleriana . . . . . . . . . . . . . . . . 39

2.1.2.1 Conservação de Massa . . . . . . . . . . . . . . . . . . . 39

2.1.2.2 Equação da Difusão Molecular . . . . . . . . . . . . . . . . 40 
2.1.3 Difusão Molecular - Formulação estatística . . . . . . . . . . . . . . . . 42

2.1.3.1 Teorema de Taylor . . . . . . . . . . . . . . 43

2.1.3.2 Movimento Browniano . . . . . . . . . . . . . . 44

2.1.3.2.1 Dispersão de partículas Brownianas . . . . . . . . 45

2.1.3.2.2 Modelo do Simples Caminho Aleatório . . . . . . . 46

2.1.4 Difusão Turbulenta . . . . . . . . . . . . . . . . . . 48

2.1.4.1 Equação de Langevin para Turbulência . . . . . . . . . . . . 48

2.1.4.2 A Forma Gaussiana da Distribuição de Concentração para Difusão Turbulenta . . . . . . . . . . . . . . . . . 49

2.2 Modelagem Numérica da Dispersão de Partículas no SPRAY . . . . . . . . . 49

3 Metodologia $\quad 52$

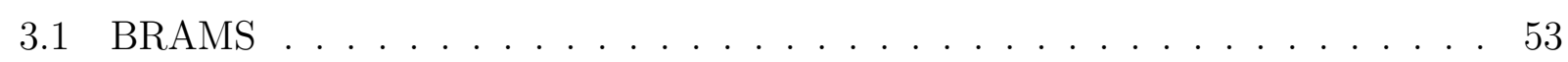

3.1.1 Configuração da simulação meteorológica . . . . . . . . . . . . . . 53

3.1.1.1 Grade ......................... 53

3.1.1.2 Parametrizações Físicas . . . . . . . . . . . . . . . 54

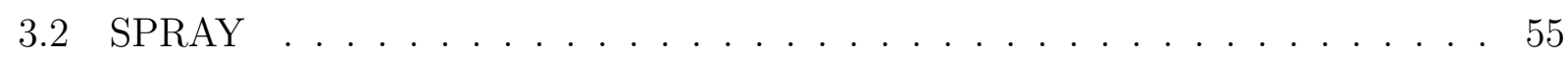

3.2.1 Tornando o acoplamento BRAMS/SPRAY operacional . . . . . . . . 55

3.2.2 Configuração do modelo de dispersão de poluentes . . . . . . . . . . . 56

3.2.2.1 Simulação das fontes de CO para RMSP e sua relação com $M P_{10} \ldots \ldots \ldots \ldots \ldots \ldots \ldots$

3.2.2.2 Fontes $M P_{10}$ para Cubatão . . . . . . . . . . . . 59

3.3 Estações de Medidas . . . . . . . . . . . . . . . . . . . . . . . 61

3.4 Métodos de avaliação dos resultados simulados . . . . . . . . . . . . 63

3.4.1 Critérios de realidade para avaliar a performance dos modelos . . . . 65

4 Resultados e Discussão $\quad 68$

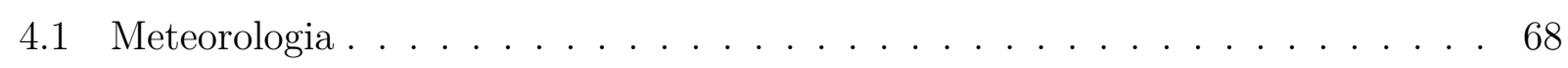

4.1 .1 Pressão . . . . . . . . . . . . . . . . . . 68

4.1 .2 Umidade . . . . . . . . . . . . . . . . . 69

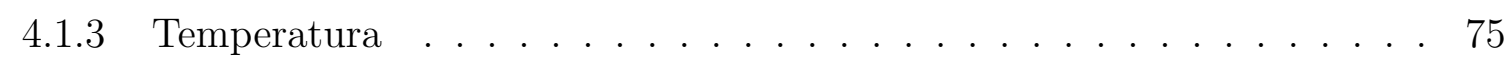

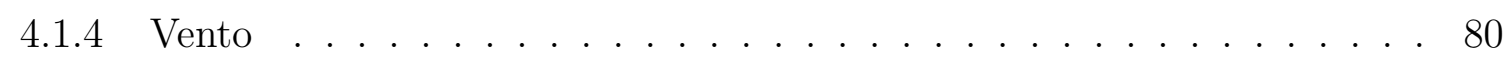

4.1.4.1 Vento Zonal . . . . . . . . . . . . . . . 80

4.1.4.2 Vento Meridional . . . . . . . . . . . . . . 88 
4.1.4.3 Magnitude ..................... . . 95

4.1.5 Radiossondagem . . . . . . . . . . . . . . . . . . . . 104

4.1.5.1 Pressão . . . . . . . . . . . . . . . . . . . . . 104

4.1.5.2 Umidade . . . . . . . . . . . . . . . . . . . 108

4.1.5.3 Temperatura . . . . . . . . . . . . . . . 112

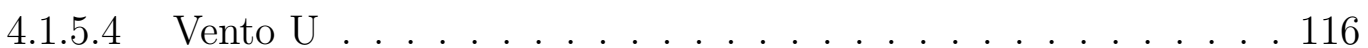

4.1.5.5 Vento V....................... 120

4.1.5.6 Direção do Vento . . . . . . . . . . . . . . . . . . . . . . . . 125

4.1.5.7 Magnitude do Vento . . . . . . . . . . . . . . . . . . . . . 129

4.2 Dispersão de Poluentes . . . . . . . . . . . . . . . . . . . . 132

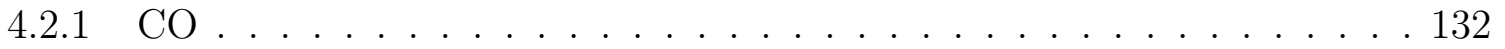

4.2.1.1 Transporte de CO nos arredores . . . . . . . . . . . . . . 142

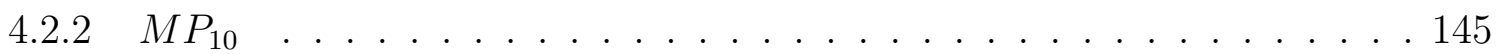

4.2 .3 Experimento de Inverno . . . . . . . . . . . . . . . . 150

5 Conclusão 152

$\begin{array}{lr}\text { Bibliografia } & 154\end{array}$ 


\section{Introdução}

\subsection{Apresentação}

Uma das grandes vontades humanas - quando se trata de tomada decisões para o bem-estar, apoiadas na investigação científica e no conhecimento vigente - é conseguir prognosticar eventos a partir da compreensão da natureza e dos demais processos que afetam nossa vida cotidiana. Dependendo dos eventos e circunstâncias, pode-se evitá-los, mitigá-los, e/ou tomar decisões de apoio para adaptar-se a estes.

Com o conhecimento da meteorologia e do clima, pode-se decidir o que ou quando plantar, ou ajudar a Defesa Civil a prever e evitar desastres, ou mitigar os seus efeitos. O nosso modo de vida estão associados, também, a processos de conversão de energia, de produção e a formas de locomoção que causam danos à nossa saúde, a animais, a vegetais e materiais, além de outros impactos ao meio ambiente em geral. Da mesma forma, o conhecimento sobre a propagação de poluentes, pode ajudar-nos a tomar decisões para mitigar seus efeitos, repensar locais e procedimentos para instalação de indústrias, gerir nossa economia, e até pensar em um urbanismo social e ecologicamente sustentável.

É necessário frisar que à própria natureza, em alguns locais e em certas circunstâncias (atividade vulcânica, bio-aerossóis alergênicos ou patológicos etc), também está associada poluição, o que reforça a necessidade de investigação de seu transporte na atmosfera.

A evolução das cidades propiciou maior aglomeração e desenvolvimento urbano. A instalação de indústrias e utilização de combustível fóssil, seja para produzir energia elétrica, seja para o transporte, fez com que a poluição atmosférica tenha se tornado cada vez mais intensa, sendo necessárias medidas para prevê-la, controlá-la e mitigá-la. A produção de energia elétrica por usinas nucleares, ou mesmo atividade nuclear com fins bélicos, tornou o problema da dispersão de poluentes ainda mais relevante frente aos graves riscos que acarretam (Slade, 1968).

No Brasil, com o avanço do café, no fim do século XIX e início do século XX, parte dos 
latifundiários investiram seu capital em indústrias na cidade de São Paulo e/ou arredores. Porém, a industrialização no país começou mesmo, por volta da década de 30 do século XX, após o fim da República Velha, e a partir do governo Vargas (Prado Júnior, 1978).

Na década de 50, no governo de Juscelino Kubitschek, houve outro surto de industrialização, e a indústria automobilística foi a principal escolha para o desenvolvimento do país (Prado Júnior, 1978), (Caputo \& Melo, 2009), (Sader, 2010). "Engarrafamento é sinal de progresso", diziam alguns políticos.

Neste período, a região Sudeste foi a que mais se desenvolveu, principalmente o Estado de São Paulo, gerando êxodo rural e concentração de pessoas sem o devido planejamento urbano nas cidades mais desenvolvidas (Camarano \& Abramovay, 1999).

Neste trabalho realizamos simulações da dispersão de poluentes por fontes da maior região metropolitana do país, a Região Metropolitana de São Paulo (RMSP), e em um dos maiores polos industriais do país, também no estado de São Paulo, a cidade de Cubatão. Os poluentes simulados em cada uma destas áreas, foram, respectivamente, CO (quase toda emissão é devida a veículos), e $P M_{10}$. A simulação foi realizada entre 23 a 26 de agosto de 2006, no inverno, quando as condições de dispersão, são, geralmente, ruins. Um experimento de inverno realizado entre estes dias mostrou episódios de poluição do ar mesmo em uma área remota. Os resultados da simulação foram comparados tanto com medições da CETESB quanto com os dados desse experimento de inverno.

Para a realização deste trabalho, foram utilizados os modelos atmosférico de meso-escala BRAMS (Brazilian Regional Atmospheric Modeling System), e o lagrangiano de dispersão de partículas, SPRAY. O BRAMS é uma versão do RAMS (Regional Atmospheric Modeling System, desenvolvido na Colorado State University) com diversos ajustes e parametrizações para que o modelo tenha resultados melhores diante das especificidades brasileiras. O SPRAY foi desenvolvido pelo Centro Ricerca Ambiente e Materiali da ENEL (Ente Nazionale per Energia Elettrica) e pelo Istituto di Cosmo-Geofisica do Consiglio Nazionale di Richerca da Itália. O Acoplamento destes dois modelos já foi utilizado para simulações em trabalhos anteriores para esta área. 


\subsection{Estado de São Paulo}

\subsubsection{Geografia e Clima da RMSP e Cubatão}

${ }^{1}$ O Estado de São Paulo localiza-se na Região Sudeste do Brasil, com centro aproximado a $22^{\circ} \mathrm{S}$ e $49^{\circ} \mathrm{O}$, com uma área de $248209,4 \mathrm{~km}^{2}$. É banhado pelo oceano Atlântico a leste, faz fronteiras com Rio de Janeiro, e Minas Gerais ao norte, e com o estado do Paraná ao sul e é limitado pelo Rio Paraná a oeste, fazendo fronteira com o estado de Mato Grosso do Sul.

A planície litorânea alcança até cerca de $40 \mathrm{~km}$ de largura e, indo-se em direção a oeste, há a Serra do Mar com uma largura de cerca de $50 \mathrm{~km}$ e alturas típicas variando entre 800m e 1100m. O resto do estado está situado sobre um planalto com aproximadamente $600 \mathrm{~km}$ de extensão (leste-oeste).

A maior parte do Estado situa-se ao norte do Trópico de Capricórnio e apresenta clima tropical. Na parte do Planalto Paulista, onde se encontra a Região Metropolitana de São Paulo e o sudeste do estado, o clima é subtropical.

De maneira geral os invernos são frios e secos (fruto da passagem de frentes frias oriundas do Sul), enquanto que os verões são quentes e úmidos (salvo eventuais períodos de estiagem em algumas regiões). A RMSP sofre tanto influência da circulação terra-mar (dista cerca de $45 \mathrm{~km}$ do litoral) quanto do aquecimento continental.

Cubatão encontra-se no litoral Sul. Está entre a Serra do Mar ao norte, e as cidades de São Vicente e Santos ao Sul. Possui topografia acidentada, principalmente nos arredores do Vale do Mogi. A área urbana de Cubatão situa-se ente a Serra do Mar e o mangue, que a separa de São Vicente e Santos. A topografia local é um fator que dificulta a dispersão dos poluentes em qualquer condição meteorológica. A noite, em função da diminuição da camada limite, forma-se um "tampão" para os poluentes, que ficam muito próximos à superfície. Os ventos noturnos ligados à circulação terra-mar e de montanha têm baixa intensidade, prevalecendo calmaria, contribuindo, também, para o aumento das concentrações. No inverno, dada a menor intensidade do sol, a camada limite diurna pode ser mais baixa que a altitude da serra, fazendo com que a concentração de poluentes seja mais alta nesta estação.

\footnotetext{
${ }^{1}$ Informações sobre geografia e clima do estado extraídas de CETESB (2007).
} 


\subsubsection{Desenvolvimento Econômico e Urbano da RMSP e de Cuba-}

tão

O Estado de São Paulo cresceu economicamente em torno do café ao longo do século XIX, com produção no Interior, tendo a capital como centro comercial de convívio das elites e sua educação (escolas de medicina, direito e engenharia) (Gois Júnior, 2013), (Ferreira, 2007), (de Souza, 2000).

Ferrovias foram desenvolvidas para ligar a produção aos portos, no litoral. Antes disto, no período colonial, Cubatão era ponto de passagem entre o porto e o planalto. Já o rio Tietê fornecia a rota para alcançar o interior, passando antes, pela cidade de São Paulo (Novo Milênio, 2016).

Entre o final do século XIX e início do século XX, o capital acumulado pelo café permitiu uma pequena industrialização, mais voltada à transformação de matérias-primas naturais. Depois, com o final da República Velha, houve dois períodos em que o Brasil se industrializou fortemente: um iniciado em 1930 (Era Vargas), e outro em 1955 (governo Juscelino Kubitschek) (Prado Júnior, 1978). No primeiro, houve substituição de importações e forte apoio estatal, culminando inclusive com a criação da Petrobras na década de 50. O segundo foi marcado por ampliação do mercado interno e, embora tenha havido massivo apoio estatal, houve forte presença de capital estrangeiro e grande pressão da indústria automobilística nas decisões de infra-estrutura do país. Essa passou a produzir no Brasil para escapar de mão-de-obra cara em seus países de origem. Soma-se a isto o fato das transnacionais, automobilísticas ou não, procurarem evitar a legislação ambiental mais pesada nos países desenvolvidos (Gutberlet \& Gutberlet, 1996).

A industrialização e desenvolvimento econômico do país deram-se de forma desigual e desorganizada, sendo São Paulo, o mais desenvolvido e industrializado estado da nação. Esta forma de desenvolvimento gerou problemas socioambientais, como a poluição do ar e das águas, colocando em risco a saúde na metrópole e nas cidades industriais, além de êxodo rural e desigualdade social, com pessoas sofrendo péssimas condições de vida nas cidades.

Na RMSP, o desenvolvimento econômico girou, em grande parte, em torno da indústria automobilística, sendo responsável também pelas soluções urbanísticas desenvolvidas. Como a indústria automobilística produz veículos que se movem impulsionados por motores alimentados por combustíveis fósseis, o problema de poluição atmosférica está intimamente relacionado ao transporte de pessoas e cargas. A RMSP tornou-se a região metropolitana de maior densidade populacional, em função do seu desenvolvimento industrial e comercial. Concentra 
praticamente a metade da população do estado (21 milhões de habitantes (IBGE, 2014)), ou cerca de $10 \%$ da população do país. Em 2006, a RMSP contabilizava cerca de 7,3 milhões de veículos, dos quais, 6,0 milhões realizando ciclo Otto (movidos a etanol ou gasolina). Tal volume representava cerca de $1 / 5$ da frota total do país. Cerca de $97 \%$ da emissão de CO da Região é originada de sua frota veicular (CETESB, 2007). A região, conta ainda com mais de 2000 indústrias com alto potencial poluidor.

\subsubsection{Cubatão}

A Baixada Santista, capitaneada justamente pela cidade de Cubatão, tornou-se um dos maiores polos industriais do país, também atraindo uma grande quantidade de migrantes. Para a nascente industrialização, ainda com capital oriundo do café, aproveitando-se de uma queda d'água de aproximadamente 700m, a Light (então uma companhia de geração de energia elétrica de capital canadense) instalou uma hidrelétrica em Cubatão, propiciando energia elétrica especialmente para a capital (Gutberlet \& Gutberlet, 1996).

Aproveitando-se da infraestrutura ferroviária e de rotas existentes desde o período colonial, Cubatão, do ponto de vista econômico parecia perfeita para basear um polo industrial petroquímico, siderúrgico e de apoio à agricultura intensiva (produção de fertilizantes e defensivos agrícolas). Está próximo ao mais importante mercado consumidor do país, ao porto, a ferrovia e estradas e, com oleodutos, o petróleo pode facilmente ser transportado para o planalto.

Além dos fatores econômicos estratégicos, há também os motivos de segurança: A COSIPA foi instalada em Cubatão para ter o oceano Atlântico e a Serra do mar como proteção (Uchôa, 2016); no pós-guerra montou-se a Refinaria Presidente Bernardes encrustada na Serra, em local de difícil acesso a aviões e grandes embarcações, para contar também com a "proteção visual" de nuvens orográficas' contra bombardeios (Kerr, 1995) (Mendes, 2016a); e a usina Hidrelétrica Henry Borden possuía uma usina espelho dentro da montanha, buscando evitar destruição da capacidade de gerar energia por conta de eventuais bombardeios (Mendes, $2016 b)$.

A geografia torna a cidade, entretanto, uma das piores escolhas em termos ambientais para haver indústrias como as citadas acima. Em virtude da Serra do Mar e da acidentada topografia, há grande dificuldade para dispersão de poluentes, prejudicando a saúde humana e animal, propiciando, como em passado recente, ataque à vegetação e ao ecossistema de transição que o mangue representa. Além disto, houve aterramento de mangues para instalação de indústrias 
e locais de moradia, improvisados ou planejados, sem levar em conta considerações ambientais (Gutberlet \& Gutberlet, 1996).

Graças à intensa mobilização da comunidade científica, sociedade civil e da classe trabalhadora residente em Cubatão no período de redemocratização do país, governos e indústrias tiveram de fazer planos para mitigar os danos ambientais naquela área. O problema ambiental de Cubatão é algo que já chamava a atenção desde o final da década de 70, também com a poluição das águas (Kucisnki, 1982).

Em 1982, o GEPA - Grupo de Estudos de Poluição do Ar - realizou medidas de poluição do ar pela primeira vez (Kucisnki, 1982) (Kerr, 1995). As medidas da CETESB existiam, mas a empresa estatal sofria ingerências do então governo biônico nomeado pela ditadura militar. O estudo determinou a concentração e composição elementar de material particulado inalável, separado em suas frações grossa e fina, assim como correlacionou-o com a material particulado total em suspensão, para o qual havia padrão de qualidade do ar definido à época.

A sociedade civil continuava pressionando, seja através de clérigos progressistas, associação de moradores - trabalhadores das indústrias da cidade - e comunidade científica de um lado, e representantes do empresariado que visam o lucro imediato de outro (Kucisnki, 1982).

Em 1984, o GEPA fez um experimento em conjunto com a CETESB e com a NEA (empresa estadunidense responsável por produzir um relatório para a CETESB sobre as fontes de poluentes, utilizando modelo receptor e balanço químico de massa). Outros trabalhos foram realizados em anos seguintes, mas esse estudo marcou o início das ações de controle que passaram a ser adotadas naquele polo industrial.

Embora cerca de $98 \%$ das fontes emissoras de Cubatão sejam dadas como controladas, as concentrações de material particulado ainda superam tanto os padrões nacionais quanto os da Organização Mundial da Saúde (CETESB, 2007). Vê-se, assim, que mesmo com a redução da incidência de níveis críticos, o problema ambiental continua grave, não sendo incomum, inclusive, acidentes que provocam emissões descontroladas e danos à população.

A RMSP e Cubatão, são os dois locais do estado mais afetados pela poluição do ar, predominando hoje problemas relacionados ao Material Particulado (MP) e ozônio $\left(O_{3}\right)$.

\subsection{Diretrizes para Controle de Poluentes Atmosféricos}

A discussão sobre os poluentes atmosféricos, como surgem, e seus efeitos tem por base as informações contidas em CETESB (2007), Boubel et al. (2013) e World Health Organization (2006). 
Mais de 2 milhões de pessoas morrem por ano por motivos relacionados à poluição atmosférica, e mais da metade das mortes ocorrem em países de terceiro mundo (World Health Organization, 2006).

Poluente atmosférico é todo o material ou energia que, liberado na atmosfera em concentração ou intensidade além de determinados níveis, pode causar algum mal-estar à saúde, ou causar danos aos animais e meio-ambiente CETESB (2007).

Os poluentes mais comuns em ambientes com intensa ação e presença dos seres humanos são alvo de legislações, diretrizes, monitoramento e política de mitigação pelos governos.

Os poluentes podem ser

- Primários: Emitidos diretamente pelas fontes;

- Secundários: Provenientes de reação química entre poluentes primários e outros fatores disponíveis no ambiente (luz, reagentes, oxidantes etc).

Os principais poluentes monitorados são Monóxido de Carbono (CO), Material Particulado (MP) - tanto o fino $\left(<2,5 \mu m-M P_{2,5}\right)$ quanto o inalável $\left(<10 \mu m-M P_{10}\right)$, Dióxido de Enxofre $\left(\mathrm{SO}_{2}\right)$, Ozônio $\left(\mathrm{O}_{3}\right)$ e Dióxido de Nitrogênio $\left(\mathrm{NO}_{2}\right)$, pois ocorrem com maior frequência em decorrência de ações antropogênicas.

As diretrizes da OMS para os poluentes atmosféricos têm por objetivo diminuir os impactos da poluição do ar. Foram, primeiramente produzidos em 1987, tendo passado por duas revisões - baseadas nas evidências científicas disponíveis em cada uma delas - sendo a última em 2005. Como é difícil para muitos países reduzir suas diretrizes para, imediatamente, atingir as diretrizes da OMS, esta propôs metas intermediárias para cada poluente.

Nas tabelas 1.1, 1.2, 1.3, 1.4, 1.5 e 1.6 são mostradas as concentrações máximas recomendadas pelo CONAMA e pela OMS para os poluentes $M P_{10}, M P_{2,5}, N O_{2}, O_{3}$, CO e $S_{2}$, respectivamente. O $M P_{2,5}$ não é legislado pelo CONAMA.

\subsection{1 $\quad M P_{10}$}

Na tabela 1.1, aparecem os padrões para o Material Particulado Inalável para o CONAMA e a Organização Mundial da Saúde.

O padrão anual de $20 \mathrm{\mu gm}^{-3}$ foi escolhido por ser o dobro do padrão para Material Particulado fino, pois de acordo com a OMS, nas grandes cidades de países em desenvolvimento, a razão $\frac{M P_{10}}{M P_{2,5}}$ é 2 (World Health Organization, 2006), e o padrão para o Material Particulado fino é $10 \mu \mathrm{gm}^{-3}$. A razão pela qual estes valores foram escolhidos pela OMS está dita na 
sessão sobre o material particulado fino. Ainda, de acordo com a OMS, seguir as diretrizes recomendadas para exposição de curto prazo faz com que a população esteja protegida contra picos de concentração do poluente.

Para o CONAMA, o padrão para curto prazo (24h) não deveria ser excedido mais do que 1 vez no ano (Conselho Nacional do Meio Ambiente, 1990), enquanto que para a OMS, não deveria ser ultrapassado em mais de $1 \%$ dos dias avaliados no ano (World Health Organization, 2006).

Tabela 1.1: Padrões de Qualidade do Ar para $M P_{10}$ : Valores estabelecidos pelo CONAMA e OMS. As metas referem-se a padrões intermediários sugeridos pela OMS antes da principal ser atingida.

\begin{tabular}{lll}
\hline \hline$M P_{10}$ & $\begin{array}{l}\text { Média diária } \\
\left(\mu \mathrm{gm}^{-3}\right)\end{array}$ & $\begin{array}{l}\text { Média anual } \\
\left(\mu \mathrm{gm}^{-3}\right)\end{array}$ \\
CONAMA & 150 & 50 \\
Meta 1 & 150 & 70 \\
Meta 2 & 100 & 50 \\
Meta 3 & 75 & 30 \\
Diretriz OMS & 50 & 20 \\
\hline
\end{tabular}

O Material Particulado não é um ente que se apresenta sempre com os mesmos elementos. É constituído de partículas sólidas, líquidas, ou ambas, podendo formar neblina, aerossol, fumaça etc.

O Material Particulado Inalável, de diâmetro médio $<10 \mu m$ surge por processos mecânicos, como moagem, "borbulhar do mar", ressuspensão de poeira no solo etc. Apesar de não surgir através de combustão, há uma relação entre este e o tráfego de veículos, não apenas associado à ressuspensão do solo, como também pelo desgaste de materiais como pneus etc.

Material Particulado com diâmetro médio $>10 \mu m$ tem baixa penetração nas vias respiratórias devido à ação da gravidade ser maior que o arraste promovido pelo nariz.

\subsection{2 $\quad M P_{2,5}$}

Na tabela 1.2, são apresentados os padrões para o Material Particulado fino. Este poluente não tem legislação nacional no Brasil, então estão disponíveis a regulação da Agência de Proteção Ambiental dos EUA (EPA, na sigla em inglês) e as diretrizes da OMS, cujas metas estão sendo admitidas em sequência pela CETESB. Mesmo não sendo legislado nacionalmente no Brasil, dada a razão de 0,5 para a fração $\frac{M P_{2,5}}{M P_{10}}$ nos ambientes urbanos e o fato de que as pesquisas para os riscos do material particulado à saúde serem avaliados em pesquisas com base no material particulado fino (World Health Organization, 2006), é importante citá-lo.

Os padrões para curto prazo foram definidos pela OMS porque evitam que a população 
seja exposta a picos de concentração, e seja evitada uma grande morbidade (World Health Organization, 2006).

Os padrões para longo prazo foram selecionados de acordo com os resultados do estudo de Pope III et al. (2002).

O padrão de $24 \mathrm{~h}$ (curto prazo) não deve ser ultrapassado em mais do que $1 \%$ dos dias avaliados no ano.

No caso dos padrões da EPA, a forma de verificar sua observância é um pouco diferente. Para o padrão anual, uma média em 3 anos deve ser calculada, enquanto que não mais do que $2 \%$ dos dias, em um intervalo de 3 anos, devem exceder o padrão de 24 h (Environmental Protection Agency, 1990).

Tabela 1.2: Padrões de Qualidade do Ar para $M P_{2,5}$ : Valores estabelecidos pelo CONAMA e OMS. As metas referem-se a padrões intermediários sugeridos pela OMS antes da principal ser atingida.

\begin{tabular}{lll}
\hline \hline$M P_{2,5}$ & $\begin{array}{l}\text { Média diária } \\
\left(\mu \mathrm{gm}^{-3}\right)\end{array}$ & $\begin{array}{l}\text { Média anual } \\
\left(\mu \mathrm{gm}^{-3}\right)\end{array}$ \\
CONAMA & - & - \\
Meta 1 & 75 & 35 \\
Meta 2 & 50 & 25 \\
Meta 3 & 37,5 & 15 \\
EPA & 35 & 12 \\
Diretriz OMS & 25 & 10 \\
\hline
\end{tabular}

O Material Particulado fino (diâmetro $<2,5 \mu m$ ) é gerado através de combustão e conversão gás-partícula, e podem penetrar fundo no sistema respiratório, chegando aos alvéolos pulmonares, onde ocorrem as trocas gasosas dentro do corpo. Se está contaminado com compostos de enxofre - ou qualquer outro material nocivo - pode causar desde simples tosse a doenças respiratórias graves, como câncer de pulmão.

\subsection{3 $N O_{X}$}

Na tabela 1.3 estão listados os padrões para $\mathrm{NO}_{2}$ de acordo com o CONAMA (Conselho Nacional do Meio Ambiente, 1990) e a OMS (World Health Organization, 2006).

Tem sido mais difícil encontrar evidências dos problemas à saúde pública associados exclusivamente ao $\mathrm{NO}_{2}$, contudo, há aumento de sintomas de bronquite de crianças asmáticas quando há aumento de $\mathrm{NO}_{2}$ na mistura do ar (World Health Organization, 2006).

A OMS acredita que manter as diretrizes nos níveis atuais, como exposto na tabela, ajuda a controlar a poluição da mistura dos gases relacionados à combustão (World Health Organization, 2006). 
Tabela 1.3: Padrões de Qualidade do Ar para $\mathrm{NO}_{2}$ : Valores estabelecidos pelo CONAMA e OMS.

\begin{tabular}{lll}
\hline \hline $\mathrm{NO}_{2}$ & $\begin{array}{l}\text { Média horária } \\
\left(\mu \mathrm{gm}^{-3}\right)\end{array}$ & $\begin{array}{l}\text { Média anual } \\
\left(\mu \mathrm{gm}^{-3}\right)\end{array}$ \\
CONAMA & 190 & 100 \\
Diretriz OMS & 200 & 40 \\
\hline
\end{tabular}

Nota-se que o padrão para curta exposição ao $\mathrm{NO}_{2}$ do CONAMA é menor que o da OMS.

O $N O_{X}$ participa das reações de produção e destruição de ozônio troposférico, sendo este último um poluente secundário. $\mathrm{O} \mathrm{NO}_{2}$ pode contribuir para a formação de chuva ácida, além de ajudar a diminuir a resistência à infecções respiratórias, aumentando, também, a sensibilidade à asma e à bronquite. Origina-se naturalmente da oxidação do NO em reação fotoquímica associada a hidrocarbonetos, mas surge também em função de combustão (World Health Organization, 2006).

\subsection{4 $\mathrm{O}_{3}$}

Na tabela 1.4, estão as diretrizes para o $O_{3}$ da OMS e do CONAMA (Conselho Nacional do Meio Ambiente, 1990). Para a OMS, uma máxima diária de $240 \mu \mathrm{gm}^{-3}$ em uma média de 8 horas é considerado um nível muito alto para este poluente, com impactos significativos na saúde.

O padrão da OMS para máxima diária em uma média de 8 h é de $100 \mu \mathrm{gm}^{-3}$, por ser adequada à proteção da saúde pública. É estimado um crescimento entre $1 \%$ a $2 \%$ na mortalidade diária atribuída ao ozônio em relação a uma concentração de fundo de $70 \mu \mathrm{gm}^{-3}$ (World Health Organization, 2006).

Para o CONAMA, o padrão é para máxima calculada em 1h, e não deve ser excedida mais do que uma vez por ano.

Tabela 1.4: Texto para a tabelaPadrões de Qualidade do Ar para $O_{3}$ : Valores estabelecidos pelo CONAMA e OMS. As metas referem-se a padrões intermediários sugeridos pela OMS antes da principal ser atingida.

\begin{tabular}{lll}
\hline \hline $\mathrm{O}_{3}$ & $\begin{array}{l}\text { Média de 8h } \\
\left(\mu \mathrm{gm}^{-3}\right)\end{array}$ & Observação \\
Níveis altos & 240 & \\
CONAMA & 160 & Média de 1h \\
Meta 1 & 160 & \\
Diretriz OMS & 100 & \\
\hline
\end{tabular}

O Ozônio é um poluente secundário. É gerado na troposfera a partir da presença de uma correta proporção de $\mathrm{NO}_{2}$ (reação de produção), NO (reação de destruição), orgânicos voláteis, e radiação solar. O Ozônio é um oxidante muito reativo, e em seres humanos causa 
irritação em vias respiratórias, diminuição da capacidade pulmonar. Em concentração altas os alvéolos podem sofrer avarias e os sintomas tornam-se mais severos, ocorrendo dor e sensação de "aperto" no peito, tosse e chiado na respiração.

Em velórios, para impedir a contaminação dos seres humanos pelos agentes patogênicos que podem exalar do corpo do defunto, usa-se ozônio para matar estes agentes.

Pode haver, por conta do Ozônio, danos à vegetação de maneira geral.

Tanto a RMSP quanto Cubatão ultrapassam as concentrações máximas legisladas pelo CONAMA, bem como as recomendações da OMS, nos meses de primavera e verão (nesta última, um pouco menos, por causa do aumento de nebulosidade), uma vez que há uma dependência direta da luz para a produção de Ozônio.

\subsubsection{CO}

A tabela 1.5 mostra as diretrizes da OMS e do CONAMA (Conselho Nacional do Meio Ambiente, 1990) para CO.

As diretrizes para a OMS são estabelecidas de modo que, o nível de carboxiemoglobinas no sangue não supere 2,5\%, mesmo quando uma pessoa normal pratica exercícios leves ou moderados (World Health Organization, 1999).

Tabela 1.5: Padrões de Qualidade do Ar para CO: Valores estabelecidos pelo CONAMA e OMS.

\begin{tabular}{lllll}
\hline \hline CO & Média em 8h & & Média em 1h & \\
& ppm & $\mathrm{mgm}^{-3}$ & $\mathrm{ppm}$ & $\mathrm{mgm}^{-3}$ \\
CONAMA & 9 & 10 & 35 & 40 \\
Diretriz OMS & 9 & 10 & 26 & 30 \\
\hline
\end{tabular}

O Monóxido de Carbono (CO) é gerado através da combustão incompleta. Ele apresenta mais afinidade às hemoglobinas do que o próprio oxigênio, inutilizando a célula sanguínea com a qual venha a formar ligação. Em grandes concentrações, pode colocar em perigo a vida, e as sensações típicas envolvem prejuízo dos reflexos, diminuição da percepção de tempo, prejuízos visuais e na capacidade de trabalho.

\subsection{6 $\mathrm{SO}_{2}$}

A tabela 1.6 apresenta os padrões para $\mathrm{SO}_{2}$ do CONAMA (Conselho Nacional do Meio Ambiente, 1990) e da OMS (World Health Organization, 2006).

O padrão de 24h da OMS foi escolhido com base nos estudos de Pope III et al. (2002), mostrando significativa associação entre $\mathrm{SO}_{2}$ e mortalidade em que a concentração média foi 
de $18 \mu \mathrm{gm}^{-3}$ e a máxima, de $85 \mu \mathrm{gm}^{-3}$, mas levando em consideração incertezas na relação causal para o poluente, e a necessidade de maior proteção, levando em consideração que uma redução na exposição ao mesmo resulta em redução da mortalidade (Buringh et al., 2000).

Nota-se que o padrão do CONAMA é cinco vezes maior que o da OMS para a média diária.

O enxofre é emitido em atividades antropogênicas na combustão de óleos pesados, bem como na atividade industrial. Na combustão e na atmosfera, pode gerar o Dióxido de Enxofre $\left(\mathrm{SO}_{2}\right)$, e participar da formação de chuva ácida, causando danos à vegetação.

Nos seres humano, causa problemas respiratórios, com agravamento de doenças que comprometem a respiração e o coração. Em função da sua periculosidade, curtas exposições para este poluente são para períodos de $10 \mathrm{~min}$, e exposições de longo prazo para $24 \mathrm{~h}$, pelo menos no entender da OMS. Para o CONAMA, os padrões continuam sendo de $24 \mathrm{~h}$ e 1 ano, respectivamente, para curto e longo prazo.

Tabela 1.6: Padrões de Qualidade do Ar para $\mathrm{SO}_{2}$ : Valores estabelecidos pelo CONAMA e OMS.

\begin{tabular}{llll}
\hline \hline $\mathrm{SO}_{2}$ & $\begin{array}{l}\text { Média diária } \\
\left(\mu \mathrm{gm}^{-3}\right)\end{array}$ & $\begin{array}{l}\text { Média anual } \\
\left(\mu \mathrm{gm}^{-3}\right)\end{array}$ & Média em 10min \\
CONAMA & 100 & 40 & - \\
Meta 1 & 125 & - & - \\
Meta 2 & 50 & - & - \\
Diretriz OMS & 20 & - & 500 \\
\hline
\end{tabular}

\subsection{Poluição do Ar na RMSP e Cubatão}

Na cidade de São Paulo, há cerca de 80 km de Metrô, 200 km de trilhos de trens suburbanos, e $17.000 \mathrm{~km}$ de vias para veículos. De acordo com (CETESB, 2016), a frota circulante (não a total) da cidade de São Paulo é de 4,48 milhões de autos. Considerando-se um tamanho médio de $4 \mathrm{~m}$ para os autos e colocando-os enfileirados sem espaço entre si, obter-se-ia uma fila de $17,920 \mathrm{~km}$. A maioria dos empregos concentra-se no centro da cidade, que apresenta menos moradores. Em compensação, a periferia é superpovoada, havendo necessidade de se fazer viagens longas para chegar ao trabalho. Nos deslocamentos entre bairros próximos há pouca disponibilidade de transporte público. Mesmo saturado ele ainda é voltado para responder apenas a demanda por locomoção ao local de trabalho, e não outras demandas como o lazer e a facilidade de interligação da cidade.

A malha de transporte público atende acima de sua capacidade, ao mesmo tempo em que há uso intensivo de carros particulares para a locomoção, geralmente com apenas 1 pessoa 
em cada veículo. Além disso, grande parte da economia e empregos dos moradores das outras cidades da região metropolitana gira em torno da capital. Algumas delas são conhecidas como "cidades-dormitório".

Assim, a maior parte dos poluentes emitidos na RMSP está direta ou indiretamente relacionada à circulação de veículos com motores alimentados por combustível fóssil, muito embora haja algumas indústrias com emissões não desprezíveis. Trocar motores à combustão por motores elétricos em veículos de passeio, simplesmente, não resolve outros problemas associados ao desperdício de energia, qualidade de vida e urbanidade do modelo de cidade adotado.

A cidade de Cubatão tem em sua indústria petroquímica e de produção de insumos agrícolas a maior parte das fontes de poluentes.

Ambas as cidades superam às recomendações de concentração máxima de poluentes para Material Particulado $\left(M P_{10}\right.$ e $\left.M P_{2,5}\right)$, ozônio $\left(O_{3}\right)$ e óxidos de nitrogênio $\left(N O_{X}\right)$, precursores do primeiro.

Em 2006, houve ultrapassagens de padrão nas estações de São Caetano do Sul e Taboão da Serra em alguns dias (CETESB, 2007, Relatório de 2006, Resumo Executivo, pag I).

Cubatão, continua a apresentar níveis de concentração para $M P_{10}$ não apenas superiores às recomendações da OMS, mas também acima do limite permitido nas resoluções da CONAMA.

\subsubsection{Planos de Controle de Emissões e Redução das Concentra- ções de Poluentes}

Os veículos com motores a combustão interna são a principal fonte de emissão de poluentes na atmosfera dos grandes centros urbanos brasileiros, passando a ter suas emissões controladas no Brasil. Tais medidas tiveram impacto na RMSP especialmente a partir da implementação do PROCONVE.

Em função das intensas emissões industriais em Cubatão e ocorrência de acidentes, houve estudos, discussõese até pressão da comunidade internacional, em uma época marcada pela redemocratização do país, fazendo governos desenvolverem planos para mitigar o problema ambiental na região e tomar outras providências.

\subsubsection{PROCONVE}

PROCONVE é o Programa de Controle de Poluição do Ar por Veículos Automotores. Este programa foi criado em 1986, por uma resolução do CONAMA, órgão ligado ao IBAMA. Apesar 
de fazer parte de sua competência atuar visando o desenvolvimento de sistemas de transportes coletivos seu foco, em suas várias fases, tem sido apenas o controle progressivamente restritivo às emissões de poluentes em cada veículo. Em 1993, uma lei reforçou a obrigatoriedade de reduzir a emissão veicular, fazendo com que veículos nacionais e importados obedecessem os mesmos padrões de emissão. Em resumo, o PROCONVE tem atuado apenas procurando mitigar o problema pela via tecnológica. O programa possui fases diferentes para veículos leves (L) e pesados (P). Antes da implementação do programa, os veículos chegavam a emitir mais de $50 \mathrm{~g} / \mathrm{kg}$ de CO (MMA, 2013). As fases para os veículos leves estão descritas abaixo²:

- Fase L1 (1988-1991): Nesta fase, os níveis de emissão para cada poluente eram:

- CO: $24 \mathrm{~g} / \mathrm{kg}$

- HC (Hidrocarbonetos): 2,10 g/kg

- NMHC (Hidrocarbonetos não-metano): não se aplica

$-N O_{X}: 2,0 \mathrm{~g} / \mathrm{kg}$

- HCO (Aldeídos): não se aplica

- MP (para veículos do ciclo diesel): não se aplica

- Emissão Evaporativa (para veículos do ciclo Otto, exceto GNV): 6,0 g/teste

- CO em marcha lenta (veículos de ciclo Otto): $3 \%$ do volume emitido

As inovações tecnológicas desta fase foram a reciclagem dos gases do escapamento para controle das emissões de $N O_{X}$; injeção secundária do ar no coletor de exaustão para controle de $\mathrm{CO}$ e HC; implantação de amortecedor da borboleta do carburador para controle do HC e a otimização do avanço da ignição.

- Fase L2 (1992-1996): Nesta fase, os níveis de emissão para cada poluente eram:

- CO: $12,00 \mathrm{~g} / \mathrm{kg}$

- HC (Hidrocarbonetos): 1,20 g/kg

- NMHC (Hidrocarbonetos não-metano): não se aplica

- $N O_{X}: 1,4 \mathrm{~g} / \mathrm{kg}$

- HCO (Aldeídos): 0,15 g/kg

- MP (para veículos do ciclo diesel): não se aplica

${ }^{2}$ Dados das fases extraídos de CETESB (2016) e MMA (2013) 
- Emissão Evaporativa (para veículos do ciclo Otto, exceto GNV): 6,0 g/teste

- CO em marcha lenta (veículos de ciclo Otto): 2,5\% do volume emitido

Nesta fase, procurou-se observar os limites de emissão da resolução do CONAMA em 1986 que implementou o PROCONVE. Os principais avanços são a implementação de catalisadores e injeção eletrônica adaptados à mistura com etanol.

- Fase L3 (1997-2004): Nesta fase, os níveis de emissão para cada poluente eram:

- CO: $2,00 \mathrm{~g} / \mathrm{kg}$

- HC (Hidrocarbonetos): 0,30 g/kg

- NMHC (Hidrocarbonetos não-metano): não se aplica

- $N O_{X}: 0,6 \mathrm{~g} / \mathrm{kg}$

- HCO (Aldeídos): 0,03 g/kg

- MP (para veículos do ciclo diesel): 0,05 g/ kg

- Emissão Evaporativa (para veículos do ciclo Otto, exceto GNV): 6,0 g/teste (2,0 g/teste a partir de maio de 2003)

- CO em marcha lenta (veículos de ciclo Otto): 0,5\% do volume emitido

Para esta fase, em 1995, houve diminuição dos limites de emissão, e isto forçou a melhoria da tecnologia para formação de mistura e controle eletrônico no motor, como o sensor de oxigênio ("sonda lambda").

- Fase L4 (2005-2008): Nesta fase, os níveis de emissão se aplicavam para $40 \%$ da produção a partir de 2005, 70\% em 2006 e 100\% em 2007. Para cada poluente eram:

- CO: $2,00 \mathrm{~g} / \mathrm{kg}$

- HC (Hidrocarbonetos): 0,30 g/kg

- NMHC (Hidrocarbonetos não-metano): 0,16

- $N O_{X}: 0,25 \mathrm{~g} / \mathrm{kg}$ (veículos do ciclo Otto) e $0,60 \mathrm{~g} / \mathrm{kg}$ (veículos do ciclo diesel)

- HCO (Aldeídos): 0,03 g/kg

- MP (para veículos do ciclo diesel): 0,05 g/ kg

- Emissão Evaporativa (para veículos do ciclo Otto, exceto GNV): 2,0 g/teste

- CO em marcha lenta (veículos de ciclo Otto): 0,5\% do volume emitido 
Nesta fase, houve melhorias na geometria da câmara de combustão, e dos bicos de injeção, aumento da pressão da bomba injetora e a injeção eletrônica com vistas a reduzir as emissões de $\mathrm{HC}$ e $N O_{X}$.

- Fase L5 (2009-2013): Nesta fase, as emissões de HC e $N O_{X}$ sofreram nova redução em seus limites, e novas geometrias para a câmara de combustão e dos bicos, além de novo aumento da pressão da bomba injetora e melhoria da injeção eletrônica.

- CO: $2,00 \mathrm{~g} / \mathrm{kg}$

- HC (Hidrocarbonetos): 0,30 g/kg

- NMHC (Hidrocarbonetos não-metano): 0,05

- $N O_{X}: 0,12 \mathrm{~g} / \mathrm{kg}$ (veículos do ciclo Otto) e $0,25 \mathrm{~g} / \mathrm{kg}$ (veículos do ciclo diesel)

- HCO (Aldeídos): 0,02 g/kg

- MP (para veículos do ciclo diesel): 0,05 g/ $\mathrm{kg}$

- Emissão Evaporativa (para veículos do ciclo Otto, exceto GNV): 1,5 g/teste ou 2,0 g/teste (em caso de procedimento de câmara de volume variável)

- CO em marcha lenta (veículos de ciclo Otto): 0,5\% do volume emitido

- Fase L6 (2013): Nesta fase, houve continuidade na restrição das emissões de poluentes precursores do $O_{3}$. Os níveis de emissão para cada poluente são:

- CO: $1,30 \mathrm{~g} / \mathrm{kg}$

- HC (Hidrocarbonetos): 0,30 g/kg

- NMHC (Hidrocarbonetos não-metano): 0,05

$-N O_{X}: 0,08 \mathrm{~g} / \mathrm{kg}$

- HCO (Aldeídos): 0,02 g/kg

- MP (para veículos do ciclo diesel): 0,025 g/kg

- Emissão Evaporativa (para veículos do ciclo Otto, exceto GNV): 1,5 g/teste ou 2,0 g/teste (em caso de procedimento de câmara de volume variável)

- CO em marcha lenta (veículos de ciclo Otto): 0,2\% do volume emitido

As emissões máximas permitidas para cada fase estão expostas na figura 1.1, extraída de (MMA, 2013). 


\begin{tabular}{cc}
\hline Fase & Anos \\
\hline L1 & $1988-1991$ \\
L2 & $1992-1996$ \\
L3 & $1997-2004$ \\
L4 & $2005-2008$ \\
L5 & $2009-2013$ \\
L6 & 2013
\end{tabular}

Tabela 1.7: Anos das fases do PROCONVE 

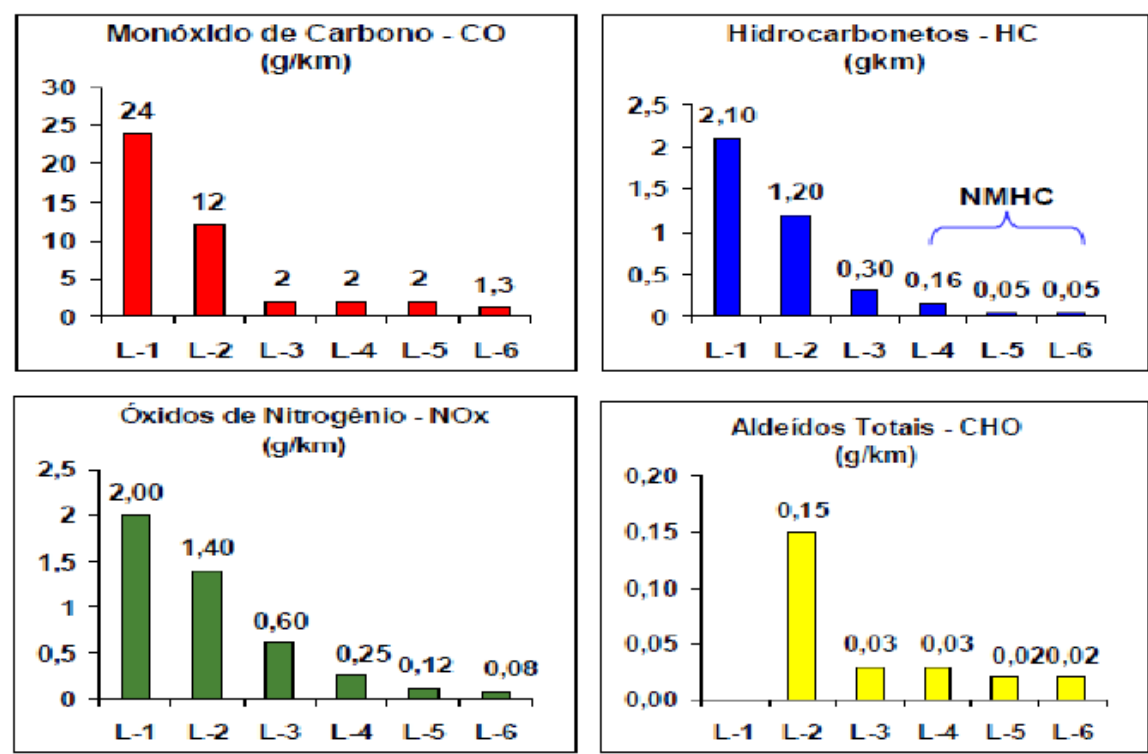

Figura 1.1: Limites máximos de emissão de cada poluente para veículos leves em cada fase do PROCONVE

Os gráficos nas figuras 1.2 e 1.3 mostram uma substancial redução no número de ultrapassagens de padrão, estados de atenção, alerta e máximas de concentração nas estações de Cerqueira César e Congonhas, respectivamente, quando os veículos que atendem às progressivas fases do PROCONVE gradualmente começam a ir às ruas, mesmo com o aumento substancial da frota.

O aumento da frota, a complexidade do controle dos poluentes primários, bem como a melhoria da combustão nos motores não conseguiu ter a mesma repercussão sobre os índices de ozônio troposférico. Apesar de uma redução inicial do número de episódios, desde o início dos anos 90 o quadro para esse índices não tem alteração significativa, tampouco o registro das $1^{\mathrm{a}}$ e $2^{\mathrm{a}}$ máximas. Isto é visível nos gráficos das figuras 1.4 e 1.5, respectivamente para as estações de Ibirapuera e Moóca. Junto com o material particulado, o Ozônio é o maior problema de poluição do ar na RMSP. 


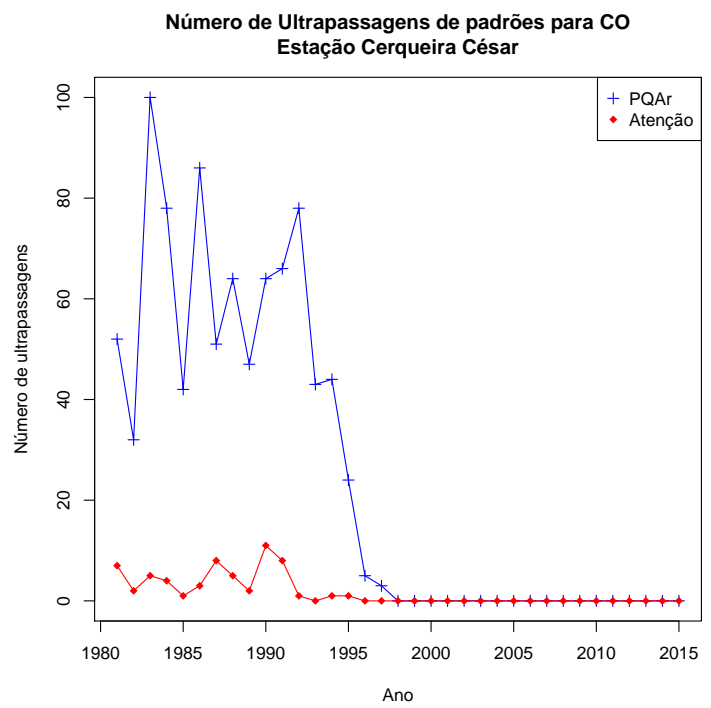

(a) Ultrapassagens do padrão de qualidade do ar e de atenção na estação de Cerqueira César

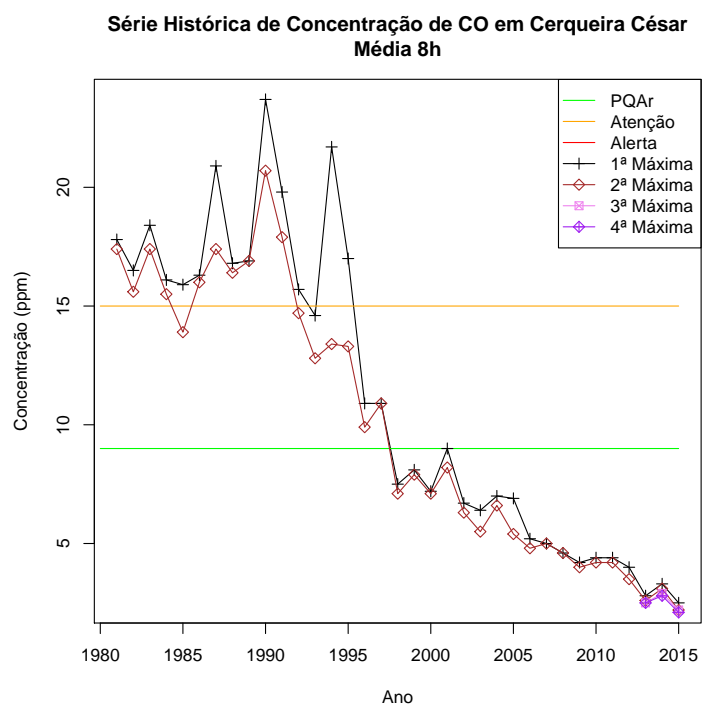

(b) Máximas de CO na Estação de Cerqueira César

Figura 1.2: Série Temporal de medidas de CO na Estação de Cerqueira César

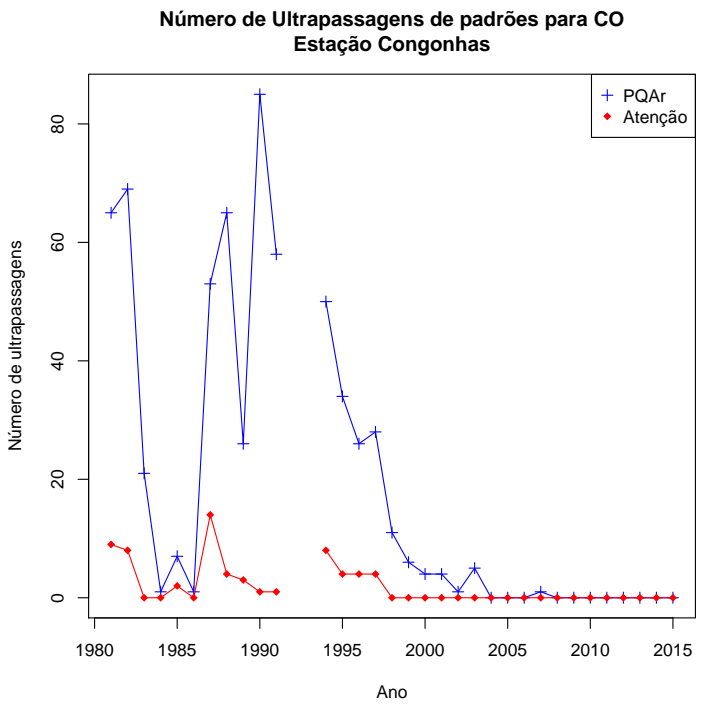

(a) Ultrapassagens do padrão de qualidade do ar e de atenção na estação de Congonhas

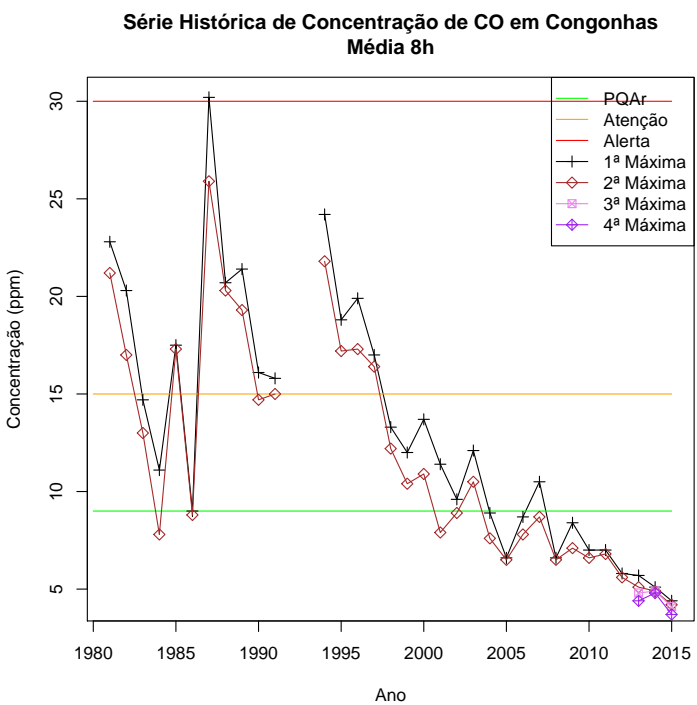

(b) Máximas de CO na Estação de Congonhas Figura 1.3: Série Temporal de medidas de CO na Estação de Congonhas 


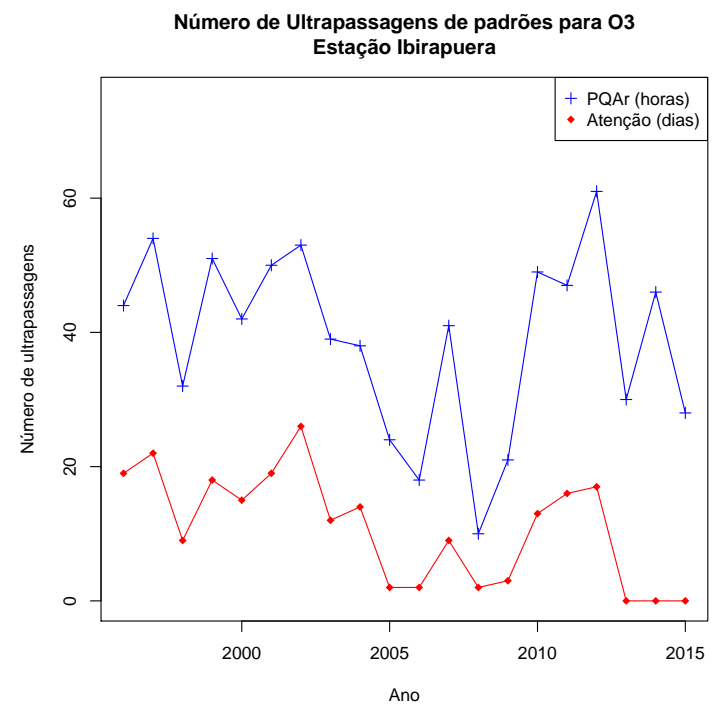

(a) Ultrapassagens do padrão de qualidade do ar e de atenção na estação de Ibirapuera

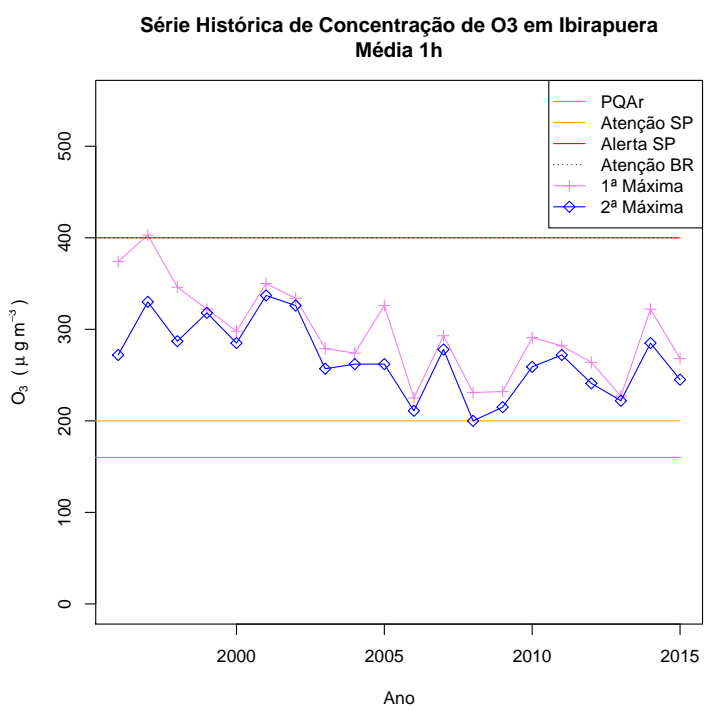

(b) Máximas de $O_{3}$ na Estação de Ibirapuera

Figura 1.4: Série Temporal de medidas de $O_{3}$ na Estação de Ibirapuera

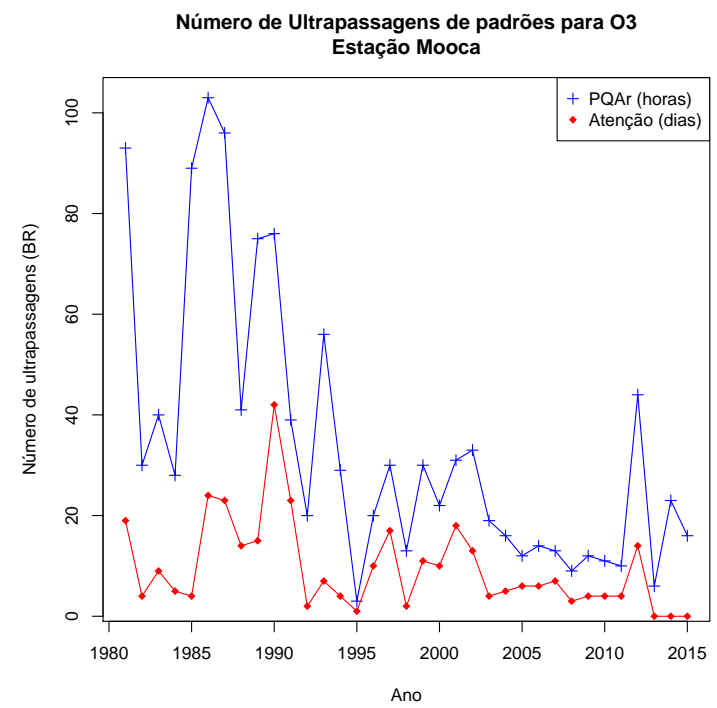

(a) Ultrapassagens do padrão de qualidade do ar e de atenção na estação de Moóca

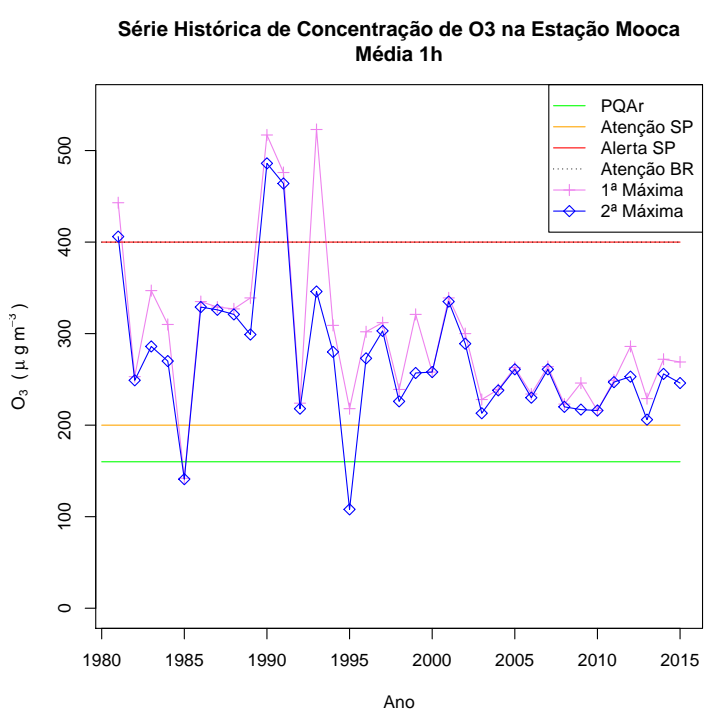

(b) Máximas de $O_{3}$ na Estação de Moóca Figura 1.5: Série Temporal de medidas de $O_{3}$ na Estação de Moóca

\subsubsection{Cubatão}

O mecanismo de redução de episódios de poluição do ar adotado adotado inicialmente pela CETESB para mitigar a poluição do ar em Cubatão, era a observação horária das concentrações e, caso um episódio estivesse se configurando, comunicá-lo às empresas para que diminuíssem o nível de atividade até que as concentrações fossem reduzidas (CETESB, 2007, relatório de 1985). Buscava-se, assim evitar a suspensão total de atividades como previa a lei nestes casos. Ao mesmo tempo, previa-se naquela época que as empresas enviassem estudos à CETESB 
para aplicar a melhor tecnologia disponível para a filtragem dos poluentes e sua redução. As medidas emergenciais aplicadas à época estão de acordo com as propostas no relatório da NEA (Miller et al., 1985).

$\mathrm{Na}$ disputa intra sociedade civil (CIESP e empresários em geral contra classe trabalhadora e outros setores interessados em soluções com foco na população e no meio ambiente em detrimento do lucro imediato), houve uma derrota. Em 1992 foi implantado o Projeto "Vale da Vida", que basicamente removeu a população moradora de Vila Parisi para que a área fosse considerada industrial - passando a ser submetida à legislação mais flexível de emissões de poluentes. De quebra as indústrias ganharam mais terreno para ocuparem e a população operária que trabalhava nas indústrias, em número superior à população que ali residia, viuse mais desprotegida quanto à qualidade do ar. Apesar de grande parte da população ter sido removida para um novo assentamento que foi denominado Jardim Nova República, os problemas sociais ainda não foram resolvidos: muitos moram em favelas, em bairros Cota, e submetidos, ainda, a eventuais acidentes ou sofrendo com a poluição em dias pouco favoráveis à sua dispersão. Embora a CETESB estime que as emissões foram reduzidas em mais de 90\%, as concentrações de Vila Parisi continuam altas, superando com frequência o padrão de qualidade do ar para Material Particulado. Os gráficos nas figuras 1.6 e 1.7 mostram que a opção pelo projeto "Vale da Vida" significou que em Vila Parisi os esforços para reduzir as emissões de poluentes não colocou as concentrações dentro do Padrão Brasileiro para $M P_{10}$, ultrapassando-se, inclusive, o nível de atenção.

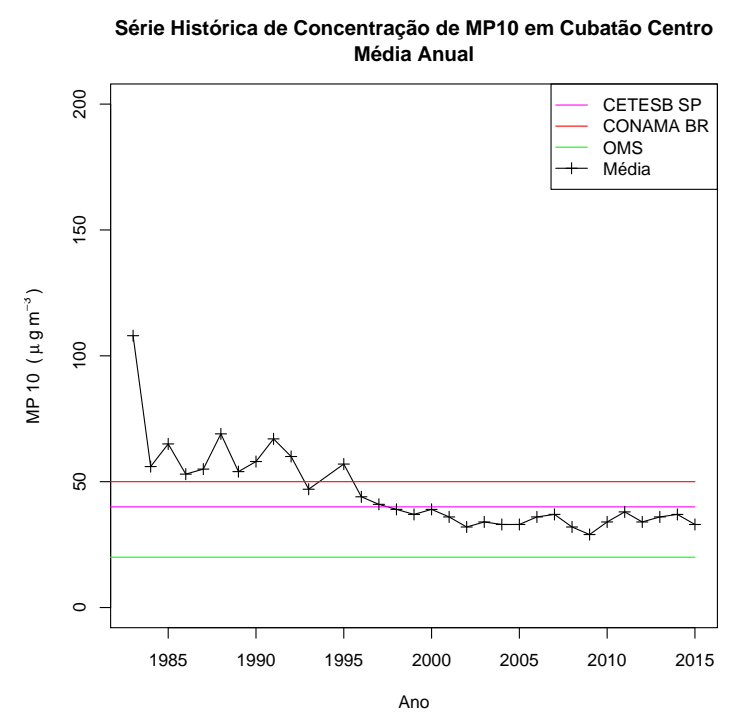

(a) Média anual de concentrações de $M P_{10}$ em Cubatão Centro

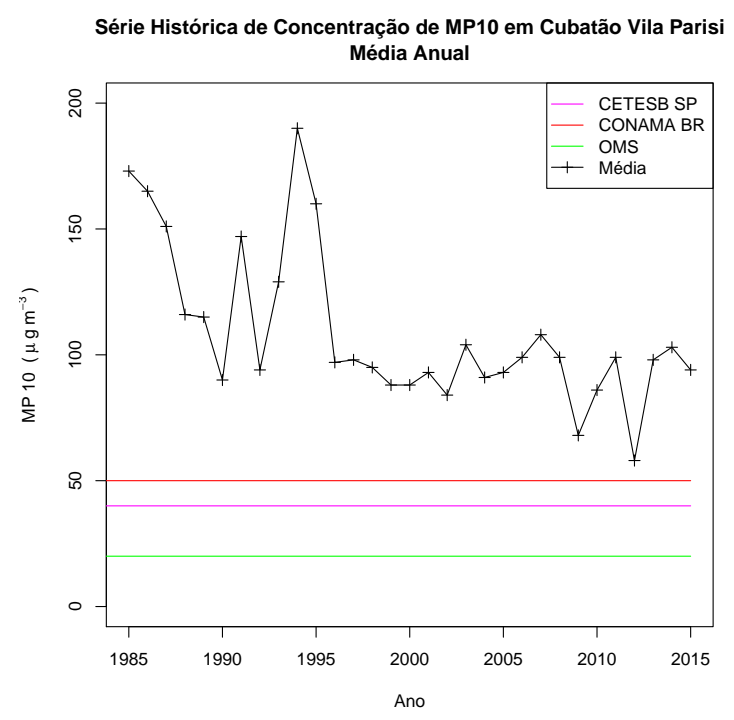

(b) Média anual de concentrações de $M P_{10}$ em Cubatão - Vila Parisi

Figura 1.6: Série Temporal de $M P_{10}$ em Cubatão - Estações Centro e Vila Parisi. 


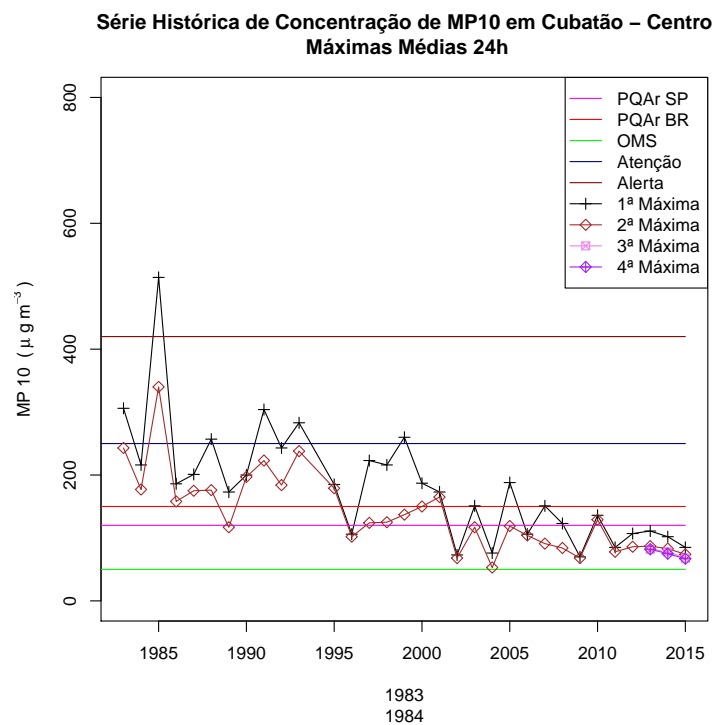

(a) Máximas Concentrações de $M P_{10} \mathrm{em} \mathrm{Cu-}$ batão Centro - Média 24h

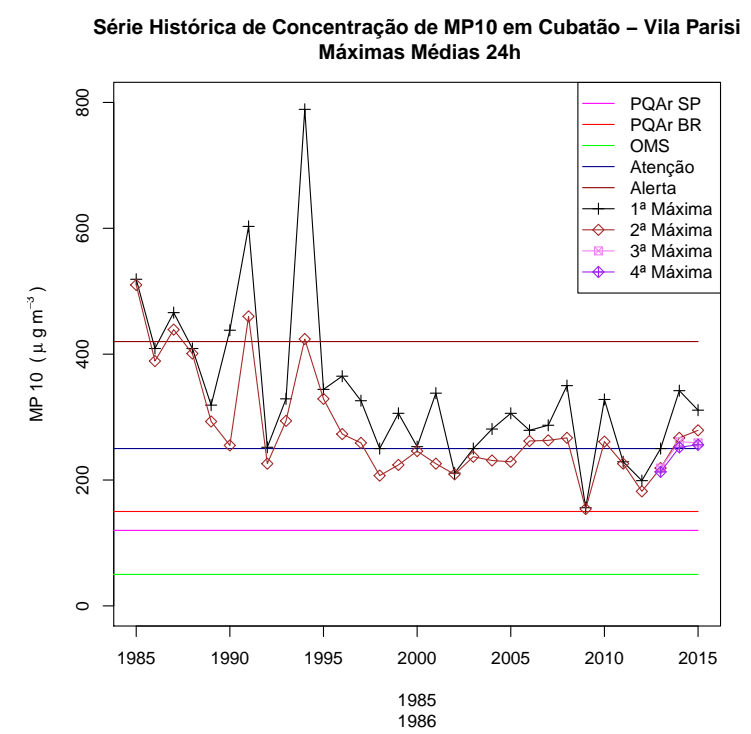

(b) Máximas Concentrações de $M P_{10}$ em Cubatão Vila Parisi - Média 24h

Figura 1.7: Série Temporal de Máximas $M P_{10}$ em Cubatão - Estações Centro e Vila Parisi.

Atualmente, a CETESB considera que a execução do plano de controle de poluentes apresentado pelas empresas foi exitosa, e investe em controlar emissões fugitivas e de fontes secundárias, além de estudo de novos padrões de emissões de poluentes para proteger a vegetação da Serra do Mar. Entretanto, esta necessidade de vigilância constante mostra que, na verdade, o problema não está resolvido, e que em caso de acidentes (que não são raros), não só a vegetação continua em risco, como também a população. 


\section{Teoria da Difusão Atmosférica}

\subsection{Modelos Estocásticos Lagrangianos - Uma Introdu- ção}

Mais de um século antes da era atômica e da corrida armamentista, já havia preocupação em regular a poluição do ar em suas fontes, entretanto, tais tentativas fracassaram. Com o advento da capacidade de quebrar átomos instáveis para gerar energia, tanto para propósitos bélicos quanto pacíficos, a necessidade de prever os efeitos das emissões de poluentes tornouse muito mais premente, dado o potencial de danos de acidentes nucleares, fazendo com que meteorologistas estudassem com mais afinco a dispersão de poluentes atmosféricos e os governos das superpotências fossem mais criteriosos no controle das atividades atômicas, em relação à regulação de outras.

O desenvolvimento contido neste capítulo foi baseado especialmente em Csanady (2012), pois oferece um desenvolvimento tão pedestre quanto completo da teoria de difusão atmosférica, seja na formulação euleriana, ou lagrangeana e estocástica para uma atmosfera homogênea e estacionária.

Para o desenvolvimento das equações do SPRAY e como ele lida com uma atmosfera mais próxima do real (turbulência nem homogênea, nem estacionária), o texto acompanha Tinarelli (2013).

\subsubsection{Difusão Atmosférica}

A difusão na atmosfera possui três causas: simples advecção por conta do vento médio, difusão turbulenta por conta do vento turbulento e difusão molecular. A difusão molecular na troposfera é desprezível comparada às outras.

Entretanto, para entender como a difusão turbulenta funciona, é necessário estudar a difusão molecular, sob a qual sua teoria foi desenvolvida por analogia. 


\subsubsection{Difusão Molecular - Formulação Euleriana}

Seja $\chi$ a concentração de um poluente na atmosfera, em unidades de massa por volume, num determinado volume fechado.

$$
\chi=\frac{\Delta M}{\Delta V}
$$

Onde M é a massa e $\mathrm{V}$, o Volume. $V \gg a^{3}$, onde a é a distância entre as partículas na difusão.

Seguindo a lei de Fick, o fluxo, dado em unidades de massa por tempo e área, considerando apenas a difusão neste volume é:

$$
\vec{F}=-D \vec{\nabla} \chi
$$

Onde D é a constante de difusão.

\subsubsection{Conservação de Massa}

A massa total no volume, em um dado instante é:

$$
M(t)=\oint_{V} \chi d V
$$

O fluxo total no volume, em um dado instante, é:

$$
J(t)=\oint_{S} \vec{F} \cdot \widehat{n} d S
$$

Onde $\widehat{n}$ é o vetor normal à superfície. Se não há fontes ou sumidouros, a massa se conserva, então:

$$
J=-\frac{\partial M}{\partial t}
$$

Usando o teorema da divergência 2.6, podemos obter a equação da continuidade.

\section{Teorema da Divergência}

$$
\oint_{S} \vec{F} \cdot \widehat{n} d S=\oint_{V} \vec{\nabla} \cdot \vec{F} d V
$$

Usando 2.3, 2.4 e 2.5 em 2.6, obtemos a equação da continuidade, expressando a conservação de massa:

$$
\oint_{V}\left(\frac{\partial \chi}{\partial t}+\vec{\nabla} \cdot \vec{F}\right) d V=0
$$


com

$$
\frac{\partial \chi}{\partial t}=-\vec{\nabla} \cdot \vec{F}
$$

uma vez que não há advecção. Ou seja, de acordo com a equação da continuidade, a variação da massa no tempo é igual ao fluxo total no volume, como esperado, se há conservação de massa.

\subsubsection{Equação da Difusão Molecular}

Substituindo 2.2 em 2.8, obtemos:

$$
\frac{\partial \chi}{\partial t}=\vec{\nabla} \cdot(D \vec{\nabla} \chi)
$$

o que nos fornece a Equação da Difusão Molecular em seu formato usual:

$$
\frac{\partial \chi}{\partial t}=D \nabla^{2} \chi
$$

Se, além da difusão molecular, um fluxo laminar contribui com o fluxo total, reescrevemos 2.2 como:

$$
\vec{F}=\vec{u} \chi-D \vec{\nabla} \chi
$$

Supondo, por enquanto, que temos fluidos incompressíveis,

$$
\vec{\nabla} \cdot(\vec{u} \chi)=\vec{u} \cdot \vec{\nabla} \chi
$$

e temos a equação da difusão envolvendo tanto advecção por vento quanto difusão molecular:

\section{Equação geral da difusão}

$$
\frac{d}{d t} \chi=\frac{\partial \chi}{\partial t}+\vec{u} \cdot \vec{\nabla} \chi=D \nabla^{2} \chi
$$

, onde $\frac{d}{d t} \equiv$ derivada total.

A solução para a equação da difusão molecular 2.10 é uma gaussiana, o que em uma dimensão fica:

$$
\chi=\frac{A}{\sqrt{t}} \exp \left(\frac{-x^{2}}{4 D t}\right), A \equiv \text { constante. }
$$

A quantidade de material em uma coluna, na direção x pode ser calculada como:

$$
Q=\int_{-\infty}^{\infty} \chi d x=\int_{-\infty}^{\infty} \exp \frac{-x^{2}}{4 D t}=2 A \sqrt{\pi D}
$$


de onde obtém-se a constante A e, substituindo este valore em 2.14, temos:

$$
\chi=\frac{Q}{2 \sqrt{\pi D t}} \exp \left(-\frac{x^{2}}{4 D t}\right)
$$

$$
\begin{array}{r}
\text { Para } \\
\chi \rightarrow 0,|x|>0 \\
\chi \rightarrow \infty, x=0
\end{array}
$$

O comportamento assintótico da solução 2.16 mostrado em 2.17 evidencia seus caráter pontual, como uma função delta de Dirac. Também possui um caráter instantâneo, quando $t \rightarrow 0$.

$$
\begin{array}{r}
\chi=Q \delta(x), \\
t=0
\end{array}
$$

O desvio padrão para a concentração de $\chi$ pode ser dado por:

$$
\sigma^{2}=\frac{1}{Q} \int_{-\infty}^{\infty} x^{2} \chi d x=2 D t
$$

Substituindo 2.19 em 2.16, temos:

$$
\chi=\frac{Q}{\sqrt{2 \pi} \sigma} \exp \left(\frac{-x^{2}}{2 \sigma^{2}}\right)
$$

Podemos ter, ainda, uma forma normalizada: $\frac{\chi \sigma}{Q}=\frac{1}{\sqrt{2 \pi}} \exp \left(\frac{-1}{2} \frac{x^{2}}{\sigma^{2}}\right)$

Como solução da equação de difusão geral 2.13, envolvendo tanto o vento médio na direção x quanto difusão molecular, aplicamos o método de separação de variáveis, e temos a equação 2.21

$$
\chi=\frac{Q}{(\sqrt{2 \pi} \sigma)^{3}} \exp \left(-\frac{(x-u t)^{2}+y^{2}+z^{2}}{2 \sigma^{2}}\right)
$$

$\operatorname{Com} \vec{u}=u \widehat{x}$, e $\sigma_{x}=\sigma_{y}=\sigma_{z}=\sigma$.

Levando em consideração que a troposfera tem cerca de 10Km de altura, e que a pluma se propaga muito mais na horizontal do que em z, podemos fazer a aproximação $z \ll x$. Em z, a gaussiana também não é simétrica, e podemos supor a reflexão das partículas que atingem o 
solo. Para satisfazer as duas considerações, reescrevemos

$$
r-x \simeq \frac{y^{2}+z^{2}}{2 x^{2}}
$$

E aplicamos a condição de reflexão $F_{z}(0)=0$.

$$
F_{z}=\left(-D \frac{\partial \chi}{\partial z}\right)_{0}=0
$$

Assim, temos a equação 2.24, já integrada em relação ao tempo, de 0 a infinito, expressando uma emissão contínua no tempo, com q representando uma taxa de emissão de massa por unidade de tempo.

$$
\chi=\frac{q}{2 \pi u \sigma^{2}} \exp \left(\frac{-y^{2}}{2 \sigma^{2}}\right)\left(\exp \left(\frac{-(z-h)^{2}}{2 \sigma^{2}}\right)+\exp \left(\frac{-(z+h)^{2}}{2 \sigma^{2}}\right)\right)
$$

onde reescrevemos $\sigma=\sqrt{2 D} \frac{x}{u}$ e h é altura da fonte em relação ao solo.

\subsubsection{Difusão Molecular - Formulação estatística}

Seja uma partícula na posição $\overrightarrow{x^{\prime}}$ em $\mathrm{t}=0 . \vec{x}-\overrightarrow{x^{\prime}}$ é o vetor deslocamento de $\overrightarrow{x^{\prime}}$ a $\vec{x}$, dependendo do tempo de forma aleatória e descrito por uma função densidade de probabilidade $P\left(\vec{x}-\overrightarrow{x^{\prime}}\right) d x \equiv$ probabilidade de que o vetor deslocamento terminará dentro do elemento dx em torno de $\vec{x}$. Uma outra interpretação possível é que $P\left(\vec{x}-\overrightarrow{x^{\prime}}\right)$ é a probabilidade de, no tempo t, $\vec{x}$ estar imerso no elemento difundido em questão. Essa abordagem parte da suposição que o campo de difusão é homogêneo e P não depende explicitamente de $\overrightarrow{x^{\prime}}$, sendo todos os pontos de lançamento equivalentes entre si.

A distribuição de densidade de partículas $\chi$ é dada por:

$$
\chi\left(\vec{x}, t \mid \overrightarrow{x^{\prime}}\right)=Q P\left(\vec{x}-\overrightarrow{x^{\prime}}\right)
$$

Supondo um processo estocástico estacionário,

$$
\begin{array}{r}
\overline{u(t)}=0 \\
\overline{u^{2}}(t)=\text { constante }=\overline{u^{2}}
\end{array}
$$

e relações similares valem para as demais componentes da velocidade. 


\subsubsection{Teorema de Taylor}

Seja $R(\tau) \equiv$ a função de autocorrelação.

Para $t<\tau$, os valores de $\mathrm{u}$ são similares. $R(\tau)$ mede a p̈ersistênciä̈e um dado valor de uma variável aleatória. Seja $\overline{u(t) u(t+\tau)} \equiv$ covariança de velocidade. Para $\tau \rightarrow 0$, ela tende a $\overline{u^{2}(t)}$. Para um tempo $\tau$ suficientemente grande, $u(t)$ e $u(t+\tau)$ variam independentemente e $\overline{u(t) u(t+\tau)}$ representa a média sobre uma variável aleatória, o que é 0 por hipótese. Para um processo estacionário, a covariança da velocidade tem, como propriedade, o fato de que é independente de t escolhido como base de cálculo, ou seja:

$$
\overline{u(t) u(t+\tau)}=\overline{u(0) u(\tau)}=\overline{u(-\tau) u(0)}=\ldots \text { etc }
$$

Assim, $\overline{u(t) u(t+\tau)}$ é uma função par de $\tau$.

A função de autocorrelação, adimensional, pode ser definida como:

$$
R(\tau)=\frac{\overline{u(t) u(t+\tau)}}{\overline{u^{2}}}
$$

Se $\tau \rightarrow 0, R \rightarrow 1$, se $\tau \rightarrow \infty, R \rightarrow 0$ e

$$
-1 \leq R(\tau) \leq 1, \forall \tau
$$

A equação de posição para qualquer partícula no conjunto é:

$$
x(t)=\int_{0}^{t} u\left(t^{\prime}\right) d t^{\prime}
$$

o que nos permite escrever:

$$
\frac{d}{d t} x^{2}(t)=2 x \frac{d}{d t} x=2 \int_{0}^{t} u(t) u\left(t^{\prime}\right) d t^{\prime}
$$

Usando 2.28, e substituindo em 2.31, chegamos a:

$$
\frac{d}{d t} \overline{x^{2}}=2 \overline{u^{2}} \int_{0}^{t} R(\tau) d \tau
$$

onde foi usado o fato de que $R(\tau)$ é par para transformar a variável de integração de t' para $\tau=t^{\prime}-t$

A equação 2.32 é o Teorema de Taylor (Taylor, 1922), como é conhecido na difusão 
turbulenta. Taylor estudou a difusão turbulenta baseado na teoria estatística do movimento Browniano.

Vejamos como esse resultado pode ser usado para um conjunto de partículas lançado em $\vec{x}=0$ e em $\mathrm{t}=0$. O desvio padrão é:

$$
\sigma_{x}^{2}=\frac{1}{Q} \iiint x^{2} \chi(x, y, z, t) d x d y d z
$$

que é uma boa medida da dispersão desta nuvem de partículas.

Usando 2.25, pode ser definido também como:

$$
\sigma_{x}^{2}=\iiint x^{2} P(x, y, z, t) d x d y d z=\overline{x^{2}}
$$

e pode ser calculado a partir do teorema de Taylor, se houver informação sobre a história da partícula em difusão. Usando 2.32,

$$
\frac{d}{d t} \sigma_{x}^{2}=2 \overline{u^{2}} \int_{0}^{t} R(\tau) d \tau
$$

Integrando 2.35 no tempo:

$$
\sigma_{x}^{2}=2 \overline{u^{2}} \int_{o}^{t} \int_{o}^{t^{\prime}} R(\tau) d \tau d t^{\prime}=2 \overline{u^{2}} \int_{0}^{t}(t-\tau) R(\tau) d \tau
$$

integrando em t' antes, e sabendo que $t^{\prime}=t-\tau$

\subsubsection{Movimento Browniano}

Hipóteses:

- 1) A partícula é muito maior que as moléculas do fluido. Nela, atua a força de viscosidade $-\beta \vec{u},[\beta]=s^{-1}$

- 2) A partícula é pequena o bastante para ser afetada pelas colisões moleculares.

Assim, a outra força a afetar a partícula é aleatória (estocástica), de modo que a equação do movimento Browniano é uma Equação de Langevin.

$$
\frac{d}{d t} \vec{u}=-\beta \vec{u}+\vec{A}(t)
$$

onde $\overrightarrow{A(t)}$ é uma aceleração estocástica. 
Para uma partícula esférica, $\beta$, o coeficiente de viscosidade pode ser definido pela Lei de Stokes abaixo:

$$
\beta=6 \pi a \mu / m,\left[s^{-} 1\right]
$$

onde a é o raio da partícula, $\mu$ é a viscosidade do fluído e m é a massa da partícula. $\beta^{-1}$ é o tempo de relaxação.

A solução homogênea de 2.37 é $\vec{u}=\overrightarrow{u_{o}} \exp (-\beta t)$, com $\overrightarrow{u_{o}}=\vec{u}(t=0)$. A solução geral é:

$$
\vec{u}=\overrightarrow{u_{0}} \exp (-\beta t)+\exp (-\beta t) \int \exp (+\beta t) \overrightarrow{A\left(t^{\prime}\right)} d t^{\prime}
$$

Nota-se que para $t \gg \beta^{-1}$, a partícula "esquece" sua velocidade inicial, ficando apenas com o termo estocástico.

2.1.3.2.1 Dispersão de partículas Brownianas A energia cinética das partículas que se difundem em um gás é resultado da energia cinética média das moléculas do gás onde estão imersas, portanto, observando apenas uma direção, temos:

$$
\frac{1}{2} m \overline{u^{2}}=\frac{1}{2} \kappa T
$$

onde $\kappa$ é a constante de Boltzmann e T a temperatura absoluta.

Partindo de 2.39, pode-se achar a velocidade de covariança e a autofunção de correlação:

$$
R(\tau)=\frac{\overline{u(0) u(\tau)}}{\overline{u^{2}}}=\exp (-\beta t)
$$

Substituindo no teorema de Taylor, temos:

$$
\sigma_{x}^{2}=2 \overline{u^{2}}\left[\frac{t}{\beta}-\frac{-1}{\beta}(1-\exp (-\beta t))\right]
$$

Para $t \gg \beta^{-1}$,

$$
\sigma_{x}^{2}=\frac{2 \overline{u^{2}}}{\beta} t
$$

Comparando com o desvio padrão da solução para a equação de difusão clássica 2.19, A difusão molecular pode, agora, ser definida em termos estatísticos.

$$
D=\frac{\overline{u^{2}}}{\beta}
$$


e, para partículas esféricas no movimento Browniano, usando 2.38 e 2.40, temos

$$
D=\frac{\kappa T}{6 \pi a \mu}
$$

2.1.3.2.2 Modelo do Simples Caminho Aleatório Com $\Delta t \gg \beta^{-1}$, entre uma colisão e outra da partícula com as moléculas do meio, o movimento da partícula é governada, basicamente, por passos aleatórios. O Deslocamento $x_{j}$ que a partícula executa em cada passo, para cada intervalo de tempo é:

$$
x_{j}=\int_{j \Delta t}^{(j+1) \Delta t} u\left(t^{\prime}\right) d t^{\prime}
$$

No caminho aleatório, a partícula, após N passos, pode estar em quaisquer dessas posições $-N,-N+1,-N+2, \ldots,-1,0,+1, \ldots N-1, N$

se a probabilidade de ir para frente ou para traz for $\frac{1}{2}(50 \%)$, e a partir da origem. Seja $\mathrm{P}(\mathrm{m}, \mathrm{N})$, a probabilidade da partícula atingir $-N<\mathbf{m}<N$, após $\mathrm{N}$ passos. Obtêmse enumerando-se todos os possíveis resultados de um passo aleatório feito de $\mathrm{N}$ passos e determinando quais destes farão a partícula atingir $\mathbf{m}$. Cada passo tem probabilidade $\frac{1}{2}$, então cada sequência individual tem probabilidade $\left(\frac{1}{2}\right)^{N}$ dos passos serem todos independentes.

Seja o número de passos para frente f (forward), e o número de passos para trás b (backward), então:

$$
\begin{aligned}
& f+b=N \\
& f-b=m
\end{aligned}
$$

Obtém-se que $f=\frac{N+m}{2}$ e $b=\frac{N-m}{2}$. Da teoria de análise combinatória, o número de sequências diferentes de exatamente f passos para frente e b passos para trás é $\frac{N !}{f ! b !}$.

Assim, obtém-se uma distribuição binomial, que também é uma distribuição de Bernoulli, pois $\mathrm{P}(\mathrm{m}, \mathrm{N})$ é o número de sequências distintas que levarão $\boldsymbol{a} \boldsymbol{m}$, vezes a probabilidade dos passos serem todos independentes:

$$
P(m, N)=\frac{N !}{\left[\frac{1}{2}(N+m)\right] !\left[\frac{1}{2}(N-m)\right] !}\left(\frac{1}{2}\right)^{N},
$$

Onde $\mathrm{N}$ e m tem de ser ambos par ou ímpar. 
Por ser uma distribuição de Bernoulli, ela tem as seguintes propriedades:

$$
\begin{array}{r}
\bar{m}=\sum_{m=-N}^{N} m P(m, N)=0 \\
\overline{m^{2}}=\sum_{m=-N}^{N} m^{2} P(m, N)=N
\end{array}
$$

No movimento Browniano, até por sua formulação estatística, o interesse na análise é para $N \gg 1$.

Nestas condições, de acordo com o teorema de De Moivre-Laplace (Feller, 1968), a distribuição binomial para um evento de probabilidade de sucesso converge para uma distribuição gaussiana.

Assim, a distribuição binomial torna-se:

$$
P(m, N)=\sqrt{\frac{2}{\pi N}} \exp \left(\frac{-m^{2}}{2 N}\right)
$$

A distribuição discreta pode ser considerada contínua se temos passo pequenos comparados com o comprimento $\Delta x$ em que se define a concentração de partícula.

Assim,

$$
m=\frac{x}{l}
$$

onde m é o número de passos, le e comprimento do passo, e x é o deslocamento da partícula a partir da origem.

$P(m, N) \cdot \frac{\Delta x}{2 l} \equiv$ Probabilidade de se encontrar a partícula numa região $\Delta x$ (centrada em $\mathrm{x})$. O material contido na região $\Delta x$ é:

$$
\Delta M=Q P(m, N) \frac{\Delta x}{2 l},
$$

e a distribuição da concentração torna-se:

$$
\chi=\frac{\Delta M}{\Delta x}=\frac{Q}{2 l} \sqrt{\frac{2}{\pi N}} \exp \left(-\frac{x^{2}}{2 N l^{2}}\right)
$$

O número total de passos está associado ao tempo de difusão. Se a partícula faz n deslocamentos por unidade de tempo, $t=\frac{N}{n}$, e $u=\frac{1}{2} n l$ é um tipo de v̈elocidade de difusão:

Assim,

$$
D=\frac{1}{2} n l^{2}=u l
$$


e a distribuição da concentração torna-se,

$$
\chi(x, t)=\frac{Q}{2 \sqrt{\pi D t}} \exp \left(-\frac{x^{2}}{4 D t}\right)
$$

ou seja, o mesmo resultado encontrado para a difusão clássica formulada na equação 2.16

\subsubsection{Difusão Turbulenta}

A difusão turbulenta é um processo que tem uma componente determinística e outra estocástica, obedecendo, portanto, a Equação de Langevin.

Assim, o desenvolvimento teórico para a difusão molecular pelo movimento Browniano é empregado para o estudo do movimento de partículas na atmosfera, até porque processos estocásticos, em geral, sugerem a possibilidade de uso de uma distribuição gaussiana. Entretanto, o tempo de escala lagrangiano $T_{L}$ é maior que o de $\beta^{-1}$ usado na difusão molecular.

São assumidas duas hipóteses para este desenvolvimento:

- 1) A turbulência é homogênea no espaço

- 2) A turbulência é estática

\subsubsection{Equação de Langevin para Turbulência}

$$
\frac{d}{d t} u^{\prime}=-\frac{1}{T_{L}} u^{\prime}(t)+\eta(t)
$$

, onde $T_{L i}, i=u^{\prime}, v^{\prime}, w^{\prime}$ é a escala de tempo Lagrangiana, que, assim como $\beta^{-1}$ está associado ao tempo em que a correlação da componente determinística da turbulência "desaparece". u', v' e w' são componentes da velocidade turbulenta em x, y e z.

Embora na atmosfera as partículas também estejam sofrendo difusão molecular, esta é praticamente desprezível, frente à difusão turbulenta, então $\sigma_{x}$ é exclusivamente turbulento no modelo, assim como os desvios padrões para as demais componentes.

A função de autocorrelação segue desenvolvimento análogo ao que foi feito para a difusão molecular, portanto:

$$
R(\tau)=\exp \left(-\frac{\tau}{T_{L i}}\right)
$$




\subsubsection{A Forma Gaussiana da Distribuição de Concentração para Difusão Tur- bulenta}

Embora não haja nenhuma prova formal, através de experimentos e observações como os do Pasquill (Slade, 1968), verifica-se que a distribuição média da concentração de partículas na atmosfera pode ser representada por uma gaussiana em condições aproximadas como homogêneas e estacionárias.

Com estas hipóteses assumidas para a difusão turbulenta verificadas nestes experimentos (em breves momentos e em condições espaciais específicas), verifica-se que os desvios padrões são os mesmos que os esperados de uma distribuição gaussiana, com $\sigma_{x i}=\overline{x_{i}^{2}}, x_{i}=x, y, z \mathrm{e}$ $\bar{x}=\bar{y}=\bar{z}=0$.

Para $t \ll T_{L}, \mathrm{P}(\mathrm{x}, \mathrm{y}, \mathrm{z})$ é aproximadamente gaussiana, porque é proporcional à distribuição de velocidade turbulenta de cada componente, que é gaussiana.

Além disso, $\overline{x y}=\overline{y z}=\overline{x z}=0$.

Assim, a forma da solução para a distribuição de concentração de poluentes é:

$$
\chi(x, y, z, t)=\frac{Q}{(2 \pi)^{2 / 3} \sigma_{x} \sigma_{y} \sigma_{z}} \exp \left[-\frac{(x-U t)^{2}}{2 \sigma_{x}^{2}}-\frac{y^{2}}{2 \sigma_{y}^{2}}-\frac{z^{2}}{2 \sigma_{z}^{2}}\right]
$$

onde $U=\overrightarrow{\vec{U}}$. Integrando no tempo, assumindo que $z \ll x$, e a condição de reflexão em z, expressa em 2.23, como foi feito em 2.24, chegamos à Distribuição Gaussiana Para Emissão Contínua:

$$
\chi(x, y, z)=\frac{q}{2 \pi U \sigma_{y} \sigma_{z}} \exp \left(-\frac{y^{2}}{2 \sigma_{y}^{2}}\right)\left[\exp \left(-\frac{(z-h)^{2}}{2 \sigma_{z}^{2}}\right)+\exp \left(-\frac{(z+h)^{2}}{2 \sigma_{z}^{2}}\right)\right],
$$

q é a taxa de emissão de massa por unidade de tempo.

\subsection{Modelagem Numérica da Dispersão de Partículas no SPRAY}

Até aqui, foi mostrado o desenvolvimento tanto euleriano quanto estocástico da solução da concentração de partículas, inicialmente no movimento Browniano, e depois de uma breve discussão, sua razoabilidade para a difusão turbulenta na atmosfera, quando, em condições homogêneas e estacionárias, esta solução é gaussiana.

Entretanto, a atmosfera não apresenta turbulência homogênea e estacionária, além do 
próprio vento médio variar sua direção e intensidade com o tempo.

Assume-se que as partículas são carregadas pelo vento, possuindo, ambos, a mesma, velocidade.

As emissões de uma fonte são divididas em partículas virtuais.

O SPRAY, a partir de informações inseridas pelo modelo meteorológico, a fonte, e configurações ajustadas em arquivos de inicialização, calcula a trajetória de cada partícula emitida a cada intervalo de tempo.

As informações de entrada oriundas do modelo meteorológico fornecem a velocidade do vento em diferentes níveis de altura, a topografia do terreno e demais variáveis necessárias para o cálculo da turbulência nas várias equações do modelo: $z_{o}, u_{*}, \mathrm{~L}, \mathrm{~h}, w *$ e $h_{\text {res }}$, respectivamente, rugosidade do solo, velocidade de fricção, cumprimento de Monin-Obukhov, altura da camada de mistura, escala vertical de velocidades convectivas e altura da camada de mistura residual do dia anterior.

A partir desses parâmetros, são calculados $\sigma_{u_{i}}, \mathrm{i}=\mathrm{x}, \mathrm{y}, \mathrm{z}, \overline{w^{3}}$ (obliquidade da curva de distribuição de w), $T_{L_{i}}$.

A trajetória de uma partícula pode ser integrada a partir da equação:

$$
\overrightarrow{x(t+d t)}=\overrightarrow{x(t)}+\overrightarrow{U(x(t), t) d t}
$$

onde $\vec{x}$ é a trajetória da partícula, $\overrightarrow{U(x(t), t)}$ é a velocidade da partícula (na verdade, a velocidade do vento carregando a partícula), e $d t$ é o intervalo de tempo para a integração discreta.

$\vec{U}$ é dividida em duas componentes: Uma velocidade média determinística, e outra turbulenta:

$$
\vec{U}=\overrightarrow{\bar{U}}+\overrightarrow{U^{\prime}}
$$

onde $\overrightarrow{\vec{U}}$ é a velocidade média, e $\overrightarrow{U^{\prime}}$ é a velocidade turbulenta.

Para tentar obter a velocidade turbulenta, são resolvidas equações de Langevin mais complexas, baseadas no esquema não-linear, descrito em Thomson (1987), levando em consideração o fato da atmosfera não ser, na verdade, nem homogênea nem estacionária. Baseando-se em ajustes empíricos sobre parâmetros meteorológicos que permitem definir a turbulência na atmosfera, determinam-se os $\sigma_{u i}$ e $T_{L_{i}}$ que determinarão as características da Função de Distribuição de Probabilidade (PDF) para o cálculo de U'. Na horizontal utiliza-se PDFs gaussianas, enquanto na vertical, é necessário utilizar uma função densidade de probabilidade não-gaussiana, usualmente uma Bi-Gaussiana ou Gram-Charlier truncada na $3^{\mathrm{a}}$ ou $4^{\mathrm{a}}$ ordem. 
Neste trabalho, foi utilizada uma função oriunda da expansão das séries de Gram-Charlier truncada na $3^{\mathrm{a}}$ ordem.

A expansão Gram-Charlier de $4^{\mathrm{a}}$ ordem tem a forma:

$$
P(x)=\frac{\exp ^{-\frac{x^{2}}{2}}}{\sqrt{2 \pi}}\left(1+C_{3} H_{3}+C 4_{4}\right),
$$

onde $H_{3}=x^{3}-3 x, H_{4}=x^{4}-6 x+3$ são os polinômio de Hermite, $C_{3}=\frac{\overline{\mu^{3}}}{6}, C_{4}=\frac{\overline{\mu^{4}}-3}{24}$ são constantes, $\overline{\mu^{3}}$ e $\overline{\mu^{4}}$ são momentos padronizados de $\mathrm{w}$, e $x=\frac{w}{\sigma_{w}}$.

Quando $C_{4}=0$, a expansão está truncada na $3^{\mathrm{a}}$ ordem. 


\section{Metodologia}

O modelo lagrangiano estocástico de dispersão de partículas SPRAY foi empregado para simular campos de concentração do CO emitido pela frota veicular na RMSP e do material particulado emitido pelas fábricas de fertilizantes instaladas na região da Vila Parisi, em Cubatão, além das emissões de todas as fábricas inventariadas pela CETESB nesta cidade, sendo de fertilizantes, ou não. Buscou-se a partir destas simulações analisar o transporte destes poluentes nesta área e em seu entorno, particularmente durante os episódios registrados nos $\operatorname{dias} 25$ e $26 / 08 / 2006$.

A escolha do CO para a RMSP considerou a estabilidade deste componente nos limites temporais destas simulações e a capacidade de definição de suas emissões. Já as fábricas de fertilizantes historicamente representam o maior impacto na qualidade do ar na região da Vila Parisi. Seu MP poderia ser destacado de outras emissões por um elemento traçador como o fósforo, presente na rocha fosfática, matéria-prima básica na produção de fertilizantes. Infelizmente essa possibilidade não se concretizou, nos limites de tempo deste trabalho, porque verificamos que os espectros das amostras coletadas para este período particular do experimento ainda não haviam sido completadas.

As simulações do MP emitido por Cubatão, por fontes inventariadas pela CETESB, foram comparadas com os valores medidos nas estações de monitoramento da cidade para avaliar sua performance. Além disto, os resultados desta simulação também foram comparados com os dados dos episódios nos dias supracitados para verificar quanto o modelo se aproximou das medidas em Cubatão.

As variáveis meteorológicas necessárias para a operação do SPRAY foram geradas pelo modelo meteorológico de meso-escala BRAMS. Discutimos a seguir características gerais destes modelos, as parametrizações empregadas e o processo de validação de seus resultados. 


\subsection{BRAMS}

O BRAMS, Brazilian Regional Atmospheric Modeling System, é um modelo de simulação meteorológica de meso-escala desenvolvido em conjunto pelo IAG (Instituto Astronômico e Geofísico), IME (Instituto de Matemática e Estatística), ambos unidades da USP (Universidade de São Paulo), pelo CPTEC/INPE (Centro de Previsão de Tempo e Estudos Climáticos/Instituto Nacional de Pesquisas Espaciais) e pela ATMET (Fazenda et al., 2013). Suas raízes encontram-se no RAMS (Regional Atmospheric Modeling System), desenvolvido originalmente na Colorado State University (Pielke et al., 1992) (Cotton et al., 2003). O BRAMS adiciona correções e funcionalidades para que o modelo simule melhor a meteorologia na América do Sul. Tendo como entrada informações sobre a vegetação, uso do solo, topografia, temperatura da superfície dos oceanos, e reanálises globais das variáveis meteorológicas fornecidas pelo CPTEC, parametrizações sobre formação de nuvens e microfísica, o BRAMS resolve as equações diferencias que governam o movimento na atmosfera, bem como equações termodinâmicas (ATMET, 2003) (Fazenda et al., 2013), e geram como saída resultados prognósticos das variáveis meteorológicas, tais como campo de vento, temperatura, umidade, precipitação etc. O BRAMS pode trabalhar com grades aninhadas com comunicação bidirecional entre elas, permitindo que as regiões de interesse sejam resolvidas com informações de entrada com melhor resolução do que as utilizadas para inicializar o modelo.

\subsubsection{Configuração da simulação meteorológica}

\subsubsection{Grade}

Para inicializar o BRAMS, foram utilizados arquivos com reanalises meteorológicas globais do CPTEC, com resolução de tempo de $12 \mathrm{~h}$, e $0,9375^{\circ}$ de latitude e longitude, cobrindo uma área entre $90^{\circ} \mathrm{S}$ a $40^{\circ} \mathrm{N}$ de latitude e $120^{\circ} \mathrm{O}$ a $50^{\circ} \mathrm{L}$ de longitude, em 28 níveis verticais.

Foram utilizadas 3 grades aninhadas, cujos limites e detalhes estão na tabela 3.1: A grade 1 é a mais ampla, abrangendo um maior número de pontos de inicialização, permitindo mais solidez na troca de informações com as áreas menores de interesse para as análises. A resolução da grade 1 era de $12 \mathrm{Km}$, enquanto a grade 2, contendo a RMSP, a Baixada Santista e a Região Metropolitana de Campinas, tinha 3Km de resolução, e na grade 3, abrangendo a RMSP e a Baixada Santista, usou-se 1Km de resolução, para analisar melhor a região de Cubatão, devido à sua topografia acidentada. A resolução temporal foi de $2 \mathrm{~s}$, mas os resultados eram gravados a cada uma hora. 
Tabela 3.1: Grade utilizada nos modelos BRAMS e SPRAY. Em negrito, as regiões de interesse para as simulações

\begin{tabular}{llllll}
\hline Grade & Centro da Grade & Resolução & Área & Limites & Limites \\
\hline & lat/lon & $\mathbf{m}$ & $\mathbf{K m x K m}$ & Latitudinais & Longitudinais \\
1 & $23,077^{0} \mathrm{~S} / 46,345^{0} \mathrm{E}$ & 12000 & $456 \times 456$ & $20,985^{0} \mathrm{~S}-25,141^{0} \mathrm{~S}$ & $48,579^{0} \mathrm{~W}-44,049^{0} \mathrm{~W}$ \\
$\mathbf{2}$ & $23,293^{0} \mathrm{~S} / 46,342^{0} \mathrm{E}$ & 3000 & $279 \times 231$ & $22,231^{0} \mathrm{~S}-24,344^{0} \mathrm{~S}$ & $47,713^{0} \mathrm{~W}-44,949^{0} \mathrm{~W}$ \\
$\mathbf{3}$ & $23,714^{0} \mathrm{~S} / 46,615^{0} \mathrm{E}$ & 1000 & $118 \times 94$ & $23,284^{0} \mathrm{~S}-24,143^{0} \mathrm{~S}$ & $47,199^{0} \mathrm{~W}-46,028^{0} \mathrm{~W}$ \\
\hline
\end{tabular}

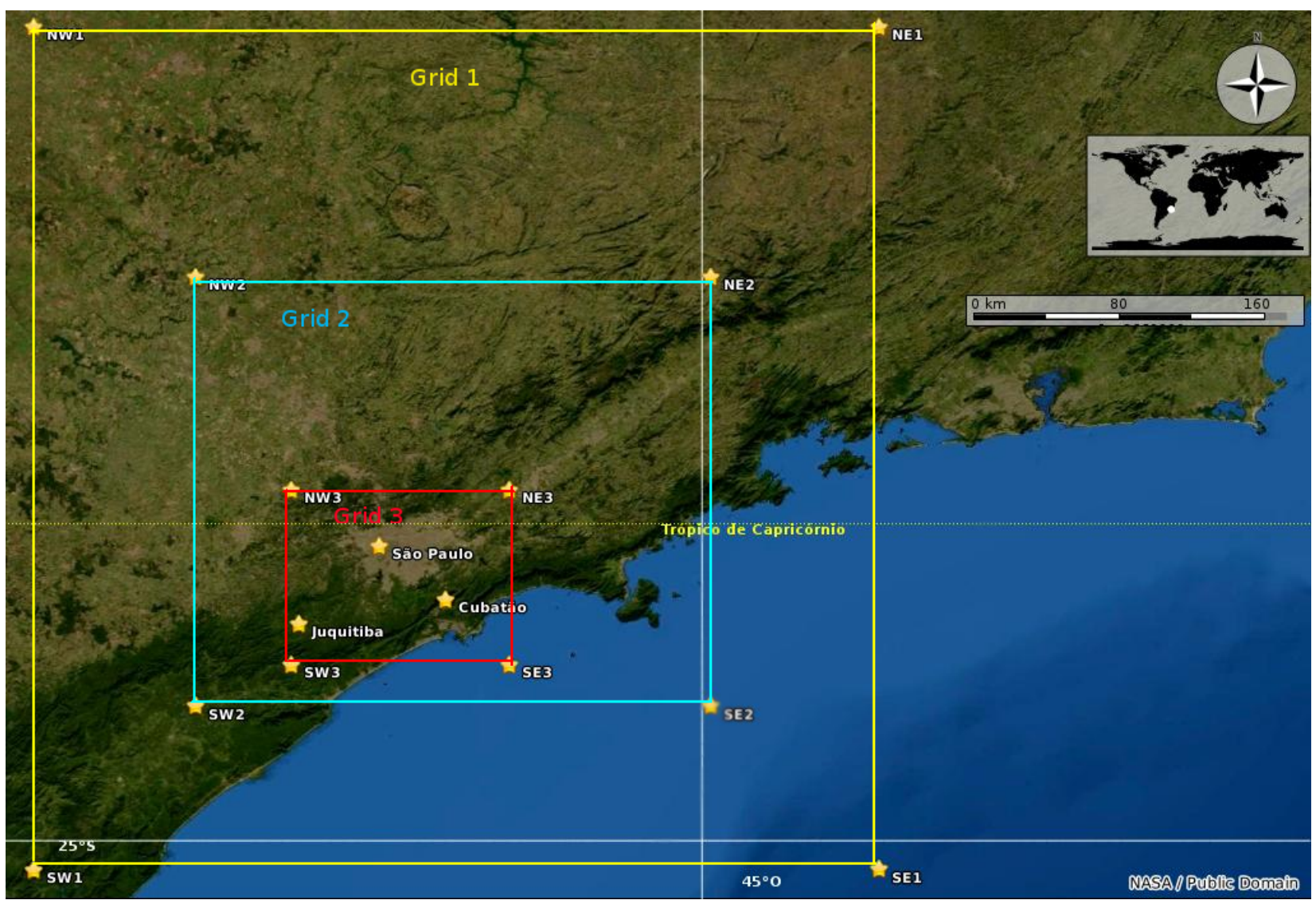

Figura 3.1: Grades da simulação no Mapa. As grades 2 e 3 são as regiões de interesse para a simulação.

Imagem de Domínio Público forncedida pela NASA editada com os softwares Marbles, GIMP e kolourpaint.

\subsubsection{Parametrizações Físicas}

As parametrizações radiativas foram ajustas de modo a ser recalculadas a cada 1800s.

A convecção foi parametrizada utilizando esquema de Kain-Fritch (Kain, 2004), com atualização dos parâmetros conectivos a cada 1200s.

A simulação foi ajustada de forma a ter parametrização de microfísica em massa, o que inclui água em nuvens, chuva, granizo, neve, agregados etc. 


\subsection{SPRAY}

O SPRAY foi o modelo de dispersão lagrangiano utilizado para simular a dispersão dos poluentes. Os parâmetros meteorológicos relevantes para sua operação foram obtidos das simulações feitas previamente com o BRAMS. Os resultados do BRAMS precisam ser adaptados para assimilação no SPRAY, o que é feito pelo programa GAP (Grid Adaptator). Ele converte o sistema de coordenadas (lat/lon) para UTM, e interpola os dados para a grade que compõe a base de dados para o SPRAY. Essa base de dados ainda é previamente processada pelo programa SurfPRO, juntamente com informações de uso do solo da USGS (United States Geological Survey), estimando os parâmetros de escala da turbulência na camada limite que o SPRAY necessita seja capaz de gerar as componentes estocásticas do vento e, consequentemente do movimento das partículas emitidas.

O SPRAY foi desenvolvido pelo Centro Ricerca Ambiente e Materiali da ENEL (Ente Nazionale per Energia Elettrica) e pelo Istituto di Cosmo-Geofisica do Consiglio Nazionale di Richerca da Itália, e tem o seu desenvolvimento continuado pela empresa ARIANET. Suas bases são descritas em Tinarelli et al. (1994) e Tinarelli et al. (2000), além de ter a teoria pertinente para este experimento desenvolvida na sessão 2.2.

\subsubsection{Tornando o acoplamento BRAMS/SPRAY operacional}

Um dos primeiros objetivos deste projeto de mestrado, era tornar o acoplamento BRAMS/SPRAY operacional.

Qualquer modelo meteorológico de diagnóstico ou prognóstico pode ser usado para fornecer as informações meteorológicas necessárias para se operar o modelo SPRAY, compondo um sistema de modelos capaz de gerar campos tridimensionais de concentração de poluentes. Basta que se proveja uma interface de comunicação para a transferência destas informações, que seguem acompanhadas da topografia sobre a qual o sistema meteorológico trabalhou. O SPRAY conta com interfaces para os códigos do SWIFT (diagnóstico) (Tech, 2010), WRF (Michalakes et al., 2001) e RAMS (prognósticos).

No contexto da análise pretendida da dispersão de poluentes da RMSP e das Fábricas de fertilizantes de Cubatão, pretendia-se também atualizar o ambiente de emprego do Modelo Lagrangiano de Dispersão de Partículas, SPRAY. Particularmente a sua conexão com o modelo meteorológico de meso-escala BRAMS, sobre o qual um conjunto expressivo de pesquisadores brasileiros investiu tempo e habilidades para adequá-lo a especifidades brasileiras. Nesse 
sentido, também, o uso dos dados de inicialização do CPTEC preenche lacunas regionais das bases de dados de uso global.

A nós interessava particularmente o uso do SPRAY com o BRAMS. Mas essa interface estava voltada a versões mais antigas do RAMS, sendo necessário adequá-la às mudanças introduzidas nas novas versões. Tivemos que trabalhar nestes ajustes, o que foi feito em interações sucessivas com pesquisadores da Arianet. Um momento intenso desse processo ocorreu durante a preparação e realização do Workshop on Air Quality Modeling, de 23 a 27 de fevereiro de 2015, quando participantes do evento tiveram oportunidade de trabalhar com o modelo SPRAY, sob orientação do Dr. Gianni Tinarelli. No processo preparatório do evento contribuímos para a instalação e ajustes dos softwares, particularmente relativos à interface BRAMS/SPRAY. Contribuímos com a correção de alguns bugs no modelo SPRAY disponível para pesquisa, em especial um relacionado à condição de contorno para a velocidade no solo.

Foram 2 anos até ter esse sistema de modelos bem acoplados e funcionando corretamente, inclusive com ferramentas de extração de dados para validação das simulações e processamentos gráficos. Neste último aspecto em particular, trabalhamos o acoplamento com softwares livres, em sistema operacional Linux, que oferece resolução gráfica melhor que o processador usual do SPRAY.

Nosso trabalho mostra que esse sistema BRAMS/SPRAY hoje está operacional e disponível para quem desejar utilizar um bom modelo lagrangiano estocástico de dispersão de partículas (No site http://fap.if.usp.br/ ate/mestrado.html estão os arquivos de configuração para o acoplamento, bem como o resultado das simulações).

\subsubsection{Configuração do modelo de dispersão de poluentes}

Para a dispersão horizontal de poluentes, utilizou-se uma função gaussiana para a distribuição de probabilidades da velocidade estocástica, enquanto que na vertical, foi utilizada uma GramChalier truncada na terceira ordem, posto que esta é computacionalmente mais eficiente que uma Bi-gaussiana refletida (também disponível como opção).

Foi utilizado incremento de tempo variável, com tempo máximo de 30s. O comprimento horizontal da caixa de cálculo utilizado para calcular as concentrações foi de $1 \mathrm{~km}$ na simulação do $M P_{10}$ em Cubatão, e de $3 \mathrm{~km}$ para a do CO. 


\subsubsection{Simulação das fontes de CO para RMSP e sua relação com $M P_{10}$}

A simulação da dispersão de CO foi realizada utilizando-se as informações fornecidas pela grade 2 do BRAMS, com resolução de $3 \mathrm{Km}$. Como dito anteriormente, as estimativas da CETESB para o ano do experimento apontam que $98 \%$ da emissão de CO na RMSP vinham de veículos movidos a combustíveis fósseis. Desta forma, considerou-se apenas as emissões desta fonte, desprezando-se as demais. Buscamos montar esta fonte para a simulação, com uma resolução mais refinada e dados mais atualizados do sistema viário e da densidade e composição da frota circulante na RMSP. Cremos estar próximos de concluir esta tarefa, mas não foi possível completá-la nos limites de tempo e prioridades para a conclusão deste trabalho. Mas consideramos que a solução adotada para equacionar esta fonte é bastante aceitável.

Baseamo-nos no trabalho de Kerr et al. (2005), que empregou emissões de CO avaliadas a partir da densidade de trafego veicular nas vias da RMSP, estimada por um programa da CET, e da taxa média de emissão da frota de veículos para o ano 2000. A resolução desta fonte área era de $5 X 5 \mathrm{~km}^{2}$. As emissões integradas ao longo de um ano representavam um total de 1,69 milhões de toneladas, valor bastante próximo das 1,62 milhões de toneladas estimadas então pela CETESB. (CETESB, 2007, Relatório para o ano 2000). Considerando-se que neste período de 2000 a 2006 as mudanças no sistema viário foram pequenas, utilizou-se essa mesma estrutura de fonte para o $\mathrm{CO}$, mas aplicando-se um fator de correção devido às significativas reduções nas emissões veiculares de CO introduzidas pelo PROCONVE. A razão entre as concentrações de CO no ano 2000 e 2006 foi de 1,5, tomando-se por base medidas realizadas pela CETESB em sua estação de Congonhas, na Avenida dos Bandeirantes. Tratava-se de uma artéria representativa do sistema viário e esse ponto tem captação significativa das emissões veiculares primárias devido à sua estreita proximidade à linha de tráfego. A razão calculada mostra-se coerente com a progressiva renovação da frota veicular com unidades dotadas de injeção eletrônica e catalisadores no sistema de exaustão. Da mesma forma esta estação foi escolhida para construir a modulação temporal da intensidade de emissão de CO ao longo do dia (figura 3.3). 


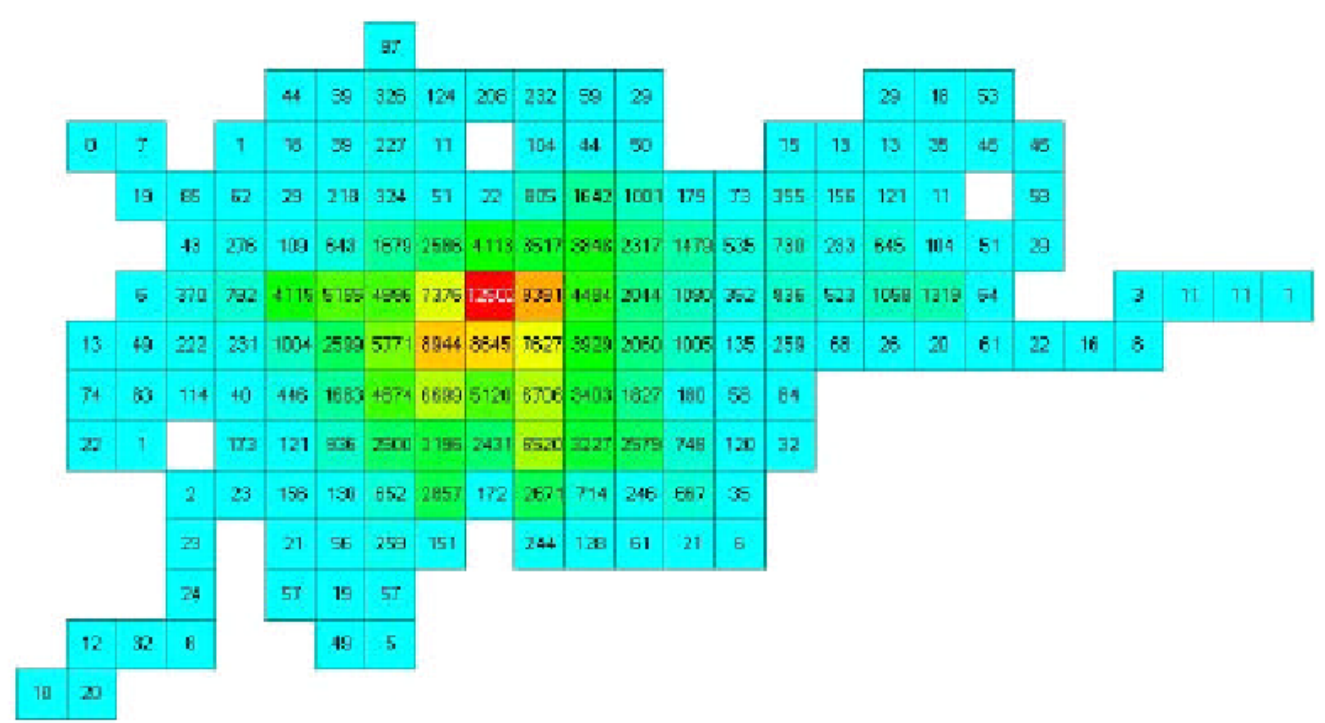

Figura 3.2: Representação da fonte de CO feita com 169 quadrados de $5 X 5 \mathrm{~km}^{2}$, representando a emissão veicular deste poluente na RMSP (valores registrados nas células em $\mathrm{kg} / \mathrm{h}$ ).

Não dispúnhamos de uma estimativa de emissões direta de material particulado relacionada a veículos. Essa, inclusive, não é uma tarefa fácil uma vez que, além da exaustão, há contribuição por desgaste de partes dos veículos (pneus,freios,erosão de peças etc), a ressuspensão de solo, ou o próprio aerossol secundário que pode ter proporções significativas. Supondo novamente que a estação Congonhas capta particularmente as emissões primárias do local, utilizamos, em uma primeira aproximação bastante simplificada, a razão entre $\frac{C O}{M P_{10}}=40,7$ nesta estação para definir, a partir da fonte área de $\mathrm{CO}$, o que seria a contribuição direta de $M P_{10}$ associada à fonte veicular na RMSP. A semelhança entre as modulações temporais das concentrações de $\mathrm{CO}$ e $P M_{10}$ na estação Congonhas pode ser vista na figura 3.3, sendo a correlação entre ambas $=0,4$, com nível de significância $<0,05$. Essa simplificação nos parece razoável para as áreas altamente urbanizadas, mas é bastante limitada para áreas mais periféricas onde deparamo-nos, por exemplo, com ruas sem pavimentação ou frota mais envelhecida. 


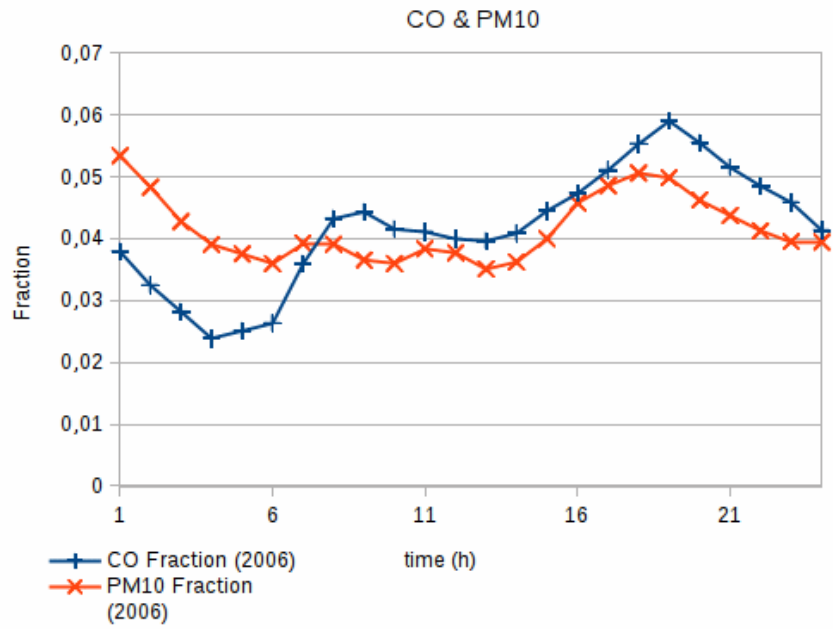

Figura 3.3: Modulação das Intensidades de $M P_{10}$ e $\mathrm{CO}$ por hora do dia, a partir das concentrações medidas na estação de Congonhas em 2006. Há boa correlaçãoentre $M P_{10}$ e $\mathrm{CO}$, o que alimentou a aproximação feita neste trabalho para relacionar as simulações de $\mathrm{CO}$ com $M P_{10}$ nas comparações com o experimento de inverno relacionadas à fonte veicular.

\subsubsection{Fontes $M P_{10}$ para Cubatão}

Na simulação da dispersão de material particulado utilizamos um inventário da CETESB sobre as fontes industriais, o que totalizava uma emissão de 3.950 toneladas de $M P$ por ano. Os resultados desta simulação foram comparados com a poluição observada nas estações de Vila Parisi, Vale do Mogi, e Cubatão Centro. As fábricas de fertilizantes, atualizando levantamento feito por Kerr et al. (2000). Essas são as indústrias que têm maior impacto na área de Vila Parisi e em 2006 representavam 15\% do total destas emissões. 


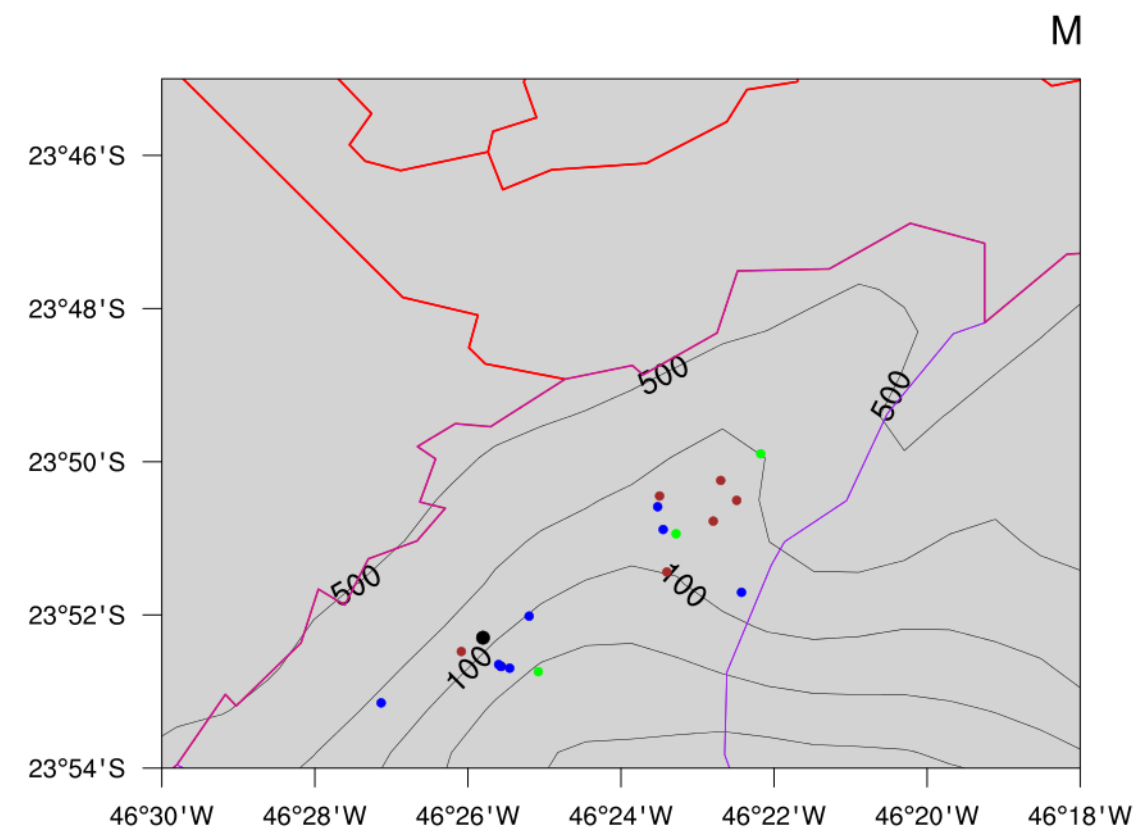

CONTOUR FROM 0 TO 9000 BY 750

Figura 3.4: Posição das fábricas inventariadas pela CETESB em 2006 cuja emissão de $M P$ em Cubatão foi simulada pelo SPRAY.

Os pontos verdes representam estações de monitoramento da CETESB.

O ponto verde extremo a NE também continha a estação Vale do Mogi do experimento de inverno. O ponto preto é a Refinaria Presidente Bernardes.

Os pontos marrons são as fábricas de Fertilizantes.

Os pontos azuis são fábricas de outros ramos.

Todas as fábricas estão, no máximo a 10m do nível do mar. Notar as limitações na resolução da topografia no BRAMS 


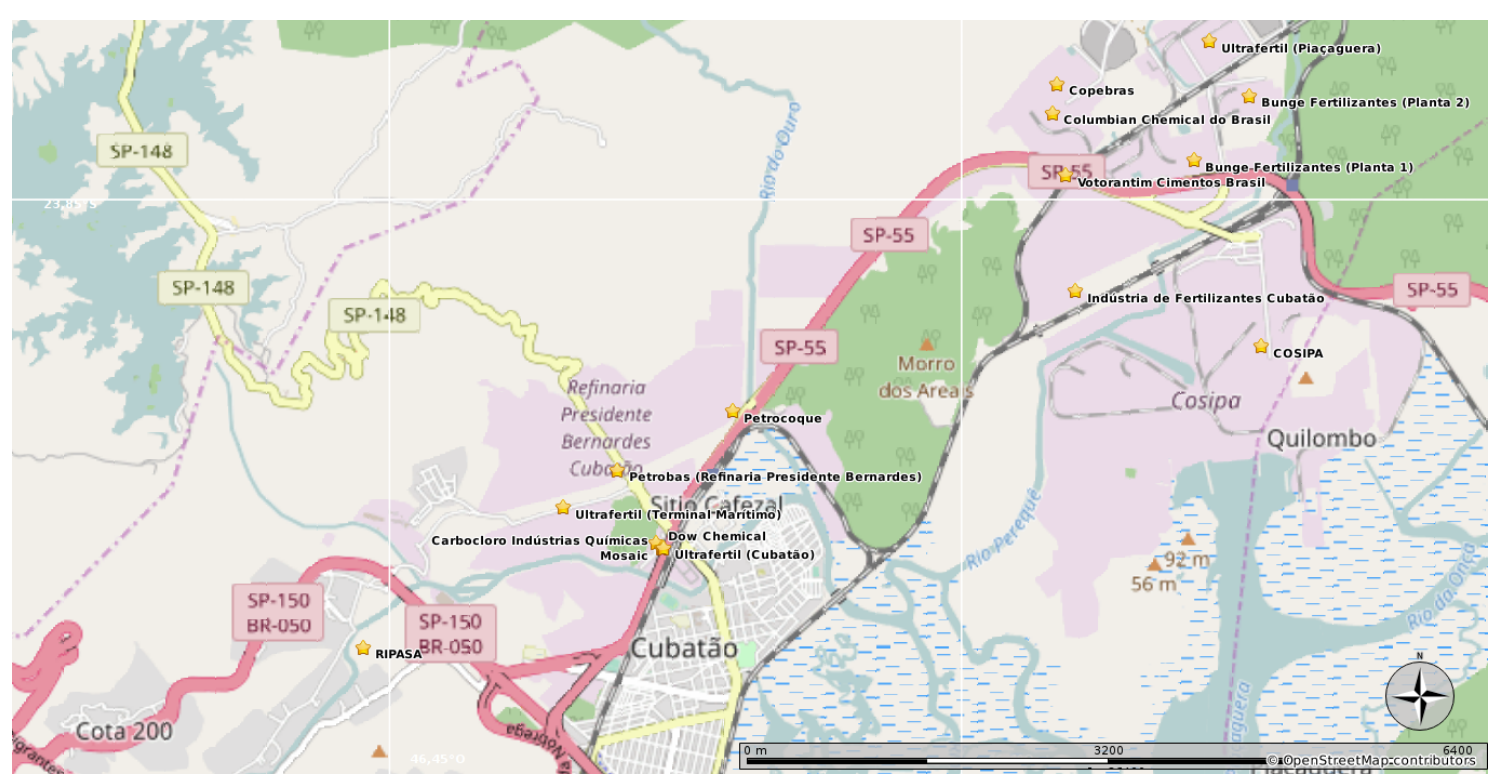

Figura 3.5: Posição das fábricas em Cubatão em mapa do projeto Open Street Maps.

Companhia Brasileira do Estireno não aparece no mapa, mas fica próximo à Ultrafertil (Cubatão), nos entornos da SP-148.

Gerado com o software Marble.

Tabela 3.2: Localização geográfica de fontes industriais em Cubatão.

\begin{tabular}{lllll}
\hline Fábrica & Tipo de Indústria & Longitude $\left({ }^{\circ} \mathrm{O}\right)$ & Latitude $\left({ }^{\circ} \mathrm{S}\right)$ & Emissão (toneladas/ano) \\
\hline Bunge Fertilizantes (Planta 1) & Fertilizantes & 46,379659 & 23,846861 & 91,55 \\
Bunge Fertilizantes (Planta 2) & Fertilizantes & 46,374804 & 23,841721 & 3,94 \\
Copebras & Fertilizantes & 46,391596 & 23,840774 & 93,47 \\
Ultrafertil (Piaçaguera) & Fertilizantes & 46,378286 & 23,837392 & 352,72 \\
Ultrafertil (Cubatão) & Fertilizantes & 46,426031 & 23,877836 & 4,5 \\
Ultrafertil (Terminal Marítimo) & Fertilizantes & 46,434764 & 23,874612 & 1,27 \\
Mosaic & Fertilizantes & 46,426122 & 23,877871 & 20,96 \\
Indústria de Fertilizantes Cubatão & Fertilizantes & 46,390014 & 23,857308 & 0,50 \\
Votorantim Cimentos Brasil & Cimento & 46,390817 & 23,848067 & 23,01 \\
Carbocloro Indústrias Químicas & Química & 46,426175 & 23,877851 & 2,15 \\
Columbian Chemical do Brasil & Química & 46,392016 & 23,843111 & 28,01 \\
Companhia Brasileira do Estireno & Plástico & 46,424244 & 23,878243 & 3,30 \\
Companhia Siderúrgica Paulista & Siderúrgica & 46,373751 & 23,861741 & 2825,00 \\
Dow Brasil & Química & 46,426646 & 23,877453 & 4,34 \\
Petrobras (Refinaria Pres Bernardes) & Petroquímica & 46,430051 & 23,871611 & 406,12 \\
Ripasa & Papéis & 46,452223 & 23,885795 & 5,49 \\
Petrocoque Indústria e Comércio & Petroquímica & 46,420001 & 23,866923 & 87,31 \\
\hline
\end{tabular}

\subsection{Estações de Medidas}

Uma vez simuladas as variáveis meteorológicas e as concentrações os resultados foram comparados com os valores observados nas estações meteorológicas e/ou de monitoramento ambiental da CETESB, do experimento de inverno, além da estação meteorológica do IAG (figura 3.6). A figura 3.4 permite observar mais claramente a posição da estação utilizada no experimento de Inverno para medir as concentrações de poluentes em Cubatão. 


\section{Topography and Monitoring Stations}

23/08/2006 1h UTC

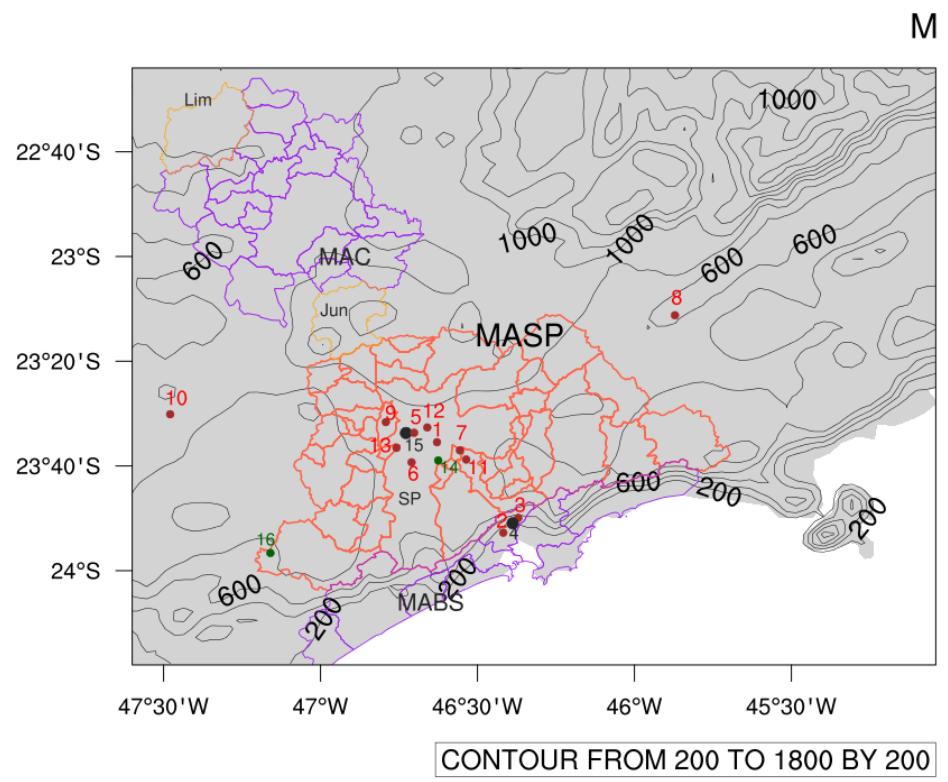

Figura 3.6: Estações de Monitoramento de poluentes e/ou meteorológicas. 13 estações da CETESB, três utilizadas para o experimento de Inverno e uma estação do IAG. Os números na figura referem-se às estações descritas na tabela 3.3

Tabela 3.3: Estações meteorológicas e/ou de monitoramento de poluentes

\begin{tabular}{|c|c|c|c|c|c|c|}
\hline Número & $\begin{array}{l}\text { Estação } \\
\text { Nome }\end{array}$ & $\begin{array}{l}\text { Latitude } \\
\left({ }^{\circ} \text { S }\right)\end{array}$ & $\begin{array}{l}\text { Longitude } \\
\left({ }^{\circ} \mathrm{O}\right)\end{array}$ & $\begin{array}{l}\text { Parâmetros Medidos } \\
\text { Meteorologia }\end{array}$ & $\mathrm{CO}$ & $P M_{10}$ \\
\hline 1 & Ibirapuera & 23,591 & 46,629 & $\mathrm{X}$ & $\mathrm{X}$ & \\
\hline 2 & Cubatão Centro & 23,879 & 46,418 & $\mathrm{X}$ & & $\mathrm{X}$ \\
\hline 3 & Cubatão Vale do Mogi & 23,832 & 46,370 & $\mathrm{X}$ & & $\mathrm{X}$ \\
\hline 4 & Cubatão Vila Parisi & 23,849 & 46,388 & $\mathrm{X}$ & & $\mathrm{X}$ \\
\hline 5 & Pinheiros & 23,561 & 46,702 & $\mathrm{X}$ & $\mathrm{X}$ & \\
\hline 6 & Santo Amaro & 23,655 & 46,710 & $\mathrm{X}$ & $\mathrm{X}$ & \\
\hline 7 & São Caetano & 23,617 & 46,556 & $\mathrm{X}$ & $\mathrm{X}$ & \\
\hline 8 & São José dos Campos & 23,187 & 45,871 & $\mathrm{X}$ & $\mathrm{X}$ & \\
\hline 9 & Osasco & 23,527 & 46,792 & $\mathrm{X}$ & $\mathrm{X}$ & \\
\hline 10 & Sorocaba & 23,502 & 47,479 & $\mathrm{X}$ & & \\
\hline 11 & Santo André & 23,646 & 46,536 & $\mathrm{X}$ & $\mathrm{X}$ & \\
\hline 12 & Pedro II & 23,544 & 46,66 & & $\mathrm{X}$ & \\
\hline 13 & Taboão da Serra & 23,609 & 46,758 & & $\mathrm{X}$ & \\
\hline 14 & IAG & 23,649 & 46,625 & $\mathrm{X}$ & & \\
\hline 15 & IGC (São Paulo) & 23,562 & 46,728 & & & $\mathrm{X}$ \\
\hline 16 & Juquitiba & 23,944 & 47,160 & & & $\mathrm{X}$ \\
\hline
\end{tabular}




\subsection{Métodos de avaliação dos resultados simulados}

Uma vez de posse dos resultados da simulação e dos dados observados nas estações meteorológicas, foram calculados índices e parâmetros para avaliar a confiabilidade estatística deles e a performance da simulação como um todo.

Para avaliar a confiabilidade estatística da simulação, foi calculada a correlação (R) entre valores simulados e observados, e feito o teste de hipótese nula.

(ou seja, no caso, a hipótese dos valores simulados e observados estarem correlacionados) para um nível de significância $\alpha \leqslant 0,05$. No caso da simulação de vento, foram calculadas $R_{u}$ e $R_{v}$, correlação das componentes zonal e meridional, respectivamente. Como as correlações zonal e meridional em cada estação são independentes, consideramos que a correlação mais baixa deve ser utilizada para definir a confiabilidade do modelo em cada estação.

A Correlação foi calculada como:

$$
R=\frac{\overline{\left(C_{o b s}-\overline{C_{o b s}}\right)\left(C_{s i m}-\overline{C_{s i m}}\right)}}{\sigma_{C_{s i m}} \sigma_{C_{o b s}}},
$$

onde $C_{o b s}$ é a concentração observada, $C_{\text {sim }}$ a concentração simulada, $\sigma_{\text {sim }}$ e $\sigma_{\text {obs }}$ são, respectivamente, o desvio padrão da concentração simulada e observada, respectivamente.

Para avaliar a performance da simulação foram calculadas grandezas como média dos valores simulados $(\overline{s i m})$ e observados $(\overline{o b s})$, razão entre estes $\left(\frac{\overline{s i m}}{\overline{o b s}}\right)$, desvios padrões destes $\left(\sigma_{\text {sim }}\right.$ e $\left.\sigma_{o b s}\right)$, respectivamente, o RMSE (Root Mean Square Error - Raiz do Erro Quadrático Médio) e o NRMSE (Normalized Root Mean Square Error - Raiz do Erro Quadrático Médio Normalizado). Para as comparações entre vento simulado e observado, foram utilizados o RMSVE (Root Mean Square Vector Error - Raiz do Erro Vetorial Quadrático Médio) e o desvio padrão $\sigma(u, v)=\sqrt{\sigma_{u}^{2}+\sigma_{v}^{2}}$.

Para o cálculo do RMSE, utilizamos:

$$
R M S E=\sqrt{\overline{\left(C_{\text {sim }}-C_{\text {obs }}\right)^{2}}}
$$

O NRMSE foi calculado como NRMSE $=100 \frac{R M S E}{\sigma_{o b s}}$.

O RMSVE para o vento foi calculado como:

$$
R M S V E=\sqrt{\left(u_{s i m}-u_{o b s}\right)^{2}+\left(v_{s i m}-v_{o b s}\right)^{2}},
$$

onde u e v são as velocidades zonal e meridional, respectivamente. Os índices sim e obs 
representam simulado e observado, respectivamente.

O NRMSVE foi calculado como $N R M S V E=100 \frac{R M S V E}{\sigma(u, v)_{o b s}}$, onde $\sigma(u, v)_{o b s}$ é o desvio padrão da magnitude do vento observado.

Os valores ideais destes parâmetros são:

- $\overline{s i m}=\overline{o b s}$. Mostra perfeita acurácia da simulação;

- $\frac{\overline{s i m}}{\overline{o b s}}=1$. Consequência direta do item acima;

- $\sigma_{\text {sim }} \approx \sigma_{o b s}$. O Desvio Padrão dos valores simulados deve ser similar (idealmente igual) ao dos valores observados, mostrando que esses dois conjuntos de valores têm dispersões similares, o que indicaria um comportamento do modelo semelhante à natureza, à física ou leis do fenômeno estudado.

- $\operatorname{RMSE}=0$ (ou NRMSE $=0$ ). A Raiz do Erro Quadrático Médio, ou a Raiz do Erro Quadrático Médio Normalizado, indica o quão distante estão os valores simulados em relação aos medidos. Tipicamente espera-se que RMSE seja próximo de $\sigma_{o b s}$. NRMSE ajuda a informar quão distante está o conjunto de dados simulados do conjunto de dados observados em termos de $\sigma_{o b s}$.

Chang \& Hanna (2004), Gudivaka \& Kumar (1990) e Kumar et al. (1993) apresentam também outros parâmetros, largamente utilizados na comparação de modelos de dispersão de poluentes e que podem, sempre que possível, ser utilizados para outras variáveis. Entre os parâmetros estatísticos apresentados, este trabalho se utilizou de FAC2 (Factor of two - Fator 2), que é a fração dos valores simulados dentro de um fator dois dos valores observados $(0,5 \leqslant$ $\left.\frac{S I M}{O B S} \leqslant 2\right)$, FB (Fractional Bias - Viés Fracional), que mede o erro sistemático da simulação que tende a sempre superestimar ou subestimar os valores medidos e NMSE (Normalized Mean Square Error - Erro Quadrático Médio Normalizado), que mede tanto o espalhamento, e reflete tanto erros sistemáticos quanto aleatórios.

O cálculo para o FB se dá como:

$$
F B=2 \frac{\overline{C_{\text {obs }}-\overline{C_{\text {sim }}}}}{\overline{C_{\text {obs }}}+\overline{C_{\text {sim }}}}
$$

O NMSE apresenta-se como:

$$
N M S E=\frac{\overline{\left(C_{o b s}-C_{\text {sim }}\right)^{2}}}{\overline{C_{\text {obs }}} \bar{C}_{\text {sim }}}
$$

Os valores ideais destes parâmetros são: 
- $\mathrm{FAC} 2=1$;

- $\mathrm{FB}=0$

- $\mathrm{NMSE}=0$.

Vários parâmetros estatísticos de performance e confiança do modelo devem ser utilizados para avaliá-lo porque todos apresentam vantagens e desvantagens, não podendo ser universalmente aplicados.

NMSE, por exemplo, pode ser influenciado por pontos de simulação muito acima dos valores observados (Poli \& Cirillo, 1993), e FB pode ser zero, mas por conter vieses negativos e positivos que se cancelam, mas que um gráfico de espalhamento mostraria que os valores estariam distantes da "reta 1 para 1", indicativa da concordância entre os dados simulados e observados. A melhor medida, geralmente, é o FAC2, por não ser influenciada por "outliers" como o NMSE, nem pelos cancelamentos de vieses positivos ou negativos. FB, mede vieses relativos médios, e indicam erros sistemáticos. Valores negativos, indicam que a simulação tende a superestimar as variáveis em relação aos dados observados. NMSE mede o espalhamento relativo médio, além de medir tanto erros sistemáticos quanto aleatórios.

\subsubsection{Critérios de realidade para avaliar a performance dos mode- $\operatorname{los}$}

A performance dos modelos dependem de muitos fatores: resolução das condições de contorno de entrada dos modelos para várias variáveis, incompletude do modelo em simular a natureza, ou das leis que governam os fenômenos estudados, erros na modelagem e/ou nas informações de grade que alimentam o modelo antes de começarem a rodar, erros na leitura dos dados observados, além de incertezas sobre as próprias leis e fórmulas que regem o fenômeno (até hoje, não se provou categoricamente a natureza gaussiana da turbulência atmosférica, ou a a microfísica de formação de nuvens sem recorrer a parametrizações experimentais, por exemplo) etc. Tais fatores tornam complicado estabelecer critérios rígidos para a comparação e validação da simulação com os dados observados.

Em Chang \& Hanna (2004), temos o estabelecimento de alguns critérios a partir da análise de muitos experimentos de comparação de modelos. Geralmente, os critérios para aceitação dos modelos quanto à performance são (não mutuamente excludentes):

- $F A C 2 \geqslant 0,5$ 
- $|F B| \leqslant 0,3$;

- $N M S E \leqslant 1,5$

Entretanto, a maioria das avaliações são de comparações com experimentos controlados, e poucas dentre elas feitas com estações de monitoramento (exemplos mais reais, como o realizado neste trabalho). Cisalhamento do vento, frentes e chuva, coisas associadas com "tempo real" podem causar deslocamento na posição das concentrações simuladas e observadas (nuvens de poluição) (Klug et al., 1992).

Um espalhamento aleatório da média dentro de um fator 2 ou 3 também é aceitável. Gudivaka \& Kumar (1990) trabalharam com lançamentos instantâneos e pontuais de gases densos, portanto, um experimento controlado, e trabalhram com um FAC2 mais rigoroso: $F A C 2 \geqslant 0,8$.

Em Steyn et al. (2012), há vários experimentos controlados, em que se preferiu, mesmo nestas circunstâncias mais simples, utilizar $F A C 2 \geqslant 0,4$, flexibilizando este fator.

Em Hanna \& Chang (2012), verifca-se que é aceitável, para ambientes urbanos, estabelecer como critérios:

- $|F B| \leqslant 0,67$, o que equivale a viés médio menor que ou igual a um fator 2 ;

- $N M S E \leqslant 6$, ou um espalhamento aleatório menor que 2,45 da média;

- $F A C 2 \geqslant 0,3$, ou $30 \%$ da simulação dentro de um fator 2 .

A razão desta relaxação deve-se ao fato de que não é esperado que os modelos se comportem tão bem devido a existência de prédios, ou topografia muito acidentada e incertezas nas fontes quanto a suas resolução, posicionamento ou intensidade. Ainda, se a simulação for bem em $50 \%$ dos parâmetros de performance, é lícito validá-la.

Levando em consideração que uma fonte de $\mathrm{CO}$ de resolução de $5 X 5 \mathrm{Km}^{2}$, quando a resolução da grade é de $3 X 3 \mathrm{Km}^{2}$, e da utilização de uma fontes para $M P_{10}$ cujas posições são estimadas na maioria das fábricas (exceto fábricas de fertilizantes, cuja localização é mais precisa) em Cubatão, foi razoável utilizar os seguintes parâmetros para analisar a simulação.

- $F A C 2 \geqslant 0,3$;

- $|F B| \leqslant 0,67$, o que equivale a uma subestimativa ou superestimativa sistemática de cerca de dois terços em relação aos valores observados;

- $N M S E \leqslant 6$, o que equivale a uma espalhamento aleatório de aproximadamente 2,4; 
- $N R M S E \leqslant 300 \%$, o que equivale a uma distância da nuvem de valores simulados de no máximo $3 \sigma_{o b s}$ da nuvens de valores observados;

- $\sigma_{s i m} \approx \sigma_{o b s}$

- $\mathrm{R}$, com nivel de significância $p \leqslant \alpha=0,05$.

Para as variáveis meteorológicas, FB, NMSE e FAC2 foram também calculadas quando foi possível (geralmente variáveis escalares, quando não foram apresentados valores negativos), e considerados caso a caso, conforme a necessidade, mas os parâmetros e critérios principais para analisá-las são o $N R M S E \leqslant 300 \%, \sigma_{\text {sim }} \approx \sigma_{o b s}$ e R, com nível de significância $\alpha \leqslant 0,05$.

Se a simulação apresentar resultados satisfatórios em mais de $50 \%$ dos parâmetros, ela foi considerada validada para a experiência, desde que $p \leqslant \alpha=0,05$, levando em consideração que isto significa que simulação e observação não estão correlacionados.

Todo o processamento estatístico realizado para a comparação da simulação com os dados observados foram realizados com o software $\mathrm{R}$ ( $\mathrm{R}$ Core Team, 2016), e os pacotes hydroGOF (Zambrano-Bigiarini, 2014) e Open Air (Carslaw \& Ropkins, 2012). 


\section{Resultados e Discussão}

Serão apresentados inicialmente os resultados das simulações meteorológicas, geradas com o BRAMS para o período do experimento, fazendo-se o confronto com medições em estações locais disponíveis Em sequência lógica, virão as simulações geradas com o SPRAY, confrontadas por sua vez com observações disponíveis na área. Desta forma estaremos validando esse sistema de modelos para avaliar de modo mais amplo os campos de concentrações gerados pelo SPRAY.

\subsection{Meteorologia}

\subsubsection{Pressão}

Tabela 4.1: Parâmetros estatísticos para Pressao em várias estações.

\begin{tabular}{llllllll}
\hline Estação & $\bar{P}_{\text {sim }}$ & $\bar{P}_{\text {obs }}$ & $\sigma_{\text {sim }}$ & $\sigma_{\text {obs }}$ & RMSE & NRMSE & $\frac{S T M}{\text { OBS }}$ \\
\hline \multirow{3}{*}{ Cubatão Centro } & $\mathrm{hPa}$ & $\mathrm{hPa}$ & $\mathrm{hPa}$ & $\mathrm{hPa}$ & $\mathrm{hPa}$ & $\%$ & \\
IAG & 1006,2 & 1026,0 & 4,6 & 6,5 & 20,1 & 307,9 & 1,0 \\
Ibirapuera & 937,6 & 926,9 & 3,6 & 3,5 & 10,8 & 306,8 & 1,0 \\
\hline
\end{tabular}

Tabela 4.2: Parâmetros estatísticos para Pressao em várias estações (Continuação)

\begin{tabular}{lllllll}
\hline Estação & $\mathrm{n}$ & $\mathrm{FB}$ & NMSE & FAC2 & $\mathrm{R}$ & valor-P \\
\hline Cubatão Centro & 168 & 0,02 & 0,00 & 1,00 & 0,84 & $1,49 \mathrm{e}-46$ \\
IAG & 168 & $-0,01$ & 0,00 & 1,00 & 0,89 & $7,49 \mathrm{e}-59$ \\
Ibirapuera & 168 & $-0,01$ & 0,00 & 1,00 & 0,87 & $6,57 \mathrm{e}-54$ \\
\hline
\end{tabular}

A simulação para Pressão apresentou bons resultados em praticamente todos os parâmetros de performance, com $\mathrm{NMSE}=0,00, \mathrm{FAC} 2=1$, e $|\mathrm{FB}|$ não maior do que 0,03 . A razão $\frac{\overline{s i m}}{\overline{o b s}}$ foi igual a $1,0, R \geqslant 0,84$ com valor-p desprezível e $\sigma_{\text {sim }}<\sigma_{o b s}$.A única exceção foi o NRMSE, pois $N R M S E>300 \%$.

Assim, pelos critérios discutidos na sessão 3.4.1, a simulação da pressão pelo BRAMS passou na avaliação da correlação e sua significância, na proximidade entre os desvios padrões 
da simulação e observação (dois dos 3 parâmetros prioritariamente escolhidos), além de apresentar baixo erro sistemático.

\subsubsection{Umidade}

A simulação para Umidade apresentou bons resultados em, praticamente, todas as estações. A performance ficou mais crítica na estação de Cubatão Centro, o que pode ser devido às dificuldades do modelo lidar com a topografia complexa da região. O terreno é bastante acidentado, e mesmo com uma resolução de $1 \mathrm{Km}$, o desempenho do modelo sofre limitações nestas condições.

Tabela 4.3: Parâmetros estatísticos para Umidade em várias estações.

\begin{tabular}{llllllll}
\hline Estação & $\overline{U R}_{\text {sim }}$ & $\overline{U R}_{\text {obs }}$ & $\sigma_{\text {sim }}$ & $\sigma_{\text {obs }}$ & RMSE & NRMSE & $\frac{S T M}{O B S}$ \\
\hline \multirow{2}{*}{ Cubatão Centro } & $\%$ & $\%$ & $\%$ & $\%$ & $\%$ & $\%$ & \\
IAG & 61,8 & 85,2 & 17,9 & 12,7 & 29,7 & 234,0 & 0,7 \\
Ibirapuera & 68,4 & 71,1 & 24,2 & 21,2 & 16,0 & 75,6 & 1,0 \\
Pinheiros & 68,0 & 72,8 & 25,0 & 17,3 & 17,2 & 99,0 & 0,9 \\
São Caetano & 67,9 & 58,1 & 25,3 & 18,4 & 19,2 & 104,6 & 1,2 \\
S José dosCampos & 67,3 & 71,3 & 24,3 & 22,3 & 17,2 & 77,3 & 0,9 \\
Taboão da Serra & 66,5 & 77,9 & 26,4 & 24,0 & 15,7 & 65,3 & 0,9 \\
\hline
\end{tabular}

Tabela 4.4: Parâmetros estatísticos para Umidade em várias estações (Continuação)

\begin{tabular}{lllllll}
\hline Estação & $\mathrm{n}$ & $\mathrm{FB}$ & NMSE & FAC2 & $\mathrm{R}$ & valor-P \\
\hline Cubatão Centro & 168 & 0,32 & 0,17 & 0,86 & 0,32 & $1,94 \mathrm{e}-05$ \\
IAG & 168 & 0,04 & 0,05 & 0,99 & 0,76 & $1,78 \mathrm{e}-33$ \\
Ibirapuera & 168 & 0,07 & 0,06 & 0,98 & 0,75 & $5,45 \mathrm{e}-32$ \\
Pinheiros & 168 & $-0,16$ & 0,09 & 0,99 & 0,76 & $2,23 \mathrm{e}-32$ \\
São Caetano & 163 & 0,06 & 0,06 & 0,98 & 0,74 & $7,31 \mathrm{e}-30$ \\
S José dosCampos & 168 & 0,13 & 0,05 & 1,00 & 0,88 & $2,39 \mathrm{e}-56$ \\
Taboão da Serra & 168 & $-0,09$ & 0,07 & 0,99 & 0,77 & $3,06 \mathrm{e}-34$ \\
\hline
\end{tabular}

$|\mathrm{FB}|$ apresentou valores nas estações entre $0,16 \leqslant|F B| \leqslant 0,32$.

O modelo tendeu a fazer ligeira subestimativa da umidade, com exceção de Pinheiros e Taboão da Serra.

NRMSE apresentou resultados entre $65,3 \%$ a 104,6\%, indicando boa habilidade do modelo em simular a umidade em quase todas as estações. Mesmo na estação de Cubatão, mostra-se que RMSE ficou dentro de $3 \sigma_{o b s}$.

Em todas as estações, os desvios padrões simulados e observados estiveram próximos.

Para FAC2, os resultados foram bem próximos do ideal (FAC2 $=0,86$ Cubatão Centro, a pior estação). 
Todas as estações passam em todos os critérios de análise dos parâmetros expostos nas tabelas. Ainda que a correlação para a estação de Cubatão esteja baixa, o valor p para esta foi desprezível. 

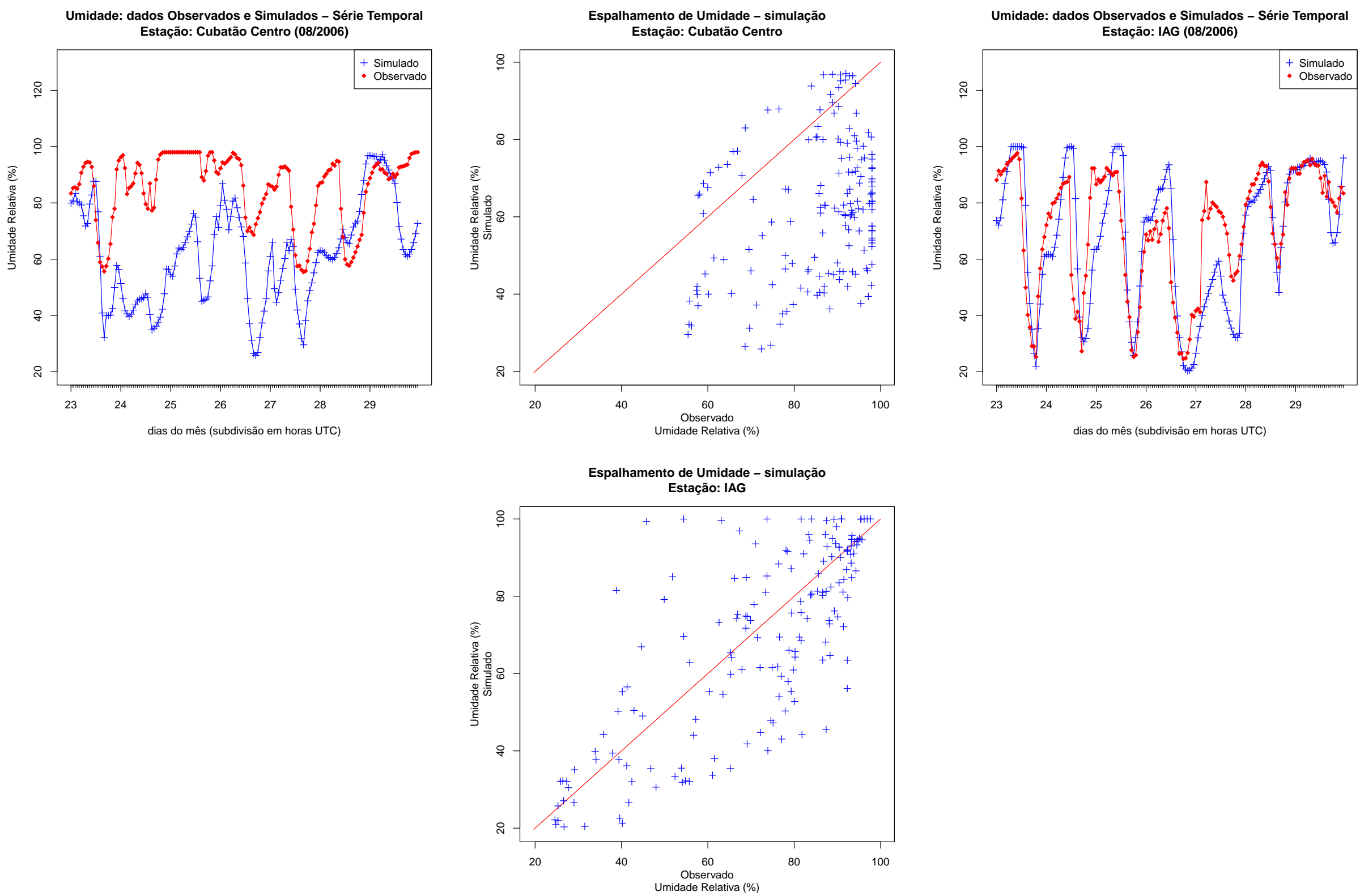

Figura 4.1: Umidade simulada pelo BRAMS e observada nas estações indicadas em cada gráfico: Série Temporal e gráfico de espalhamento 

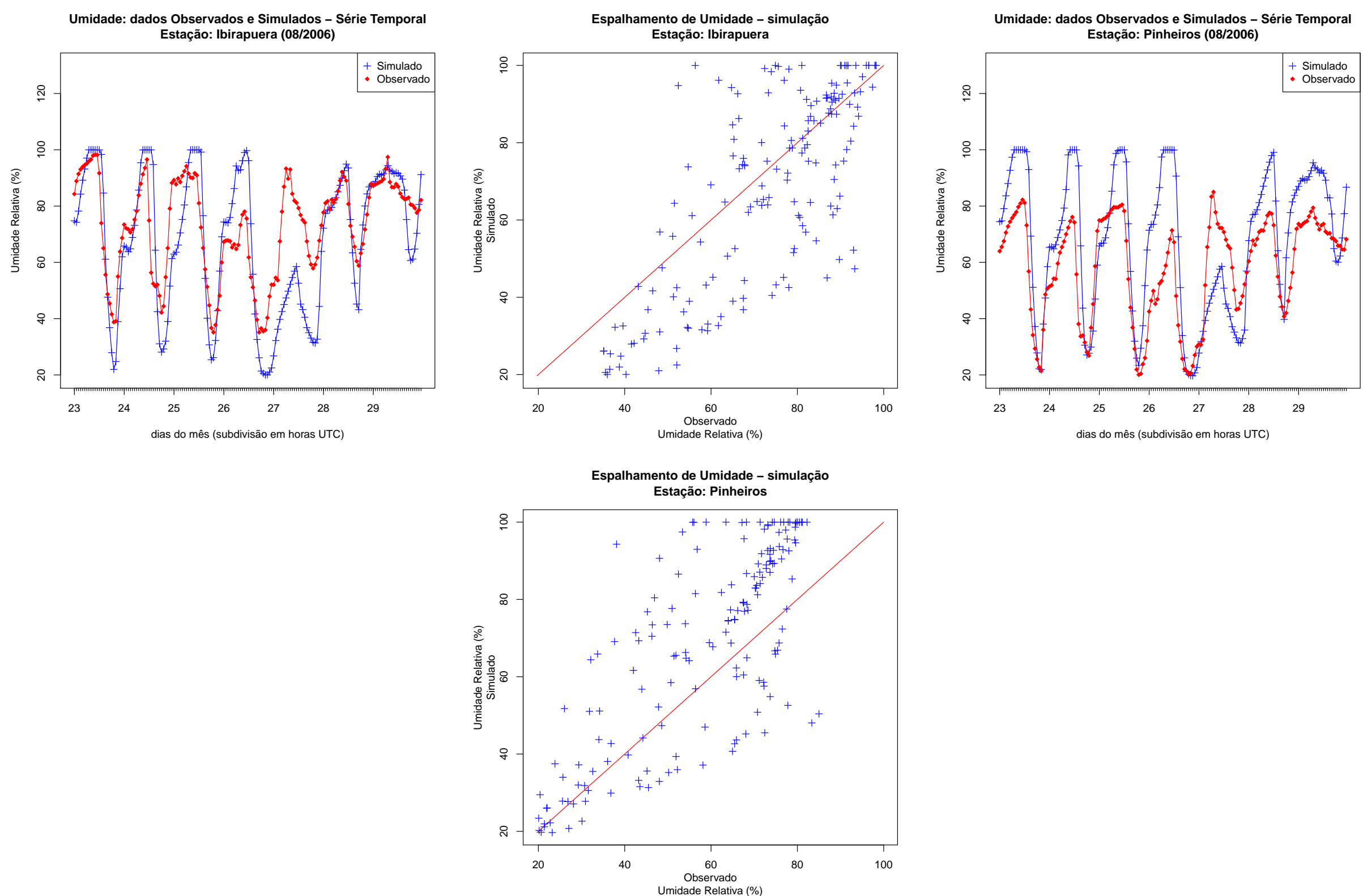

Figura 4.2: Umidade simulada pelo BRAMS e observada nas estações indicadas em cada gráfico. Continuação 

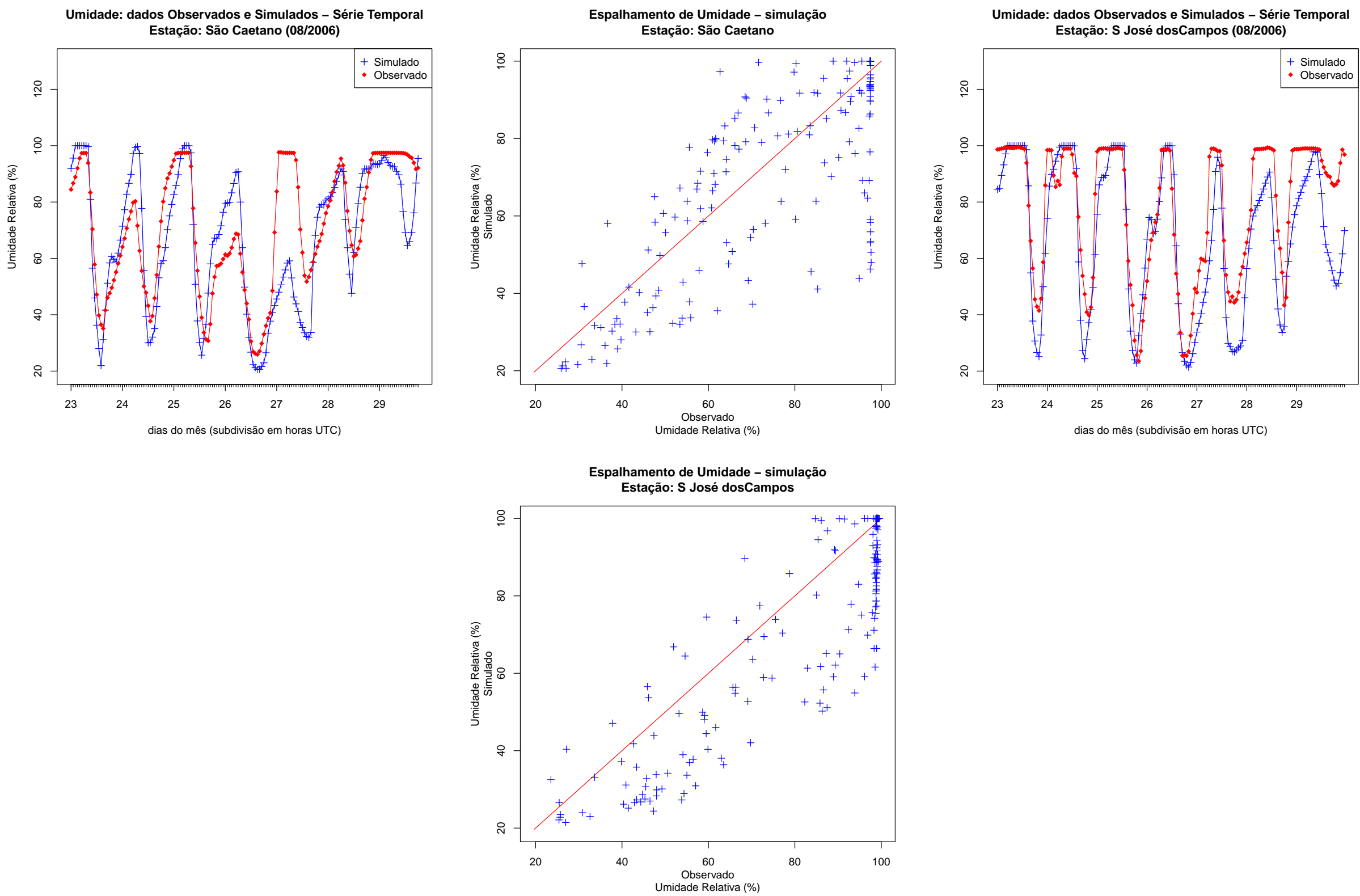

Figura 4.3: Umidade simulada pelo BRAMS e observada nas estações indicadas em cada gráfico. Continuação 

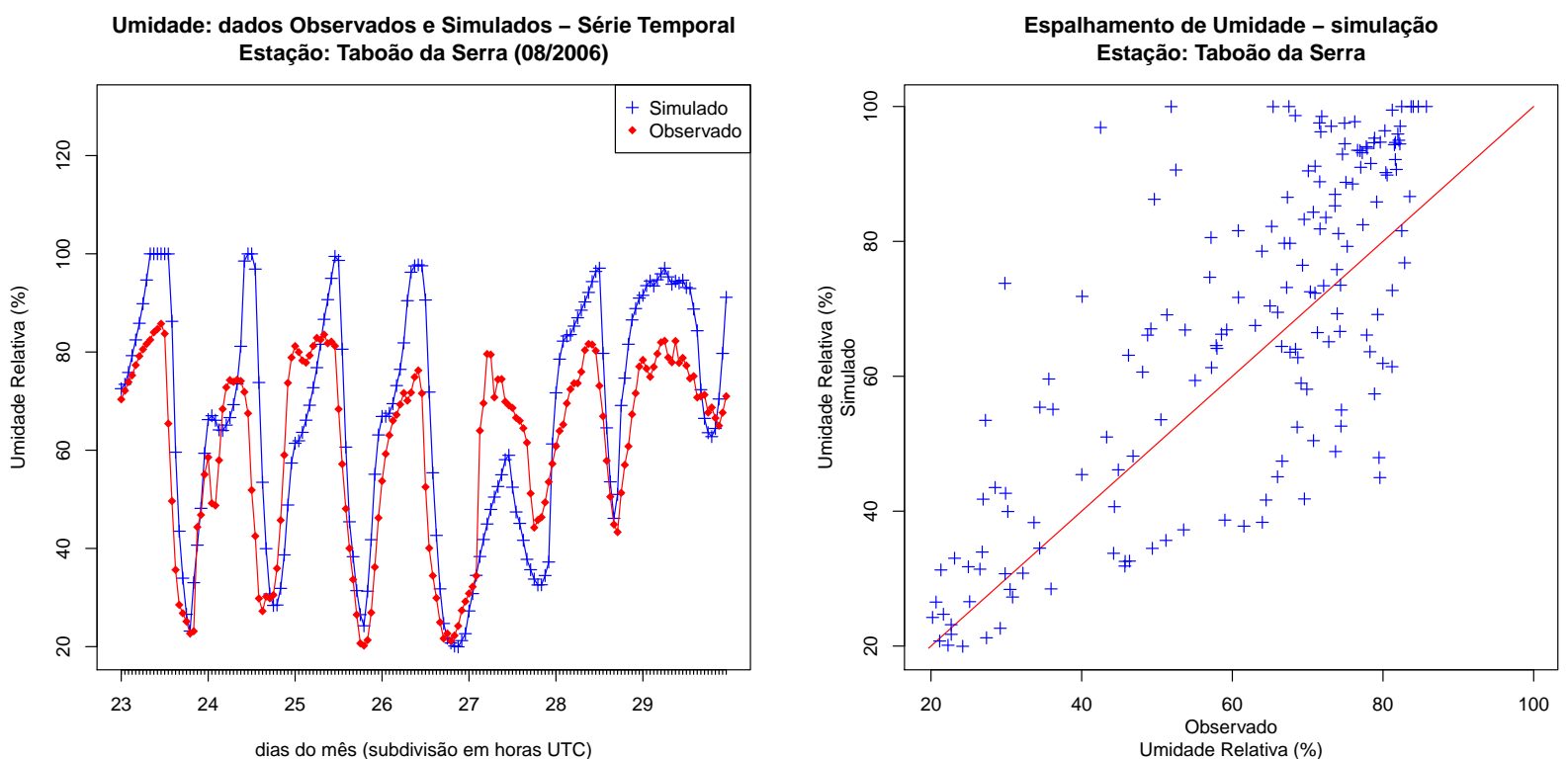

Figura 4.4: Umidade simulada pelo BRAMS e observada nas estações indicadas em cada gráfico. Continuação 
Os gráficos nas figuras para umidade indicam a qualidade dos ajustes, com as séries temporais registrando um bom acompanhamento do observado pelo simulado. A concordância na estação de Cubatão Centro mostrou-se mais limitada. Quanto aos gráficos de espalhamento, nota-se uma dispersão de valores em torno da reta 1:1, sendo novamente mais alargada, e apontando subestimativa, em Cubatão.

\subsubsection{Temperatura}

Tabela 4.5: Parâmetros estatísticos para Temperatura em várias estações.

\begin{tabular}{llllllll}
\hline Estação & $\bar{T}_{\text {sim }}$ & $\bar{T}_{\text {obs }}$ & $\sigma_{\text {sim }}$ & $\sigma_{\text {obs }}$ & RMSE & NRMSE & $\frac{{ }^{S I M}}{\text { OBS }}$ \\
\hline \multirow{3}{*}{ Cutabão Centro } & ${ }^{\circ} \mathrm{C}$ & ${ }^{\circ} \mathrm{C}$ & ${ }^{\circ} \mathrm{C}$ & ${ }^{\circ} \mathrm{C}$ & ${ }^{\circ} \mathrm{C}$ & $\%$ & \\
IAG & 20,4 & 21,7 & 4,0 & 4,4 & 3,0 & 66,8 & 0,9 \\
Ibirapuera & 16,6 & 16,9 & 5,8 & 5,6 & 3,6 & 64,4 & 1,0 \\
Pinheiros & 16,8 & 18,5 & 6,1 & 4,5 & 3,8 & 84,1 & 0,9 \\
São Caetano & 16,9 & 18,3 & 6,3 & 5,8 & 3,7 & 63,9 & 0,9 \\
S José dos Campos & 16,8 & 18,5 & 5,6 & 6,1 & 3,4 & 55,8 & 0,9 \\
Taboão da Serra & 16,9 & 21,8 & 6,5 & 5,2 & 5,1 & 97,0 & 0,8 \\
\hline
\end{tabular}

Tabela 4.6: Parâmetros estatísticos para Temperatura em várias estações (Continuação)

\begin{tabular}{lllllll}
\hline Estação & $\mathrm{n}$ & $\mathrm{FB}$ & NMSE & FAC2 & $\mathrm{R}$ & valor-P \\
\hline Cutabão Centro & 168 & 0,06 & 0,02 & 1,00 & 0,80 & $2,45 \mathrm{e}-39$ \\
IAG & 168 & 0,02 & 0,05 & 0,95 & 0,80 & $1,47 \mathrm{e}-38$ \\
Ibirapuera & 168 & 0,10 & 0,05 & 0,92 & 0,84 & $9,08 \mathrm{e}-47$ \\
Pinheiros & 168 & 0,08 & 0,04 & 0,93 & 0,84 & $1,09 \mathrm{e}-46$ \\
São Caetano & 168 & 0,10 & 0,04 & 0,99 & 0,88 & $2,90 \mathrm{e}-54$ \\
S José dos Campos & 168 & 0,20 & 0,07 & 0,94 & 0,87 & $1,90 \mathrm{e}-53$ \\
Taboão da Serra & 168 & 0,09 & 0,04 & 0,95 & 0,86 & $2,89 \mathrm{e}-51$ \\
\hline
\end{tabular}

A simulação de temperatura do BRAMS se saiu bem em todas os índices de performance utilizados em todas as estações. Nota-se, porém que, mesmo pequeno, o viés fracional indicou, sempre, subestimativa. 

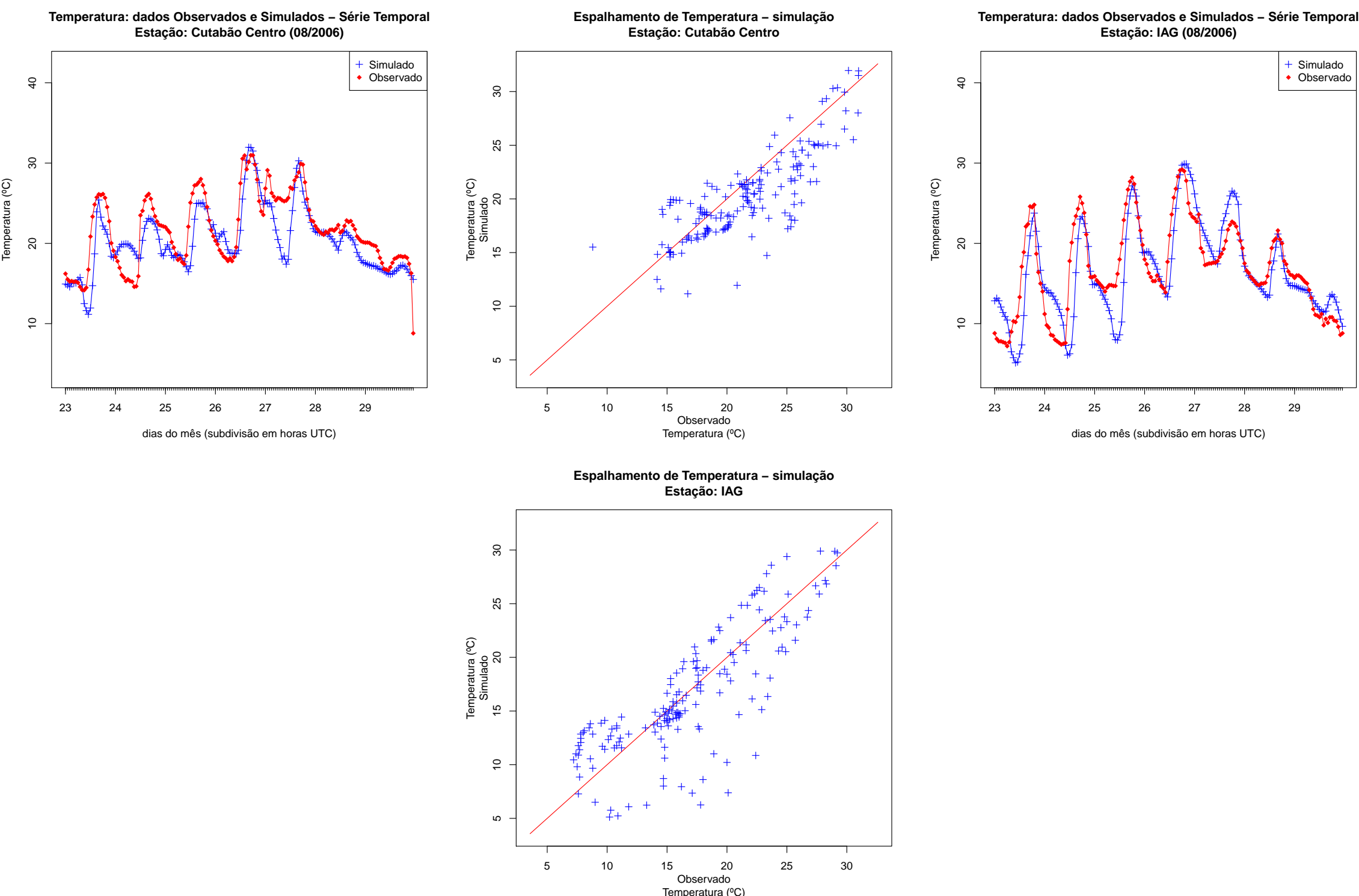

Figura 4.5: Temperaturas simuladas pelo BRAMS e observadas nas estações: Série Temporal e gráfico de espalhamento 

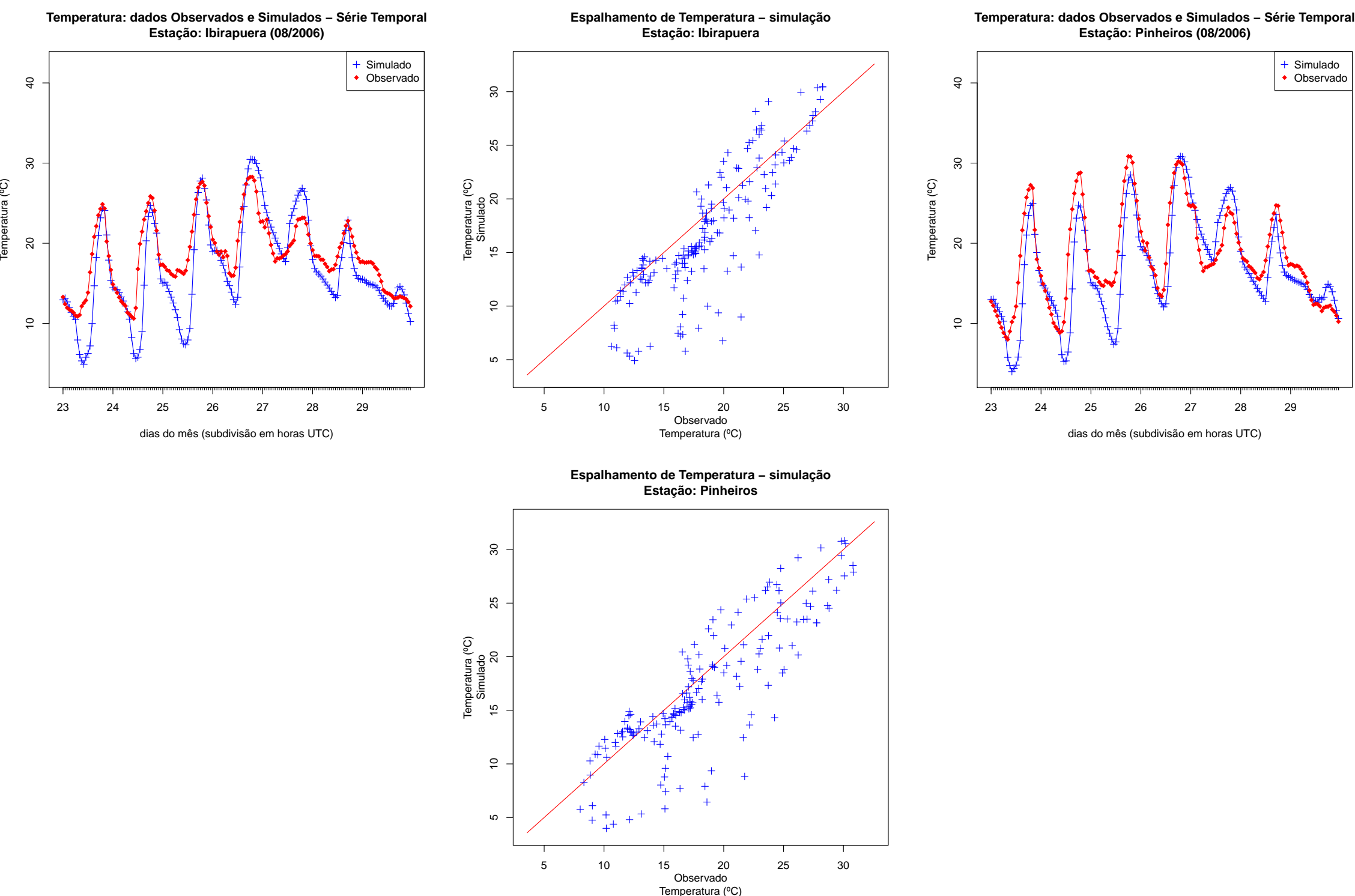

Figura 4.6: Temperaturas simuladas pelo BRAMS e observadas nas estações. Continuação 

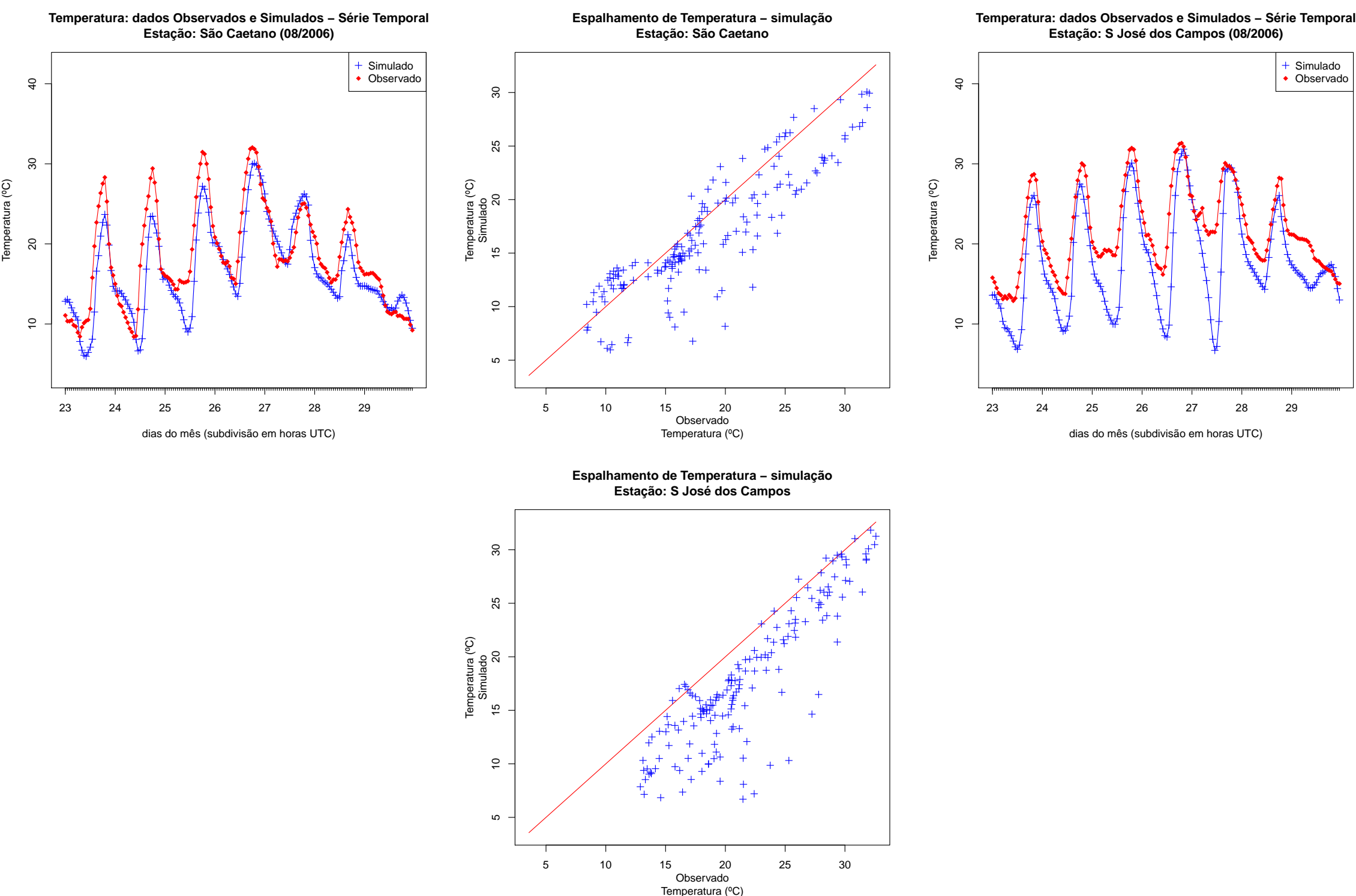

Figura 4.7: Temperaturas simuladas pelo BRAMS e observadas nas estações. Continuação 

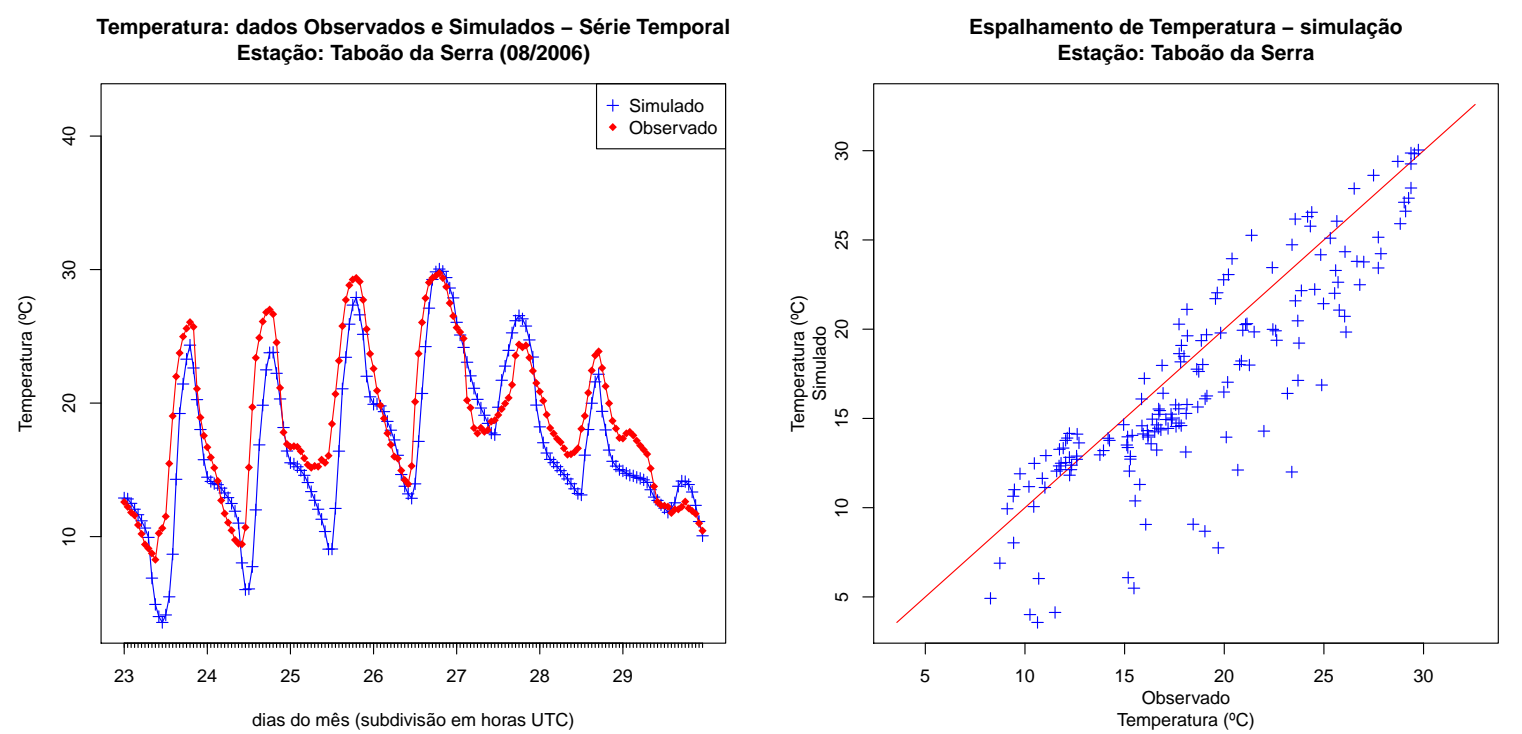

Figura 4.8: Temperaturas simuladas pelo BRAMS e observadas nas estações. Continuação 
A temperatura, em geral, foi melhor prevista do que a umidade, embora tenha sido um pouco influenciada por ela, sobretudo nos horários noturnos. Os gráficos de espalhamento estão mais próximos da "reta 1 para 1", tendo apresentado pouco espalhamento, o que é coerente com o FB calculado.

\subsubsection{Vento}

\subsubsection{Vento Zonal}

Tabela 4.7: Parâmetros estatísticos para U em várias estações.

\begin{tabular}{llllllll}
\hline Estação & $\bar{u}_{\text {sim }}$ & $\bar{u}_{\text {obs }}$ & $\sigma_{\text {sim }}$ & $\sigma_{\text {obs }}$ & RMSE & NRMSE & $\frac{\overline{s i m}}{\overline{o b s}}$ \\
\hline Cubatão Centro & $m . s^{-1}$ & $m . s^{-1}$ & $m . s^{-1}$ & $m . s^{-1}$ & $m . s^{-1}$ & $\%$ & \\
Cubatão V Mogi & $-0,2$ & 0,6 & 1,3 & 1,5 & 2,1 & 135,8 & $-0,3$ \\
Cubatão V Parisi & $-0,4$ & $-0,6$ & 0,9 & 2,4 & 2,5 & 100,4 & 0,8 \\
IAG & $-0,3$ & 0,6 & 1,0 & 1,5 & 1,9 & 124,2 & $-0,7$ \\
Ibirapuera & $-0,1$ & $-0,1$ & 1,5 & 1,7 & 1,8 & 107,6 & 0,3 \\
Osasco & $-0,3$ & $-0,2$ & 1,6 & 1,0 & 1,3 & 123,0 & 1,4 \\
Pinheiros & 0,0 & $-0,0$ & 1,5 & 1,1 & 1,2 & 111,3 & 1,9 \\
Santo Amaro & $-0,0$ & $-0,2$ & 1,4 & 1,3 & 0,9 & 110,1 & $-0,9$ \\
São Caetano & $-0,4$ & $-0,0$ & 1,6 & 1,5 & 1,3 & 88,2 & 0,0 \\
S José dos Campos & $-0,1$ & $-0,1$ & 1,4 & 1,0 & 1,3 & 123,0 & 1,6 \\
Sorocaba & $-0,3$ & $-0,2$ & 1,6 & 1,6 & 1,6 & 100,5 & 1,6 \\
\hline
\end{tabular}

Tabela 4.8: Parâmetros estatísticos para U em várias estações. (Continuação)

\begin{tabular}{llll}
\hline Estação & $\mathrm{n}$ & $\mathrm{R}$ & valor-P \\
\hline Cubatão Centro & 117 & 0,18 & 0,06 \\
Cubatão V Mogi & 141 & 0,18 & 0,04 \\
Cubatão V Parisi & 130 & 0,25 & 0,00 \\
IAG & 117 & 0,54 & 0,00 \\
Ibirapuera & 121 & 0,56 & 0,00 \\
Osasco & 133 & 0,68 & 0,00 \\
Pinheiros & 116 & 0,71 & 0,00 \\
Santo Amaro & 126 & 0,80 & 0,00 \\
São Caetano & 105 & 0,69 & 0,00 \\
S José dos Campos & 121 & 0,56 & 0,00 \\
Sorocaba & 132 & 0,52 & 0,00 \\
\hline
\end{tabular}

A exceção da estação Cubatão Centro, todas as demais apresentaram parâmetros estatísticos aceitáveis para a simulação da componente $\mathrm{U}$ do vento (vento zonal), ainda que as outras duas estações de Cubatão também tenham ficado nos limites da aceitabilidade. Os respectivos gráficos de confronto das séries temporais e do espalhamento dos resultados (1:1), também qualificam os ajustes obtidos no conjunto das estações $(4.9,4.10,4.11,4.12,4.13$ 
e 4.14). Foram mais limitados os confrontos no Centro e Vale do Mogi, em Cubatão, onde as simulações tiveram dificuldade em acompanhar a variabilidade mais elevada dos dados observados, particularmente nos episódios de em que o vento apresentou maior intensidade, registrados em 27/08. Mas, ainda em Cubatão, a Vila Parisi mostrou melhor representação do observado, mesmo com as limitações sobre os referidos episódios.

A simulação apresentou, ainda $70,2 \leqslant N R M S E \leqslant 124,2$, o que representou uma habilidade razoável do modelo em representar $u$. 

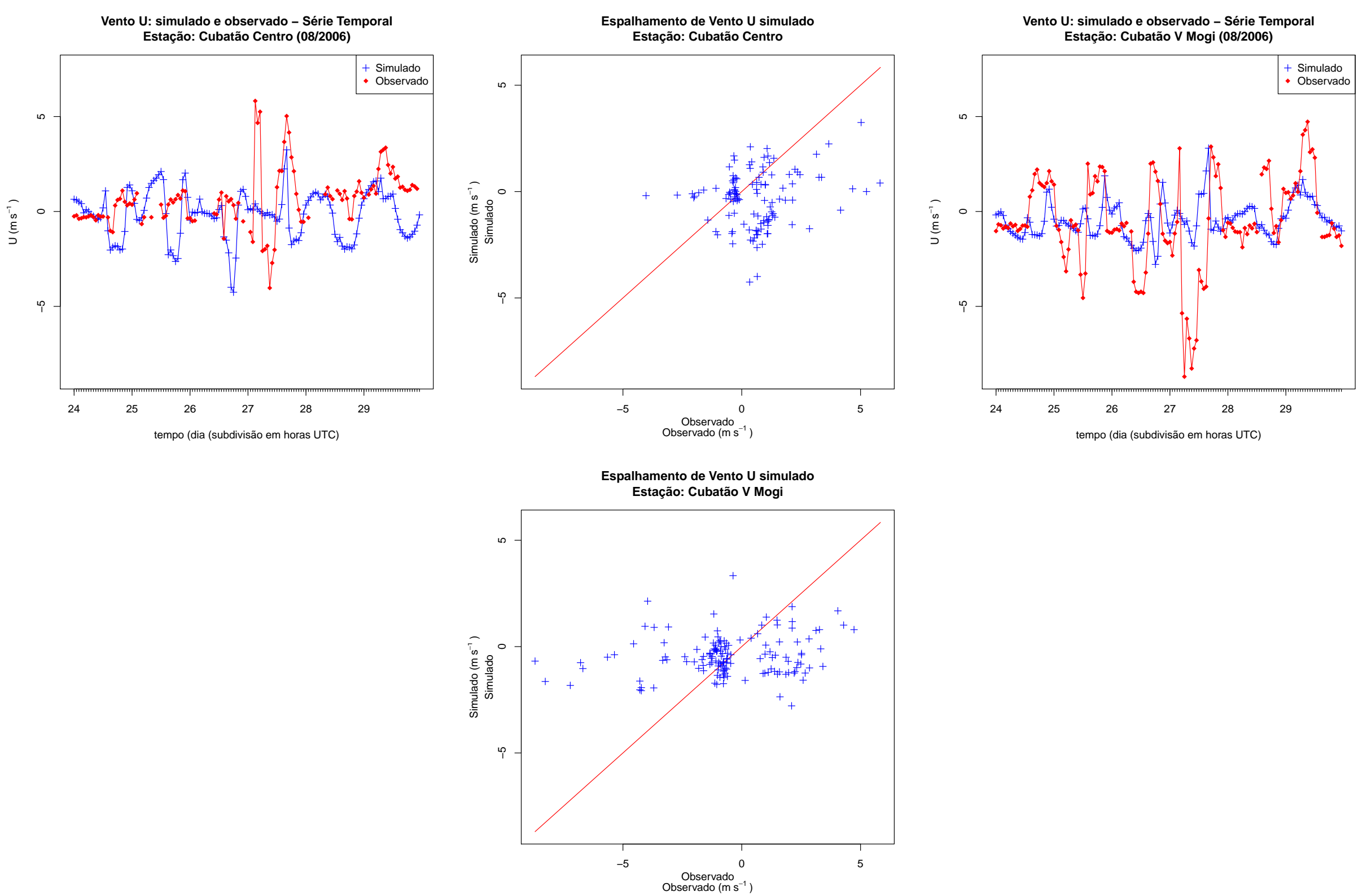

Figura 4.9: Comparação dos ventos U simulados pelo BRAMS e os medidos nas estações 

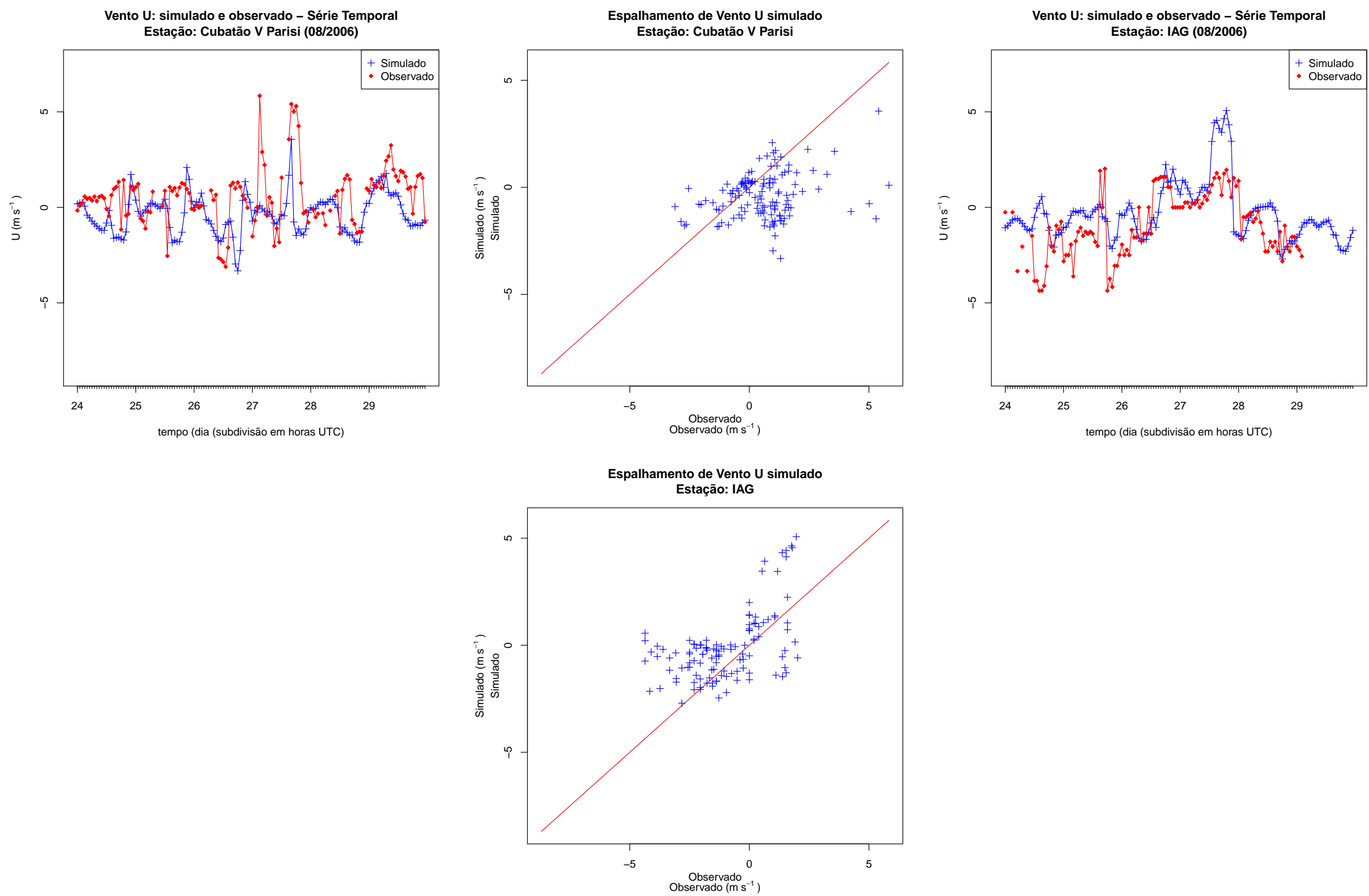

Figura 4.10: Comparação dos ventos U simulados pelo BRAMS. Continuação 

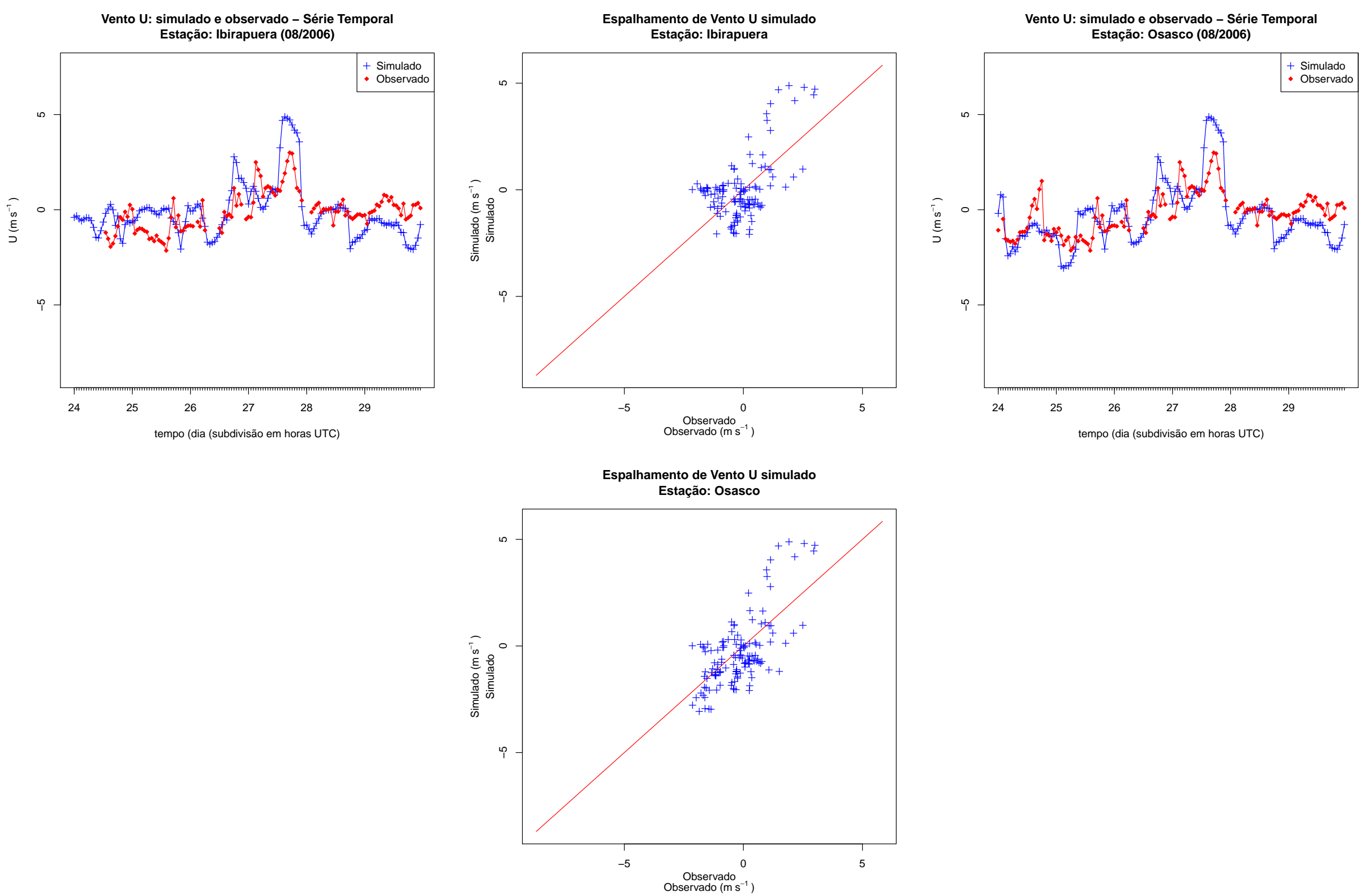

Figura 4.11: Comparação dos ventos U simulados pelo BRAMS. Continuação 

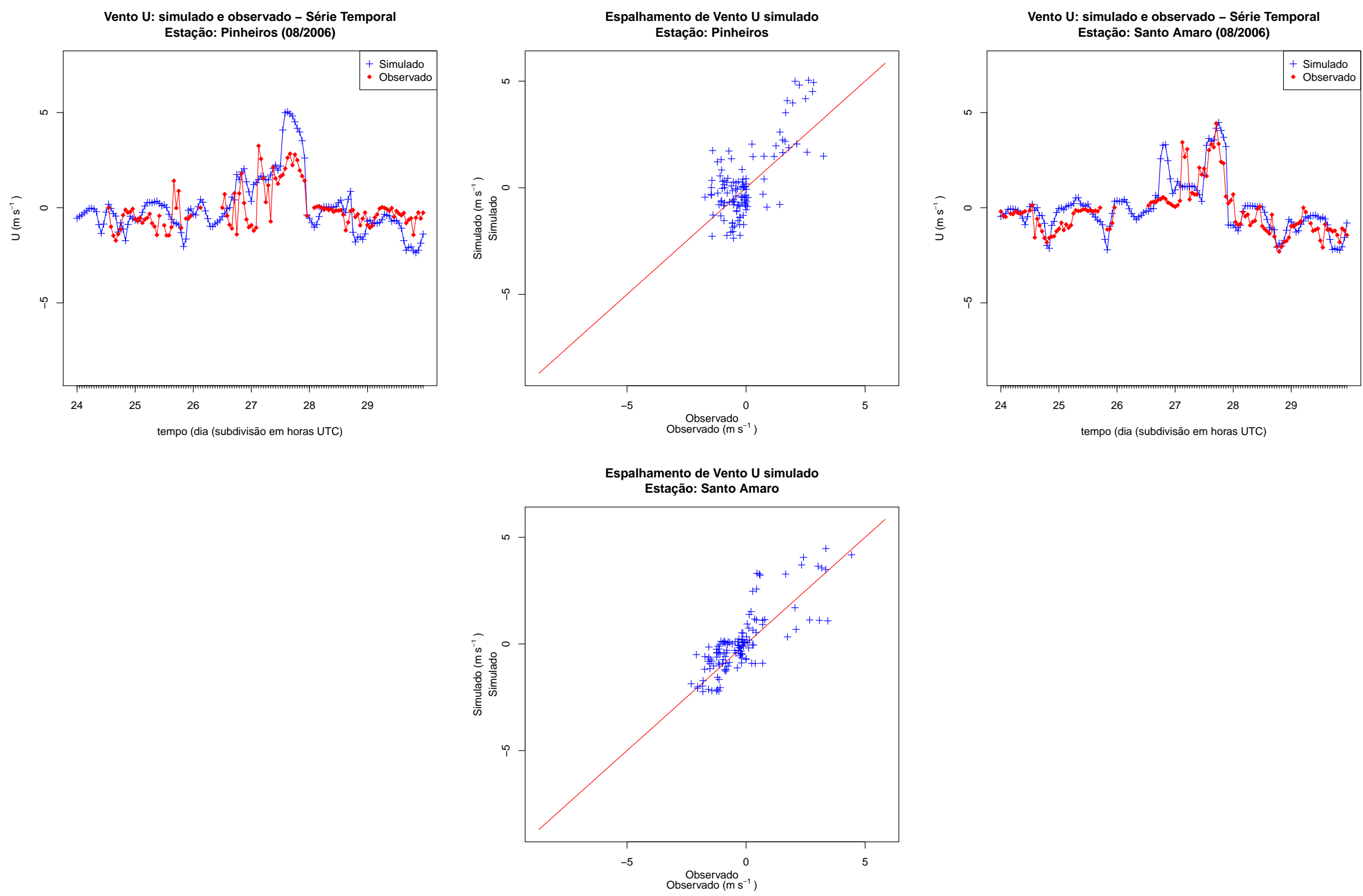

Figura 4.12: Comparação dos ventos U simulados pelo BRAMS. Continuação 

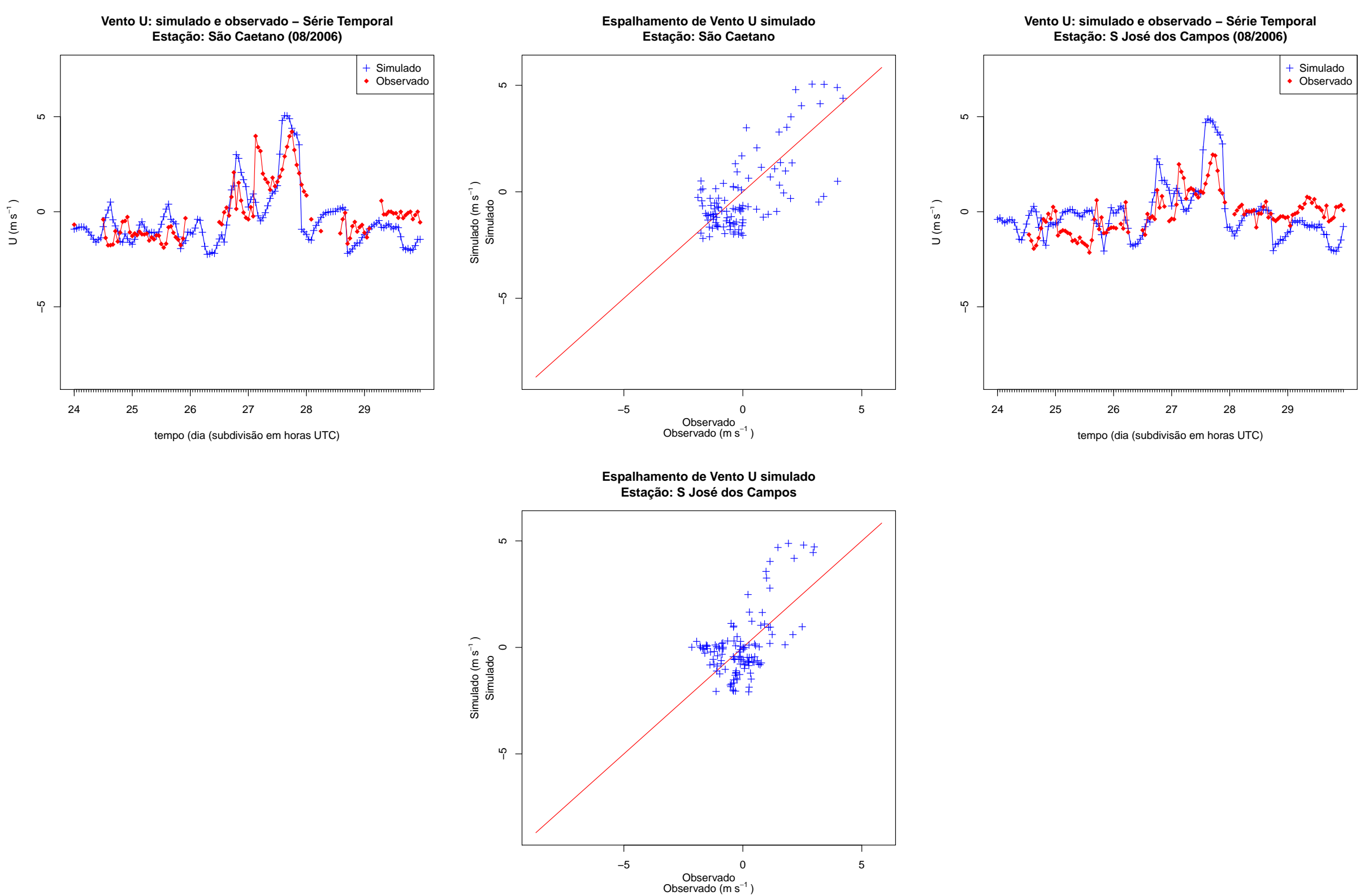

Figura 4.13: Comparação dos ventos U simulados pelo BRAMS. Continuação 

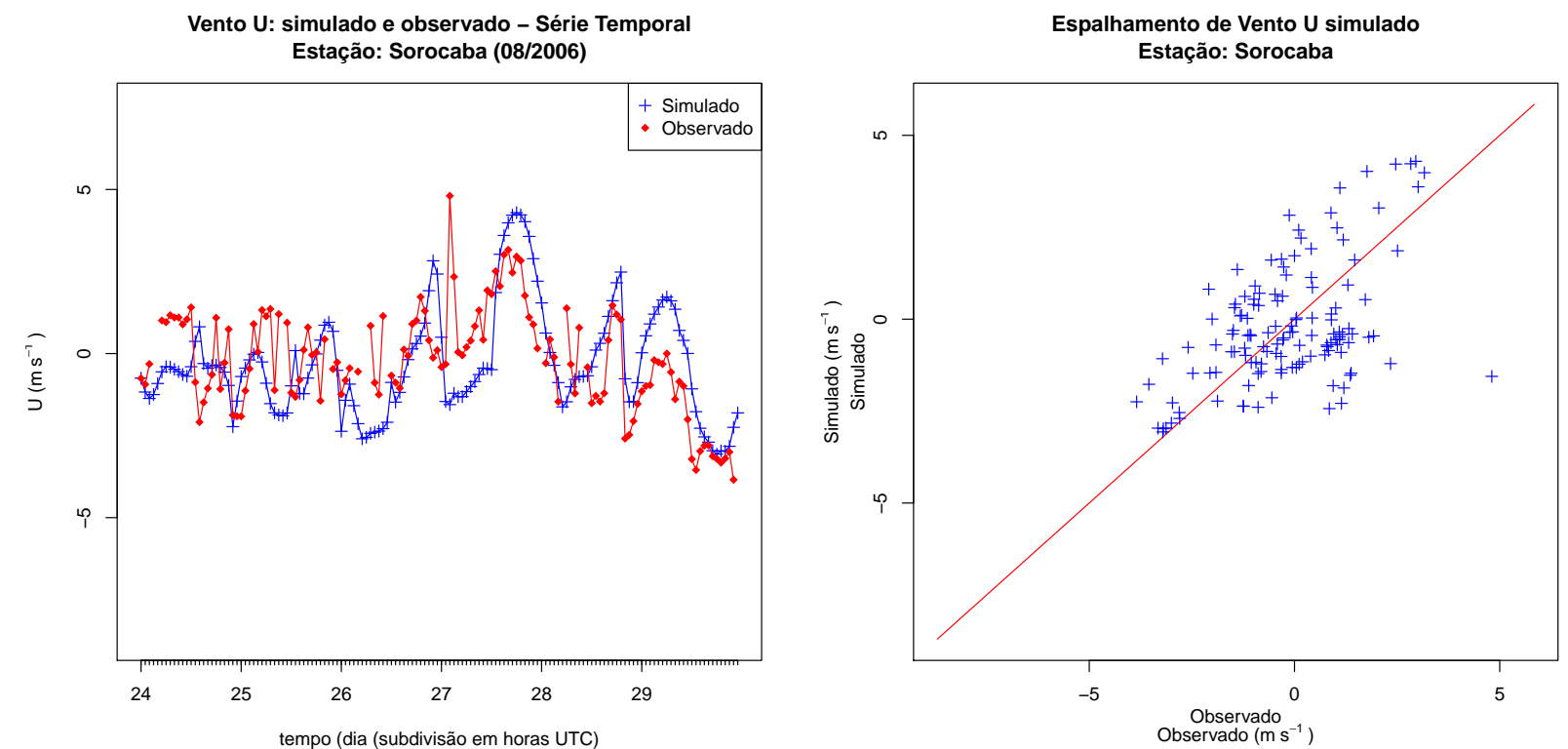

Figura 4.14: Comparação dos ventos U simulados pelo BRAMS. Continuação 


\subsubsection{Vento Meridional}

Tabela 4.9: Parâmetros estatísticos para V em várias estações.

\begin{tabular}{llllllll}
\hline Estação & $\bar{v}_{\text {sim }}$ & $\bar{v}_{\text {obs }}$ & $\sigma_{\text {sim }}$ & $\sigma_{\text {obs }}$ & RMSE & NRMSE & $\overline{\overline{s i m}}$ \\
\hline Cubatão Centro & $m \cdot s^{-1}$ & $m \cdot s^{-1}$ & $m \cdot s^{-1}$ & $m \cdot s^{-1}$ & $m . s^{-1}$ & $\%$ & \\
Cubatão V Mogi & 0,6 & $-0,2$ & 1,9 & 2,0 & 2,3 & 119,2 & $-3,2$ \\
Cubatão V Parisi & 0,3 & $-0,4$ & 2,8 & 2,0 & 2,0 & 101,2 & $-0,9$ \\
IAG & 0,7 & 0,0 & 2,3 & 2,2 & 2,2 & 102,6 & 41,2 \\
Ibirapuera & $-0,0$ & $-0,7$ & 2,2 & 1,8 & 2,0 & 11,1 & 0,0 \\
Osasco & 0,2 & 0,6 & 1,9 & 1,6 & 1,1 & 68,7 & 0,4 \\
Pinheiros & 0,8 & 1,1 & 2,1 & 1,8 & 1,1 & 63,4 & 0,7 \\
Santo Amaro & 0,4 & 0,5 & 1,9 & 2,0 & 1,1 & 57,8 & 0,9 \\
São Caetano & 0,1 & 0,4 & 2,2 & 2,1 & 1,1 & 54,0 & 0,2 \\
S José dos Campos & 0,0 & $-0,2$ & 2,3 & 1,4 & 1,8 & 129,6 & $-0,2$ \\
Sorocaba & 0,2 & 0,6 & 1,9 & 1,6 & 1,1 & 68,7 & 0,4 \\
\hline
\end{tabular}

Tabela 4.10: Parâmetros estatísticos para V em várias estações. (Continuação)

\begin{tabular}{llll}
\hline Estação & $\mathrm{n}$ & $\mathrm{R}$ & valor-P \\
\hline Cubatão Centro & 117 & 0,41 & 0,00 \\
Cubatão V Mogi & 141 & 0,71 & 0,00 \\
Cubatão V Parisi & 130 & 0,58 & 0,00 \\
IAG & 117 & 0,45 & 0,00 \\
Ibirapuera & 121 & 0,84 & 0,00 \\
Osasco & 133 & 0,86 & 0,00 \\
Pinheiros & 116 & 0,84 & 0,00 \\
Santo Amaro & 126 & 0,87 & 0,00 \\
São Caetano & 105 & 0,76 & 0,00 \\
S José dos Campos & 121 & 0,84 & 0,00 \\
Sorocaba & 132 & 0,82 & 0,00 \\
\hline
\end{tabular}

A simulação para o vento $\mathrm{V}$ (vento meridional) apresentou bons resultados em todas as estações, tantos nos testes estatísticos quanto nas comparações gráficas. O RMSE foi baixo, sendo que $R M S E>\sigma_{o b s}$ em apenas 3 estações - as três de Cubatão. Ainda assim, $R M S V E \approx \sigma_{o b s}$ nestas. 

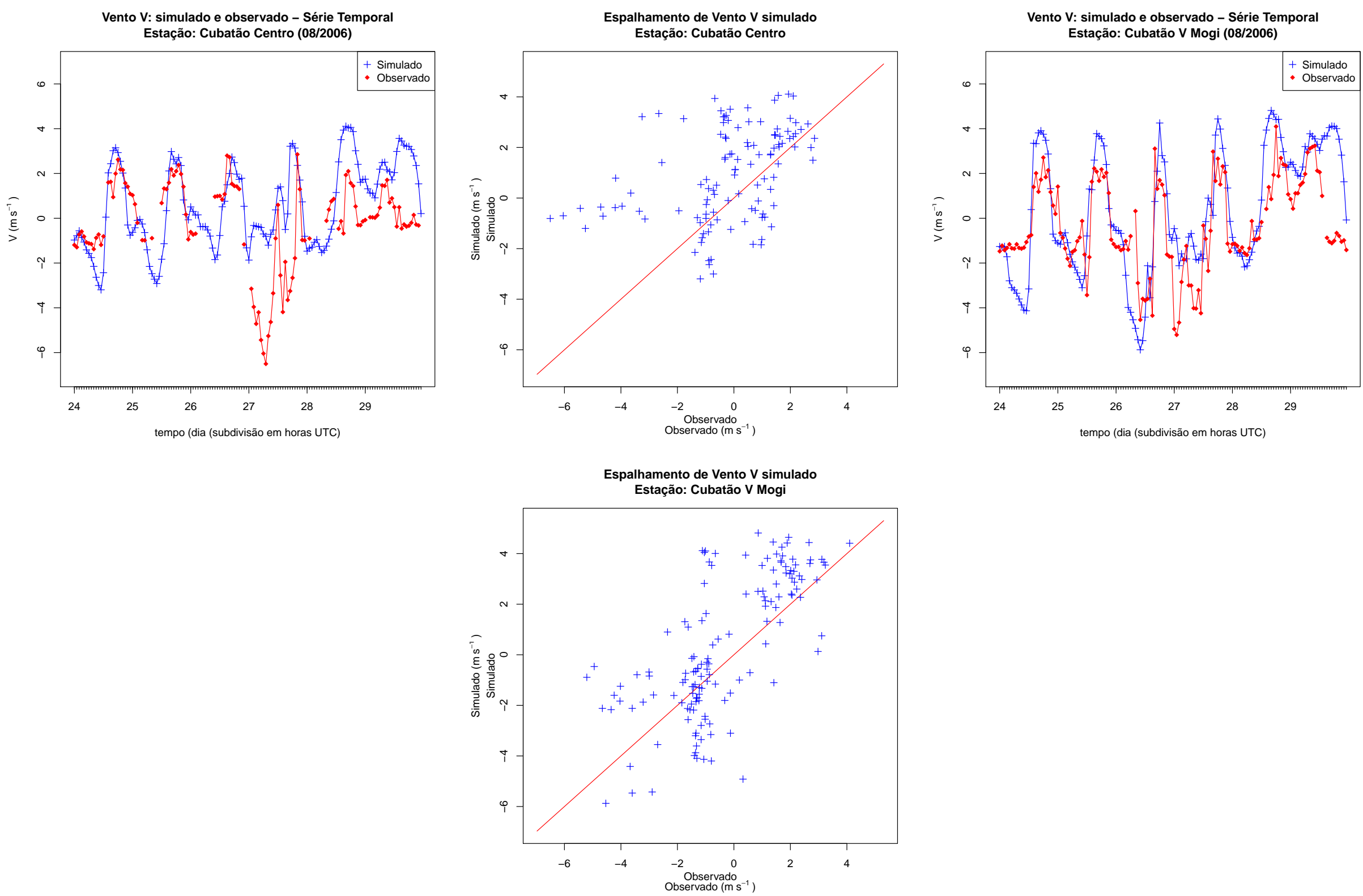

Figura 4.15: Comparação dos ventos V simulados pelo BRAMS e os medidos nas estações 

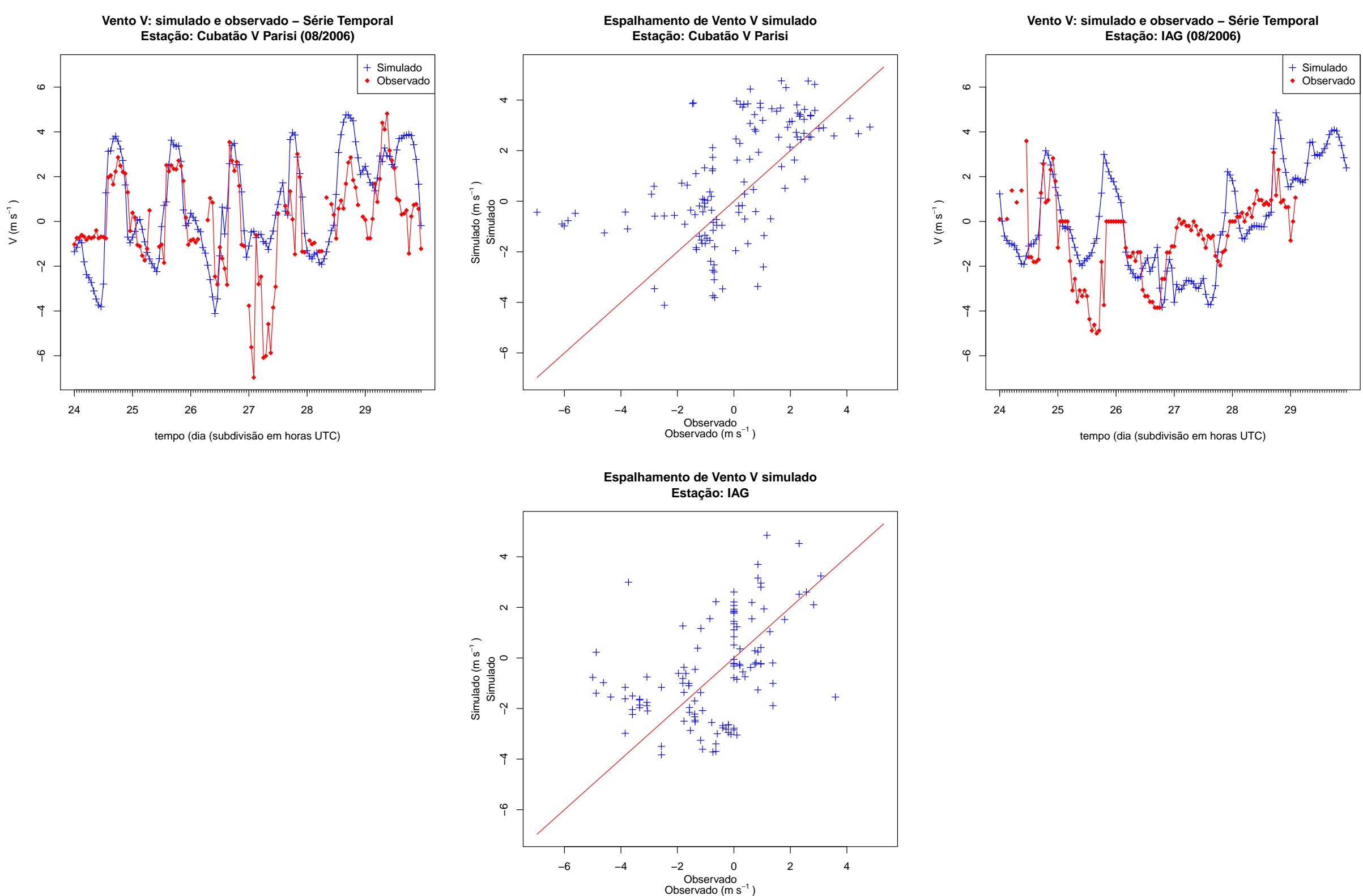

Figura 4.16: Comparação dos ventos V simulados pelo BRAMS e os medidos nas estações 

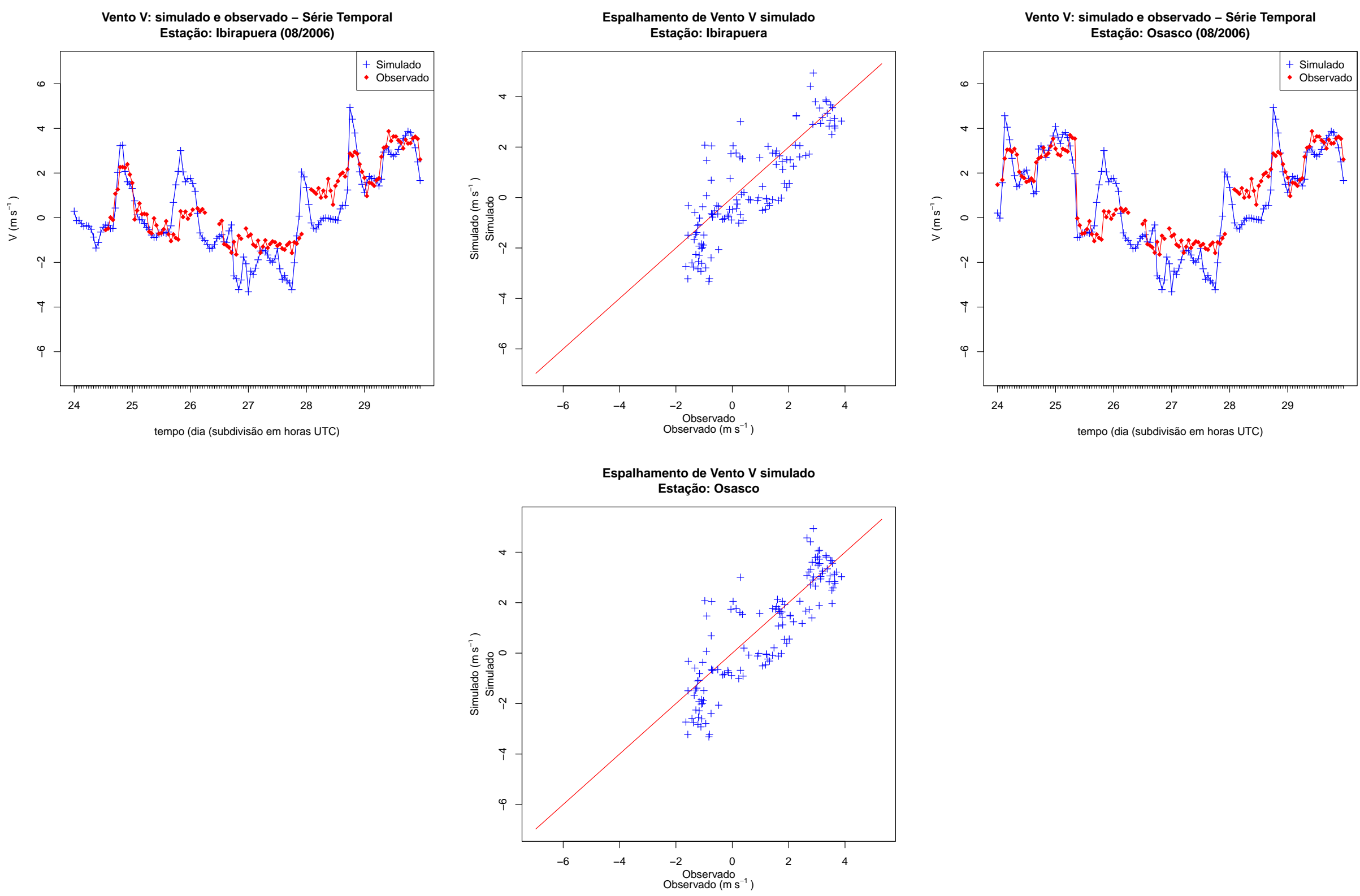

Figura 4.17: Comparação dos ventos V simulados pelo BRAMS e os medidos nas estações. Continuação 

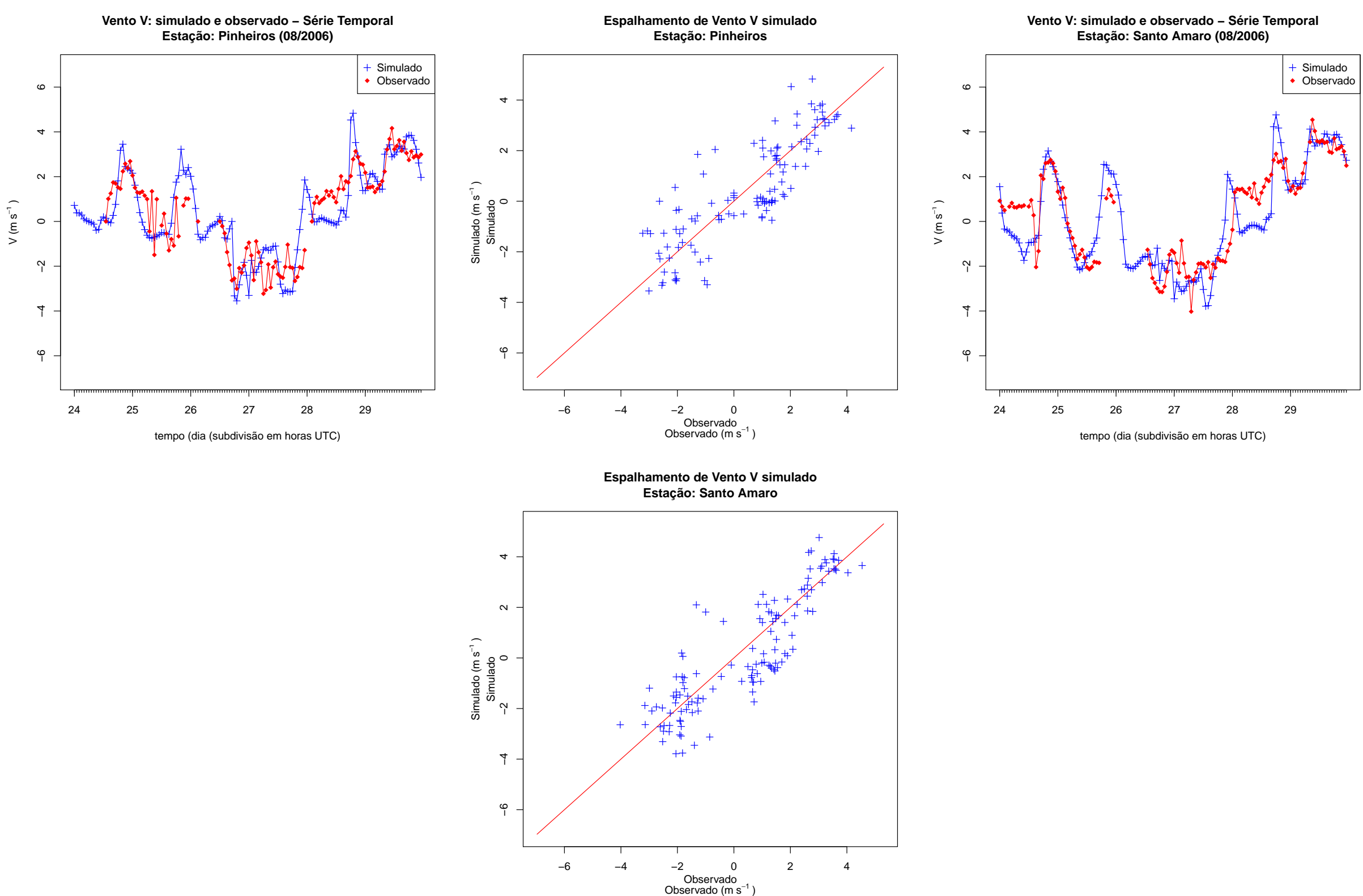

Figura 4.18: Comparação dos ventos V simulados pelo BRAMS e os medidos nas estações. Continuação 

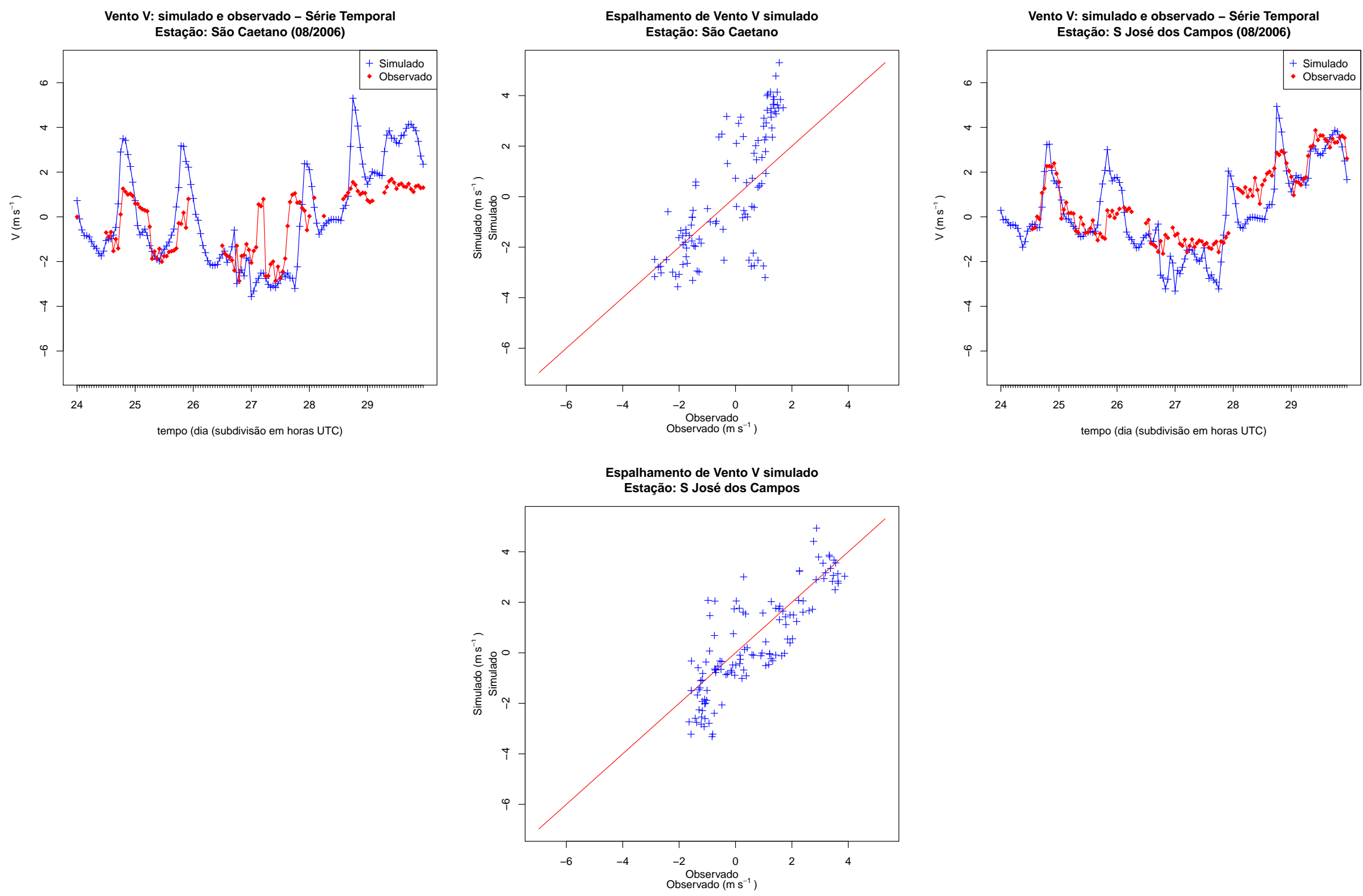

Figura 4.19: Comparação dos ventos V simulados pelo BRAMS e os medidos nas estações. Continuação 

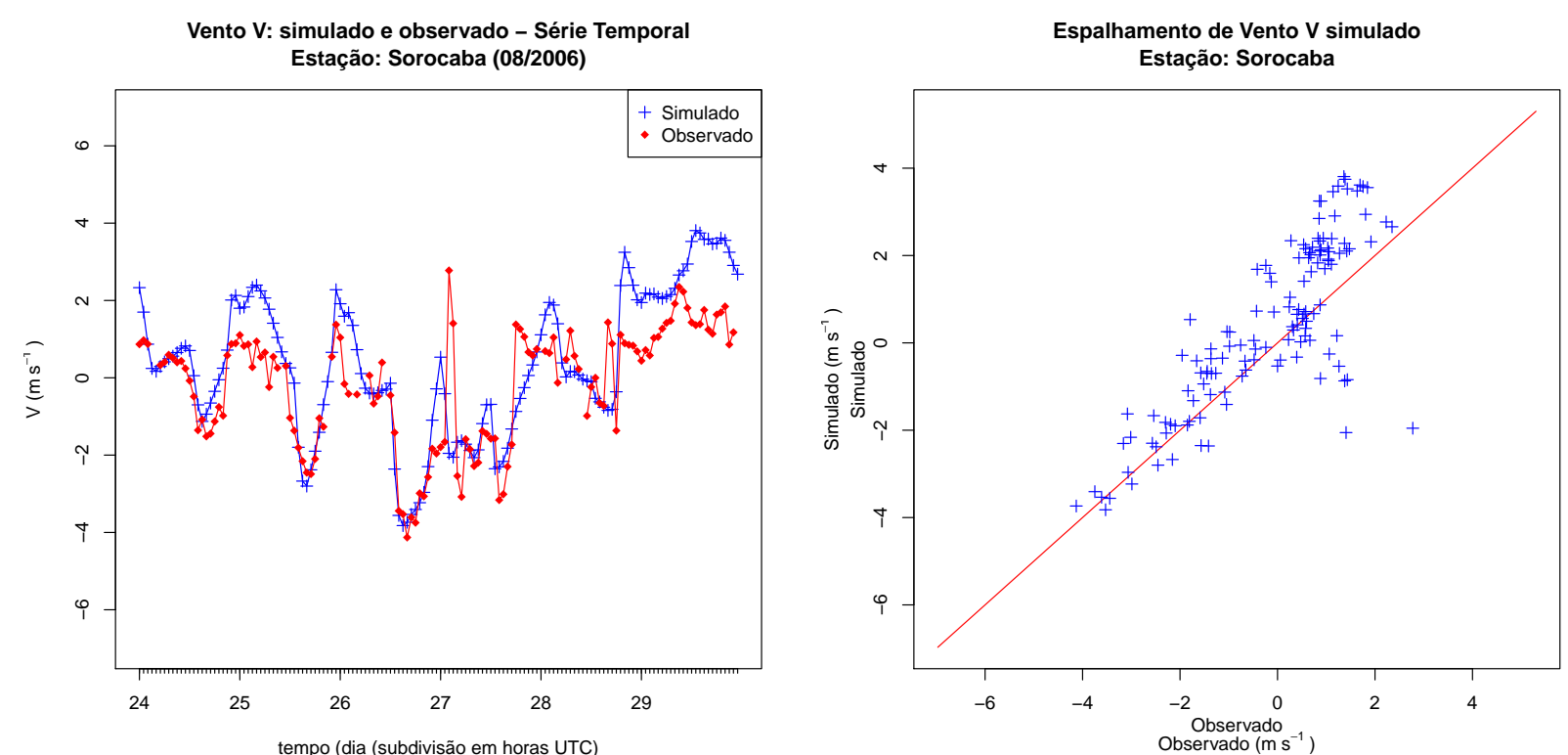

Figura 4.20: Comparação dos ventos V simulados pelo BRAMS e os medidos nas estações. Continuação 
As figuras 4.15, 4.16, 4.17, 4.18, 4.19 e 4.20 representam os gráficos de série temporal e de espalhamento dos valores simulados para todas as estações. Visualmente, percebe-se que mesmo os gráficos relativos a Cubatão indicam correlação entre observado e simulado, com menor espalhamento nos gráficos 1:1 da componente $\mathrm{U}$ do vento.

\subsubsection{Magnitude}

Cabe destacar que U e V são as projeções de uma única variável, o vetor velocidade do vento. Elas não têm vida própria. O fator básico que torna uma mais imprecisa que a outra é a magnitude de cada uma delas, podendo-se perceber que valores de $\mathrm{U}$, e respectivos $\sigma$, são menores que para $\mathrm{V}$, decorrendo daí sua maior incerteza. De qualquer modo, como já destacamos anteriormente, para obter-se melhor representação, particularmente naquela área complexa de Cubatão, seria necessário incrementar a resolução espacial da simulação. A determinação da magnitude da intensidade de vento a partir da agregação de $\mathrm{U}$ e V, mostrouse, como esperado, que essa variável foi bem representada, segundo os índices estatísticos mostrados nas tabelas 4.11 e 4.12 .

Tabela 4.11: Parâmetros estatísticos para Magnitude em várias estações.

\begin{tabular}{llllllll}
\hline Estação & $\overline{M a g}_{\text {sim }}$ & $\overline{M a g}_{\text {obs }}$ & $\sigma_{\text {sim }}$ & $\sigma_{\text {obs }}$ & RMSVE & NRMSVE & $\overline{\frac{s i m}{\overline{a b s}}}$ \\
\hline \multirow{2}{*}{ Cubatão Centro } & $m \cdot s^{-1}$ & $m \cdot s^{-1}$ & $m . s^{-1}$ & $m . s^{-1}$ & $m . s^{-1}$ & $\%$ & \\
Cubatão V Mogi & 2,0 & 1,7 & 2,3 & 2,5 & 2,8 & 112,5 & 1,2 \\
Cubatão V Parisi & 2,6 & 2,7 & 2,9 & 3,2 & 3,1 & 99,0 & 1,0 \\
IAG & 2,3 & 2,1 & 2,5 & 2,6 & 2,7 & 104,0 & 1,1 \\
Ibirapuera & 2,4 & 2,4 & 2,7 & 2,5 & 2,4 & 98,0 & 1,0 \\
Osasco & 1,9 & 1,6 & 2,4 & 1,9 & 1,5 & 79,6 & 1,2 \\
Pinheiros & 2,4 & 2,0 & 2,7 & 2,1 & 1,6 & 75,8 & 1,2 \\
Santo Amaro & 1,9 & 1,7 & 2,4 & 2,2 & 1,5 & 65,4 & 1,1 \\
São Caetano & 2,2 & 2,0 & 2,6 & 2,5 & 1,3 & 54,8 & 1,1 \\
S José dos Campos & 2,4 & 1,4 & 2,7 & 2,0 & 1,9 & 92,7 & 1,7 \\
Sorocaba & 1,9 & 1,6 & 2,4 & 1,9 & 1,5 & 79,6 & 1,2 \\
\hline
\end{tabular}

O vento horizontal a 10m do nível do solo foi bem simulado pelo BRAMS. Em quase todas as estações, os níveis de significância para a correlação é < 0,01, validando a hipótese alternativa (os valores simulados e observados estão correlacionados). A estação de Cubatão Centro não passou no teste de hipótese nula. Na maioria das estações, o viés fracional (Fractional Bias - FB) ficou baixo, com $|F B|<0,5$. Os valores simulados foram superiores aos observados na maioria das estações, como indicam os correspondentes valores com sinais negativos.

As Rosas do Vento apresentadas nas figuras de 4.21 à 4.25 mostram a diferença entre as frequências, direção e intensidade do vento simulado e observado que chegou às estações, 
Tabela 4.12: Parâmetros estatísticos para Magnitude em várias estações. (Continuação)

\begin{tabular}{lllll}
\hline Estação & $\mathrm{n}$ & $\mathrm{FB}$ & $\mathrm{NMSE}$ & $\mathrm{FAC2}$ \\
\hline Cubatão Centro & 144 & $-0,16$ & 1,13 & 0,50 \\
Cubatão V Mogi & 144 & 0,02 & 0,65 & 0,56 \\
Cubatão V Parisi & 144 & $-0,07$ & 0,72 & 0,54 \\
IAG & 123 & 0,07 & 0,74 & 0,43 \\
Ibirapuera & 144 & $-0,20$ & 0,53 & 0,51 \\
Osasco & 144 & $-0,17$ & 0,32 & 0,67 \\
Pinheiros & 144 & $-0,11$ & 0,34 & 0,58 \\
Santo Amaro & 144 & $-0,09$ & 0,20 & 0,72 \\
São Caetano & 144 & $-0,52$ & 0,71 & 0,47 \\
S José dos Campos & 144 & $-0,20$ & 0,53 & 0,51 \\
Sorocaba & 143 & $-0,20$ & 0,24 & 0,70 \\
\hline
\end{tabular}

Tabela 4.13: Correlações e valores-p do teste T para as componentes zonal e meridional do vento

\begin{tabular}{lllll}
\hline Estação & $R_{u}$ & valor- $p_{u}$ & $R_{v}$ & valor- $p_{v}$ \\
\hline Cubatão Centro & 0,18 & 0,0584131065732306 & 0,41 & $3,88813548417881 \mathrm{e}-06$ \\
Cubatão V Mogi & 0,18 & 0,037810915729054 & 0,71 & $1,2378221703575 \mathrm{e}-22$ \\
Cubatão V Parisi & 0,25 & 0,00399118169061286 & 0,58 & $5,6134022537433 \mathrm{e}-13$ \\
IAG & 0,54 & $2,94867872994005 \mathrm{e}-10$ & 0,45 & $3,40863891749454 \mathrm{e}-07$ \\
Ibirapuera & 0,56 & $1,86064719213116 \mathrm{e}-11$ & 0,84 & $1,11596584608032 \mathrm{e}-32$ \\
Osasco & 0,68 & $1,99641101690869 \mathrm{e}-19$ & 0,86 & $2,85557065680903 \mathrm{e}-40$ \\
Pinheiros & 0,71 & $7,79750000558221 \mathrm{e}-19$ & 0,84 & $8,95290995008935 \mathrm{e}-32$ \\
Santo Amaro & 0,8 & $8,63113029647052 \mathrm{e}-30$ & 0,87 & $1,37949353811565 \mathrm{e}-39$ \\
São Caetano & 0,69 & $2,8222205657116 \mathrm{e}-16$ & 0,76 & $8,9531307501739 \mathrm{e}-21$ \\
S José dos Campos & 0,56 & $1,86064719213116 \mathrm{e}-11$ & 0,84 & $1,11596584608032 \mathrm{e}-32$ \\
Sorocaba & 0,52 & $2,23627408828822 \mathrm{e}-10$ & 0,82 & $5,52101175995759 \mathrm{e}-33$ \\
\hline
\end{tabular}

permitindo uma melhor comparação visual.

Observa-se que para a maioria das estações, notadamente as da RMSP, as direções do vento são parecidas, embora ventos mais intensos tenham sido mais frequentes na simulação. A estação do IAG é exceção. Neste caso temos medições confiáveis, mas os dados que recebemos possuem passo de $45^{\circ}$.

Em geral, os resultados para os ventos é pior do que o de outras variáveis meteorológicas, possivelmente, porque é a variável que é mais sensível à estações que não estão posicionadas nos locais de topografia mais simples. As estações de Ibirapuera, IAG, São José dos Campos e Sorocaba estão em locais mais planos, cujas medidas representam melhor os ventos sinóticos, apresentando bons resultados. As demais estações que ficam em locais muito urbanos e/ou de topografia complicada, apresentam medições perturbadas por tais características, não sendo as melhores estações para fazer comparações. Pode-se observar um espalhamento grande nas estações presentes em Cubatão, mostrando visualmente o quão difícil é para o modelo representar o real comportamento do vento nesse local. Ainda assim, os gráficos de Série Temporal mostram que o modelo conseguiu captar momentos em que a velocidade aumentou 
ou diminuiu em função do tipo de circulação apresentada no litoral paulista (brisa marítima e circulação de montanha), o que mostra, ainda que qualitativamente, a habilidade para a simulação de dispersão de poluentes na área.

As Rosas do Vento apresentadas nas figuras de 4.21 à 4.25 mostram a diferença entre as frequências, direção e intensidade do vento simulado e observado que chegou às estações, permitindo mais facilmente uma comparação visual.

Foi observado que para a maioria das estações, notadamente as da RMSP, as direções do vento são parecidas tanto observadas quanto simuladas, embora ventos mais intensos tenham sido mais frequentes na simulação. A exceção é a estação do IAG. Embora as medições nela sejam confiáveis, os dados utilizados desta estação possuem passo de $45^{\circ}$.

Nas estações de Cubatão, mostra-se claramente que em todas elas, o modelo apresentou estimativas para o vento zonal em flagrante contraste com os valores observados, estando os ventos oriundos do Sul que chegam às estações em quadrantes opostos aos observados. 


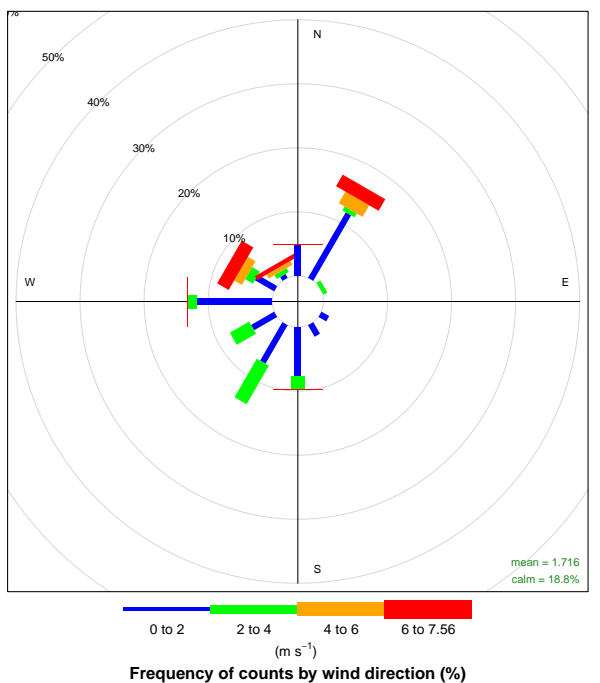

(a) Cubatão Centro - Observado

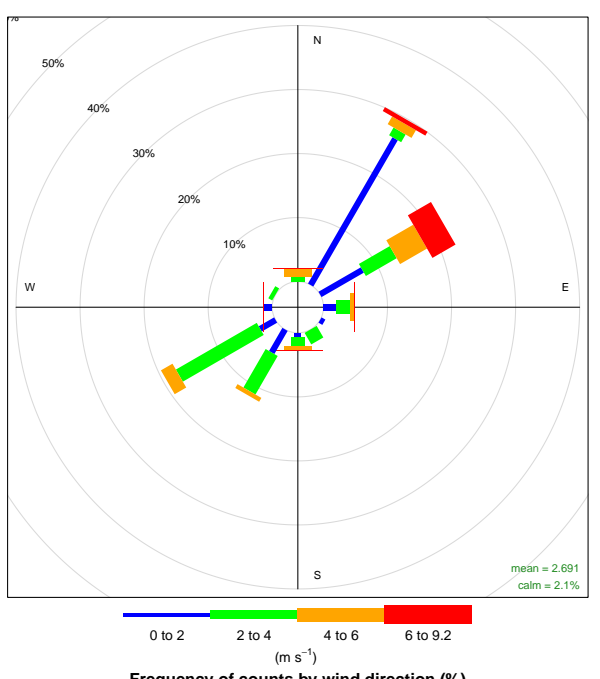

(c) Cubatão V Mogi - Observado Figura 4.21: Rosa dos Ventos nas estações. Vento Observado e Simulações

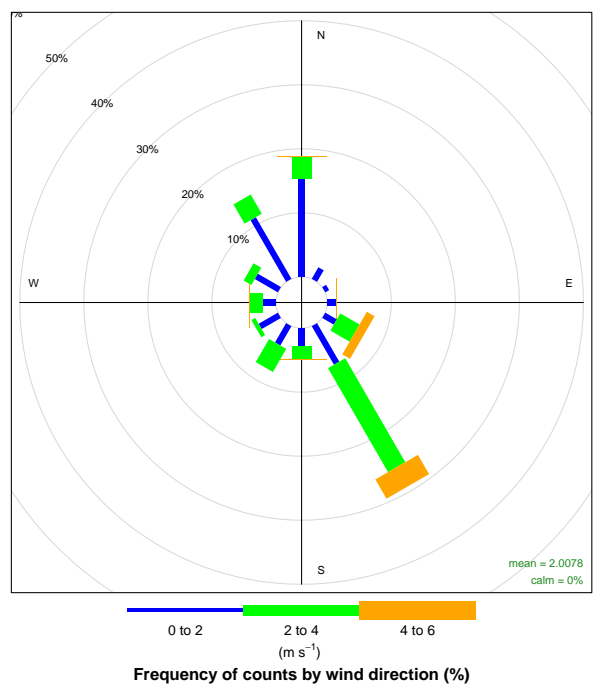

(b) Cubatão Centro - Simulação

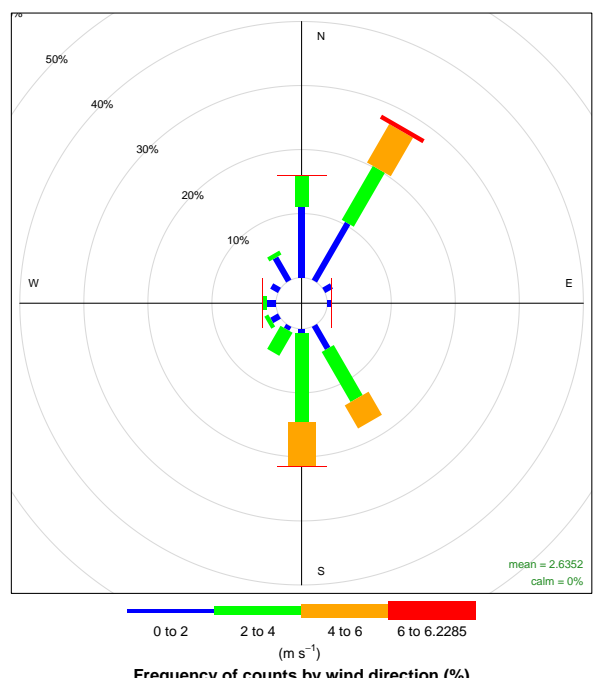

(d) Cubatão V Mogi- Simulação 


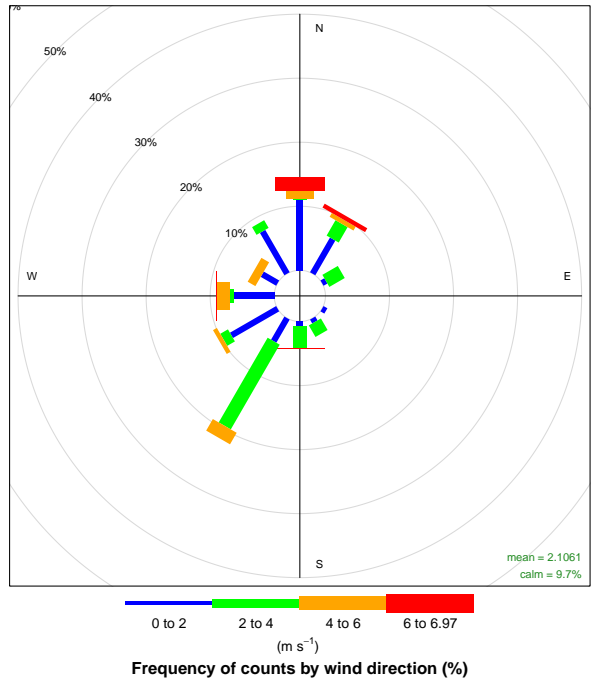

(a) Cubatã V Parisi - Observado

$\varpi$

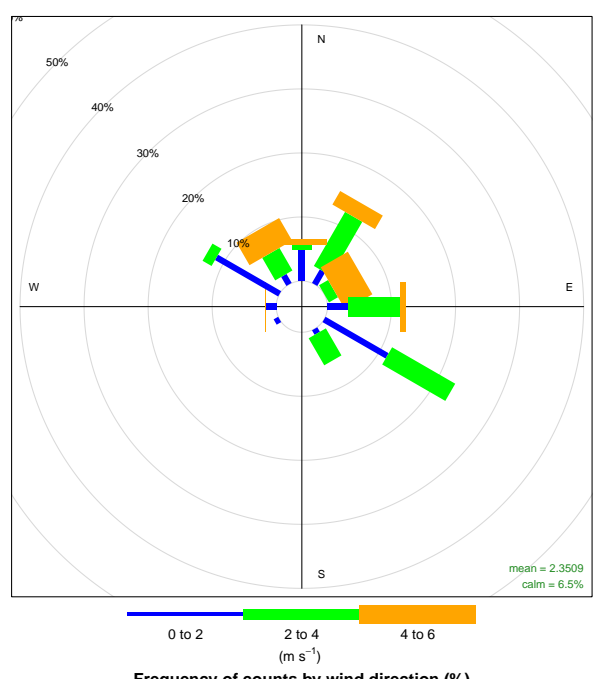

(c) IAG - Observado Figura 4.22: Rosa dos Ventos nas estações. Vento Observado e Simulações. Continuação

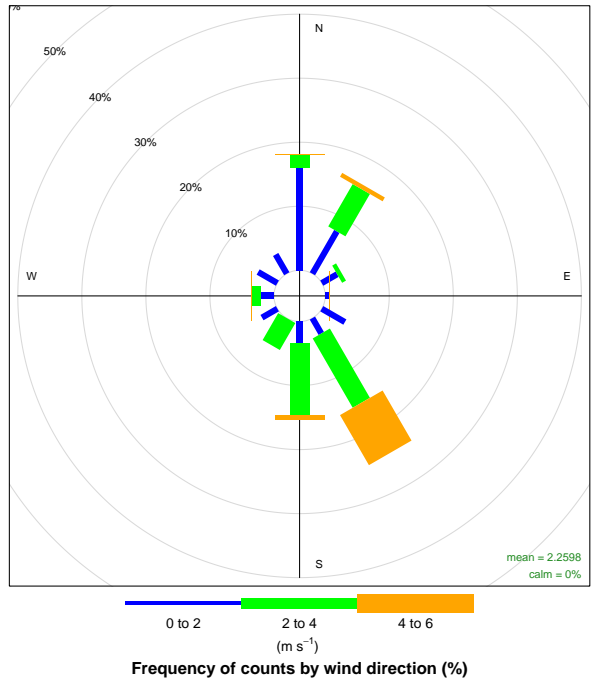

(b) Cubatão V Parisi - Simulação

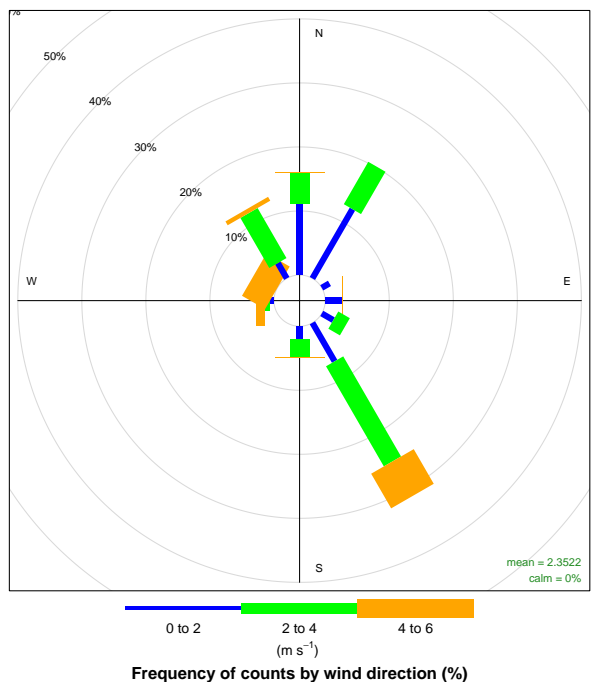

(d) IAG - Simulação 


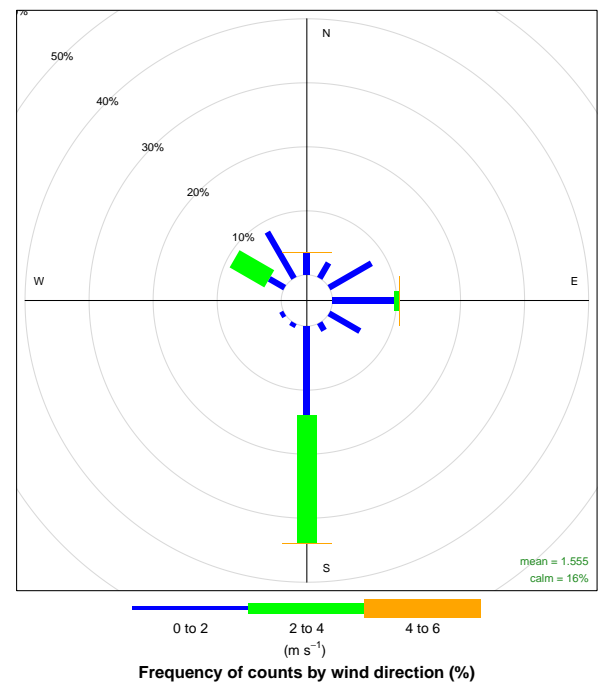

(a) Ibirapuera - Observado

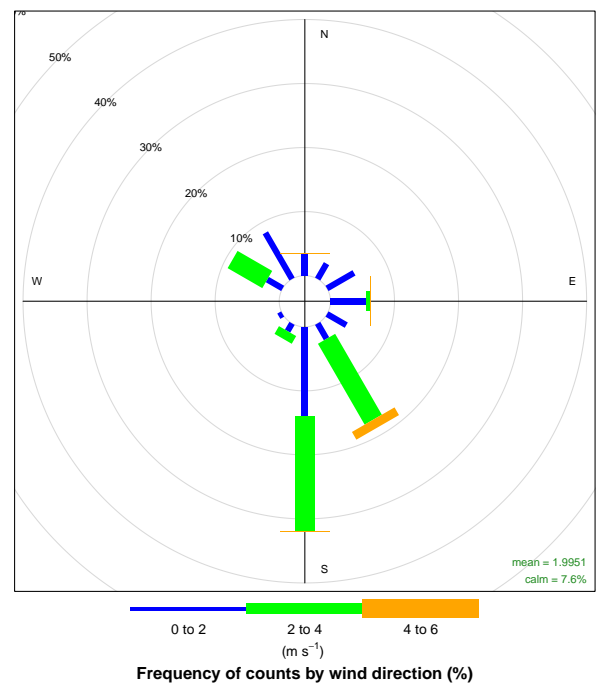

(c) Osasco - Observado

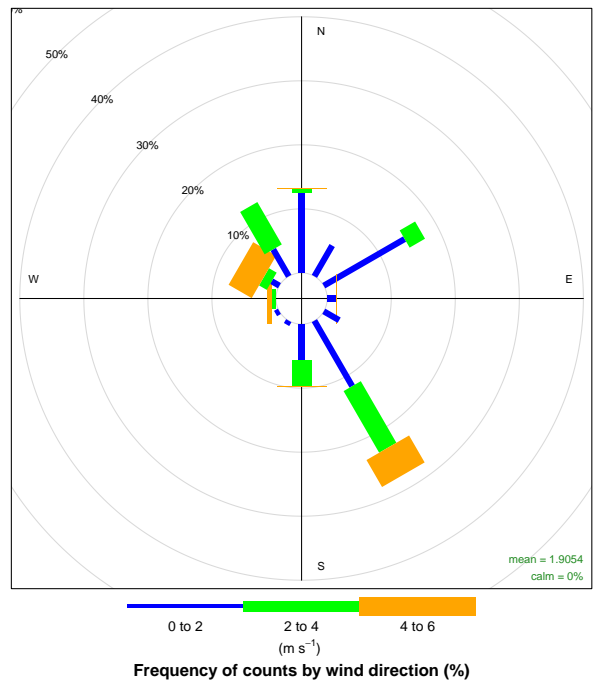

(b) Ibirapuera - Simulação

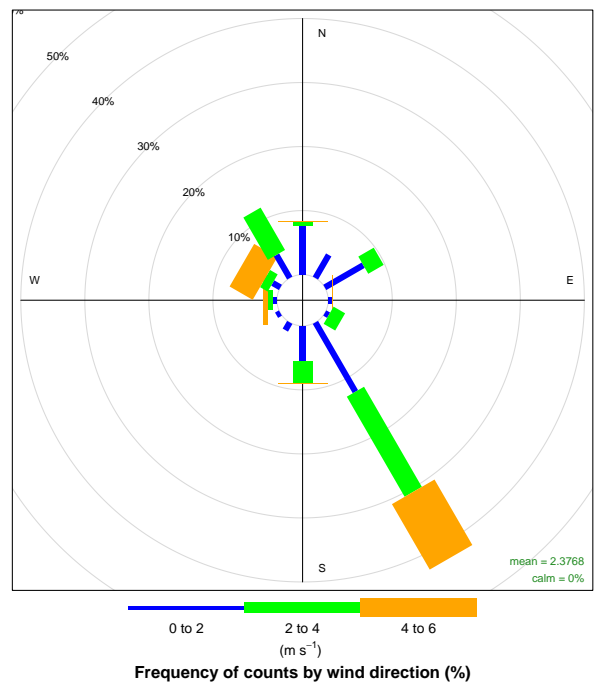

(d) Osasco - Simulação

Figura 4.23: Rosa dos Ventos nas estações. Vento Observado e Simulação. Continuação 


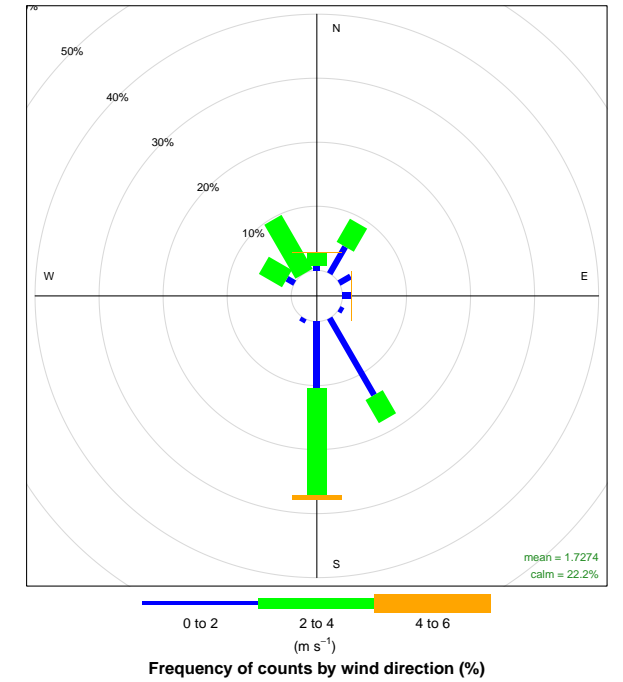

(a) Pinheiros - Observado

옹

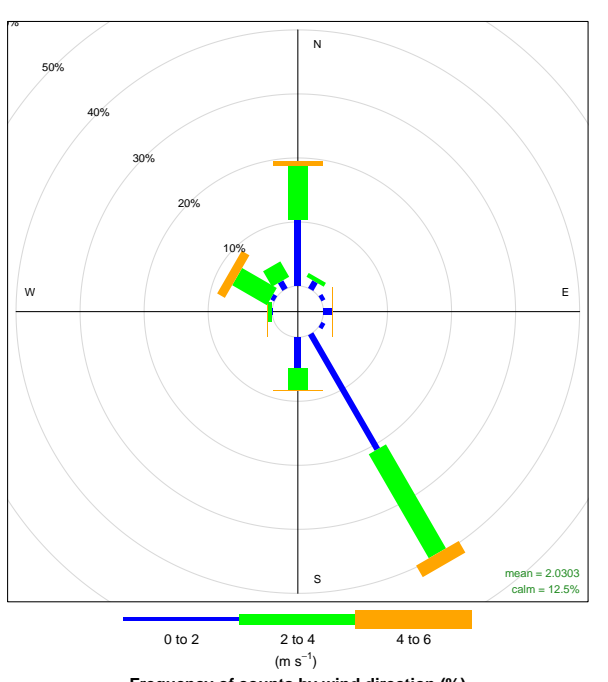

(c) Santo Amaro - Observado Figura 4.24: Rosa dos Ventos nas estações. Vento Observado e Simulação. Continuação

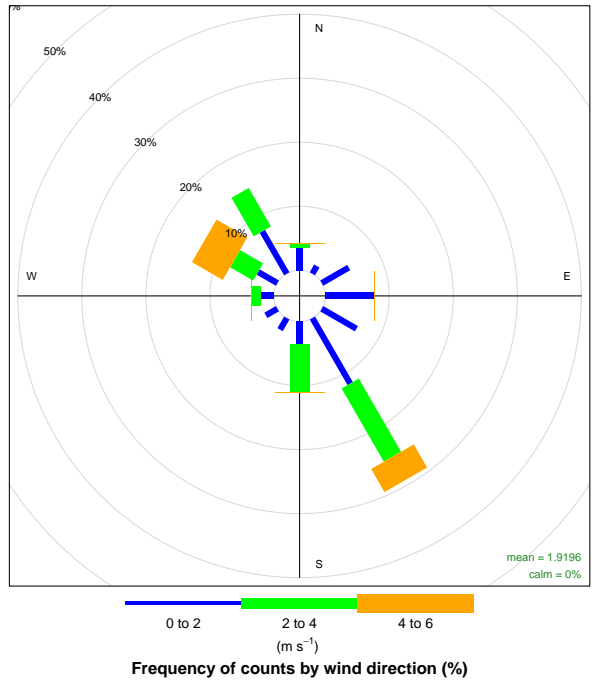

(b) Pinheiros - Simulação

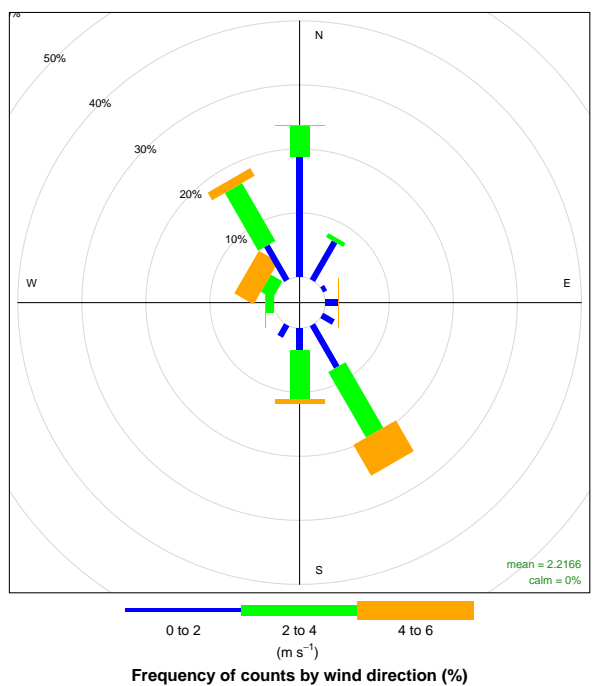

(d) Santo Amaro - Simulação 


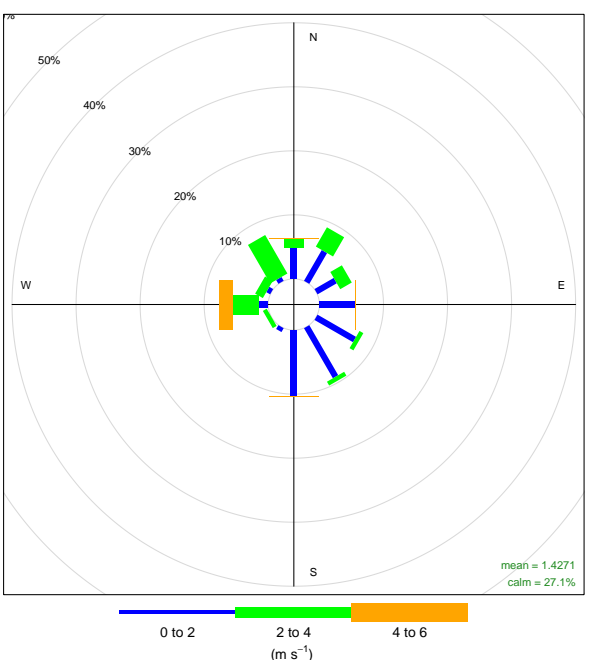

Frequency of counts by wind direction (\%)

(a) São Caetano - Observado

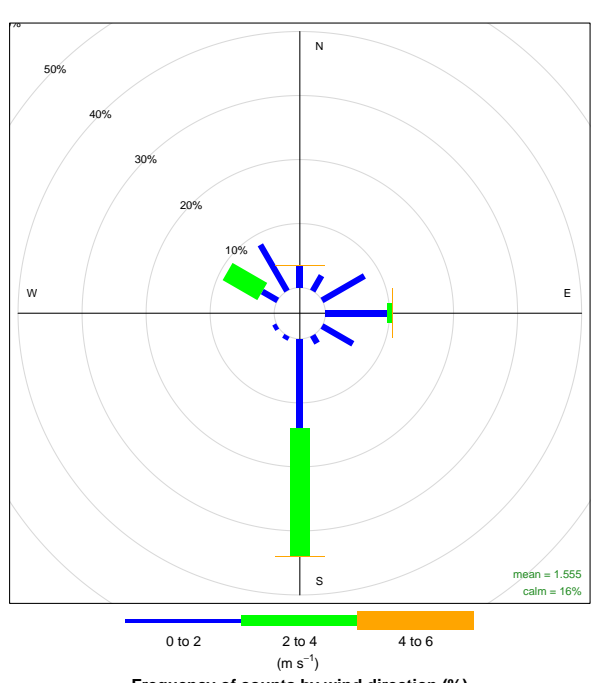

(c) S José dos Campos - Observado Figura 4.25: Rosa dos Ventos nas estações. Vento Observado e Simulação. Continuação

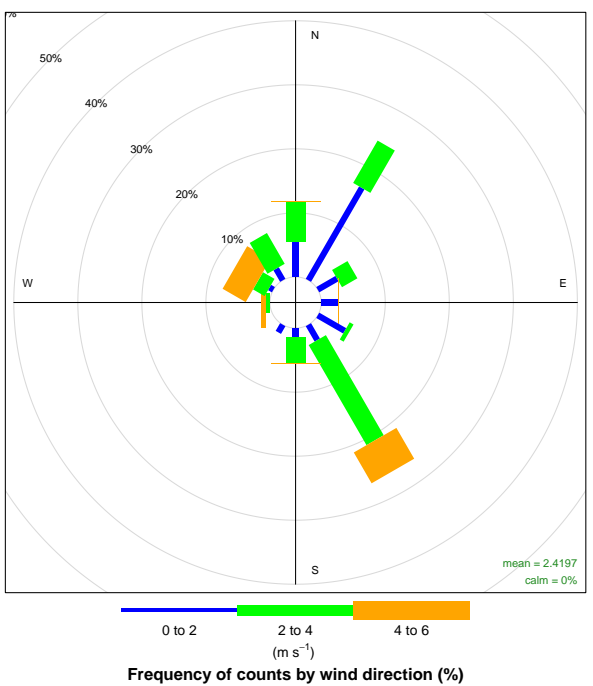

(b) São Caetano - Simulação

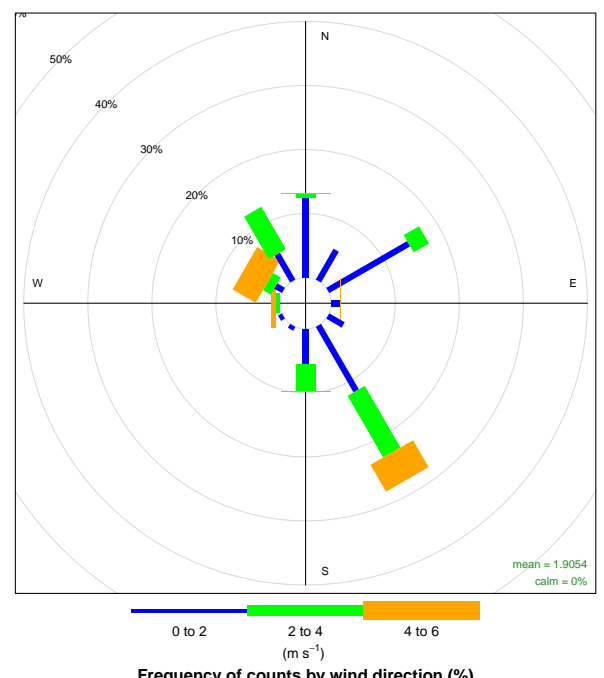

(d) S José dos Campos - Simulação 


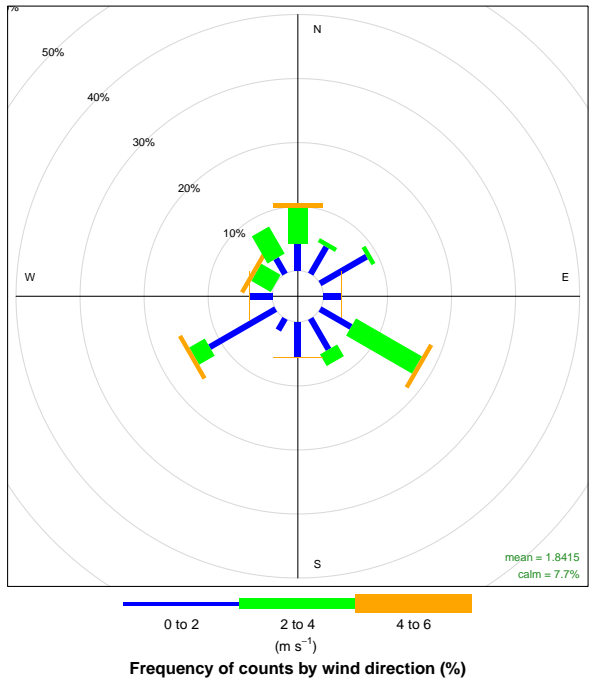

(a) Sorocaba - Observado

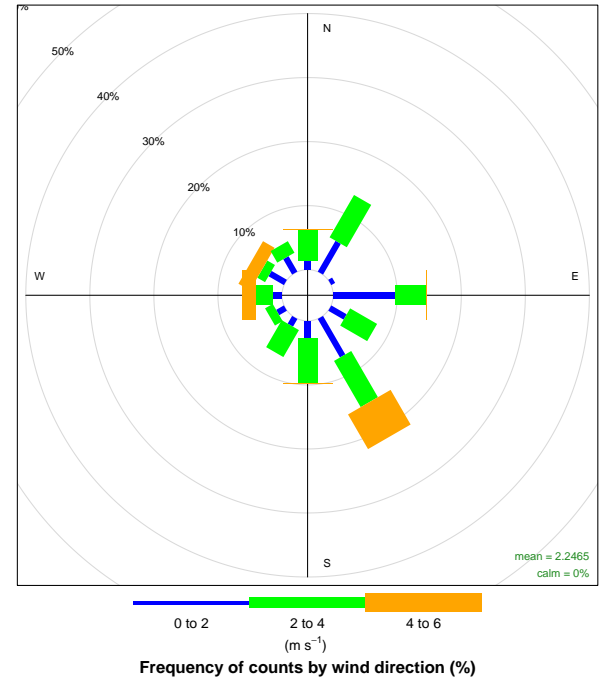

(b) Sorocaba - Simulação Figura 4.26: Rosa dos Ventos nas estações. Vento Observado e Simulação. Continuação 


\subsubsection{Radiossondagem}

Os resultados do BRAMS também foram comparados a variáveis meteorológicas medidas por radiossondagem no Campo de Marte (Coordenadas 23,51ํㅗ $/ 46,63^{\circ} \mathrm{O}, 722 \mathrm{~m}$ acima do nível do mar), entre os dias 23 e 29 de agosto de 2006, sempre às 00h e 12h UTC. Essas sondagens compõem a base de dados utilizadas pela WMO (World Meteorological Organization) em seus trabalhos de previsão meteorológica. Para fins do confronto dos dados, e sempre que necessário, os valores simulados foram interpolados para os níveis em que a Radiossonda efetuou as medidas.

\subsubsection{Pressão}

Os valores de pressão medidos e simulados mostraram-se amplamente compatíveis, como observa-se nas figuras de 4.27 à 4.30. A tabela 4.14 mostra que as correlações entre eles são muito próximas de 1,00 , com $N \geqslant 44$ e $\mathrm{P} \ll 0,001$. 

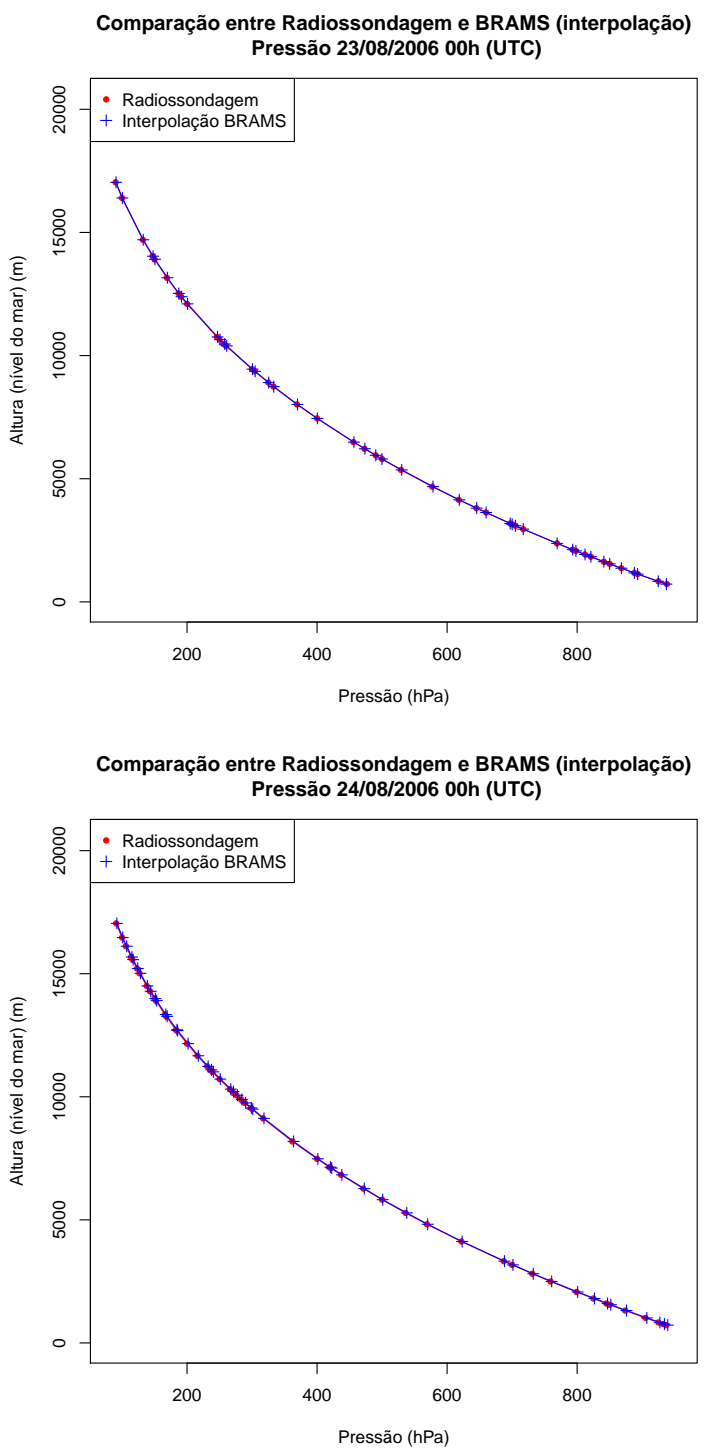

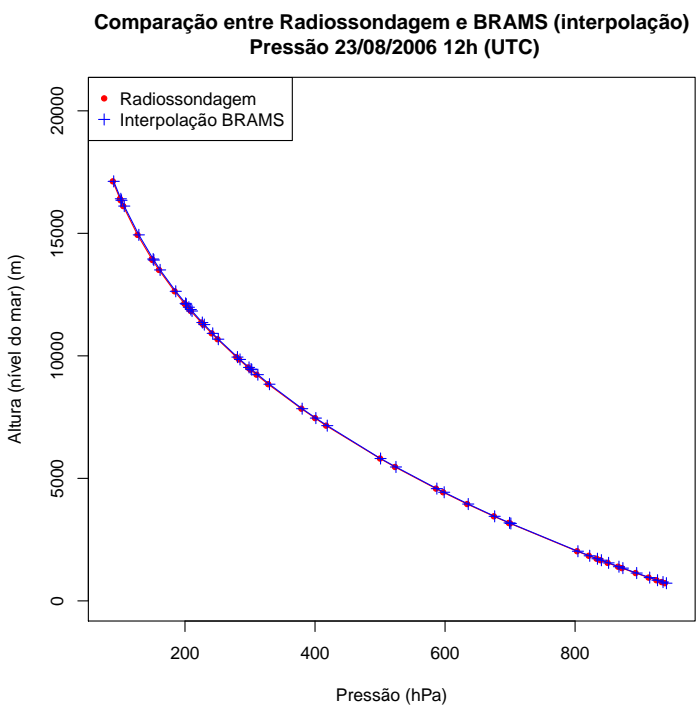

Comparação entre Radiossondagem e BRAMS (interpolação) Pressão 24/08/2006 12h (UTC)

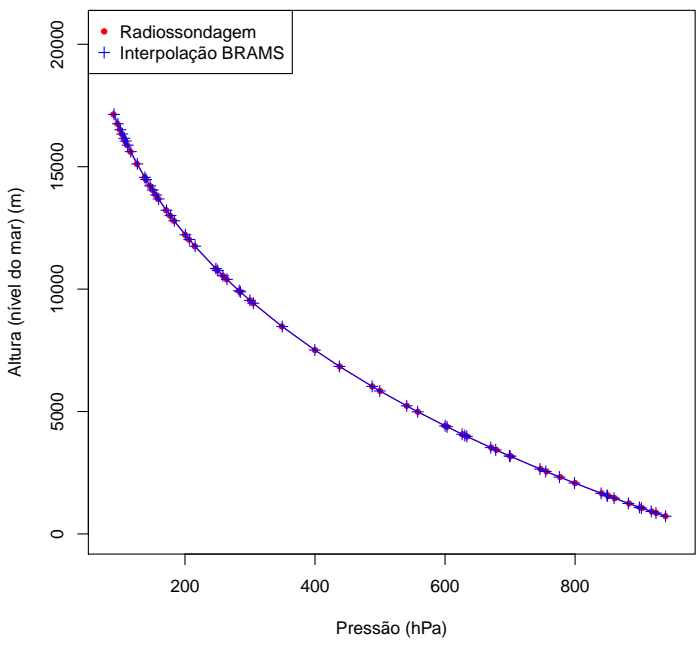

Figura 4.27: Comparação entre a Radiossondagem realizada no Campo de Marte e a interpolação dos resultados do BRAMS 

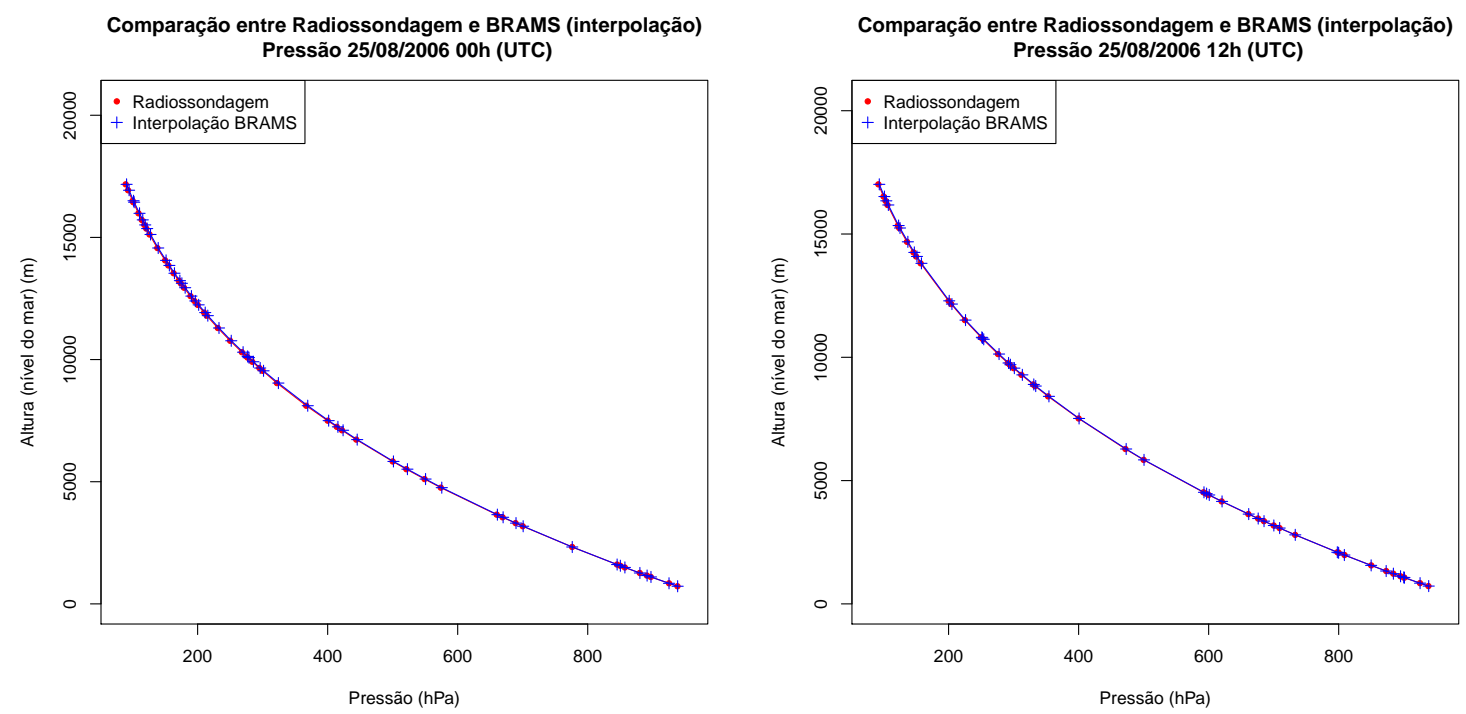

Comparação entre Radiossondagem e BRAMS (interpolação) Pressão 26/08/2006 00h (UTC)

Comparação entre Radiossondagem e BRAMS (interpolação) Pressão 26/08/2006 12h (UTC)
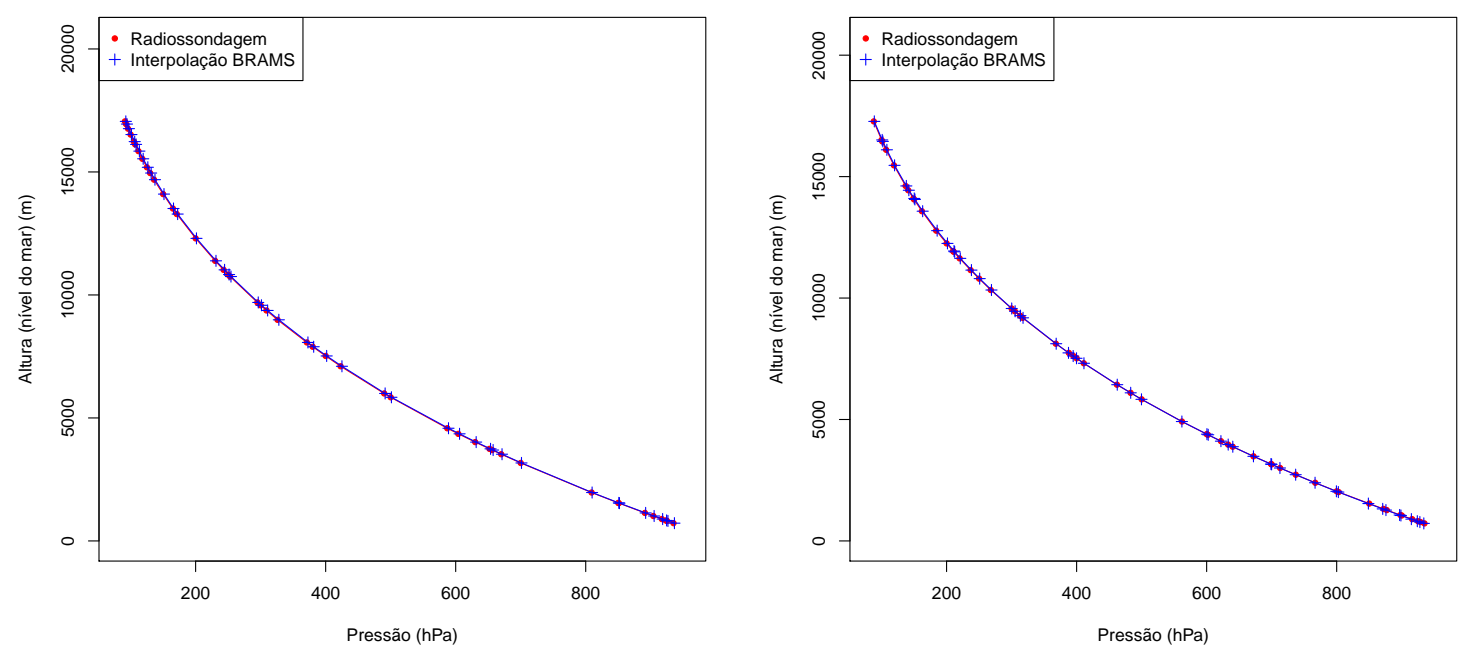

Figura 4.28: Comparação entre a Radiossondagem realizada no Campo de Marte e a interpolação dos resultados do BRAMS. Continuação 

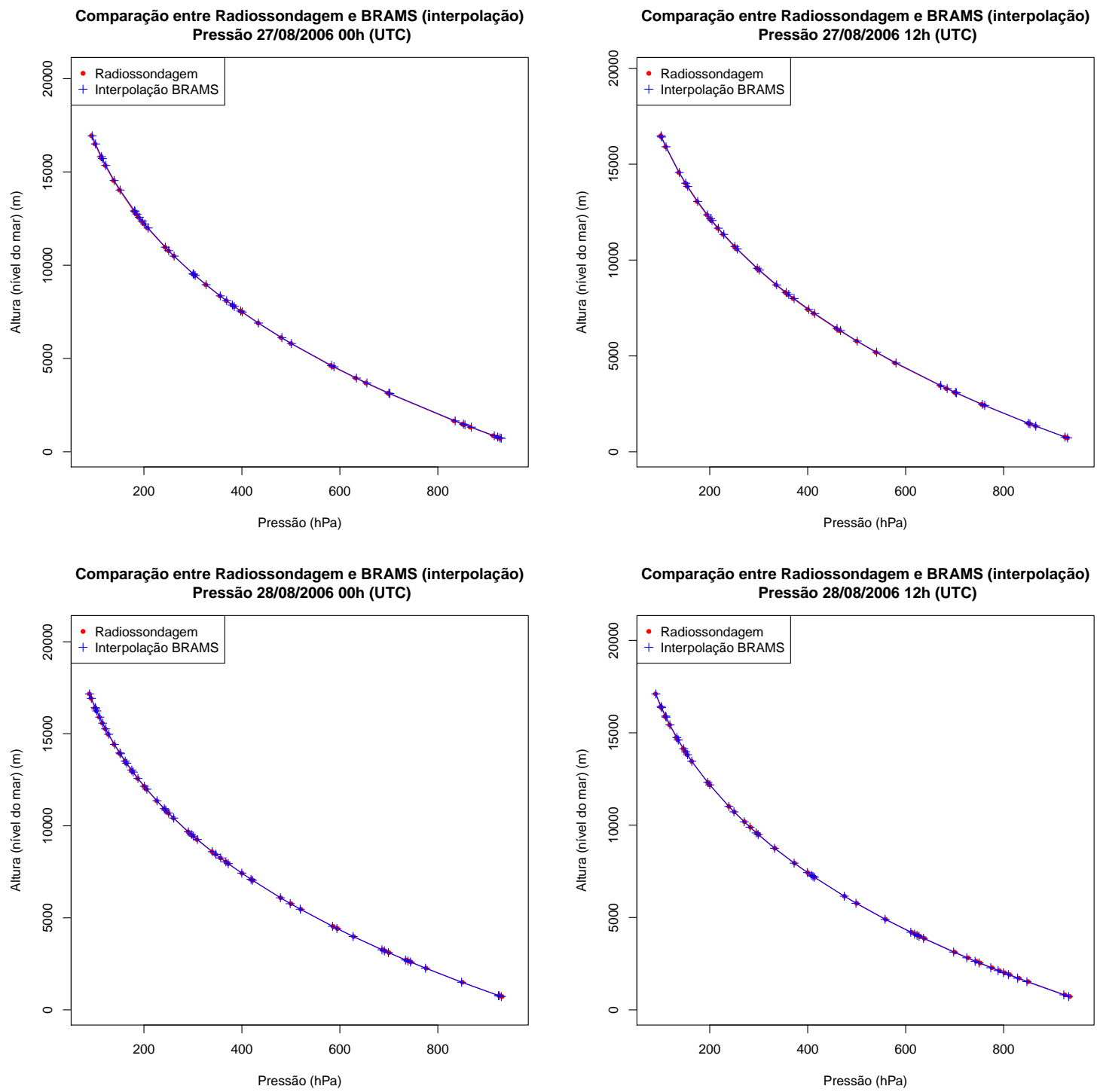

Figura 4.29: Comparação entre a Radiossondagem realizada no Campo de Marte e a interpolação dos resultados do BRAMS. Continuação 

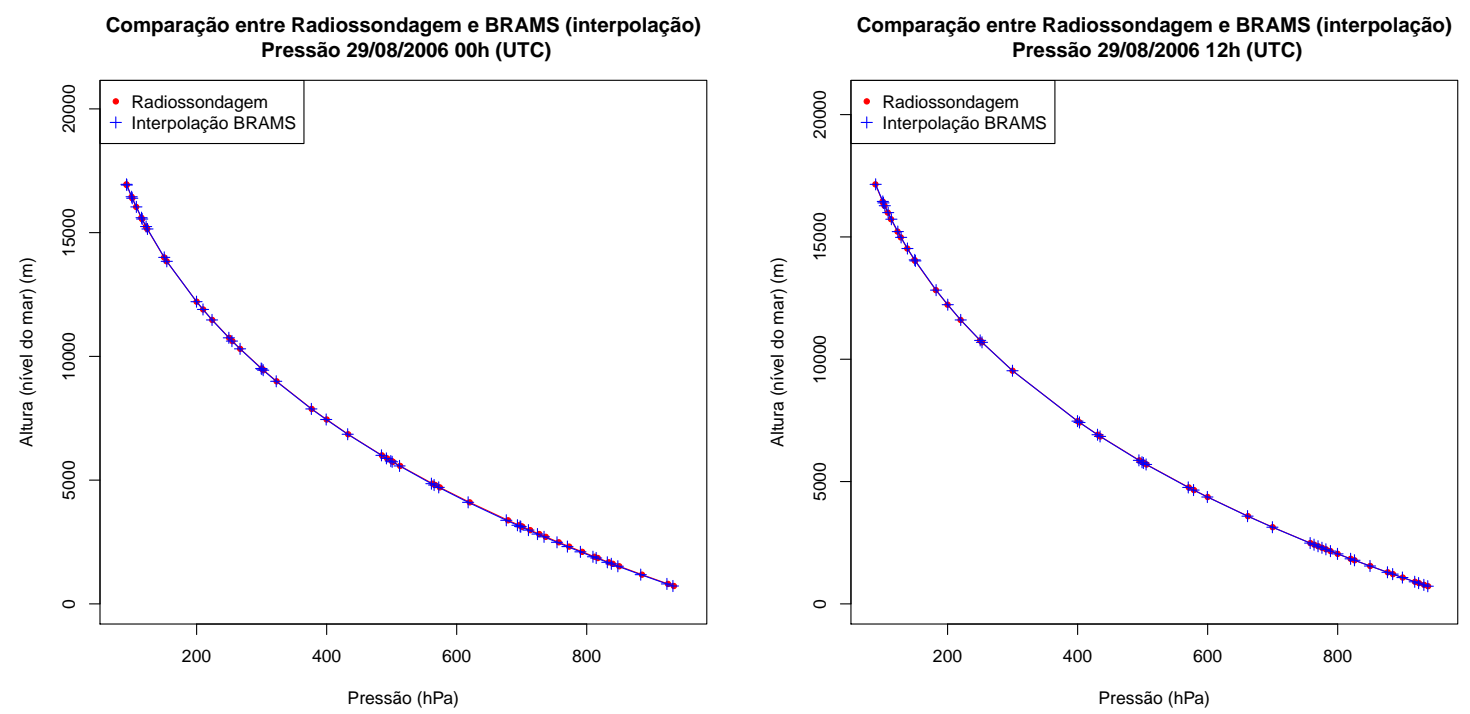

Figura 4.30: Comparação entre a Radiossondagem realizada no Campo de Marte e a interpolação dos resultados do BRAMS. Continuação

\begin{tabular}{llll}
\hline Data Hora & $\mathrm{N}$ & Correlação r & valor-P \\
\hline $23 / 08 / 200600 \mathrm{~h}$ & 44 & 1,00 & $2,49 \mathrm{e}-126$ \\
$23 / 08 / 200612 \mathrm{~h}$ & 48 & 1,00 & $3,94 \mathrm{e}-138$ \\
$24 / 08 / 200600 \mathrm{~h}$ & 52 & 1,00 & $3,51 \mathrm{e}-153$ \\
$24 / 08 / 200612 \mathrm{~h}$ & 59 & 1,00 & $1,48 \mathrm{e}-172$ \\
$25 / 08 / 200600 \mathrm{~h}$ & 52 & 1,00 & $9,00 \mathrm{e}-147$ \\
$25 / 08 / 200612 \mathrm{~h}$ & 48 & 1,00 & $4,55 \mathrm{e}-145$ \\
$26 / 08 / 200600 \mathrm{~h}$ & 45 & 1,00 & $9,12 \mathrm{e}-133$ \\
$26 / 08 / 200612 \mathrm{~h}$ & 53 & 1,00 & $1,56 \mathrm{e}-150$ \\
$27 / 08 / 200600 \mathrm{~h}$ & 44 & 1,00 & $5,52 \mathrm{e}-117$ \\
$27 / 08 / 200612 \mathrm{~h}$ & 38 & 1,00 & $2,20 \mathrm{e}-97$ \\
$28 / 08 / 200600 \mathrm{~h}$ & 53 & 1,00 & $3,99 \mathrm{e}-146$ \\
$28 / 08 / 200612 \mathrm{~h}$ & 46 & 1,00 & $2,64 \mathrm{e}-127$ \\
$29 / 08 / 200600 \mathrm{~h}$ & 51 & 1,00 & $3,33 \mathrm{e}-139$ \\
$29 / 08 / 200612 \mathrm{~h}$ & 47 & 1,00 & $7,44 \mathrm{e}-137$ \\
Tudo & 680 & 1,00 & $0,00 \mathrm{e}+00$ \\
\hline
\end{tabular}

Tabela 4.14: Pressão: Correlação entre radiossondagem e valores simulados pelo BRAMS interpolados nos mesmos níveis de medição.

\subsubsection{Umidade}

As correlações entre dados simulados e a radiossondagem foram superiores à 0,5 em todos os dias, exceto para 27/08/2006 às 00h UTC, e 28/08/2006 às 00h UTC, como mostra a tabela 4.15. A correlação ao se agrupar todos os dias, foi de 0,74. A análise visual dos gráficos (figuras 4.31 à 4.34) corrobora com os testes de correlação, mostrando tendências funcionais semelhantes entre a simulação e a radiossondagem, ainda que os valores em si possam ter bastante divergência ponto a ponto. 


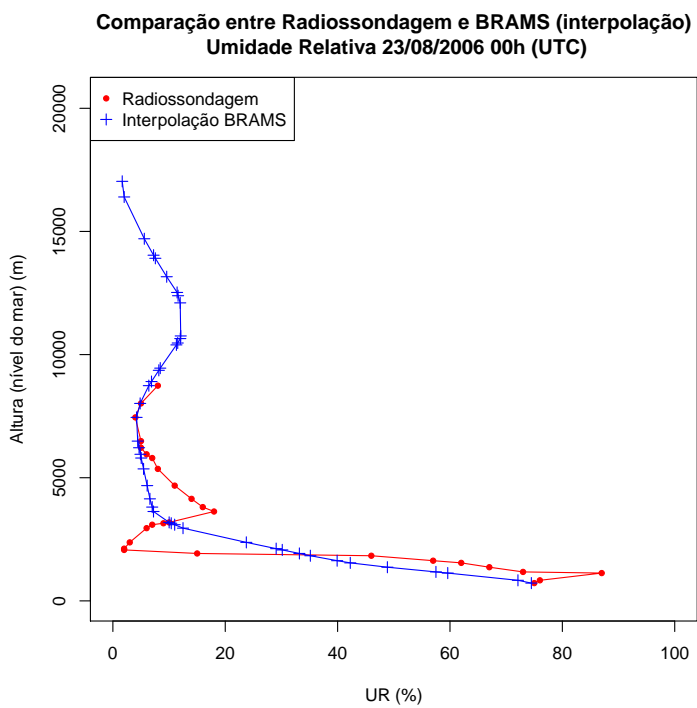

Comparação entre Radiossondagem e BRAMS (interpolação) Umidade Relativa 24/08/2006 00h (UTC)

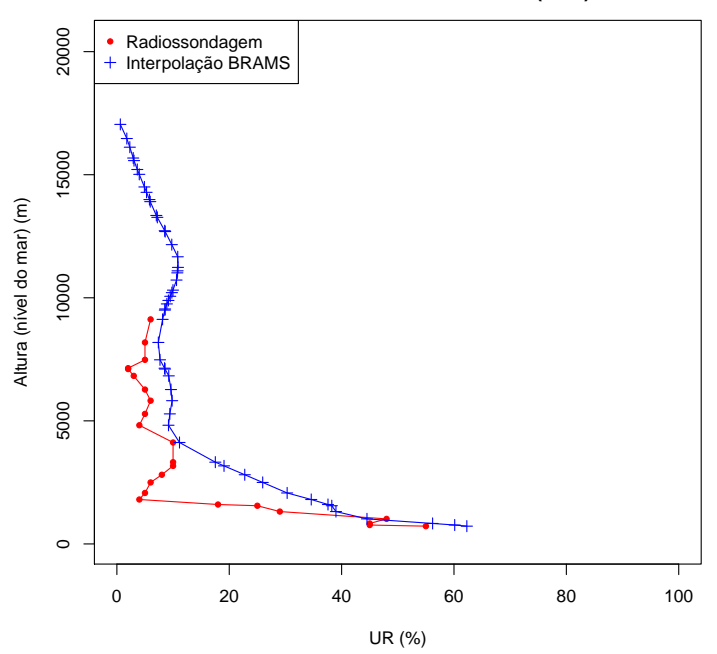

Comparação entre Radiossondagem e BRAMS (interpolação) Umidade Relativa 23/08/2006 12h (UTC)

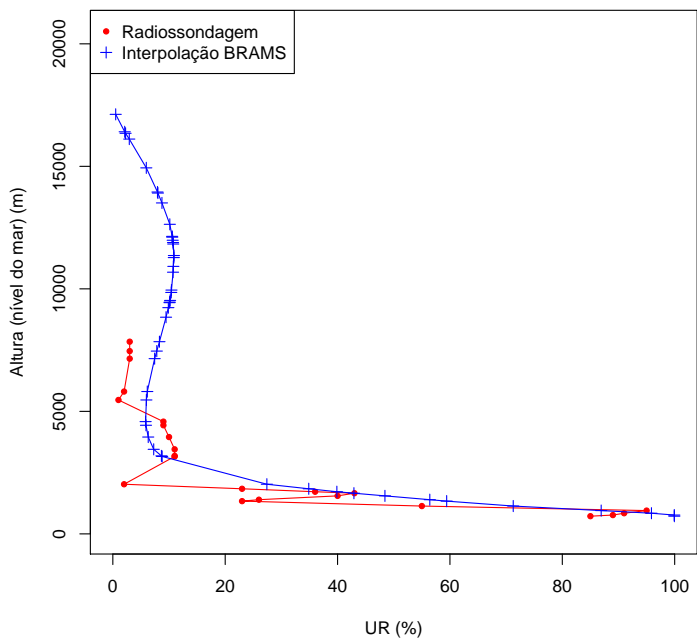

Comparação entre Radiossondagem e BRAMS (interpolação) Umidade Relativa 24/08/2006 12h (UTC)

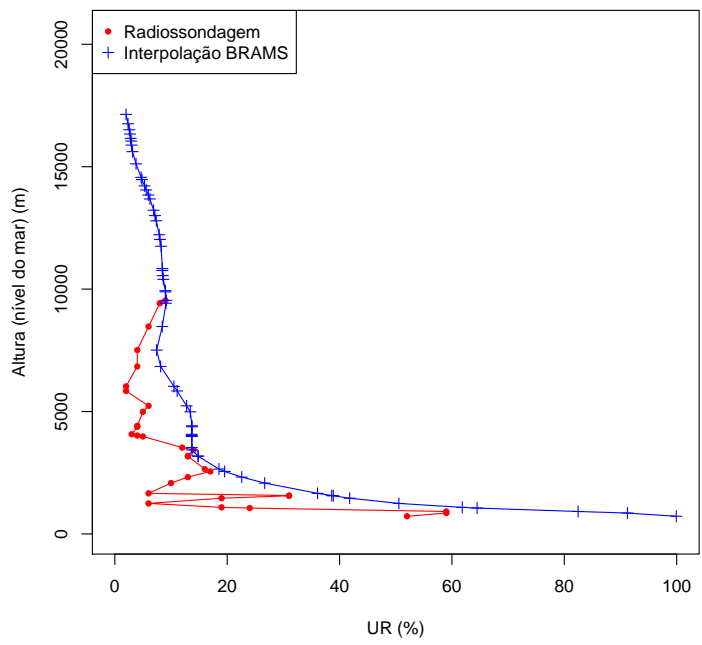

Figura 4.31: Comparação entre a Radiossondagem realizada no Campo de Marte e a interpolação dos resultados do BRAMS 

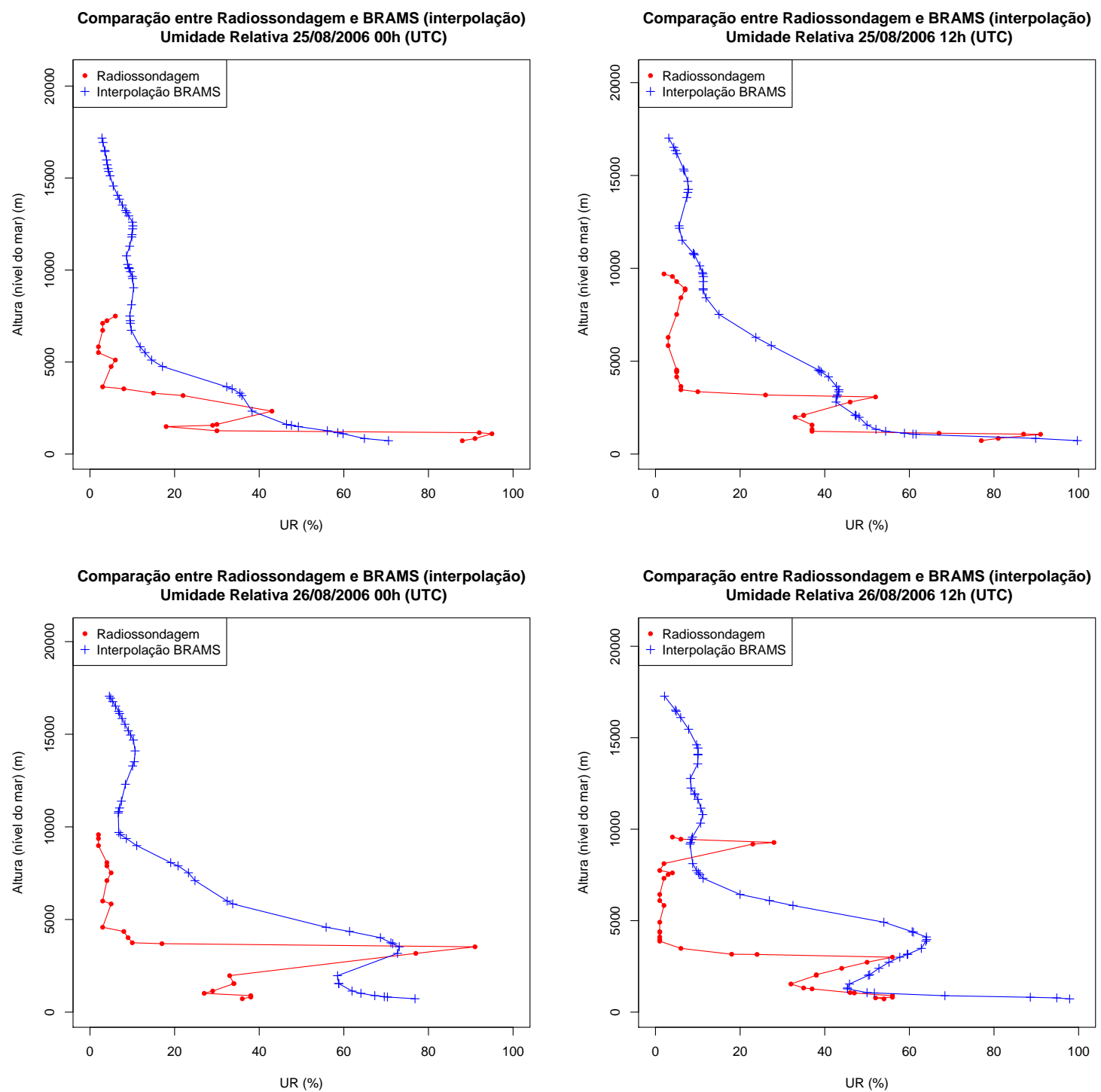

Figura 4.32: Comparação entre a Radiossondagem realizada no Campo de Marte e a interpolação dos resultados do BRAMS. Continuação 


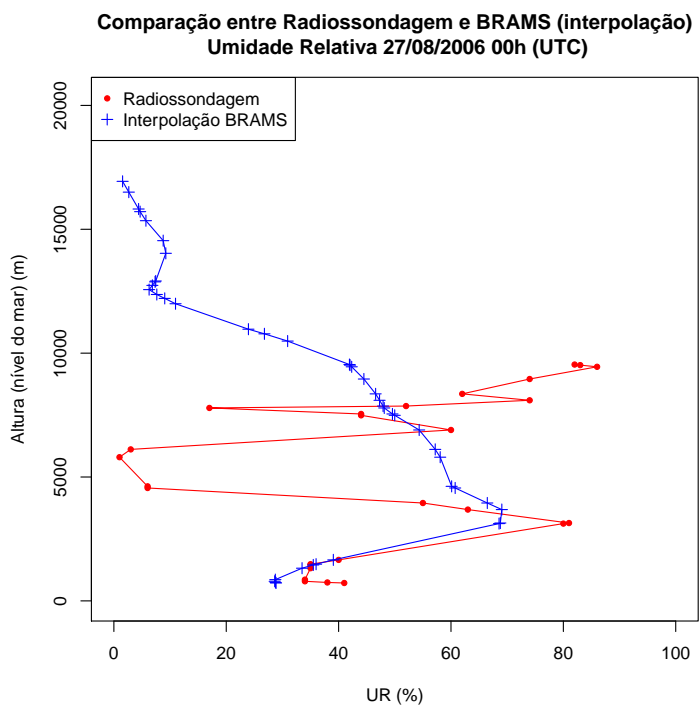

Comparação entre Radiossondagem e BRAMS (interpolação) Umidade Relativa 28/08/2006 00h (UTC)

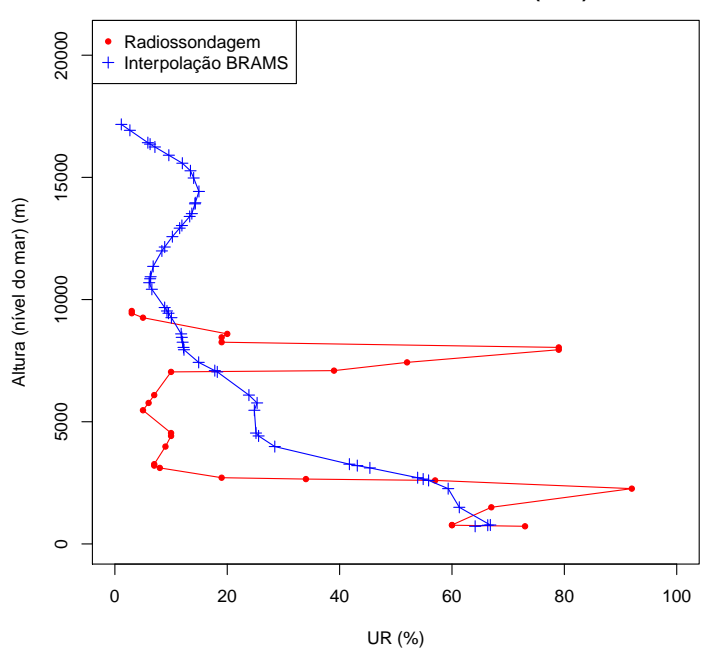

Comparação entre Radiossondagem e BRAMS (interpolação) Umidade Relativa 27/08/2006 12h (UTC)

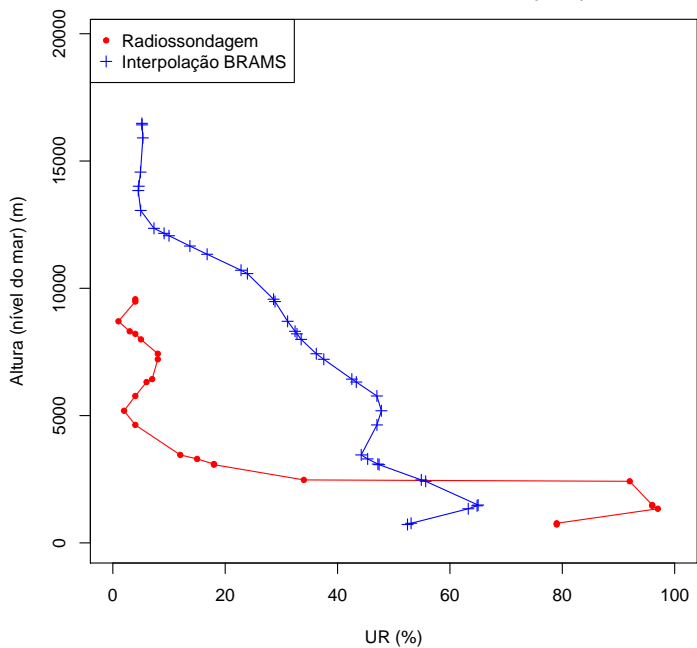

Comparação entre Radiossondagem e BRAMS (interpolação) Umidade Relativa 28/08/2006 12h (UTC)

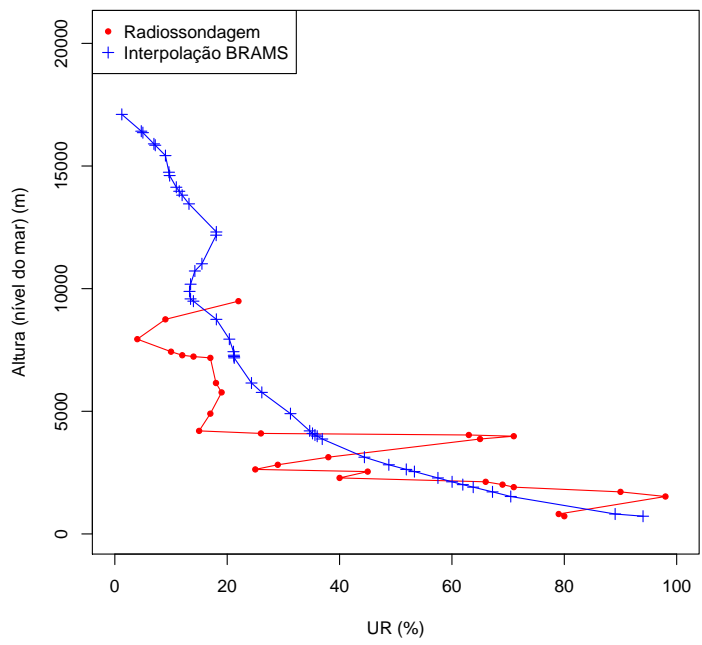

Figura 4.33: Comparação entre a Radiossondagem realizada no Campo de Marte e a interpolação dos resultados do BRAMS. Continuação 

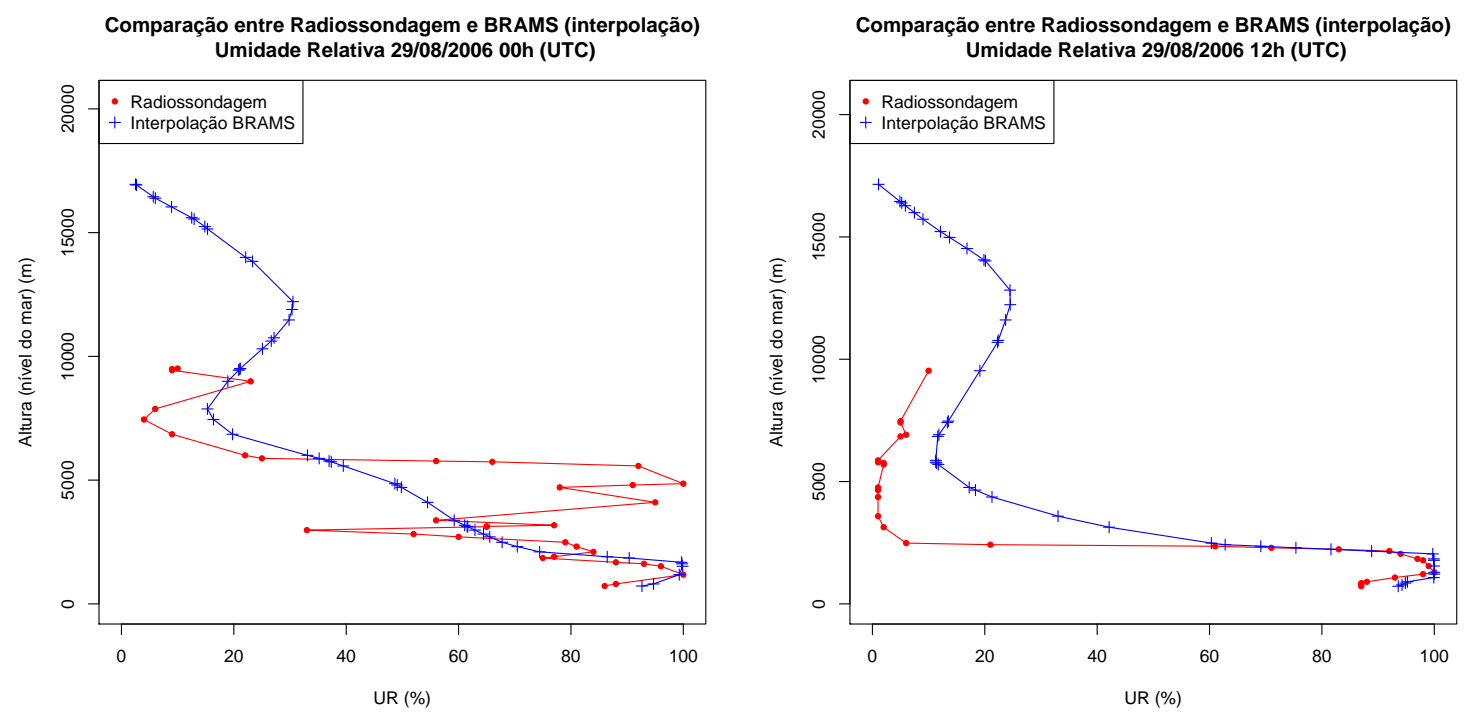

Figura 4.34: Comparação entre a Radiossondagem realizada no Campo de Marte e a interpolação dos resultados do BRAMS. Continuação

\begin{tabular}{llll}
\hline Data Hora & $\mathrm{N}$ & Correlação r & valor-P \\
\hline $23 / 08 / 200600 \mathrm{~h}$ & 44 & 0,89 & $1,49 \mathrm{e}-10$ \\
$23 / 08 / 200612 \mathrm{~h}$ & 48 & 0,94 & $1,56 \mathrm{e}-11$ \\
$24 / 08 / 200600 \mathrm{~h}$ & 52 & 0,89 & $3,65 \mathrm{e}-09$ \\
$24 / 08 / 200612 \mathrm{~h}$ & 59 & 0,87 & $7,40 \mathrm{e}-11$ \\
$25 / 08 / 200600 \mathrm{~h}$ & 52 & 0,84 & $1,49 \mathrm{e}-06$ \\
$25 / 08 / 200612 \mathrm{~h}$ & 48 & 0,80 & $1,13 \mathrm{e}-07$ \\
$26 / 08 / 200600 \mathrm{~h}$ & 45 & 0,65 & $3,97 \mathrm{e}-04$ \\
$26 / 08 / 200612 \mathrm{~h}$ & 53 & 0,53 & $1,12 \mathrm{e}-03$ \\
$27 / 08 / 200600 \mathrm{~h}$ & 44 & 0,07 & $7,42 \mathrm{e}-01$ \\
$27 / 08 / 200612 \mathrm{~h}$ & 38 & 0,83 & $5,12 \mathrm{e}-07$ \\
$28 / 08 / 200600 \mathrm{~h}$ & 53 & 0,44 & $1,88 \mathrm{e}-02$ \\
$28 / 08 / 200612 \mathrm{~h}$ & 46 & 0,81 & $2,44 \mathrm{e}-07$ \\
$29 / 08 / 200600 \mathrm{~h}$ & 51 & 0,78 & $4,53 \mathrm{e}-08$ \\
$29 / 08 / 200612 \mathrm{~h}$ & 47 & 0,96 & $4,05 \mathrm{e}-17$ \\
Tudo & 680 & 0,74 & $3,22 \mathrm{e}-69$ \\
\hline
\end{tabular}

Tabela 4.15: Umidade Relativa (UR): Correlação entre radiossondagem e valores simulados pelo BRAMS interpolados nos mesmos níveis de medição.

\subsubsection{Temperatura}

A temperatura foi uma variável muito bem simulada nos níveis verticais da radiossondagem.A tabela 4.16 mostra correlações próximas de 1,00 para todos os dias, assim como para a compilação de todos os resultados.

Os gráficos nas figuras de 4.35 à 4.38, também mostram que a performance da simulação foi bem próxima aos resultados da radiossondagem. 

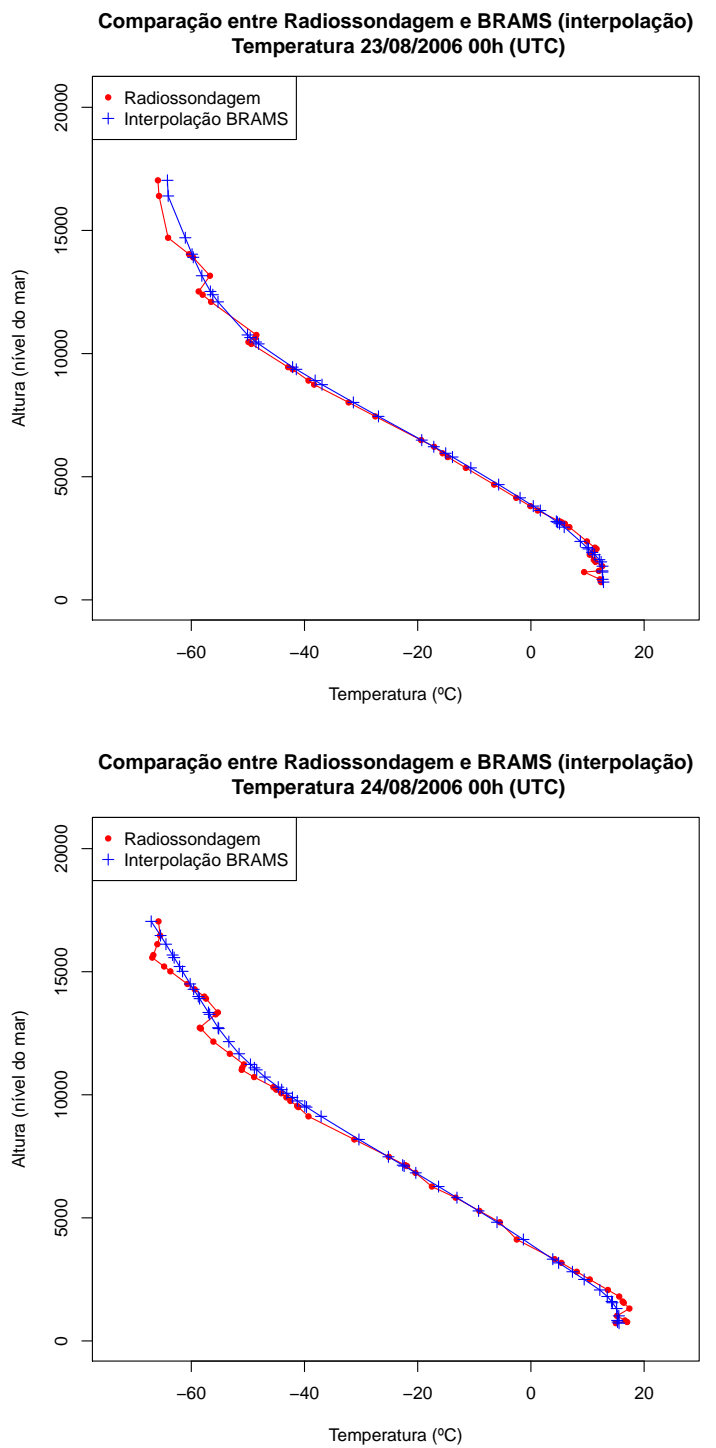

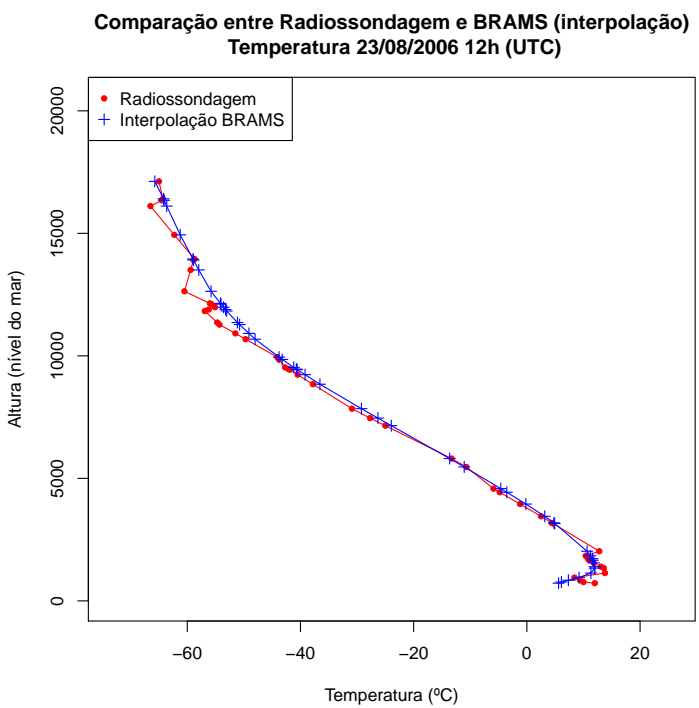

Comparação entre Radiossondagem e BRAMS (interpolação) Temperatura 24/08/2006 12h (UTC)

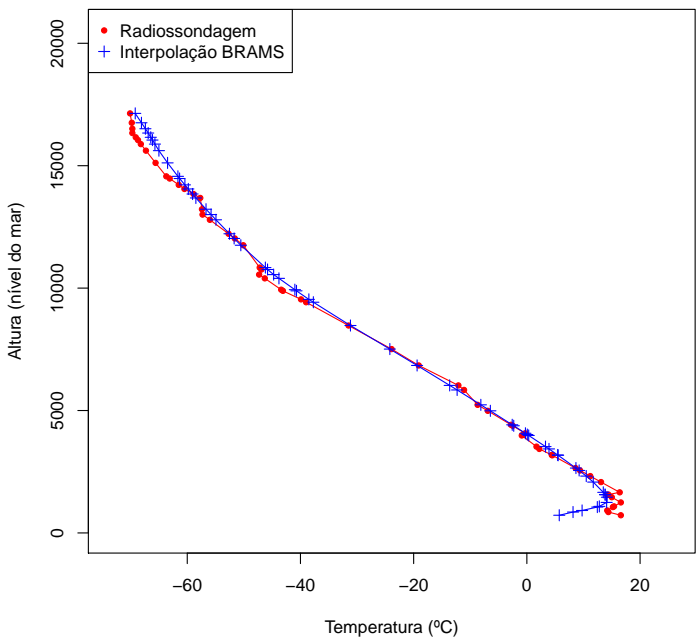

Figura 4.35: Comparação entre a Radiossondagem realizada no Campo de Marte e a interpolação dos resultados do BRAMS 

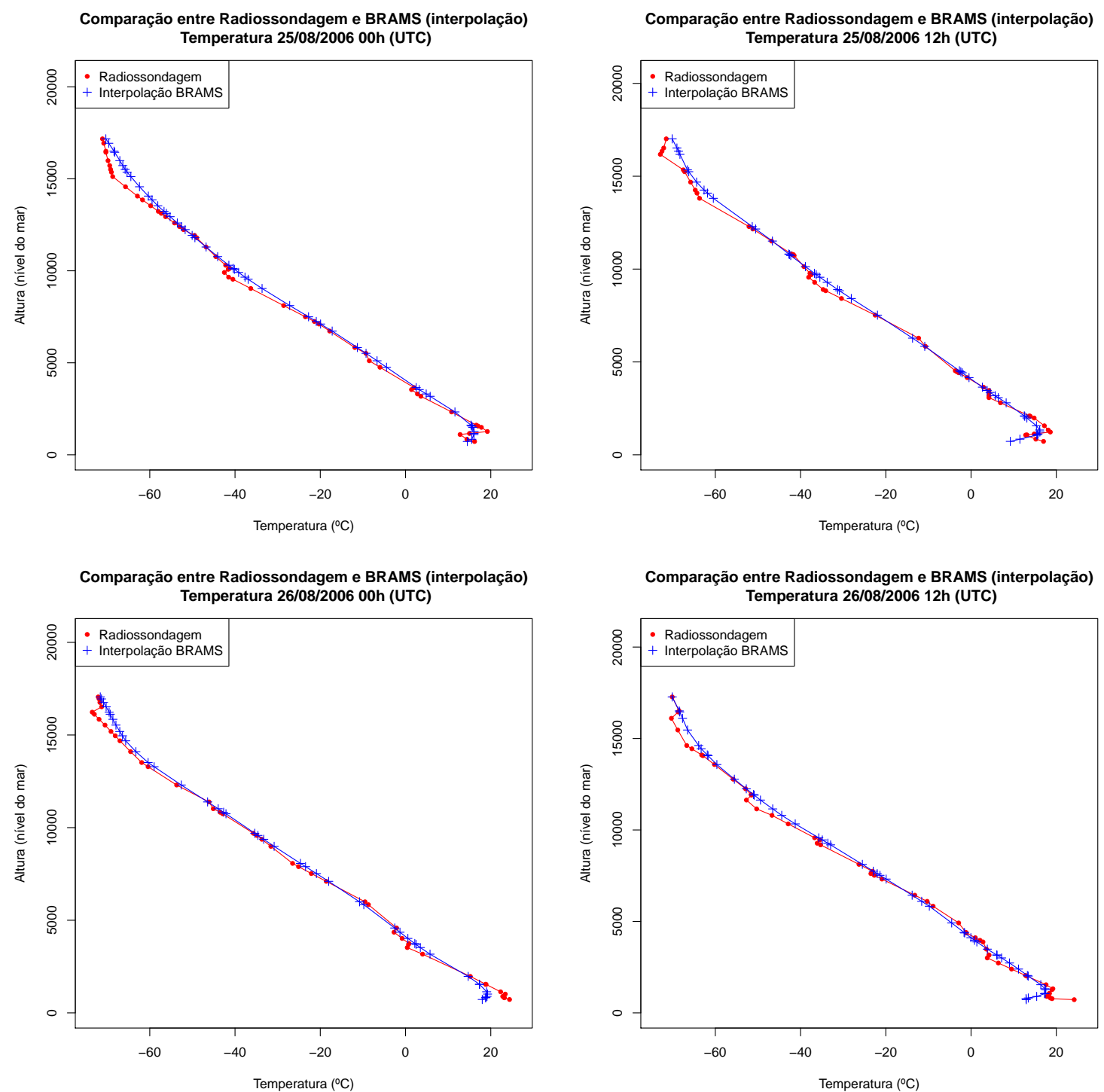

Figura 4.36: Comparação entre a Radiossondagem realizada no Campo de Marte e a interpolação dos resultados do BRAMS. Continuação 

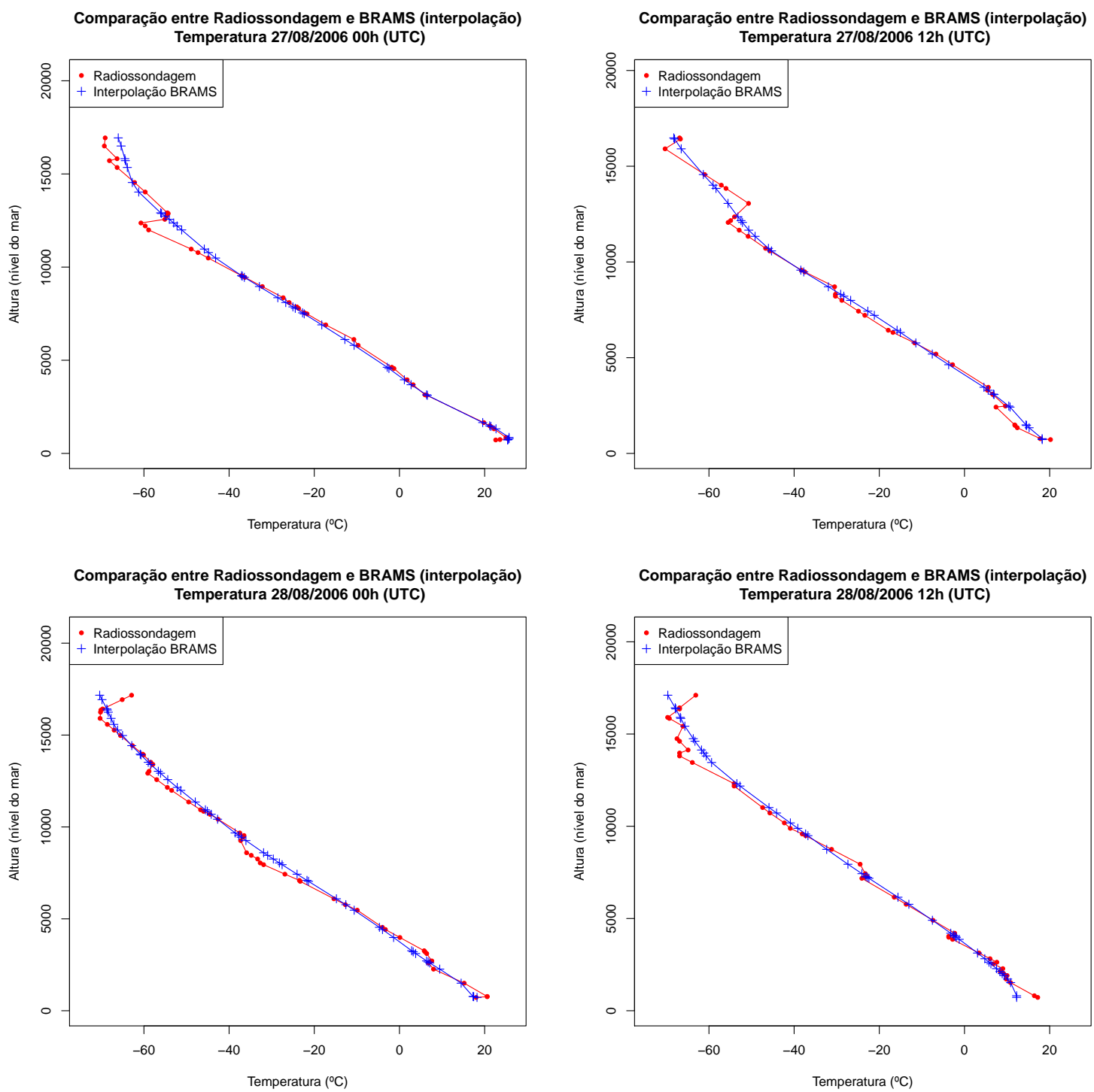

Figura 4.37: Comparação entre a Radiossondagem realizada no Campo de Marte e a interpolação dos resultados do BRAMS. Continuação 

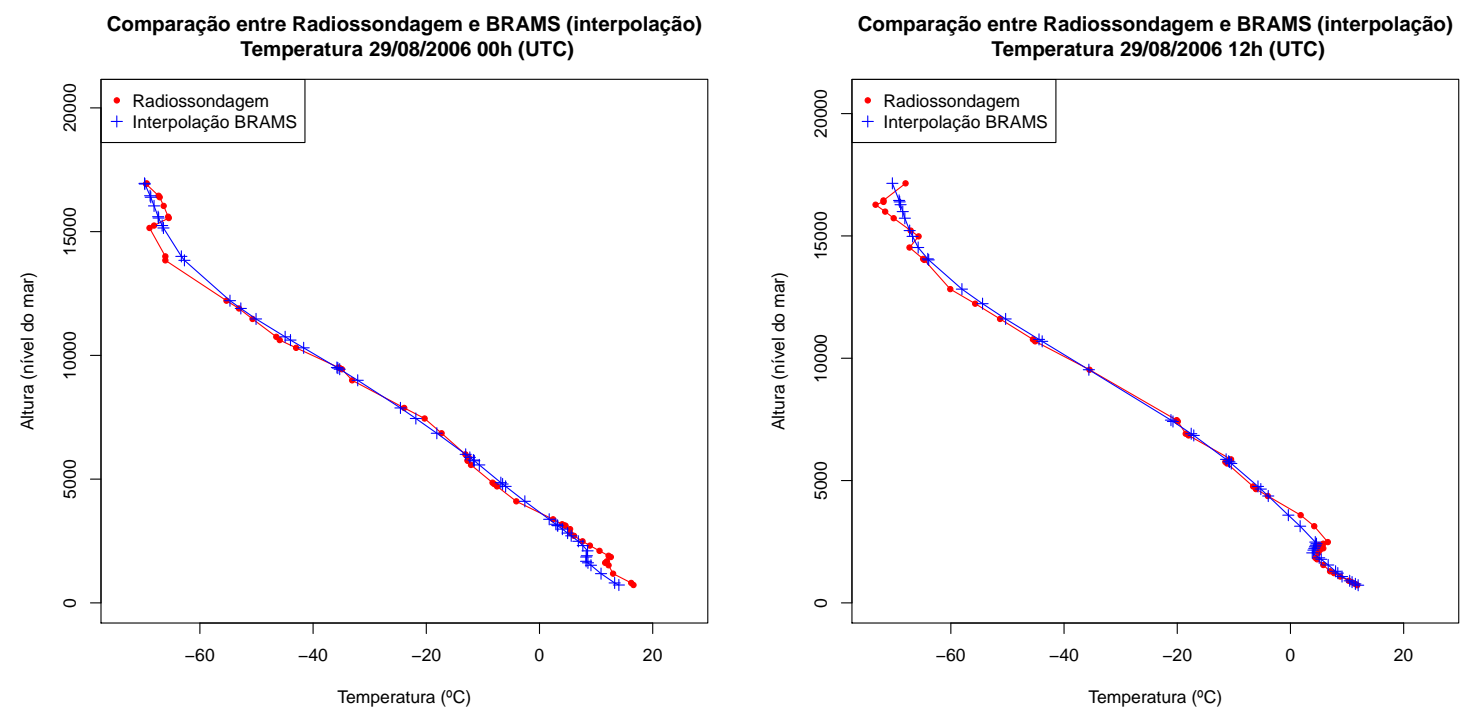

Figura 4.38: Comparação entre a Radiossondagem realizada no Campo de Marte e a interpolação dos resultados do BRAMS. Continuação

\begin{tabular}{llll}
\hline Data Hora & $\mathrm{N}$ & Correlação r & valor-P \\
\hline $23 / 08 / 200600 \mathrm{~h}$ & 44 & 1,00 & $5,25 \mathrm{e}-62$ \\
$23 / 08 / 200612 \mathrm{~h}$ & 48 & 1,00 & $6,85 \mathrm{e}-60$ \\
$24 / 08 / 200600 \mathrm{~h}$ & 52 & 1,00 & $5,77 \mathrm{e}-70$ \\
$24 / 08 / 200612 \mathrm{~h}$ & 59 & 1,00 & $7,47 \mathrm{e}-72$ \\
$25 / 08 / 200600 \mathrm{~h}$ & 52 & 1,00 & $4,35 \mathrm{e}-69$ \\
$25 / 08 / 200612 \mathrm{~h}$ & 48 & 1,00 & $3,33 \mathrm{e}-58$ \\
$26 / 08 / 200600 \mathrm{~h}$ & 45 & 1,00 & $2,93 \mathrm{e}-58$ \\
$26 / 08 / 200612 \mathrm{~h}$ & 53 & 1,00 & $5,70 \mathrm{e}-61$ \\
$27 / 08 / 200600 \mathrm{~h}$ & 44 & 1,00 & $1,02 \mathrm{e}-49$ \\
$27 / 08 / 200612 \mathrm{~h}$ & 38 & 1,00 & $2,28 \mathrm{e}-44$ \\
$28 / 08 / 200600 \mathrm{~h}$ & 53 & 1,00 & $3,22 \mathrm{e}-58$ \\
$28 / 08 / 200612 \mathrm{~h}$ & 46 & 1,00 & $5,80 \mathrm{e}-52$ \\
$29 / 08 / 200600 \mathrm{~h}$ & 51 & 1,00 & $2,00 \mathrm{e}-64$ \\
$29 / 08 / 200612 \mathrm{~h}$ & 47 & 1,00 & $1,73 \mathrm{e}-64$ \\
Tudo & 680 & 1,00 & $0,00 \mathrm{e}+00$ \\
\hline
\end{tabular}

Tabela 4.16: Temperatura: Correlação entre radiossondagem e simulação BRAMS interpolada para os níveis medidos

\subsubsection{Vento U}

A componente zonal do vento foi, em geral, bem simulada. Os gráficos nas figuras de 4.39 a 4.42 mostram que as curvas das simulações e das radiossondagens apresentaram comportamento similares.

Isso confirma-se pela alta correlação, 0,93, para a compilação de todos os dados, sendo que apenas o dia 27/08/2006 00h UTC, teve resultado abaixo de 0,80, como mostrado na tabela 4.17 . 

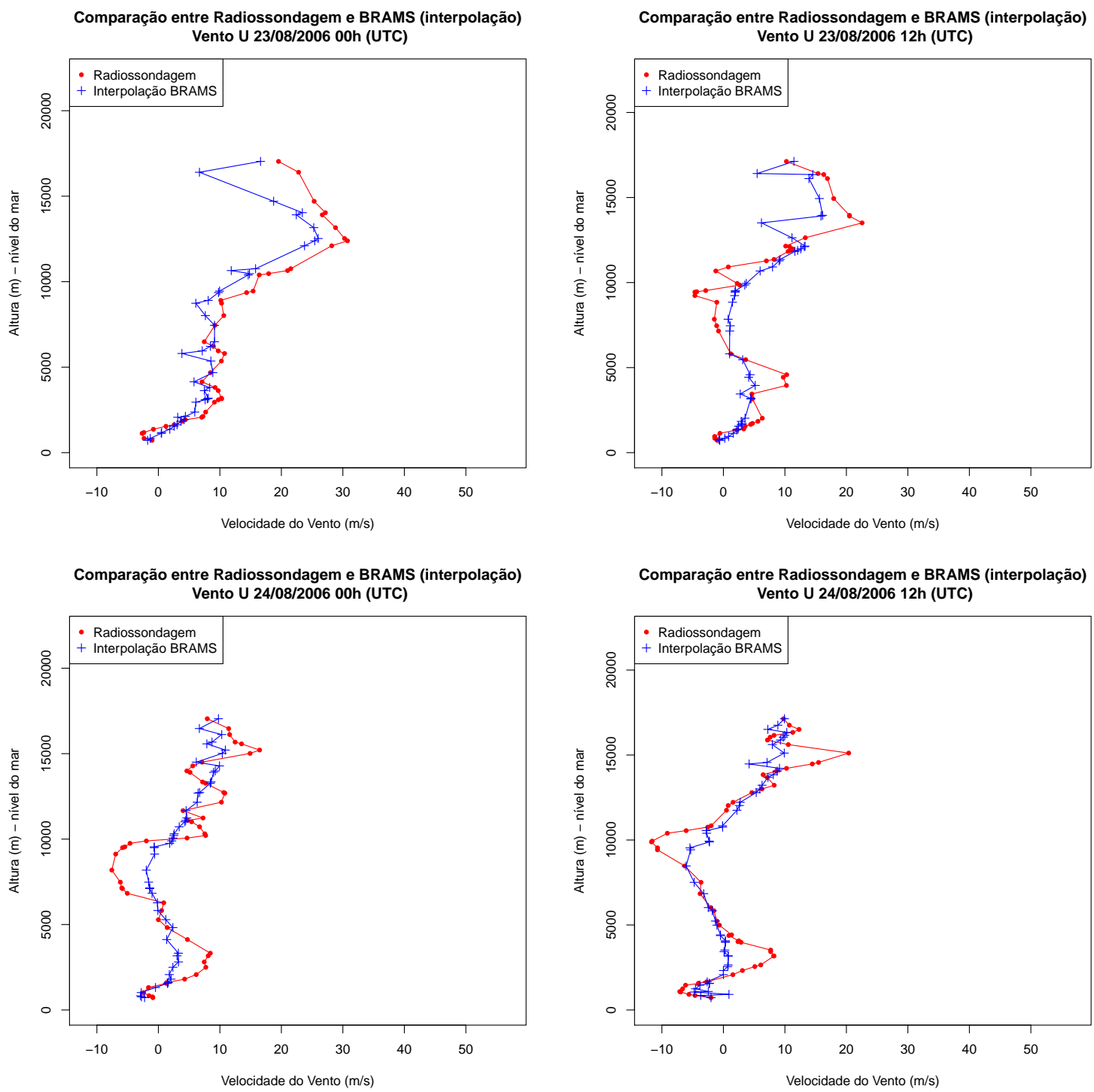

Figura 4.39: Comparação entre a Radiossondagem realizada no Campo de Marte e a interpolação dos resultados do BRAMS 

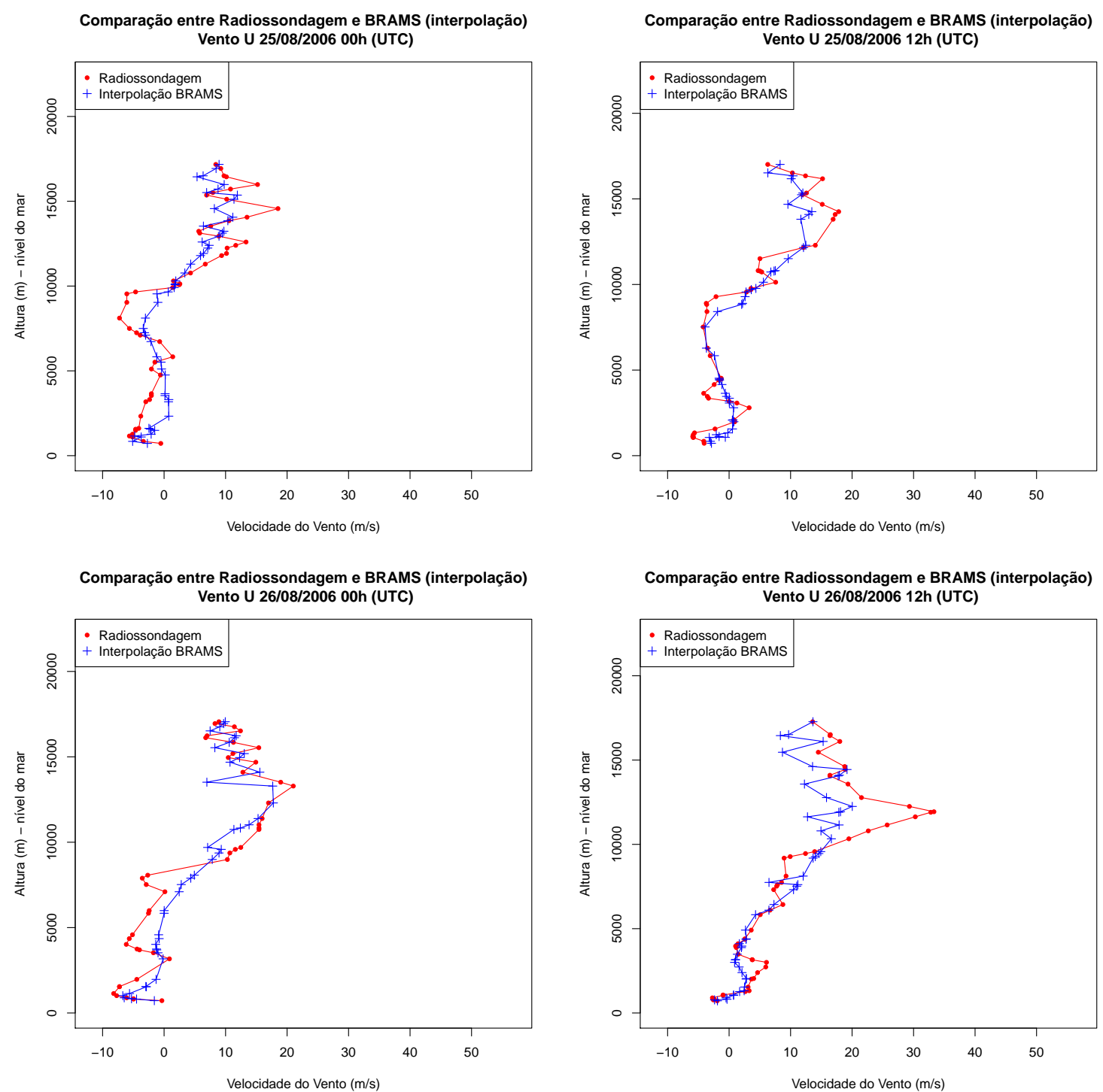

Figura 4.40: Comparação entre a Radiossondagem realizada no Campo de Marte e a interpolação dos resultados do BRAMS. Continuação 

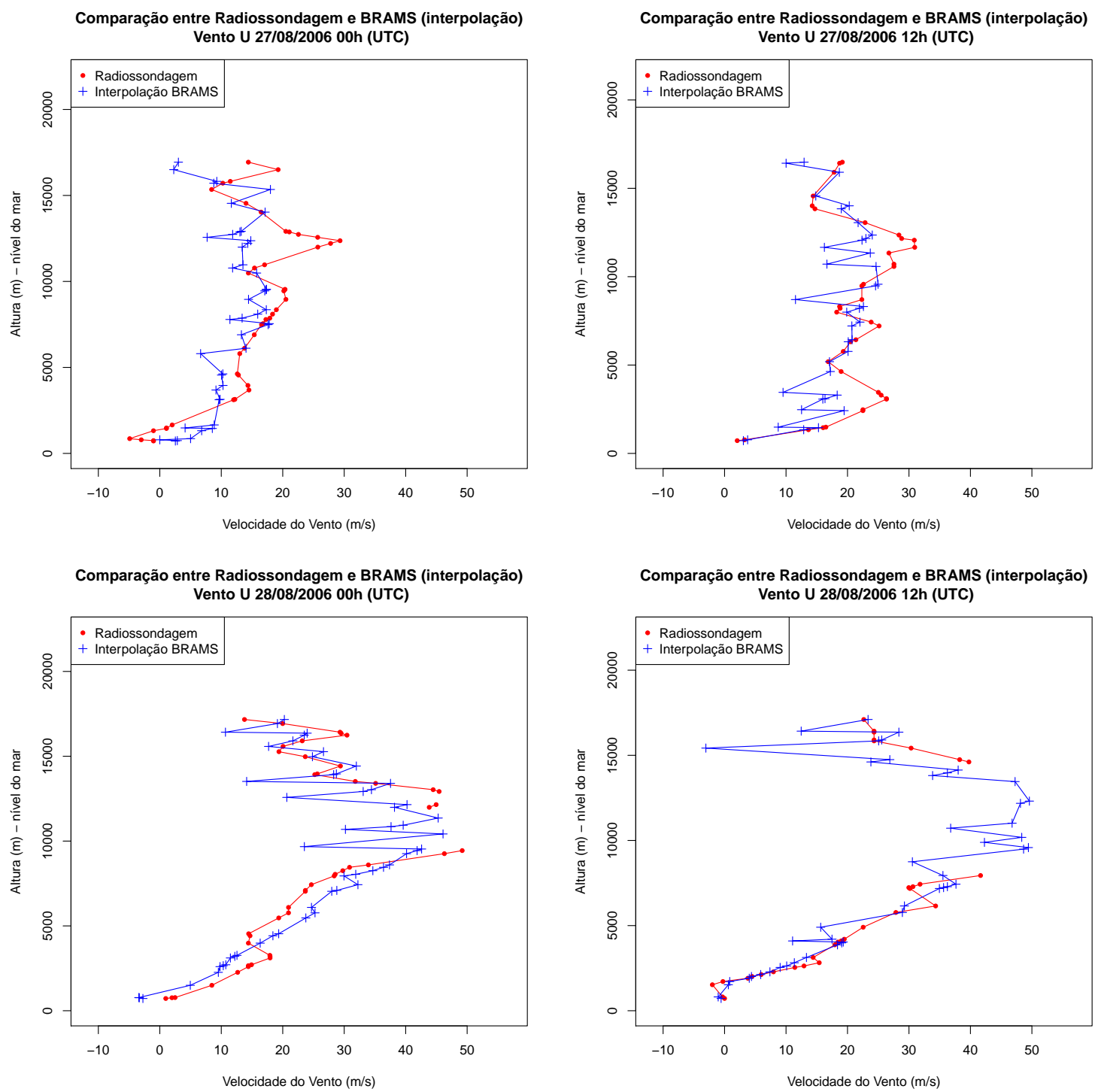

Figura 4.41: Comparação entre a Radiossondagem realizada no Campo de Marte e a interpolação dos resultados do BRAMS. Continuação 

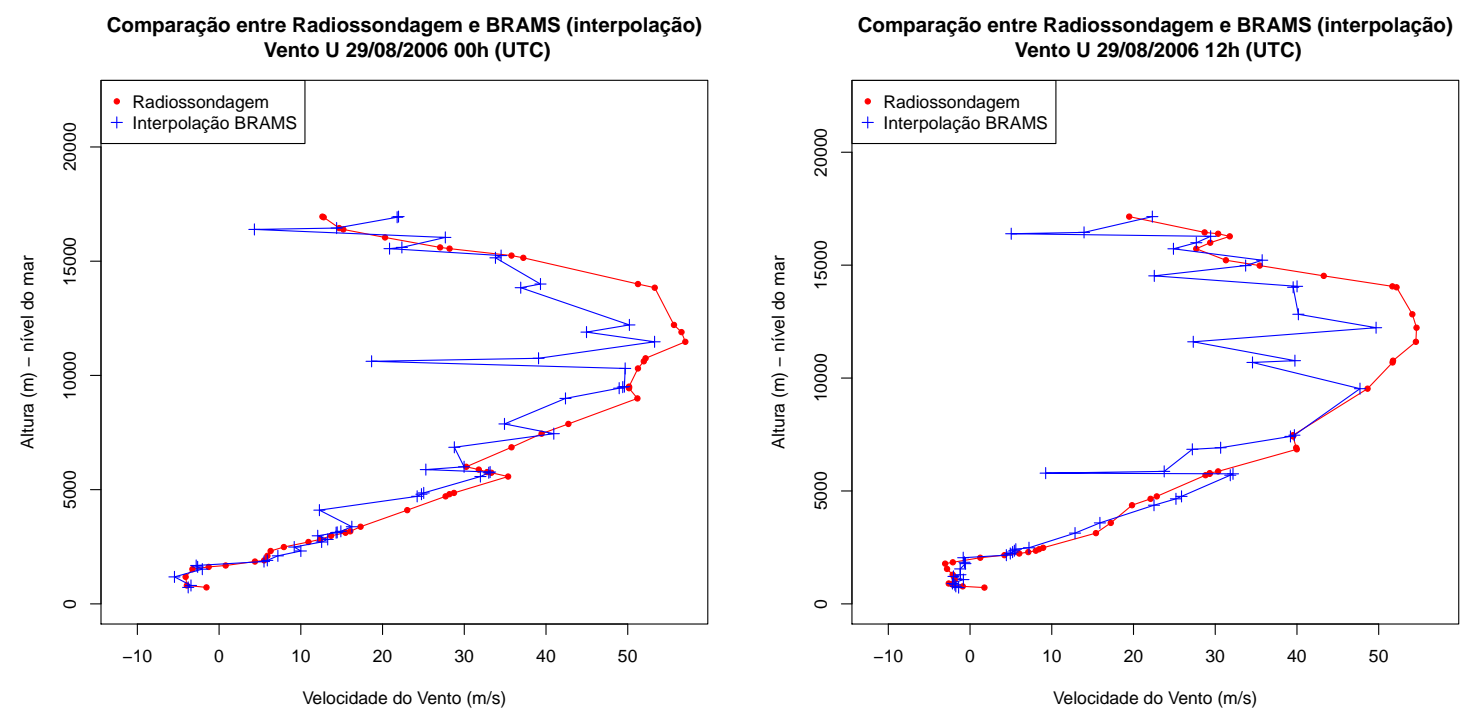

Figura 4.42: Comparação entre a Radiossondagem realizada no Campo de Marte e a interpolação dos resultados do BRAMS. Continuação

\begin{tabular}{llll}
\hline Data Hora & $\mathrm{N}$ & Correlação r & valor-P \\
\hline 23/08/2006 00h & 44 & 0,94 & $1,03 \mathrm{e}-21$ \\
$23 / 08 / 200612 \mathrm{~h}$ & 48 & 0,81 & $2,89 \mathrm{e}-12$ \\
$24 / 08 / 200600 \mathrm{~h}$ & 52 & 0,82 & $8,04 \mathrm{e}-14$ \\
$24 / 08 / 200612 \mathrm{~h}$ & 59 & 0,84 & $5,12 \mathrm{e}-17$ \\
$25 / 08 / 200600 \mathrm{~h}$ & 52 & 0,90 & $3,58 \mathrm{e}-19$ \\
$25 / 08 / 200612 \mathrm{~h}$ & 48 & 0,93 & $2,63 \mathrm{e}-22$ \\
$26 / 08 / 200600 \mathrm{~h}$ & 45 & 0,91 & $2,98 \mathrm{e}-18$ \\
$26 / 08 / 200612 \mathrm{~h}$ & 53 & 0,88 & $5,09 \mathrm{e}-18$ \\
$27 / 08 / 200600 \mathrm{~h}$ & 44 & 0,62 & $6,23 \mathrm{e}-06$ \\
$27 / 08 / 200612 \mathrm{~h}$ & 38 & 0,60 & $7,99 \mathrm{e}-05$ \\
$28 / 08 / 200600 \mathrm{~h}$ & 53 & 0,86 & $2,61 \mathrm{e}-14$ \\
$28 / 08 / 200612 \mathrm{~h}$ & 46 & 0,81 & $8,83 \mathrm{e}-09$ \\
$29 / 08 / 200600 \mathrm{~h}$ & 51 & 0,94 & $4,70 \mathrm{e}-24$ \\
$29 / 08 / 200612 \mathrm{~h}$ & 47 & 0,92 & $1,69 \mathrm{e}-19$ \\
Tudo & 680 & 0,92 & $8,72 \mathrm{e}-278$ \\
\hline
\end{tabular}

Tabela 4.17: Vento U: Correlação entre radiossondagem e simulação BRAMS interpolada para os níveis medidos

\subsubsection{Vento V}

A componente meridional do vento simulado foi pior do que a da componente zonal. As comparações nos dias 27/08/2006 UTC 12h e 28/08/2006 UTC 12h são os destaques negativos, com correlações 0,30 e -0,50, respectivamente. Entretanto, a tabela 4.19 indica que no geral as correlações foram boas, e apresentaram o valor de 0,67 no computo de todos os resultados.

Os gráficos das figuras 4.43 à 4.46, permitem visualizar o observado x simulado. Pode-se perceber que a amplitude das intensidades do vento meridional são menores que aquelas do 
vento regional (4.39 a 4.42). Parece-nos, assim, que as menores correlações aqui observadas podem ser fruto de incerteza numérica. Como já comentado com relação ao vento a 10 m, pode não haver uma distribuição equitativa da intensidade de um vetor em suas projeções, a mais fraca delas ficaria então com maior nível de incerteza. Isso também instabiliza correlações com esses dados.
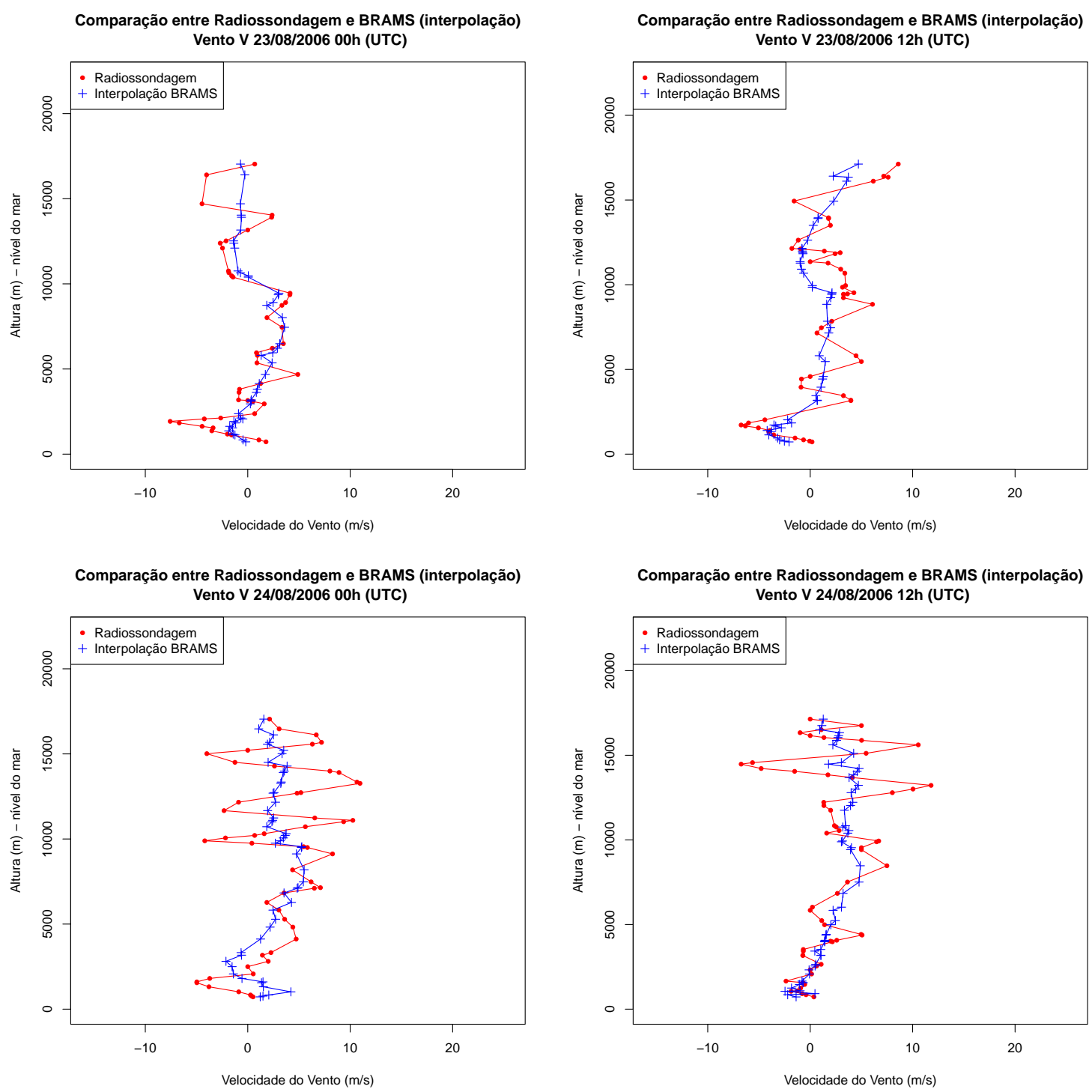

Figura 4.43: Comparação entre a Radiossondagem realizada no Campo de Marte e a interpolação dos resultados do BRAMS 

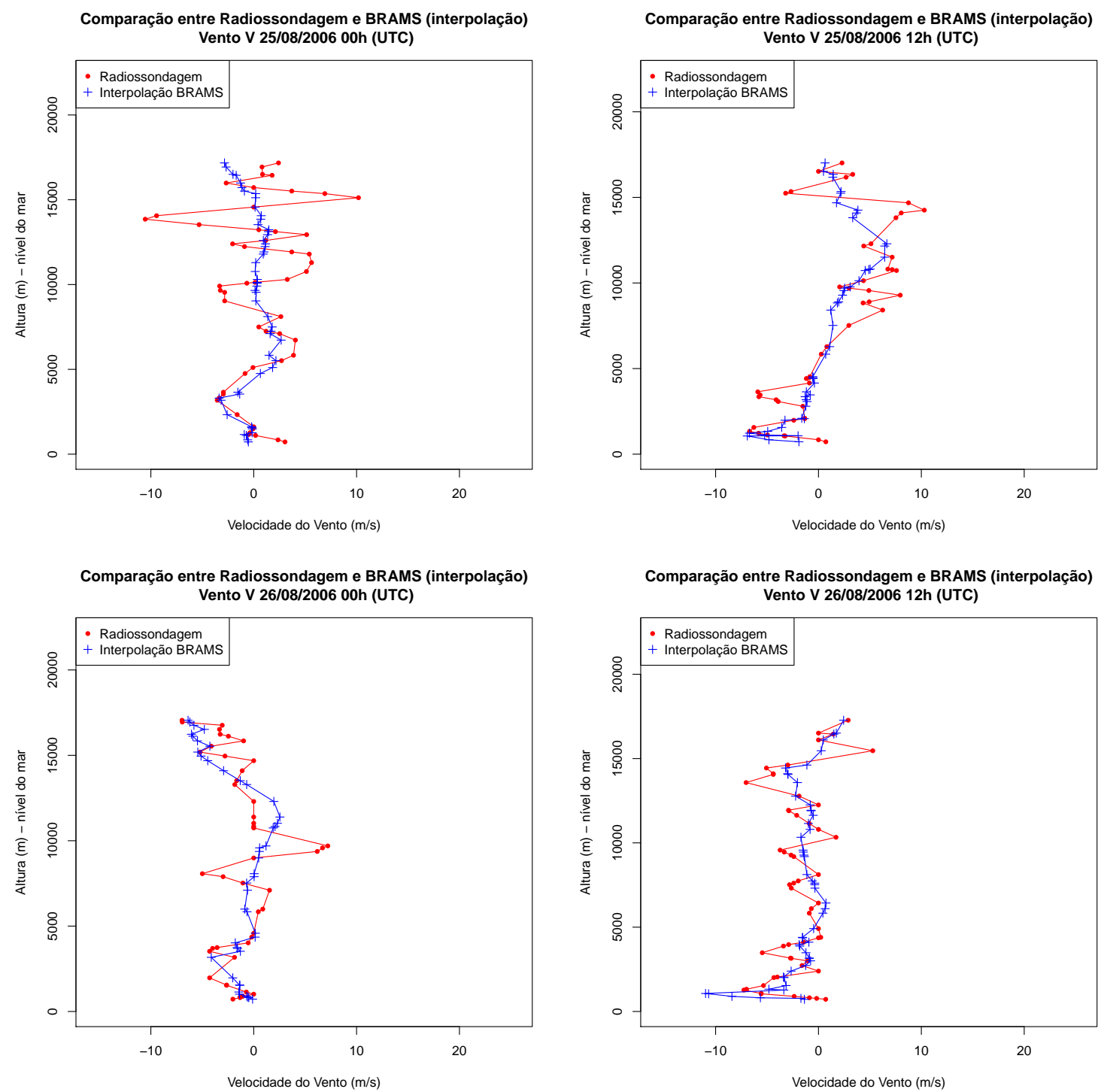

Figura 4.44: Comparação entre a Radiossondagem realizada no Campo de Marte e a interpolação dos resultados do BRAMS. Continuação 

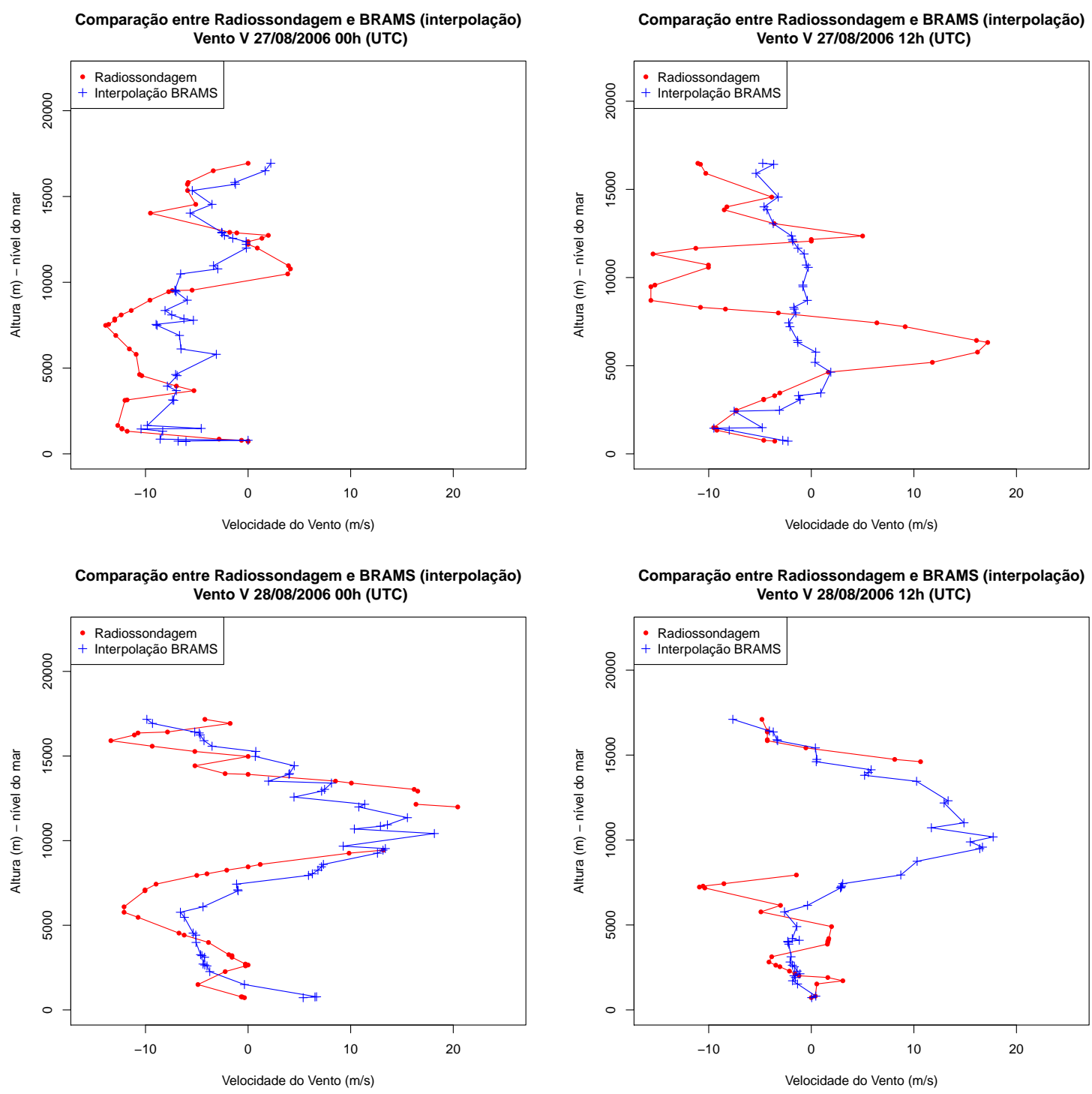

Figura 4.45: Comparação entre a Radiossondagem realizada no Campo de Marte e a interpolação dos resultados do BRAMS. Continuação 

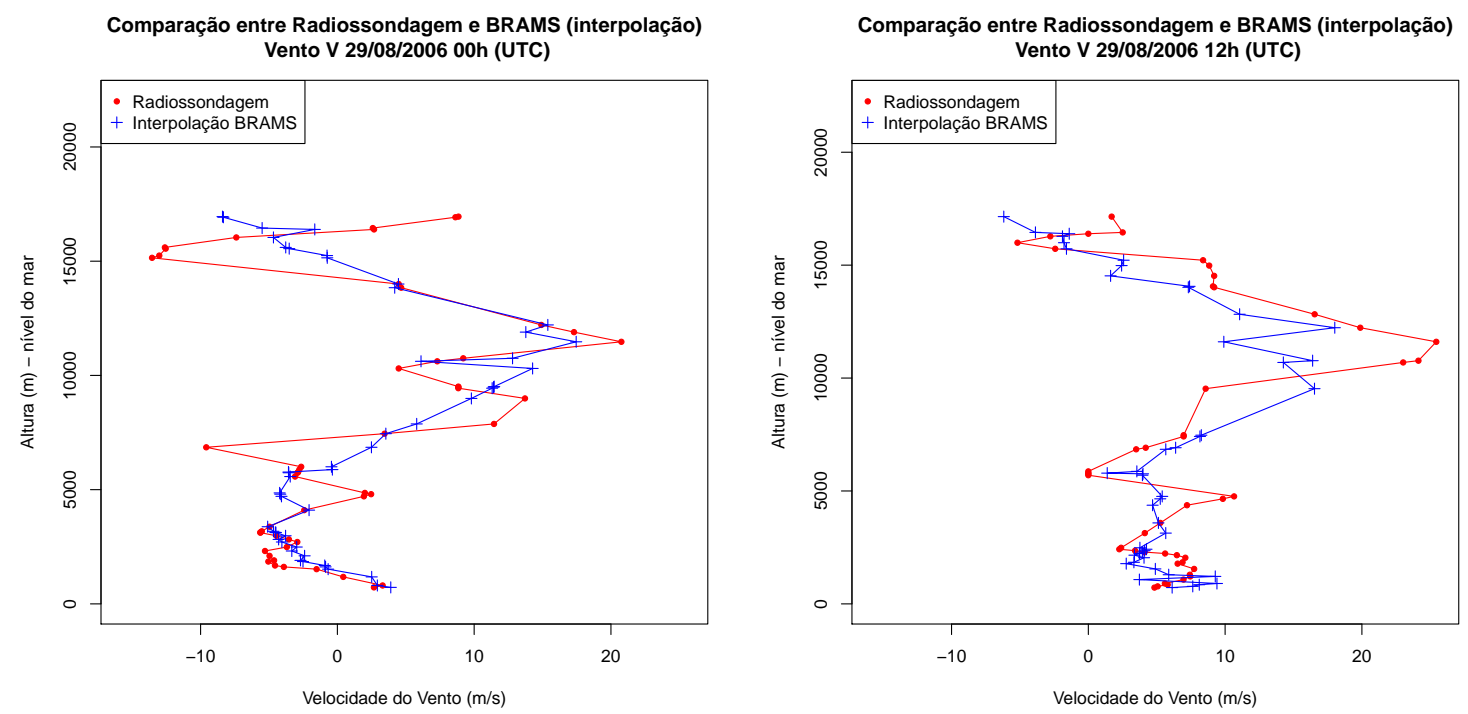

Figura 4.46: Comparação entre a Radiossondagem realizada no Campo de Marte e a interpolação dos resultados do BRAMS. Continuação

\begin{tabular}{llll}
\hline Data Hora & $\mathrm{N}$ & Correlação r & valor-P \\
\hline $23 / 08 / 200600 \mathrm{~h}$ & 44 & 0,74 & $7,67 \mathrm{e}-09$ \\
$23 / 08 / 200612 \mathrm{~h}$ & 48 & 0,79 & $3,55 \mathrm{e}-11$ \\
$24 / 08 / 200600 \mathrm{~h}$ & 52 & 0,34 & $1,49 \mathrm{e}-02$ \\
$24 / 08 / 200612 \mathrm{~h}$ & 59 & 0,45 & $3,66 \mathrm{e}-04$ \\
$25 / 08 / 200600 \mathrm{~h}$ & 52 & 0,21 & $1,44 \mathrm{e}-01$ \\
$25 / 08 / 200612 \mathrm{~h}$ & 48 & 0,78 & $5,13 \mathrm{e}-11$ \\
$26 / 08 / 200600 \mathrm{~h}$ & 45 & 0,57 & $4,24 \mathrm{e}-05$ \\
$26 / 08 / 200612 \mathrm{~h}$ & 53 & 0,54 & $3,14 \mathrm{e}-05$ \\
$27 / 08 / 200600 \mathrm{~h}$ & 44 & 0,63 & $5,43 \mathrm{e}-06$ \\
$27 / 08 / 200612 \mathrm{~h}$ & 38 & 0,29 & $8,19 \mathrm{e}-02$ \\
$28 / 08 / 200600 \mathrm{~h}$ & 53 & 0,70 & $7,34 \mathrm{e}-08$ \\
$28 / 08 / 200612 \mathrm{~h}$ & 46 & $-0,13$ & $4,74 \mathrm{e}-01$ \\
$29 / 08 / 200600 \mathrm{~h}$ & 51 & 0,69 & $1,81 \mathrm{e}-08$ \\
$29 / 08 / 200612 \mathrm{~h}$ & 47 & 0,74 & $2,68 \mathrm{e}-09$ \\
Tudo & 680 & 0,68 & $5,06 \mathrm{e}-90$
\end{tabular}

Tabela 4.18: Vento V: Correlação entre radiossondagem e simulação BRAMS interpolada para os níveis medidos 


\subsubsection{Direção do Vento}
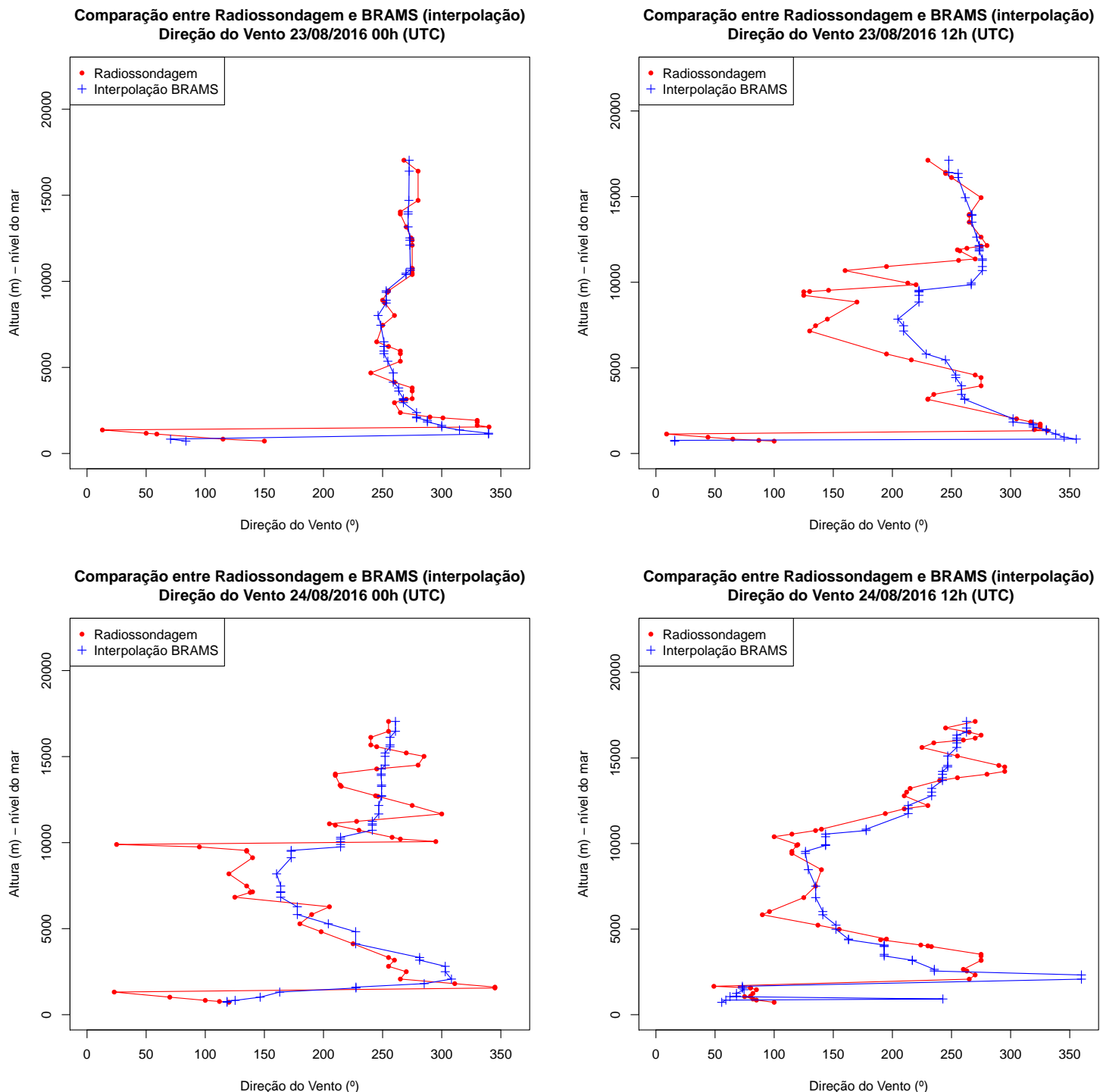

Figura 4.47: Comparação entre a Radiossondagem realizada no Campo de Marte e a interpolação dos resultados do BRAMS 

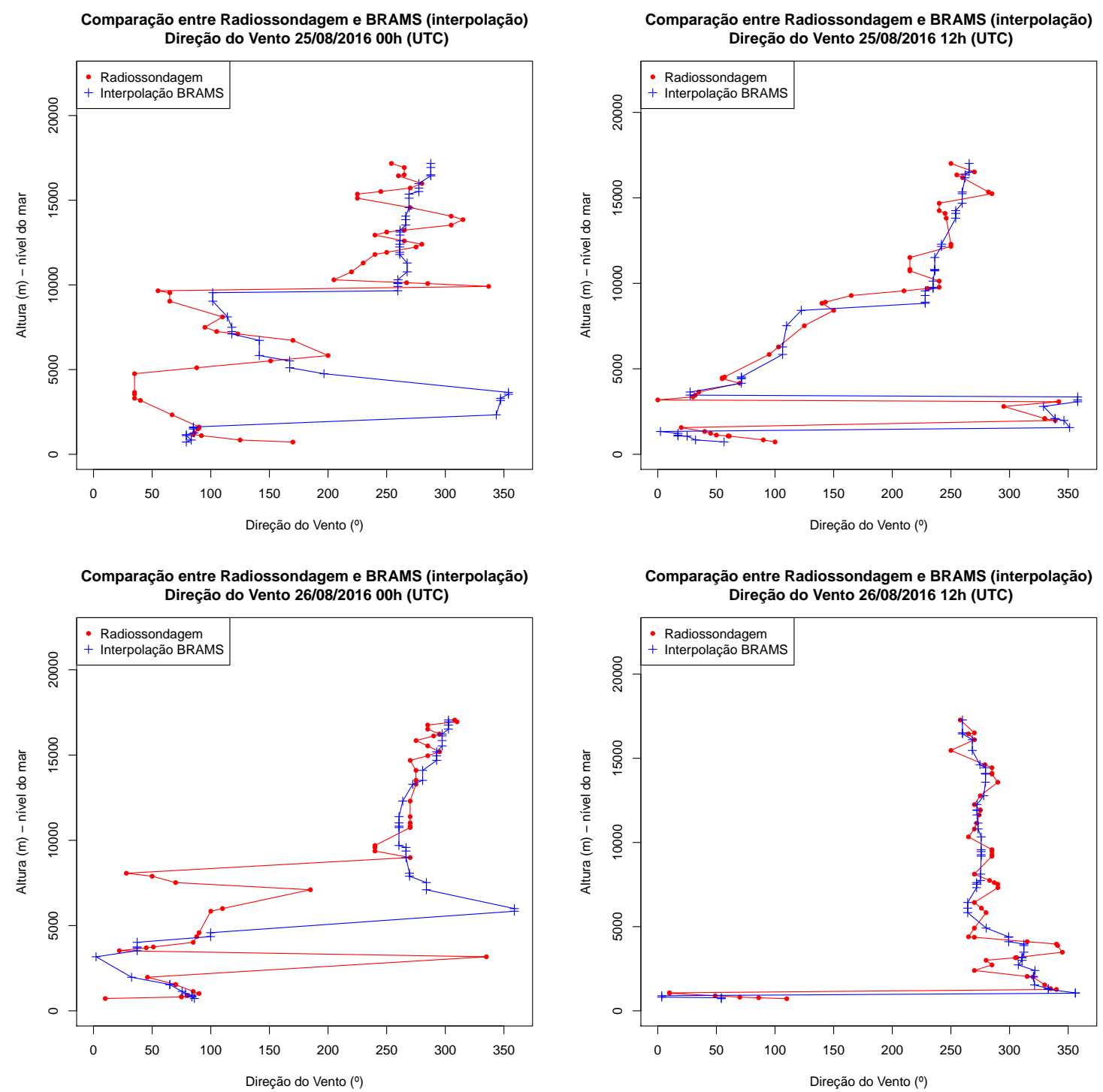

Figura 4.48: Comparação entre a Radiossondagem realizada no Campo de Marte e a interpolação dos resultados do BRAMS. Continuação 

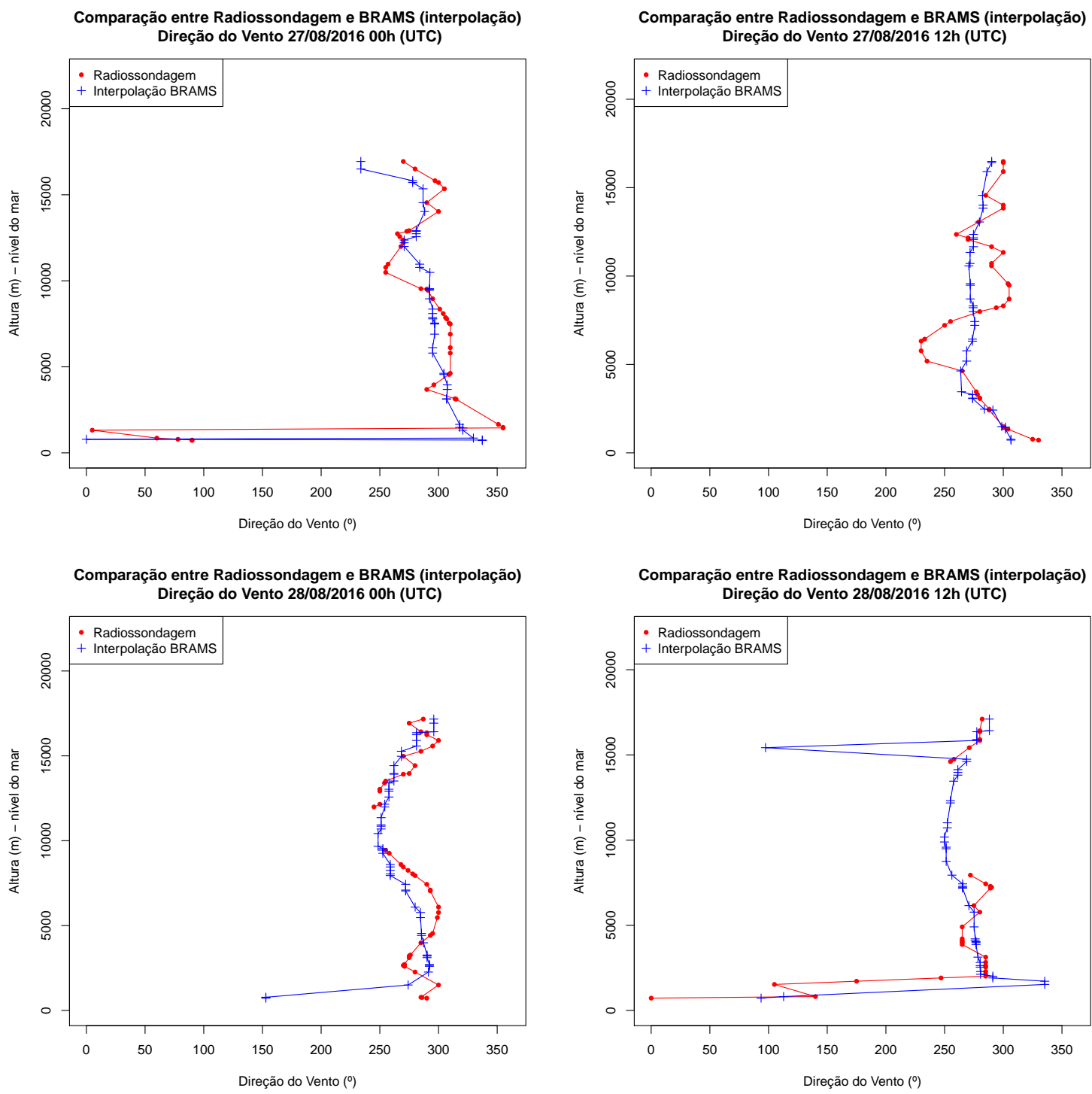

Figura 4.49: Comparação entre a Radiossondagem realizada no Campo de Marte e a interpolação dos resultados do BRAMS. Continuação 

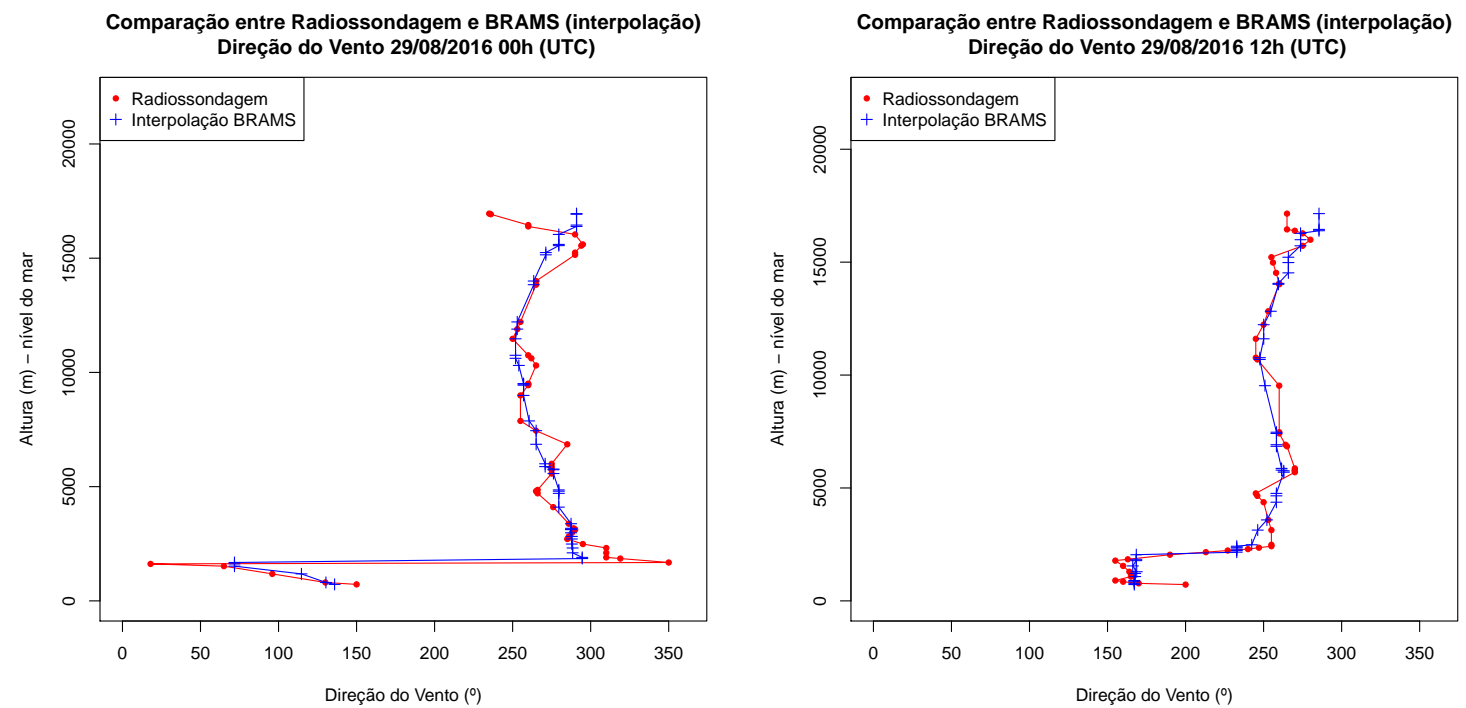

Figura 4.50: Comparação entre a Radiossondagem realizada no Campo de Marte e a interpolação dos resultados do BRAMS. Continuação 


\subsubsection{Magnitude do Vento}
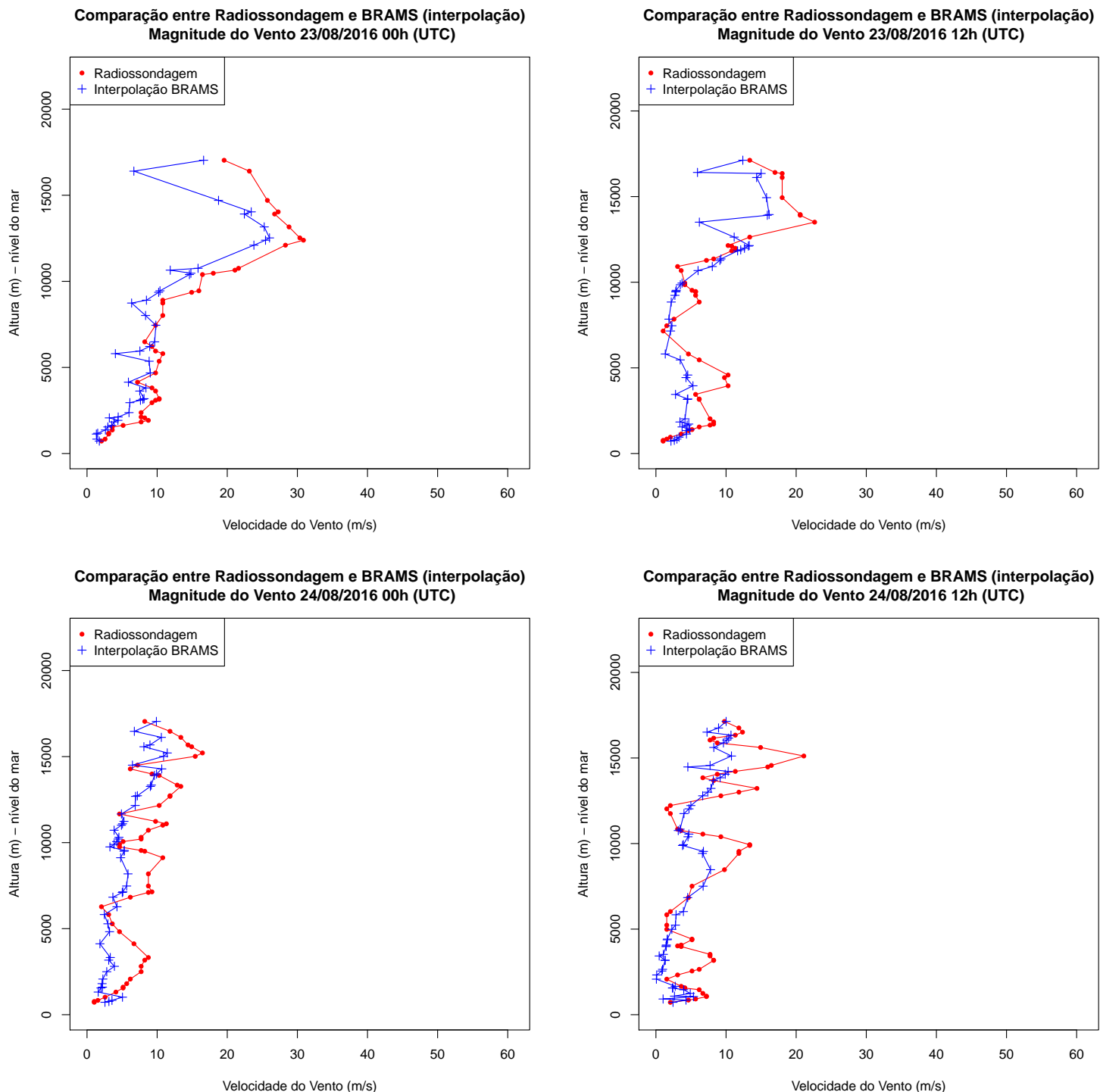

Figura 4.51: Comparação entre a Radiossondagem realizada no Campo de Marte e a interpolação dos resultados do BRAMS 

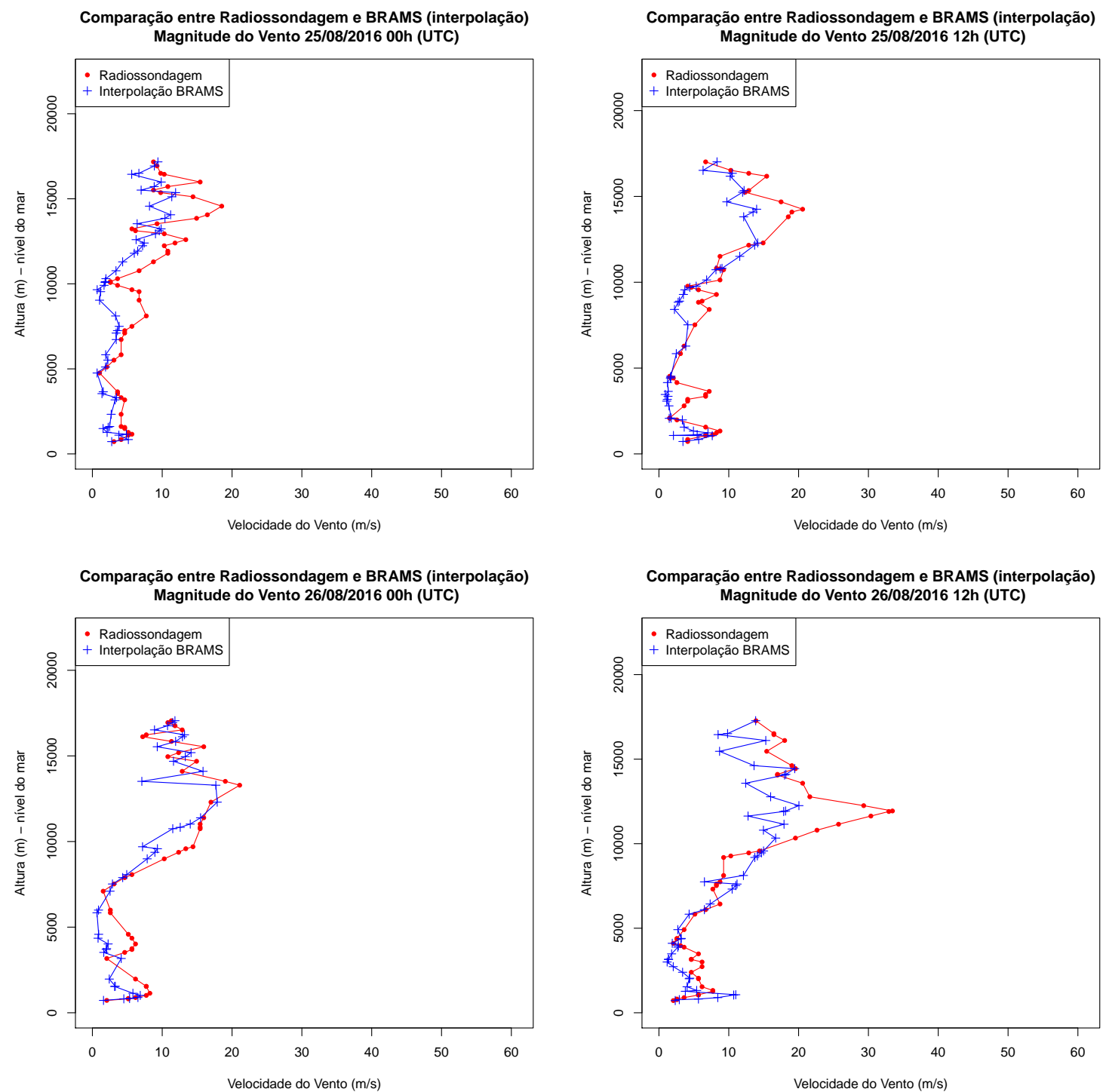

Figura 4.52: Comparação entre a Radiossondagem realizada no Campo de Marte e a interpolação dos resultados do BRAMS. Continuação 

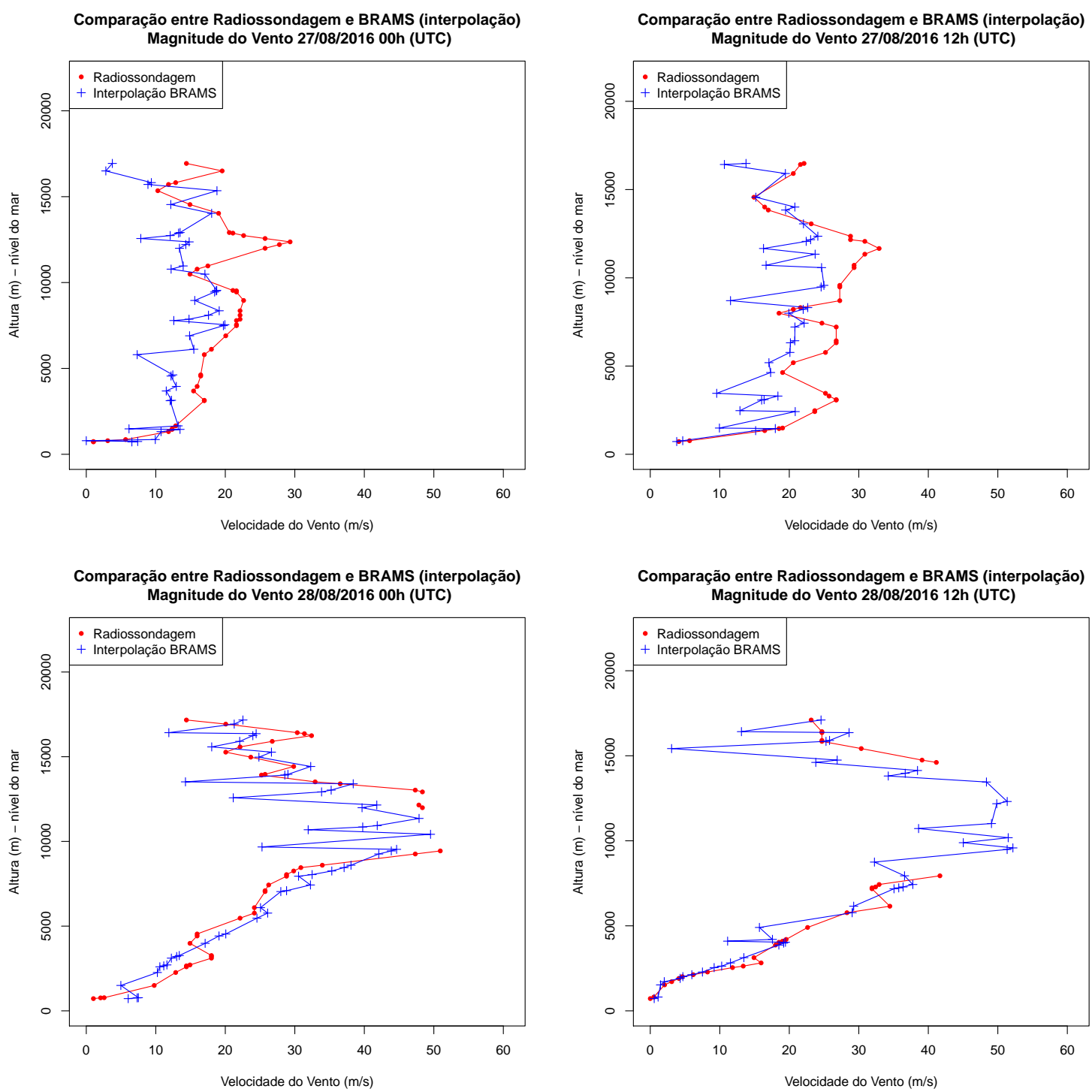

Figura 4.53: Comparação entre a Radiossondagem realizada no Campo de Marte e a interpolação dos resultados do BRAMS. Continuação 

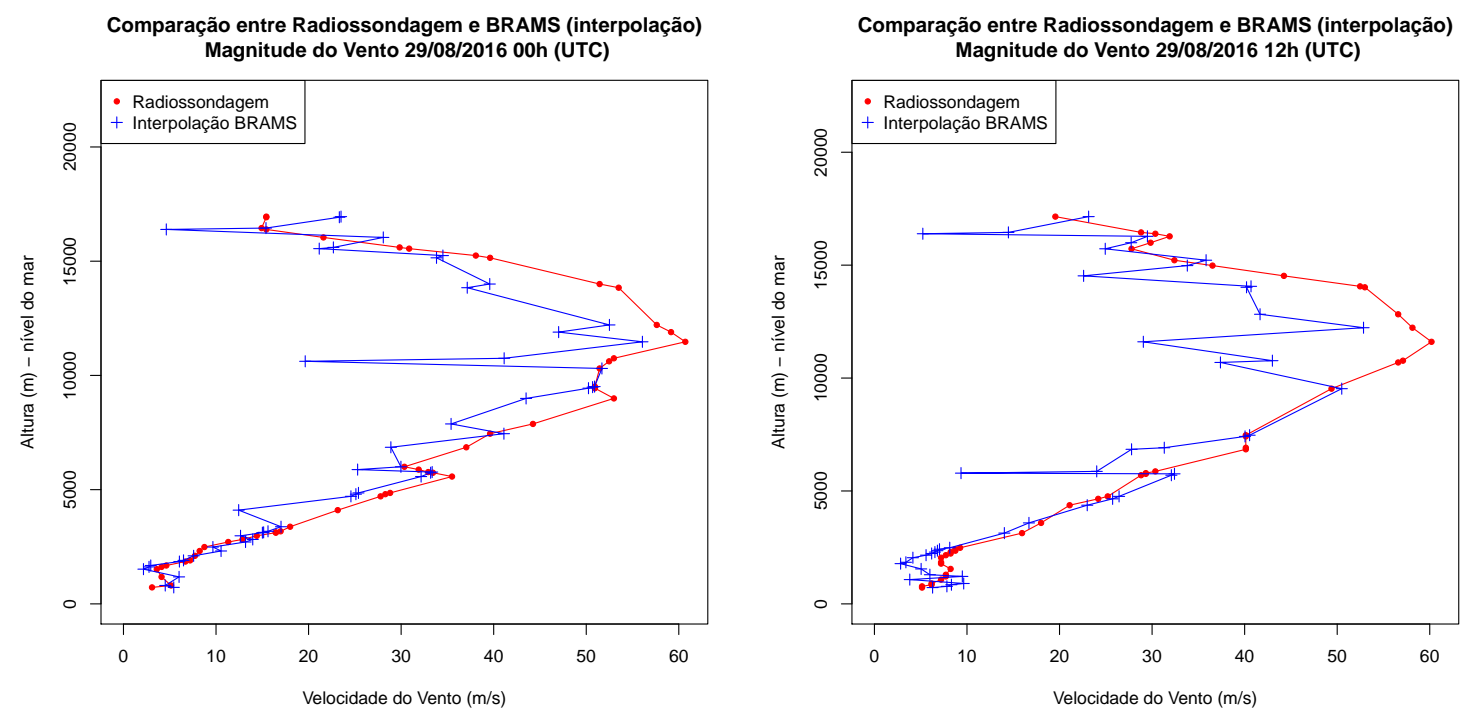

Figura 4.54: Comparação entre a Radiossondagem realizada no Campo de Marte e a interpolação dos resultados do BRAMS. Continuação

\begin{tabular}{llll}
\hline Data Hora & $\mathrm{N}$ & Correlação r & valor-P \\
\hline $23 / 08 / 200600 \mathrm{~h}$ & 44 & 0,94 & $3,86 \mathrm{e}-21$ \\
$23 / 08 / 200612 \mathrm{~h}$ & 48 & 0,77 & $1,68 \mathrm{e}-10$ \\
$24 / 08 / 200600 \mathrm{~h}$ & 52 & 0,72 & $1,79 \mathrm{e}-09$ \\
$24 / 08 / 200612 \mathrm{~h}$ & 59 & 0,60 & $5,41 \mathrm{e}-07$ \\
$25 / 08 / 200600 \mathrm{~h}$ & 52 & 0,79 & $5,47 \mathrm{e}-12$ \\
$25 / 08 / 200612 \mathrm{~h}$ & 48 & 0,85 & $1,93 \mathrm{e}-14$ \\
$26 / 08 / 200600 \mathrm{~h}$ & 45 & 0,80 & $4,94 \mathrm{e}-11$ \\
$26 / 08 / 200612 \mathrm{~h}$ & 53 & 0,82 & $6,08 \mathrm{e}-14$ \\
$27 / 08 / 200600 \mathrm{~h}$ & 44 & 0,52 & $2,83 \mathrm{e}-04$ \\
$27 / 08 / 200612 \mathrm{~h}$ & 38 & 0,59 & $8,24 \mathrm{e}-05$ \\
$28 / 08 / 200600 \mathrm{~h}$ & 53 & 0,85 & $1,79 \mathrm{e}-13$ \\
$28 / 08 / 200612 \mathrm{~h}$ & 46 & 0,85 & $4,75 \mathrm{e}-10$ \\
$29 / 08 / 200600 \mathrm{~h}$ & 51 & 0,93 & $3,22 \mathrm{e}-23$ \\
$29 / 08 / 200612 \mathrm{~h}$ & 47 & 0,89 & $8,30 \mathrm{e}-17$ \\
Tudo & 680 & 0,91 & $7,64 \mathrm{e}-258$ \\
\hline
\end{tabular}

Tabela 4.19: Magnitude do Vento: Correlação entre radiossondagem e simulação BRAMS interpolada para os níveis medidos

\subsection{Dispersão de Poluentes}

\subsubsection{CO}

As tabelas 4.20 e 4.21 mostram a avaliação de performance do sistema de modelos BRAMS/SPRAY que empregamos na simulação de concentrações de CO deste trabalho, comparando-as com medidas efetuadas em estações da CETESB. A estação Osasco teve poucas medidas no período analisado e está sendo registrada apenas para comparações qualitativas sobre os dados 
Tabela 4.20: Parâmetros estatísticos para $\mathrm{CO}$ em várias estações.

\begin{tabular}{llllllll}
\hline Estação & $\overline{C O}_{\text {sim }}$ & $\overline{C O}_{\text {obs }}$ & $\sigma_{\text {sim }}$ & $\sigma_{\text {obs }}$ & $\mathrm{RMSE}$ & NRMSE & $\overline{\overline{s i m}}$ \\
\hline \multirow{3}{*}{ Cerqueira César } & $476 m^{-3}$ & $\mu g m^{-3}$ & $\mu g m^{-3}$ & $\mu g m^{-3}$ & $\mu g m^{-3}$ & $\%$ & \\
Centro & 1674,1 & 3698,7 & 889,9 & 4728,6 & 531,3 & 2,8 \\
Congonhas & 5846,2 & 1764,2 & 4746,0 & 990,4 & 6464,4 & 652,7 & 3,3 \\
Osasco & 3963,7 & 2333,8 & 3172,7 & 1141,4 & 3715,4 & 325,5 & 1,7 \\
Ibirapuera & 3165,8 & 2738,7 & 2562,8 & 1019,6 & 2707,5 & 265,5 & 1,2 \\
Pedro II & 4328,8 & 1386,6 & 3542,7 & 781,0 & 4481,5 & 573,8 & 3,1 \\
Pinheiros & 6018,8 & 1520,4 & 4833,0 & 1184,4 & 6807,1 & 574,7 & 4,0 \\
Santo Amaro & 4792,2 & 2232,7 & 3673,6 & 1397,4 & 4193,6 & 300,1 & 2,1 \\
Santo André & 3013,4 & 1262,8 & 2396,6 & 918,7 & 2833,0 & 308,4 & 2,4 \\
São Caetano & 1041,5 & 1355,9 & 773,6 & 890,4 & 861,4 & 96,8 & 0,8 \\
Taboão da Serra & 3192,2 & 2410,4 & 2569,0 & 1955,6 & 2736,9 & 140,0 & 1,3 \\
\hline
\end{tabular}

Tabela 4.21: Parâmetros estatísticos para CO em várias estações (Continuação)

\begin{tabular}{lllllll}
\hline Estação & $\mathrm{n}$ & $\mathrm{FB}$ & $\mathrm{NMSE}$ & $\mathrm{FAC2}$ & $\mathrm{R}$ & valor-P \\
\hline Cerqueira César & 92 & $-0,94$ & 2,80 & 0,41 & 0,12 & $2,75 \mathrm{e}-01$ \\
Centro & 92 & $-1,07$ & 4,05 & 0,34 & $-0,16$ & $1,22 \mathrm{e}-01$ \\
Congonhas & 92 & $-0,49$ & 1,49 & 0,38 & $-0,04$ & $6,90 \mathrm{e}-01$ \\
Osasco & 28 & 0,11 & 0,85 & 0,18 & 0,03 & $8,71 \mathrm{e}-01$ \\
Ibirapuera & 92 & $-1,02$ & 3,35 & 0,42 & 0,30 & $3,26 \mathrm{e}-03$ \\
Pedro II & 76 & $-1,21$ & 5,06 & 0,37 & 0,27 & $1,73 \mathrm{e}-02$ \\
Pinheiros & 94 & $-0,71$ & 1,64 & 0,48 & 0,37 & $1,98 \mathrm{e}-04$ \\
Santo Amaro & 92 & $-0,78$ & 2,11 & 0,55 & 0,19 & $7,14 \mathrm{e}-02$ \\
Santo André & 92 & 0,25 & 0,53 & 0,57 & 0,54 & $2,87 \mathrm{e}-08$ \\
São Caetano & 53 & 0,23 & 0,39 & 0,60 & 0,77 & $1,67 \mathrm{e}-11$ \\
Taboão da Serra & 85 & $-0,23$ & 0,97 & 0,38 & 0,30 & $5,94 \mathrm{e}-03$ \\
\hline
\end{tabular}

disponíveis. As discussões a seguir não a incluem.

As estações de São Caetano, Santo André e Santo Amaro, apresentaram bons números para FAC2 com mais de $50 \%$ das concentrações simuladas dentro de um fator 2 . No geral, as simulação para as concentrações de CO nas estações de Taboão da Serra, São Caetano, Santo André, Pinheiros, Pedro II, Ibirapuera, Congonhas, Centro, e Cerqueira César estão dentro do critério já discutido na sessão $3.4(F A C \leqslant 0,3)$.

Para as estações de São Caetano e Santo André, $|\mathrm{FB}|$ mostrou-se baixo, não maior do que 0,23, sendo os valores simulados para São Caetano e Santo André foram subestimados em relação aos observados, porém, abaixo dos critérios estabelecidos na sessão 3.4. O Viés Fracional negativo indica superestimação da simulação em relação aos valores observados. As estações de Cerqueira César, Centro, Pedro II, Ibirapuera, Pinheiros e Santo Amaro, apresentaram um FB > 0,67, ou seja, com a média dos valores simulados sendo maior que o dobro da dos valores simulados. Todas estas estações apresentaram, também uma razão $\frac{\overline{s i m}}{\overline{o b s}}$ acima de 2 , e RMSE acima de $3 \sigma_{o b s}$. Isto pode ser explicado pelo fato destas estações estarem em locais em 
que o modelo prevê uma emissão de CO maior do que a observada, dada a baixa resolução da fonte utilizada pelo mesmo. A estação de Ibirapuera fica dentro do maior parque da cidade, a estação Pedro II, embora na região central, fica, também dentro de um parque. A estação de Pinheiros fica na borda de um bairro rico, rodeado de mansões, explicando os dados para estação similarmente às outras, embora a s obre-predição tenha sido menor.

O critério de aceitação para NMSE é $N M S E \leqslant 6$.

As estações de Pinheiros, São Caetano e Santo André apresentaram boas correlações com bons níveis de significância. A estação de Congonhas apresenta fraca correlação negativa, e a hipótese alternativa para esta não é válida (prevaleceu a hipótese nula, pois seu valor-p é maior que o nível de significância $\alpha \leqslant 0,05$ exigido como critério.

A performance da simulação nos parâmetros nas tabelas 4.20 e 4.20 atenderam aos critérios para validação discutidos na sessão 3.4.1 para a estações Ibirapuera, Pedro II, Pinheiros, Santo Amaro, Santo André, São Caetano e Taboão da Serra. Observou-se que as estações da RMSP um pouco mais distantes do centro de maior emissão da fonte apresentaram resultados melhores para NRMSE e na comparação entre os desvios padrões simulado e observado.

É possível visualizar graficamente nas séries temporais e gráficos de espalhamento das estações o que foi discutido acima para as tabelas 4.20, e 4.21 a partir das figuras 4.55 a 4.61 .

Os gráficos de espalhamento para São Caetano e Santo André apresentam pontos simulados próximos à reta "1:1", indicando pouca dispersão e ligeira sobrestimava. A série temporal da simulação é próxima do gráfico para as concentrações observadas.

Observa-se, também, pelos gráficos, correlação entre simulação e observação para as Estações de Ibirapuera, como também como a simulação apresentou uma considerável sobrestimativa (mesmo que estas estações satisfaçam os critérios para NMSE e FAC2, como anteriormente discutido. 

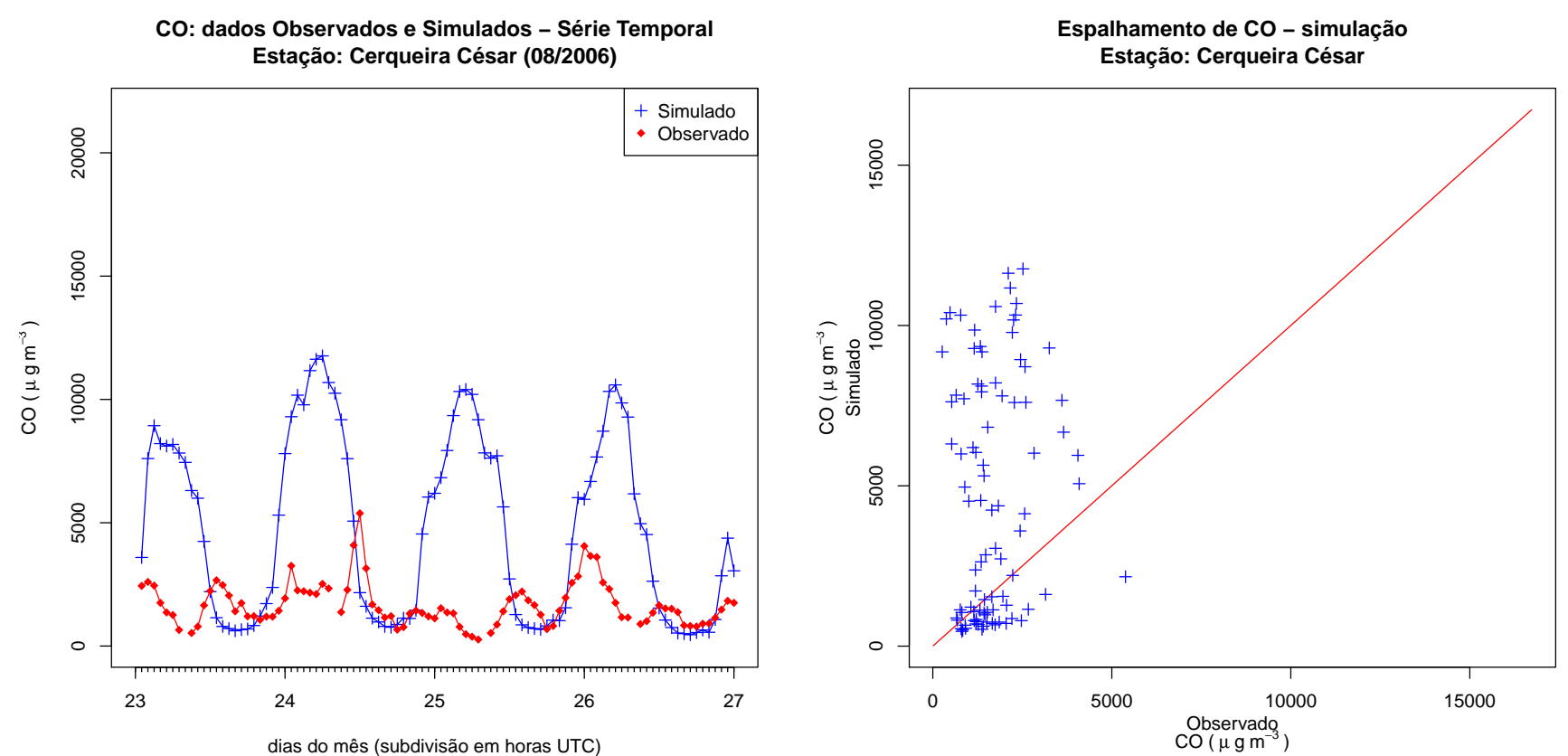

Figura 4.55: Comparação das concentrações de CO simuladas pelo modelo acoplado BRAMS/SPRAY e observadas nas estações 

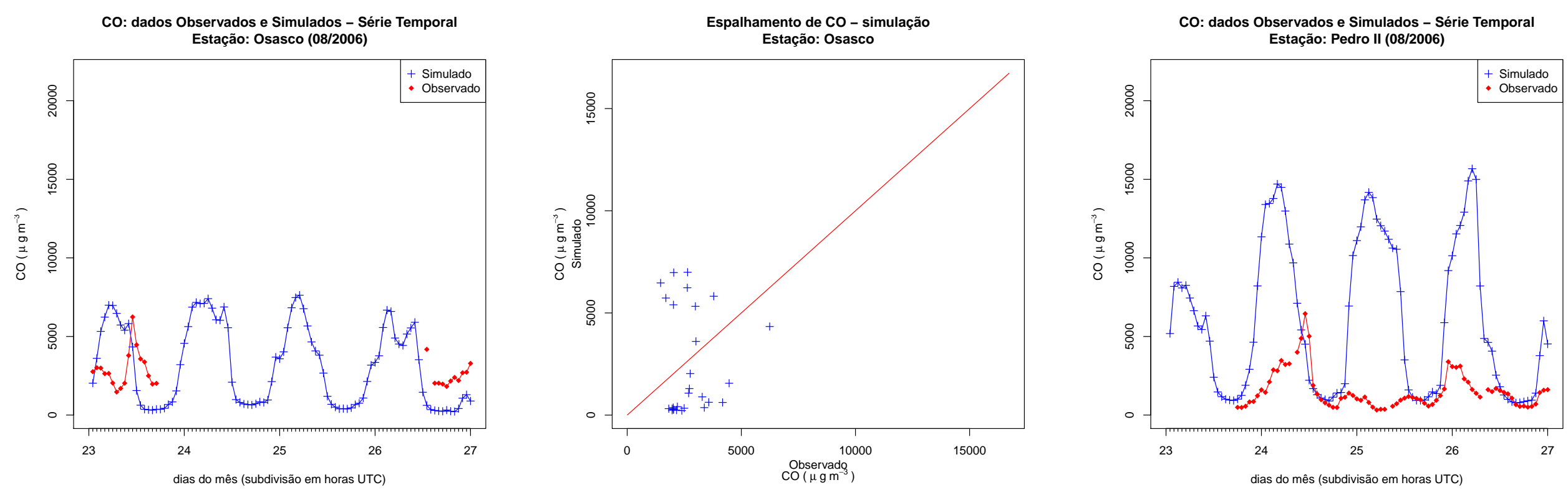

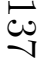

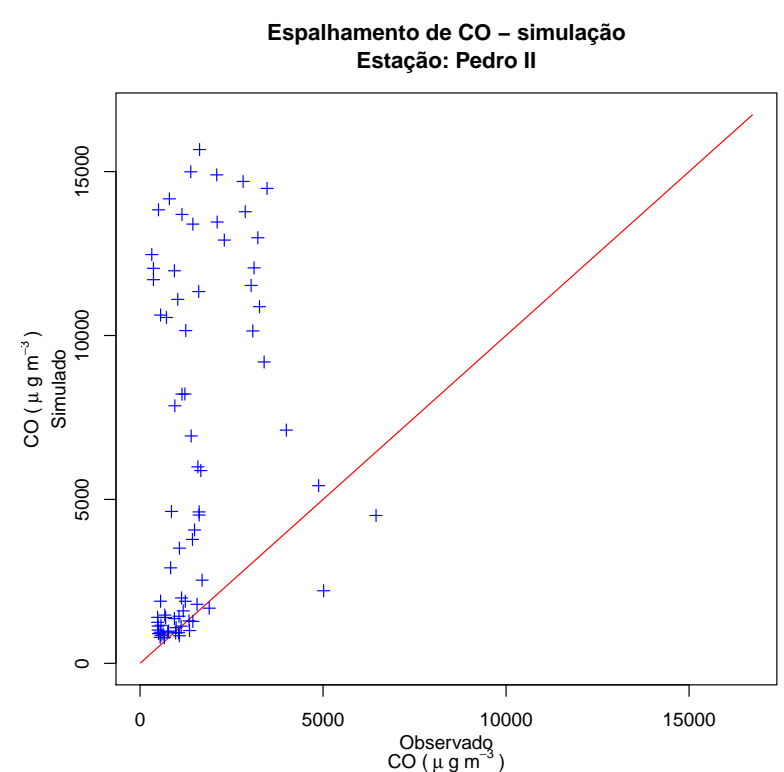

Figura 4.56: Comparação das concentrações de CO simuladas pelo modelo acoplado BRAMS/SPRAY e observadas nas estações - Parte 2 

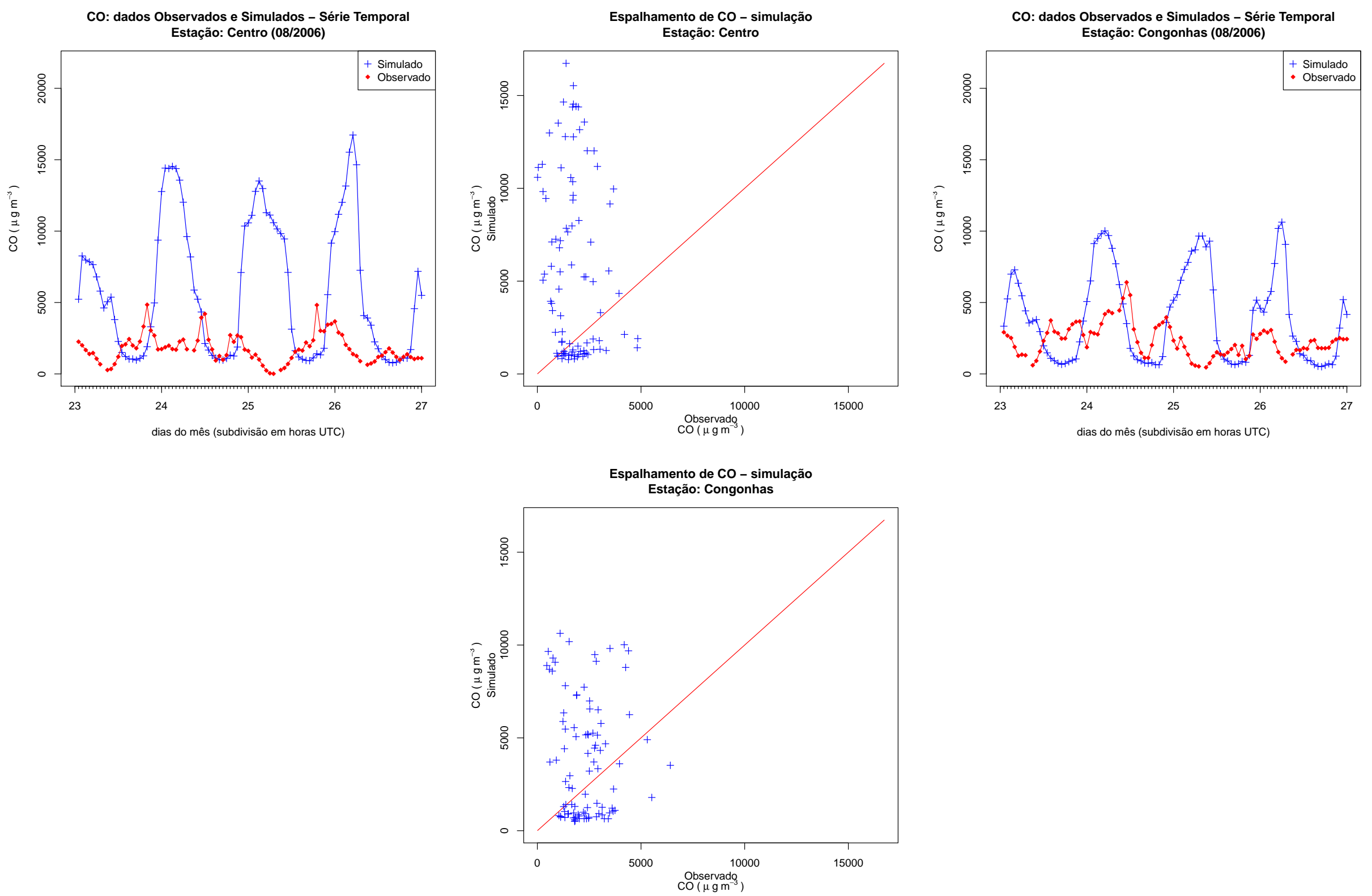

Figura 4.57: Comparação das concentrações de CO simuladas pelo modelo acoplado BRAMS/SPRAY e observadas nas estações. Continuação 

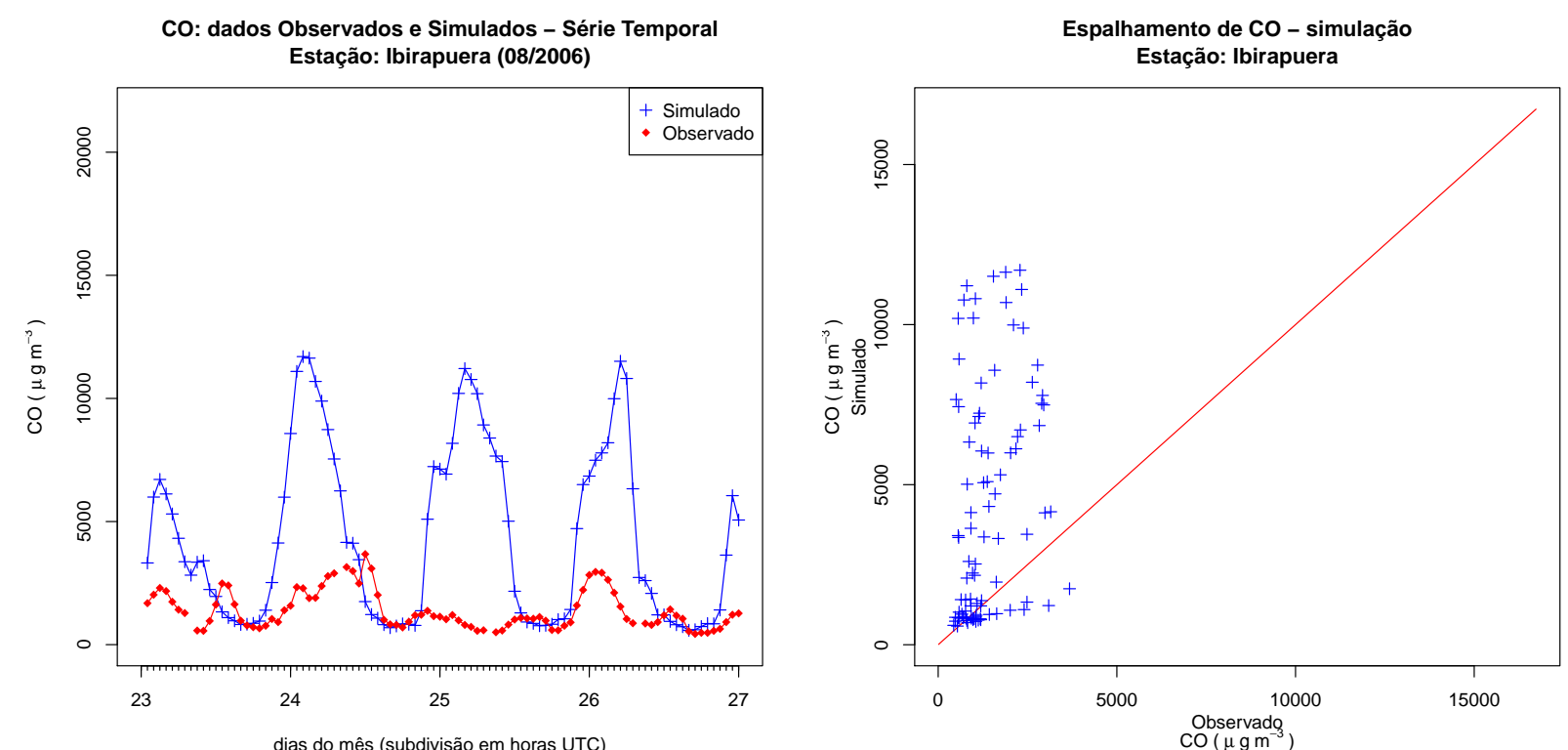

Figura 4.58: Comparação das concentrações de CO simuladas pelo modelo acoplado BRAMS/SPRAY e observadas nas estações. Continuação 

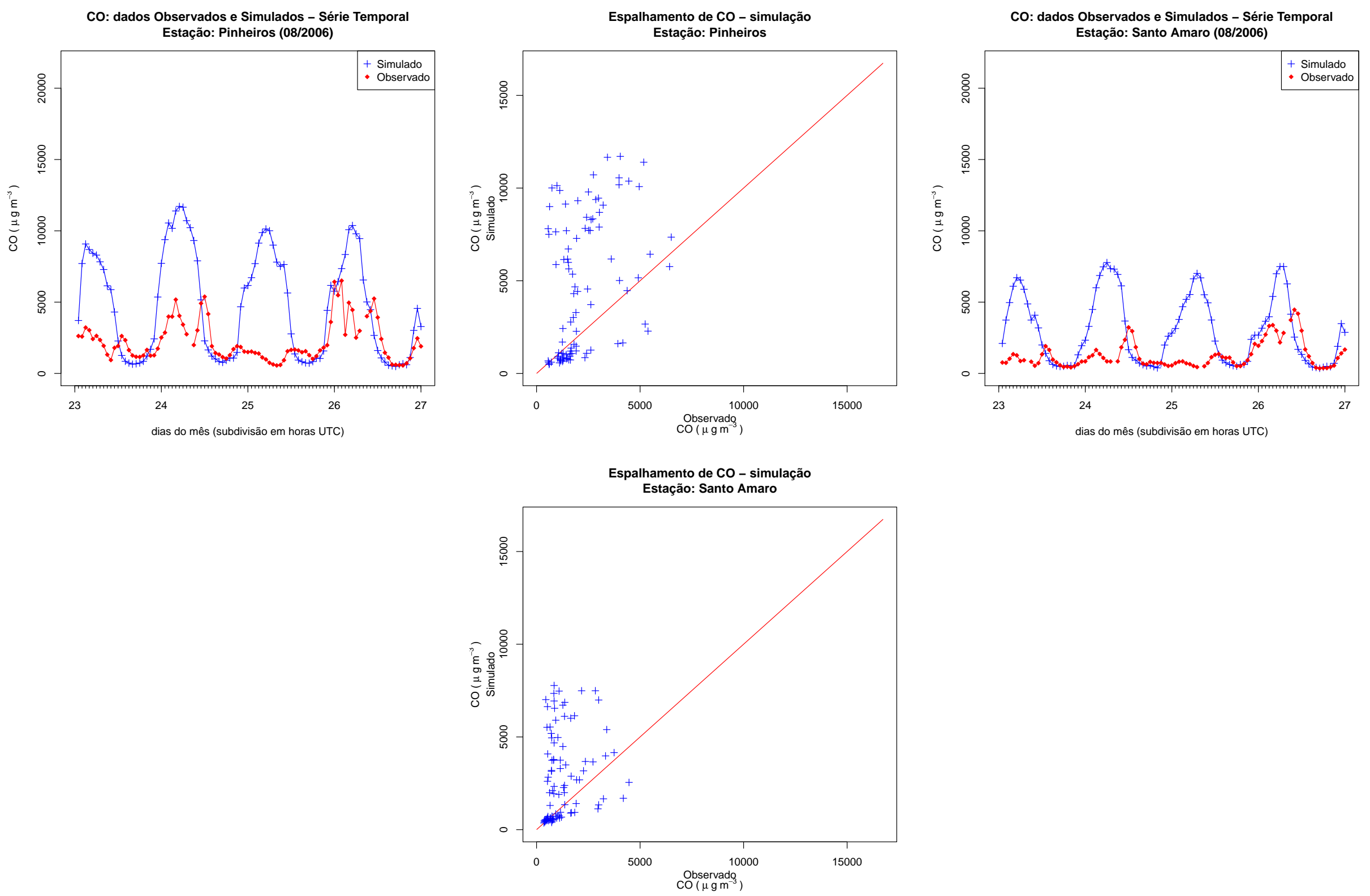

Figura 4.59: Comparação das concentrações de CO simuladas pelo modelo acoplado BRAMS/SPRAY e observadas nas estações. Continuação 

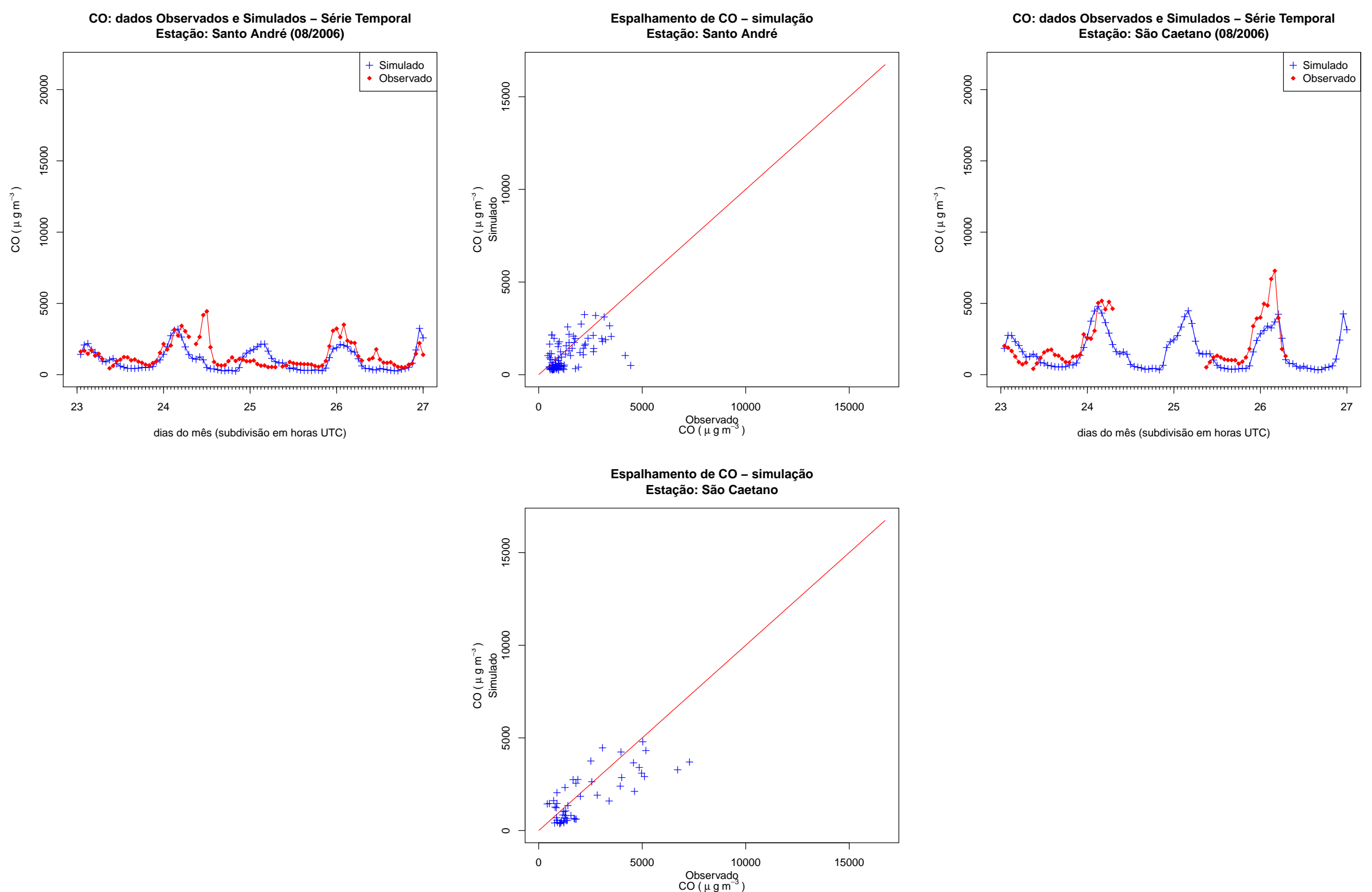

Figura 4.60: Comparação das concentrações de CO simuladas pelo modelo acoplado BRAMS/SPRAY e observadas nas estações. Continuação 

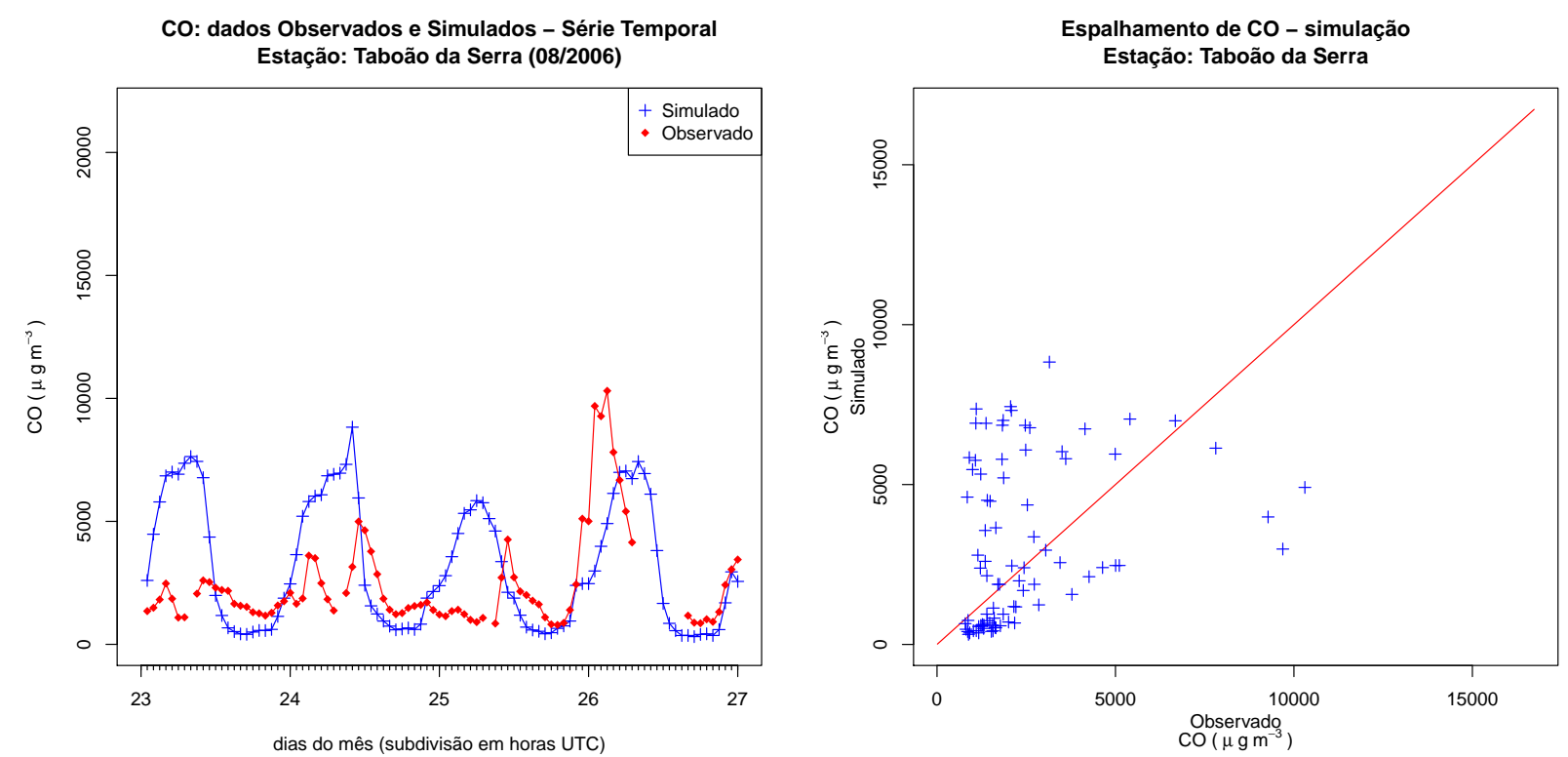

Figura 4.61: Comparação das concentrações de CO simuladas pelo modelo acoplado BRAMS/SPRAY e observadas nas estações. Continuação 


\subsubsection{Transporte de CO nos arredores}

O experimento de medidas simultâneas do aerossol atmosférico em 3 pontos da RMSP e em Cubatão, foi conduzido ao final de agosto porque nesse período do inverno usualmente observase os maiores níveis de concentração de poluentes primários. Pretendia-se, portanto, usar a modelagem de dispersão para avaliar possibilidades de transporte de poluentes dentro e entre estas regiões neste período. Houve um considerável transporte de CO da RMSP para a RMBS (Região Metropolitana da Baixada Santista) das $6 \mathrm{~h}$ às $11 \mathrm{~h}$ UTC (3h às $8 \mathrm{~h}$ no horário local) no dia 26/08/2016, como mostra as figuras 4.62 e 4.63. Em 4.63a, observa-se o transporte de CO para a RMBS no nível do solo. Em 4.63b, é mostrado um perfil vertical do CO descendo a Serra do Mar. Embora haja injeção de CO nos níveis superiores, as altas concentrações para este poluente ocorrem próximas ao solo. Mesmo que os padrões de qualidade do ar para CO não tenham sido excedidos $\left(10 X 10^{3} \mu \mathrm{g} \cdot \mathrm{m}^{-3}\right.$ ou 9,0ppm World Health Organization (2006)), há concentrações de CO, para 1h, relativamente altos e em áreas remotas e com florestas da RMSP e além. 


\section{CO Concentration for MASP and Nearby Areas}

26/08/2006 6h UTC

ug/M3

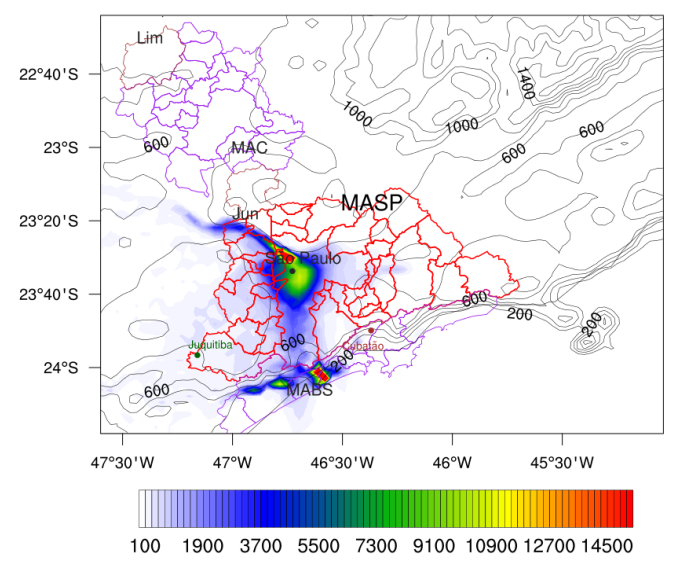

CO Concentration for MASP and Nearby Areas 26/08/2006 8h UTC

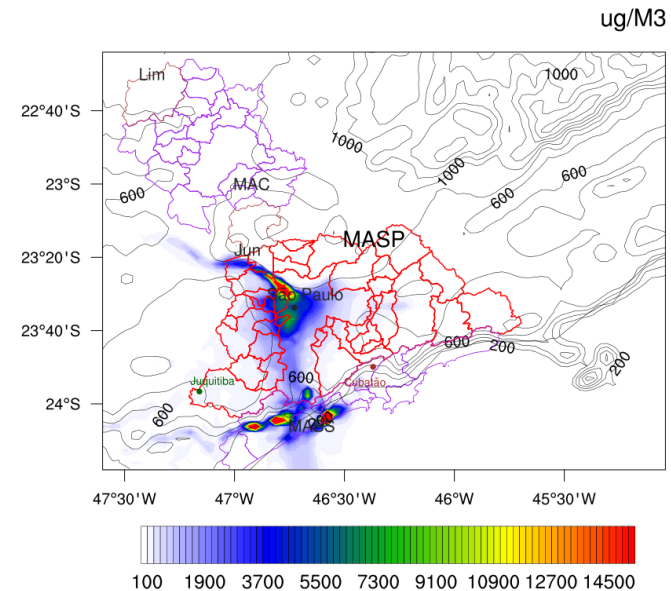

CO Concentration for MASP and Nearby Areas

26/08/2006 7h UTC

ug/M3

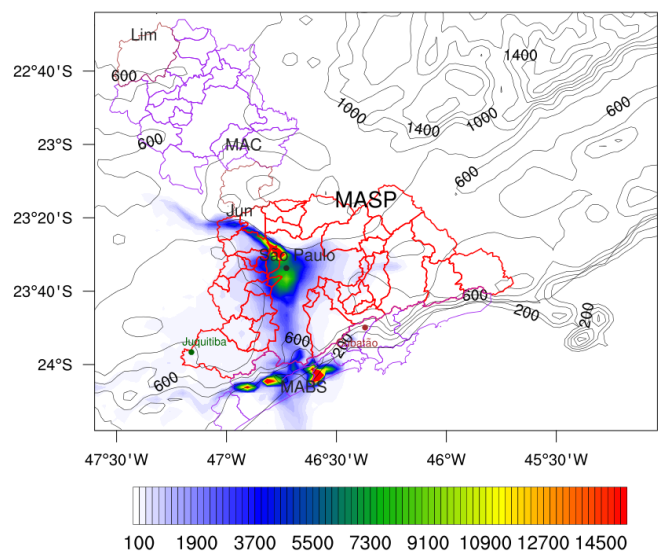

CO Concentration for MASP and Nearby Areas 26/08/2006 9h UTC

$\mathrm{ug} / \mathrm{M} 3$

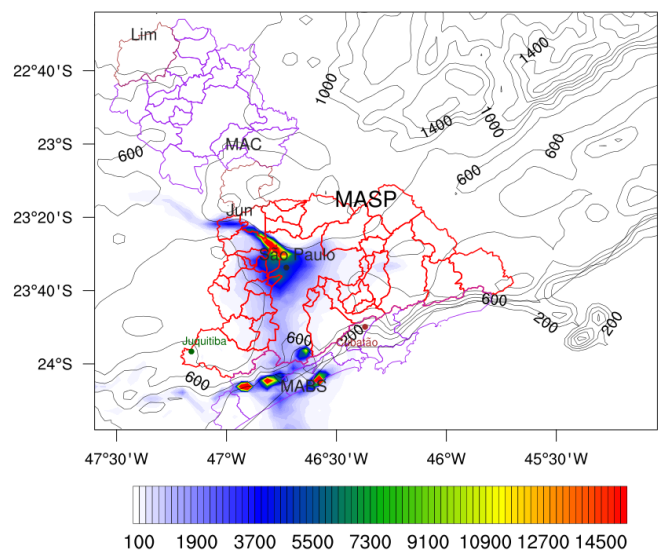

Figura 4.62: Transporte de CO da RMSP à Baixada Santista 


\section{CO Concentration for MASP and Nearby Areas}

26/08/2006 9h UTC

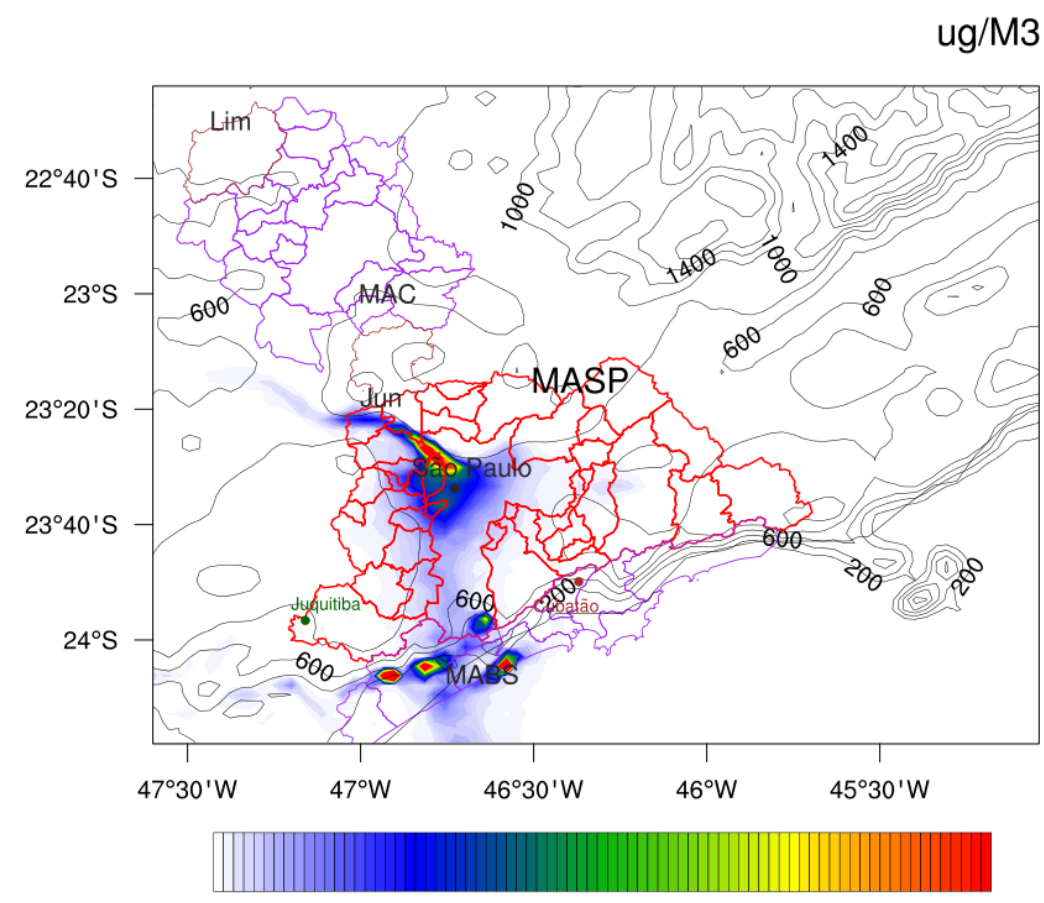

$1001900 \quad 3700 \quad 5500 \quad 7300 \quad 9100 \quad 109001270014500$

(a) Concentrações no nível do solo.

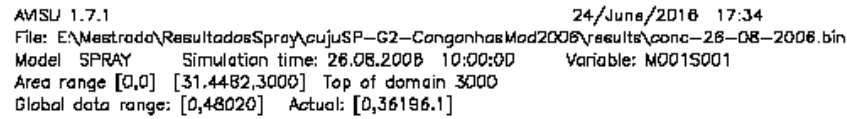

Ared range $[0,0][31,4432,3000]$ Top of dormain 35000
Global dato range: $[0,48020]$ Actual: $[0,36196,1]$

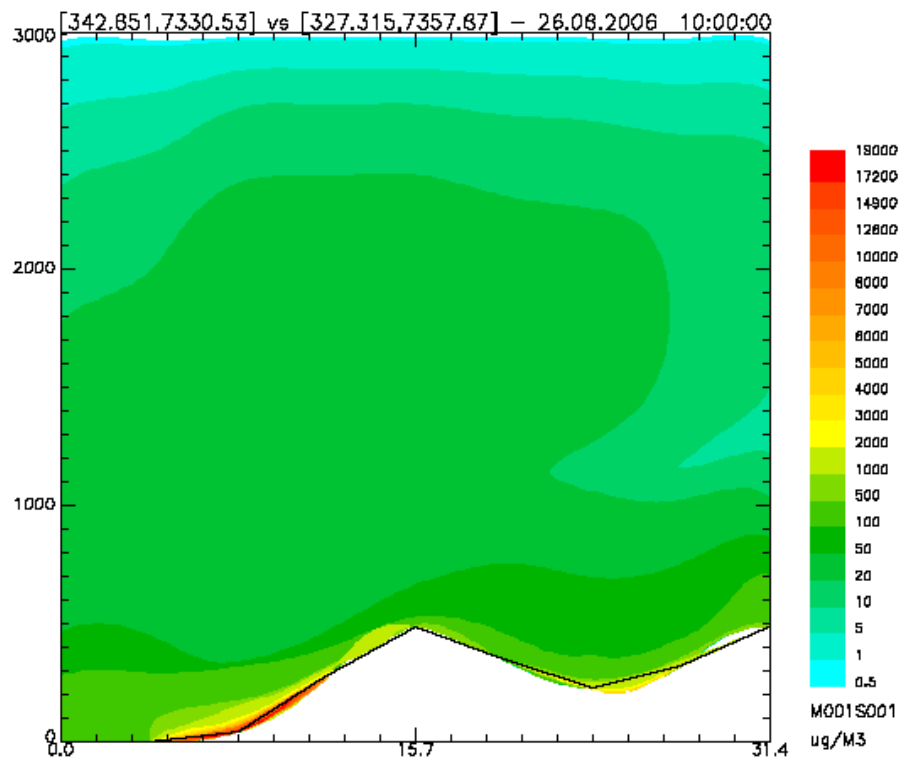

(b) Corte vertical na linha de $(-24.20836,-46.55355)$ a (22.9205,-46.89592)

Figura 4.63: Transporte de CO da RMSP para a Baixada Santista. 


\subsection{2 $\quad M P_{10}$}

Tabela 4.22: Parâmetros estatísticos para MP10 em várias estações.

\begin{tabular}{llllllll}
\hline Estação & $\overline{M P_{10} \text { sim }}$ & $\overline{M P_{10} \text { obs }}$ & $\sigma_{\text {sim }}$ & $\sigma_{\text {obs }}$ & RMSE & NRMSE & $\frac{S T M}{O B S}$ \\
\hline & $\mu g m^{-3}$ & $\mu g m^{-3}$ & $\mu g m^{-3}$ & $\mu g m^{-3}$ & $\mu g m^{-3}$ & $\%$ & \\
Cubatão V Mogi & 77,0 & 68,6 & 216,4 & 37,4 & 226,1 & 603,9 & 1,1 \\
Cubatão V Parisi & 185,5 & 152,6 & 186,8 & 55,4 & 183,6 & 331,4 & 1,2 \\
Cutabão Centro & 25,7 & 51,7 & 35,3 & 17,8 & 46,5 & 262,0 & 0,5 \\
\hline
\end{tabular}

Tabela 4.23: Parâmetros estatísticos para MP10 em várias estações (Continuação)

\begin{tabular}{lllllll}
\hline Estação & $\mathrm{n}$ & $\mathrm{FB}$ & $\mathrm{NMSE}$ & $\mathrm{FAC2}$ & $\mathrm{R}$ & valor-P \\
\hline Cubatão V Mogi & 96 & $-0,11$ & 9,68 & 0,08 & $-0,21$ & $4,08 \mathrm{e}-02$ \\
Cubatão V Parisi & 96 & $-0,19$ & 1,19 & 0,53 & 0,24 & $1,78 \mathrm{e}-02$ \\
Cutabão Centro & 96 & 0,67 & 1,63 & 0,24 & 0,05 & $6,51 \mathrm{e}-01$ \\
\hline
\end{tabular}

Os resultados da simulação mostram que a melhor correlação da simulação com as medições acontece para a estação de Vila Parisi. Embora seja uma correlação fraca, a aplicação do teste estatístico mostra que a hipótese alternativa pode ser considerada para $\mathrm{p}<0,05$, ou seja, valores observados e simulados estão correlacionados. De fato, a maioria das fábricas ficam próximas dessa região, e a estação de monitoramento está na direção do vento que recebe a carga das fábricas, fazendo com que estas sejam a fonte principal influenciando o local. Ainda, para esta estação, FAC2 $>0,3, \mathrm{NMSE}<6$, e $\mathrm{FB}<0,67$, o que reforça tal afirmação. Na comparação com as outras estações, há correlação negativa para a estação de Vale do Mogi, mas com p $<0,05$, e para a estação Cubatão Centro, a correlação é quase nula, com a hipótese nula (simulação e dados observados não estão correlacionados) confirmada por muito (p » 0,05). Ainda nestas estações, embora a maioria dos parâmetros de performance tenham sido ruins $($ NMSE $>6$ para a estação do Vale do Mogi, NRMSE $>300 \%$ para todas as estações, e FAC2 $<0,3$ para as duas), $\frac{s i m}{\text { obs }} \approx 1$ nas estações Vale do Mogi e Vila Parisi, e 0,5 para a estação Cubatão Centro.

Deste modo, apenas a estação de Vila Parisi foi aprovada nos critérios de análise dos parâmetros estatísticos.

Estes resultados mostram que tanto para a estação em que a simulação se mostrou mais hábil quanto para as demais, o fator que mais prejudicou a performance foi a qualidade de simulação do vento na região, que é influenciada pela topografia, que nesta região é muito complicada, e o modelo não a captou tão bem quanto nas estações da RMSP.

Os gráficos nas figuras 4.64 e 4.65 mostram as Séries Temporais e gráficos de espalhamento para as três estações da CETESB em Cubatão, de modo a ser verificada, visualmente, a performance do modelo. 
Nota-se que as Séries Temporais para as concentrações observadas e simuladas aparecem mais correlacionadas na estação de Vila Parisi do que nas demais. O gráfico de espalhamento para esta estação mostra que o FB quase zero se explica mais por cancelamentos entre subprevisão e sobre-previsão do que por uma maior proximidade da nuvem de pontos simulados com a "reta 1 para 1". Ainda assim, é possível verificar com este gráfico a melhor performance apresentada pela simulação no confronto com os dados observados, comparando com as demais estações. 

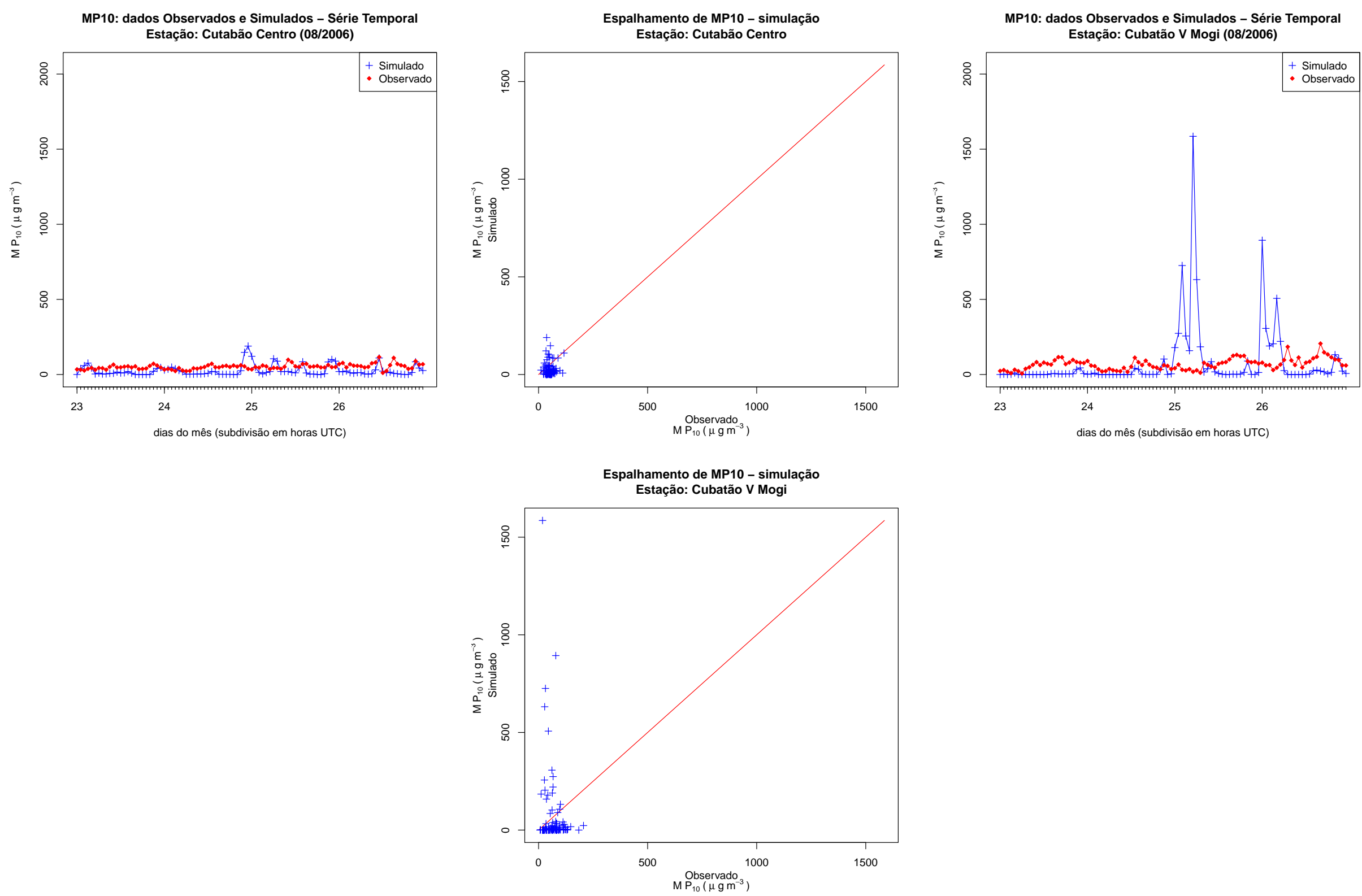

Figura 4.64: Comparação das concentrações de $M P_{10}$ imuladas pelo modelo acoplado BRAMS/SPRAY e observadas nas estações 

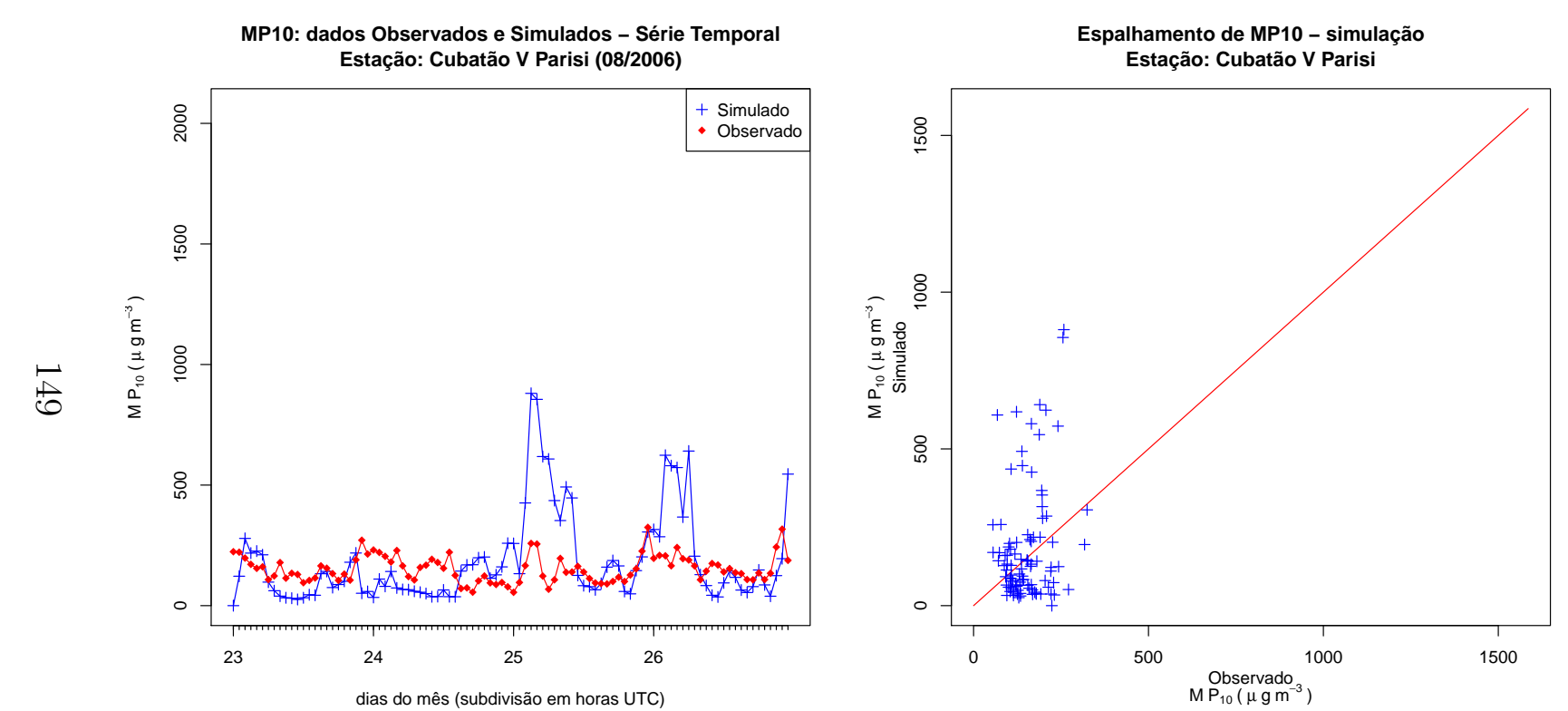

Figura 4.65: Comparação das concentrações de $M P_{10}$ simuladas pelo modelo acoplado BRAMS/SPRAY e observadas nas estações - Continuação 
A simulação da emissão de $M P_{10}$ pelas fontes de fertilizantes em Cubatão mostra que as concentrações deste poluente chegaram a valores entre 1 a $10 \mu \mathrm{g} \cdot \mathrm{m}^{-3}$ em algumas áreas da RMSP, especialmente nas cidade de Santo André (parte sul), Rio Grande da Serra e Mauá, como pode ser observado na figura 4.66. A figura 4.67 mostra o vento correspondente ao transporte de $P M_{10}$ de Cubatão até a RMSP em um corte vertical. Em 4.67a, a brisa marítima não consegue superar a Serra do Mar, e não alcança a RMSP. Em 4.67b, a intensidade da brisa aumenta, e consegue passar pela serra, avançando para a RMSP. Este avanço do vento permanece até às $23 \mathrm{~h}$ UTC. Às $23 \mathrm{~h}$ UTC, 20h locais, não há mais brisa marítima, mas uma noturna e continental, dirigindo-se ao mar, e a figura em $4.67 \mathrm{c}$, mostra quando o vento subindo a Serra já começa a perder força.

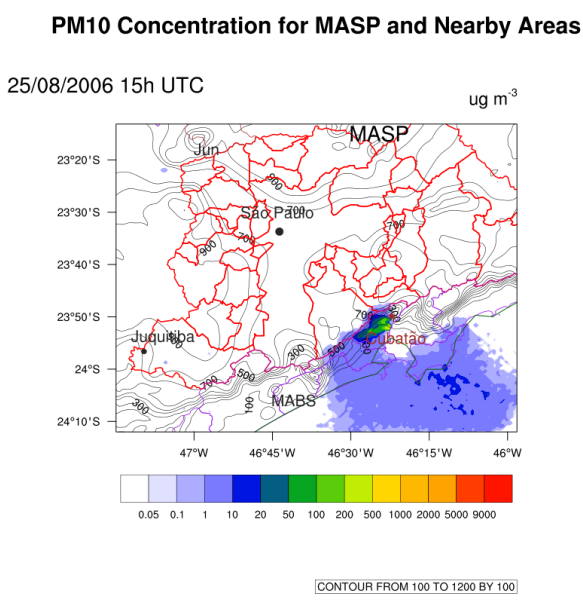

PM10 Concentration for MASP and Nearby Areas 25/08/2006 22h UTC

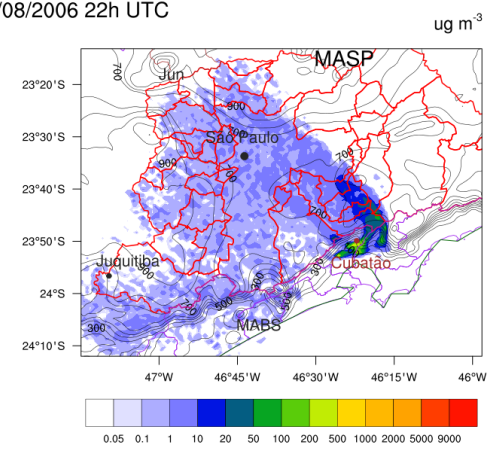

CONTOUR FROM 100 TO 1200 BY 100
PM10 Concentration for MASP and Nearby Areas

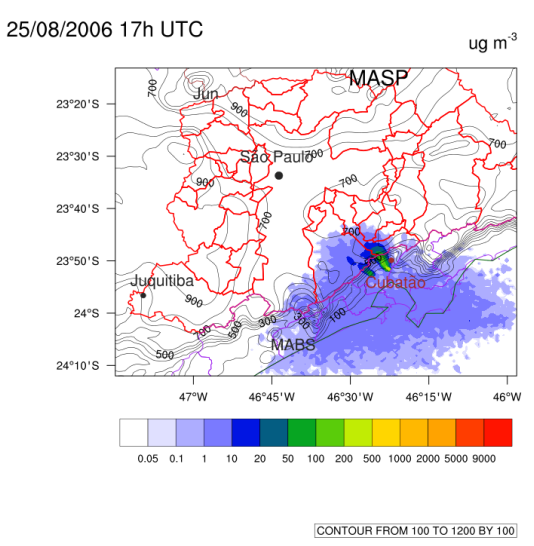

PM10 Concentration for MASP and Nearby Areas

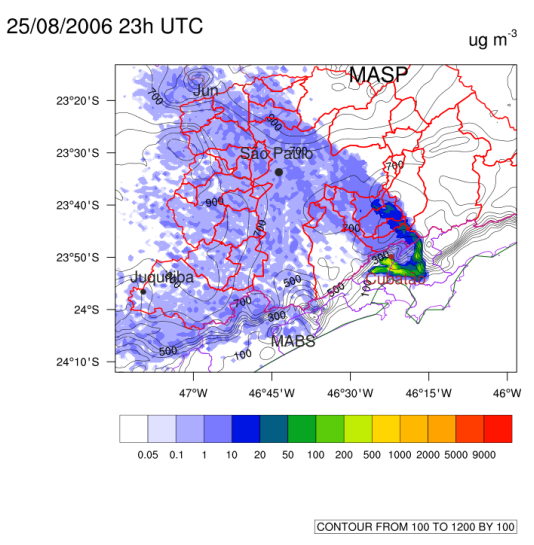

Figura 4.66: Concentrações de $P M_{10}$ no nível do solo durante o trasporte de $M P_{10}$ de Cubatão à RMSP 

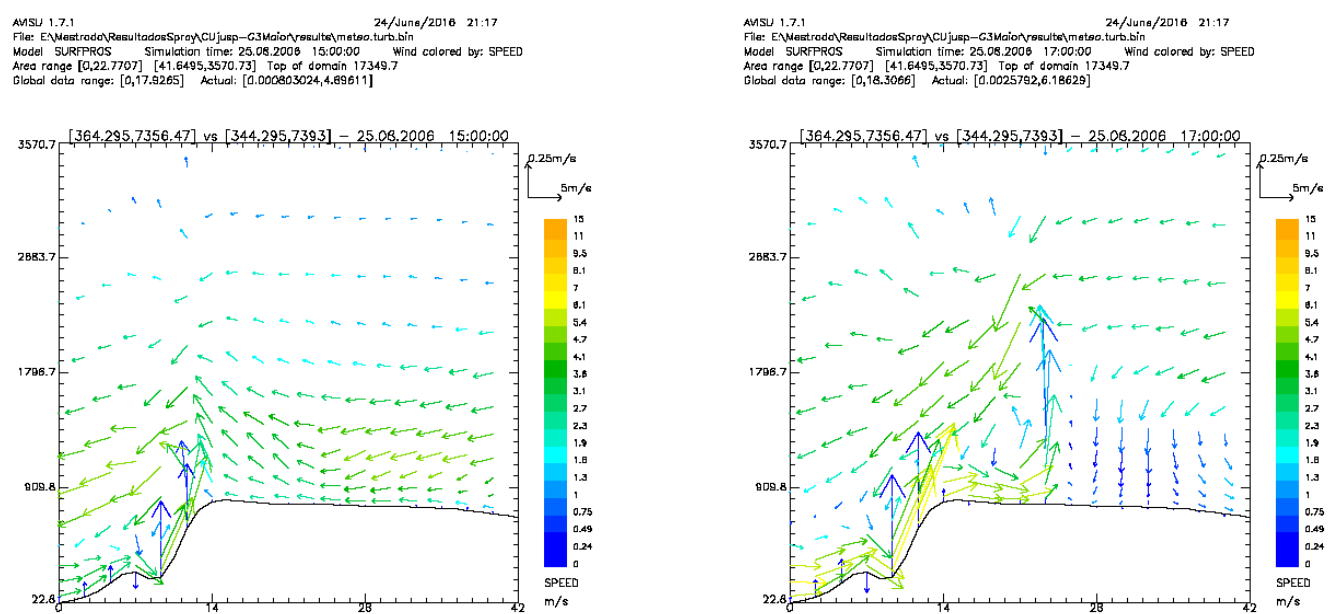

(a) Vento às $15 \mathrm{~h}(\mathrm{UTC})$

(b) Vento às $17 \mathrm{~h}$ (UTC)
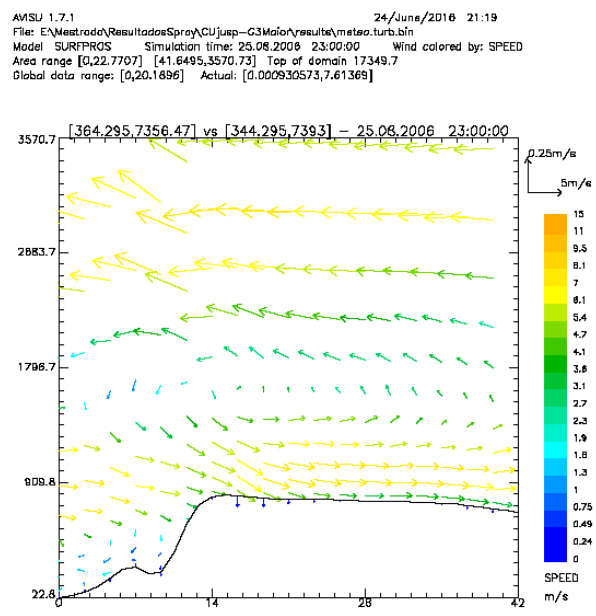

(c) Vento às $23 \mathrm{~h}(\mathrm{UTC})$

Figura 4.67: Vento associado ao Transporte de $P M_{10}$ de Cubatão para RMSP. Cortes verticais de $(-23.89763,-46.33309)$ a $(-23.56594,-46.52566)$

\subsubsection{Experimento de Inverno}

Como o $M P_{10}$ tem outras fontes além das inseridas na simulação, podemos apenas avaliar o quanto esta explica os episódios e medições no experimento de inverno. A tabela 4.24 mostra os valores de $P M_{10}$ observados no experimento de inverno e os valores apresentados nas simulações. Para Juquitiba, simulação mostra que a contribuição da fonte de RMSP relacionada à emissão veicular para as concentrações locais são apenas $3 \%$ dos observados, no máximo.

Para Cubatão, a razão entre as concentrações de $P M_{10}$ oriundas das fábricas de fertilizante e os valores observados é de 0,03 e 0,13 nos episódios diurno e noturno, respectivamente. Ou seja, até $13 \%$ do que é emitido pelas fábricas de fertilizante podem ter sido detectados pelo experimento de inverno, de acordo com a simulação. Porém, uma análise do material coletado 
no experimento de inverno é necessário para identificar as possíveis fontes.

Para São Paulo (IGC) a razão entre as concentrações da simulação e o s valores observados é de 0,88 e 1,74 nos episódios diurno e noturno, respectivamente.

Tabela 4.24: Comparação entre o $M P_{10}$ observado e simulado nas estações.

Os valores observados em Cubatão foram comparados com a simulações com fontes das fábricas de fertilizantes, e também com as fontes completas para a cidade, inventariadas pela CETESB

\begin{tabular}{|l|l|l|l|l|l|l|}
\hline Cidade & $\begin{array}{l}\text { Período da } \\
\text { medida }\end{array}$ & $\begin{array}{l}\text { Data } \\
\text { de início }\end{array}$ & $\begin{array}{l}\text { Data } \\
\text { de fim }\end{array}$ & $\begin{array}{l}\overline{M P_{10}} \\
\left(\mu g \cdot m^{-3}\right)\end{array}$ & $\begin{array}{l}\overline{M P_{10}} \\
\left(\mu g \cdot m^{-3}\right)\end{array}$ & $\frac{S T M}{O B S}$ \\
\hline Cubatão & diurno & $25 / 08 / 06$ & $25 / 08 / 06$ & 107 & 21,44 & 0,20 \\
\hline Juquitiba & diurno & $25 / 08 / 06$ & $25 / 08 / 06$ & 39 & 1,0 & 0,03 \\
\hline São Paulo & diurno & $25 / 08 / 06$ & $25 / 08 / 06$ & 57 & 50 & 0,88 \\
\hline Cubatão & noturno & $25 / 08 / 06$ & $26 / 08 / 06$ & 73 & 188,7 & 2,59 \\
\hline Juquitiba & noturno & $25 / 08 / 06$ & $26 / 08 / 06$ & 81 & 2,0 & 0,02 \\
\hline São Paulo & noturno & $25 / 08 / 06$ & $26 / 08 / 06$ & 84 & 146 & 1,74 \\
\hline
\end{tabular}




\section{Conclusão}

Um dos objetivos deste trabalho era tornar o sistema BRAMS/SPRAY operacional, e utilizálo para a investigação do transporte de poluentes na RMSP, Cubatão e arredores. Com a colaboração dos pesquisadores da ARIANET, este acoplamento está em condições de ser utilizado pelos pesquisadores que já utilizam o BRAMS ou o WRF, e desejam utilizar um modelo lagrangeano.

Este trabalho mostrou a habilidade do modelo em simular situações reais comparáveis a medidas realizadas em estações de monitoramento e em um experimento de inverno.

A simulação realizada pelo BRAMS apresentou bons resultados na comparação com os valores medidos nas estações para as variáveis meteorológicas em vários parâmetros estatísticos de performance.

A umidade foi uma variável ligeiramente subestimada pelo modelo, com valores mais reduzidos para as estações de Cubatão, próximo ao oceano. A variável meteorológica com piores resultados foi a velocidade do vento, principalmente em sua componente zonal, o que evidencia a forte dependência da resolução da topografia para uma simulação exitosa desta variável. Mesmo assim, apenas a comparação com os valores medidos na estação de Cubatão Centro não apresentou desempenho satisfatório. A boa performance do modelo para a simulação de parâmetros meteorológicos habilitou a utilização dos seus resultados como entrada para modelos de dispersão de poluentes.

As simulações de CO foram validadas pelos critérios discutidos no capítulo 3 na maioria das estações. Há, porém, necessidade de melhorar os resultados em algumas estações, particularmente melhorando a resolução das fontes de CO. Isso provavelmente acarretou limitações nos cálculos de concentrações em posições onde há grandes contrastes entre fortes emissões e pontos de diluição localizados, como em áreas com parques nas regiões centrais da metrópole. Uma fonte de CO com maior resolução pode melhorar os resultados da simulação.

A simulação de $M P_{10}$ com fontes em Cubatão apresentou bons resultados para a estação de Vila Parisi, que está sob influência das emissões das fábricas instaladas no Vale do Mogi. 
Os resultados para as demais estações ficaram piores, e insatisfatórios, em função da simulação dos ventos para a região, que depende de uma melhor resolução de topografia. Em Cubatão Centro, deve haver maior influência do material particulado relacionado ao solo e circulação de veículos, o que pode explicar, inclusive, a baixa correlação entre o observado e simulado.

Comparando o experimento de inverno à simulação com as fontes completas de $M P_{10}$ inventariadas pela CETESB, verifica-se que simulação subestimou as concentrações no período diurno (cerca de 5 vezes menor que os valores observados) e sobreestimou-as no período noturno (2,59 vezes maior que os valores observados).

A comparação dos resultados da simulação com as concentrações medidas no experimento de inverno foram boas para a RMSP, apresentando uma razão $\frac{\overline{s i m}}{\overline{o b s}}$ entre 0,88 a 1,74, portanto, inferior a um fator 2 .

Os campos de concentração gerados pelo modelo nos dias 25 e 26/8 permitiram observar transportes significativos de CO da RMSP para áreas da RMBS, assim como de material particulado de Cubatão, para a RMSP.

Com relação a Juquitiba, a simulação estimou que apenas um valor entre $2 \%$ a $3 \%$ das concentrações observadas equivale a transporte das áreas centrais da RMSP para lá. Vale lembrar que Juquitiba está na borda da RMSP, possui grande área com vegetação nativa e solo não asfaltado, e os episódios de concentração de $P M_{10}$ provavelmente foram associados apenas à ressuspensão local de poeira do solo.

Com base na comparação dos resultados da simulação e das medições nas estações, e em como eles podem ser melhorados, é lícito afirmar que uma melhor resolução das fontes de poluentes, bem como um inventário mais completo delas deverão permitir ao sistema de modelos BRAMS/SPRAY melhores condições de simulação dos campos de concentração de poluentes para esta área.Um contato com a CET para que sejam fornecidos dados que poderiam alimentar um modelo capaz de fazer um inventário de emissões com maior resolução chegou a ser feito. Entretanto não houve tempo e condições de prosseguir a interação com esta companhia antes do fechamento deste trabalho, o que se pretende conseguir em uma etapa seguinte. 


\section{Bibliografia}

ATMET (2003). RAMS, The Regional Atmospheric Modeling System - Technical Desciption. Technical report.

Boubel, R. W., Vallero, D., Fox, D. L., Turner, B., \& Stern, A. C. (2013). Fundamentals of air pollution. Elsevier.

Buringh, E., Fischer, P., \& Hoek, G. (2000). Is so2 a causative factor for the pm-associated mortality risks in the netherlands? Inhalation toxicology, 12(sup1), 55-60.

Camarano, A. A. \& Abramovay, R. (1999). Êxodo rural, envelhecimento e masculinização no brasil: panorama dos últimos 50 anos.

Caputo, A. C. \& Melo, H. P. d. (2009). A industrialização brasileira nos anos de 1950: uma análise da instrução 113 da sumoc. Estudos Econômicos (São Paulo), 39(3), 513-538.

Carslaw, D. C. \& Ropkins, K. (2012). openair - an r package for air quality data analysis. Environmental Modelling and Software, 27-28(0), 52-61.

CETESB (1985-2007). Relatório de qualidade do ar no estado de Sao Paulo. CETESB.

CETESB (2016). Emissões veiculares no estado de são paulo. http: //veicular .cetesb.sp.gov.br/wp-content/uploads/sites/35/2013/12/

Relatorio-Emissoes-Veiculares-2015-subst-011116.pdf. Online; Acessado em $19 / 12 / 2016$.

Chang, J. \& Hanna, S. (2004). Air quality model performance evaluation. Meteorology and Atmospheric Physics, 87(1-3), 167-196.

Conselho Nacional do Meio Ambiente (1990). Padrões nacionais de qualidade do ar - resolução conama $\mathrm{n}^{\mathrm{o}} 3$, de 28/06/1990. http://www.mma.gov.br/images/arquivo/80060/tabela\% 20padroes\%20qualidade.pdf. [Online; Acessado em 17/07/2017]. 
Cotton, W. R., Pielke Sr, R., Walko, R., Liston, G., Tremback, C., Jiang, H., McAnelly, R., Harrington, J., Nicholls, M., Carrio, G., et al. (2003). Rams 2001: Current status and future directions. Meteorology and Atmospheric Physics, 82(1), 5-29.

Csanady, G. T. (2012). Turbulent diffusion in the environment, volume 3. Springer Science \& Business Media.

de Souza, J. A. G. (2000). Educação na república: Um histórico das causas e conseqüências da implantação da republica brasileira no âmbito educacional.

Environmental Protection Agency (1990). Naaqs table | criteria air pollutants | us epa. https://www.epa.gov/criteria-air-pollutants/naaqs-table. [Online; Acessado em $17 / 07 / 2017]$.

Fazenda, L., Moreira, D., Panneta, J., \& Rodrigues, L. (2013). First time user's guide (brams version 4.0). http://www.cptec.inpe.br/brams/f_time.shtml. [Online; Acessado em $28 / 03 / 2013]$.

Feller, W. (1968). An introduction to probability theory and its applications: volume I, volume 3. John Wiley \& Sons New York.

Ferreira, L. F. (2007). Luiz gama: um abolicionista leitor de renan. estudos avançados, 21(60), $271-288$.

Gois Júnior, E. (2013). O esporte e a modernidade em são paulo: práticas corporais no fim do século xix e início do xx. Movimento, 19(4).

Gudivaka, V. \& Kumar, A. (1990). An evaluation of four box models for instantaneous dense-gas releases, vol. 25, pp. 237-255,. Journal of Hazardous Material, 25, 237-255.

Gutberlet, J. \& Gutberlet, K.-U. (1996). Cubatão: Desenvolvimento, Exclusão Social e Degradação Ambiental. EDUSP.

Hanna, S. \& Chang, J. (2012). Setting acceptance criteria for air quality models. In Air Pollution Modeling and its Application XXI (pp. 479-484). Springer.

IBGE (2014). Estimativas da população dos municípios brasileiros com data de referência em $1^{\mathrm{o}}$ de julho de 2014. http://www.ibge.gov.br/home/presidencia/noticias/pdf/ analise_estimativas_2014.pdf. Online; Acessado em 19/12/2016. 
Kain, J. S. (2004). The kain-fritsch convective parameterization: an update. Journal of Applied Meteorology, 43(1), 170-181.

Kerr, A. (1995). Parametrização da dispersão de pluentes e sua associção com modelos receptores em Cubatão. $\mathrm{PhD}$ thesis, Tese de Doutoramento, Instituto Astronômico e Geofísico da Universidade de São Paulo, Brasil.

Kerr, A. A., do Nascimento, S. A., Anfossi, D., \& Castelli, S. T. (2000). Investigation of inhalable aerosol dispersion at cubatão by means of a modeling system for complex terrain. Hybrid Methods in Engineering, 2(4).

Kerr, A. A. F., S, L., \& M C, C. J. (2005). INVESTIGATION OF CO DISPERSION FROM SÃO PAULO METROPOLIS BY MEANS OF A MODELLING SYSTEM FOR COMPLEX TERRAIN. In Proceedings of the 10th Int. Conf. on Harmonisation within Atmospheric Dispersion Modelling for Regulatory Purposes: Harmonisation within Atmospheric Dispersion Modelling for Regulatory Purposes.

Klug, W., Grippa, G., Tassone, C., Graziani, G., \& Pierce, D. (1992). Evaluation of long range atmospheric transport models using environmental radioactivity data from the chernobyl accident(the atmes report). EUR(Luxembourg).

Kucisnki, B. (1982). Cubatão: Uma tragédia ecológica. Revista Ciência Hoje, 1, 10-24.

Kumar, A., Luo, J., \& Bennett, G. (1993). Statistical evalution of lower flammability distance (lfd using four hazardous release models. Process Safety Progress, 12, 1-11.

Mendes, C. P. (2016a). Novo milênio: Histórias e lendas de cubatão: As origens da. http: //www.novomilenio.inf.br/cubatao/ch009.htm. Online; Acessado em 15/03/2017.

Mendes, C. P. (2016b). Novo milênio: Histórias e lendas de cubatão: As origens da siderúrgica. http://www.novomilenio.inf.br/cubatao/ch007.htm. Online; Acessado em $15 / 03 / 2017$.

Michalakes, J., Chen, S., Dudhia, J., Hart, L., Klemp, J., Middlecoff, J., \& Skamarock, W. (2001). Development of a next generation regional weather research and forecast model. In Developments in Teracomputing: Proceedings of the Ninth ECMWF Workshop on the use of high performance computing in meteorology, volume 1 (pp. 269-276).: World Scientific. 
Miller, E., Cooper, J., Frazier, C., Pritchett, L., Guimarãoes, F., Alonso, C., \& Filho, B. (1985). CUBATAO AEROSOL SOURCE APPORTIONMENT STUDY. Technical report, NEA, Inc.

MMA (2013). Proconve - programa de controle de poluição do ar por veículos automotores. http://www.mma.gov.br/images/arquivo/80060/Arquivos/PROCONVE_ atualizado\%20em\%2021nov13.pdf. Online; Acessado em 19/12/2016.

Novo Milênio (2016). Novo milênio: Histórias e lendas de cubatão: Cinco milênios de história. http://www.novomilenio.inf.br/cubatao/ch001.htm. Online; Acessado em $15 / 03 / 2017$.

Pielke, R. A., Cotton, W., Walko, R. e. a., Tremback, C. J., Lyons, W. A., Grasso, L., Nicholls, M., Moran, M., Wesley, D., Lee, T., et al. (1992). A comprehensive meteorological modeling system-rams. Meteorology and Atmospheric Physics, 49(1), 69-91.

Poli, A. A. \& Cirillo, M. C. (1993). On the use of the normalized mean square error in evaluating dispersion model performance. Atmospheric Environment. Part A. General Topics, 27(15), 2427-2434.

Pope III, C. A., Burnett, R. T., Thun, M. J., Calle, E. E., Krewski, D., Ito, K., \& Thurston, G. D. (2002). Lung cancer, cardiopulmonary mortality, and long-term exposure to fine particulate air pollution. Jama, 287(9), 1132-1141.

Prado Júnior, C. (1978). História econômica do brasil. São Paulo: Brasiliense, 15.

R Core Team (2016). R: A Language and Environment for Statistical Computing. R Foundation for Statistical Computing, Vienna, Austria, https://www.R-project.org/.

Sader, E. (2010). Brasil, de getúlio a lula. Brasil, entre o passado e o futuro. São Paulo: Fundação Perseu Abramo, (pp. 11-29).

Slade, D. H. (1968). METEOROLOGY AND ATOMIC ENERGY, 1968. Technical report, Environmental Science Services Administration, Silver Spring, Md. Air Resources Labs.

Steyn, D. G., Castelli, S. T., et al. (2012). Air pollution modeling and its application XXI. Springer.

Taylor, G. I. (1922). Diffusion by continuous movements. Proceedings of the London Mathematical Society, 2(1), 196-212. 
Tech, A. (2010). Swift wind field model. General Design Manual.

Thomson, D. (1987). Criteria for the selection of stochastic models of particle trajectories in turbulent flows. Journal of Fluid Mechanics, 180, 529-556.

Tinarelli, G. (2013). SPRAY 3.1 - General Description and User's guide. Technical report, ARIANET.

Tinarelli, G., Anfossi, D., Brusasca, G., Ferrero, E., Giostra, U., Morselli, M., Moussafir, J., Trombetti, F., \& Tampieri, F. (1994). Lagrangian particle simulation of tracer dispersion in the lee of a schematic two-dimensional hill. Journal of Applied Meteorology, 33(6), 744-756.

Tinarelli, G., Anfossi, D., Castelli, S. T., Bider, M., \& Ferrero, E. (2000). A new high performance version of the lagrangian particle dispersion model spray, some case studies. In Air Pollution Modeling and its Application XIII (pp. 499-507). Springer.

Uchôa, M. (2016). Novo milênio: Histórias e lendas de cubatão: As origens da siderúrgica. http: //www. novomilenio.inf.br/cubatao/ch027c.htm. Online; Acessado em 15/03/2017.

World Health Organization (1999). ENVIRONMENTAL HEALTH CRITERIA FOR CARBON MONOXIDE. World Health Organization.

World Health Organization (2006). Air quality guidelines: global update 2005: particulate matter, ozone, nitrogen dioxide, and sulfur dioxide. World Health Organization.

Zambrano-Bigiarini, M. (2014). hydroGOF: Goodness-of-fit functions for comparison of simulated and observed hydrological time series. R package version 0.3-8, https://CRAN . R-project.org/package=hydroGOF. 